\title{
La acción del fruto en el control del desarrollo del níspero japonés (Eriobotrya japonica Lindl.)
}



D. Manuel Agustí Fonfría, Dr. Ingeniero Agrónomo, Catedrático de Universidad del Departamento de Producción Vegetal de la Universidad Politécnica de Valencia

\section{Expone:}

Que la presente Tesis Doctoral La acción del fruto en el control del desarrollo del níspero japonés (Eriobotrya japonica Lindl.), realizada por la Ingeniera Agrónoma Carmina Reig Valor para optar al grado de Doctora, se ha llevado a cabo bajo mi dirección en el Departamento de Producción Vegetal de la Universidad Politécnica de Valencia, y por la presente

Autoriza:

La presentación de la memoria adjunta a los efectos académicos oportunos.

En Valencia, 15 de octubre de 2010

Fdo. Manuel Agustí Fonfría 

A mis padres

A Rafa. 



\section{Agradecimientos}

La mejor manera de empezar la redacción de una tesis doctoral es tener gente a la que agradecer que, de una manera o de otra, te hayan animado y ayudado a llegar hasta el final.

Empezaré por Manolo Agustí, por ser como mi brújula personal que ha permitido que no perdiera el rumbo en ningún momento, a pesar de las dificultades que han ido apareciendo. Por su confianza en mi desde el principio, por hacerme ver que el conocimiento no tiene límites, y por enseñarme a ser profesora, transfiriendo sin condiciones todo lo que se, y alumna a la vez, por no dejar de estudiar y aprender nunca. Trabajar junto a él es una garantía de progreso personal y profesional. Un ejemplo a seguir.

A Carlos y Amparo o Amparo y Carlos, da igual el orden, porque a los dos me gustaría agradecer por duplicado, todo lo que han hecho por mí, desde ayudarme a aterrizar en el laboratorio, acogiéndome como una más del equipo, hasta a despegar en el mundo científico. Pero, lo más importante, por entender perfectamente el sentido del compañerismo y ampliarlo hasta el de la amistad.

Al resto de compañeros, muchos de ellos amigos, porque aunque la mayoría están muy lejos de aquí, siempre han estado muy cerca de mí. Sin ellos esta tesis no sería lo que es.

A Vicent por su constante y valiosa ayuda en el campo pero, sobre todo, por la manera y las ganas con que lo hace.

A Carmela por su compañía en las alturas y por regalarme todos los días su sonrisa.

A mis amigos de Palermo por hacerme tan agradable y tan fácil mi estancia allí. Por su ayuda en parte de esta tesis y con los que espero seguir trabajando durante mucho tiempo.

A la Cooperativa de Callosa d'En Sarrià por pemitirme realizar allí mis experimentos, en especial a Esteban Soler, porque sus inquietudes y observaciones me han ayudado a conocer muchísimo mejor a como él llama "esta mala bestia".

A todas mis amigas, a las que he conocido aquí, a las que he conocido allá, a las que conozco desde la infancia...., porque día a día y, cada una a su manera, me han ayudado y animado a continuar esforzándome, preocupándose por mi como hace la gente a la que le importas. En especial a Ana con la que empecé esta aventura de la investigación, porque con virus o sin virus, con nísperos o sin ellos, siempre hemos encontrado un hueco para escucharnos, aconsejarnos, vernos... pero, sobre todo, para compartir nuestro tiempo en saber la una de la otra. 
Ser padres es algo más que crear una vida, le tienes que dedicar tu tiempo, tu espacio, tu propia vida en cuidarla, educarla, atenderla....Todo eso y mucho más me lo han aportado mis padres, y a quienes les debo todo lo que soy y como lo soy. Tenerlos a mi lado ha sido decisivo y todavía hoy, no he encontrado las palabras que expresen todo lo que significan para mi.

A mi hermana, porque juntas hemos crecido personalmente, juntas hemos vivido los buenos y los malos momentos, juntas hemos ido cubriendo diferentes etapas de la vida y porque siempre seguiremos 'juntas', hasta el final.

Al resto de mi familia, a los que están, porque de ellos recibo continuamente muestras de cariño, inagotables, que tan necesarias son para mi para afrontar el día a día, y a los que ya no están por todo lo que hicieron por mi cuando estuvieron.

Por último y, no por ello menos importante, a Rafa, por ser el mejor resultado de esta tesis y la conclusión más clara 'EL y YO'. Sólo por eso volvería a empezar. Porque con el he decidido compartirlo todo. 
Índice 

1. Origen y difusión de la especie 25

2. Distribución geográfica e importancia económica 25

3. Características generales del ciclo vegetativo 27

$\begin{array}{ll}\text { 4. Brotación y crecimiento vegetativo } & 27\end{array}$

$\begin{array}{ll}\text { 5. Floración } & 27\end{array}$

6. Cuajado y desarrollo del fruto 29

6.1.El control hormonal del crecimiento del fruto 30

6.2.El control nutricional del crecimiento del fruto 31

7. Maduración 32

8. El papel del fruto en la planta 32

8.1. El fruto y su relación con la brotación y floración 33

8.2.El fruto y su competencia por el desarrollo 36

$\begin{array}{ll}\text { 8.3.El fruto y el desarrollo radicular } & 37\end{array}$

8.4.Su interacción con la maduración 38

9. Hipótesis de trabajo y objetivos 40

Materiales y métodos

1. Material vegetal 43

2. Experimentos 43

- Capítulo 1.- Características morfológicas y fisiológicas del cv. 'Piera' 43

- Capítulo 2.- Influencia del fruto en la brotación y el desarrollo 44 vegetativo.

- Eliminación y/o aislamiento temporal de los frutos 
- Influencia de la semilla $\quad 45$

- Eliminación de los frutos. Estudio al árbol completo 45

- La influencia del fruto en el reparto de carbohidratos 45

- Determinaciones analíticas de carbohidratos 46

- $\quad$ La influencia del fruto en la movilización de fracciones $\quad 48$ nitrogenadas

- $\quad$ Determinaciones analíticas del Nitrógeno Proteico y 48 Nitrógeno Amoniacal $\left(\mathrm{N}-\mathrm{NH}_{4}^{+}\right)$

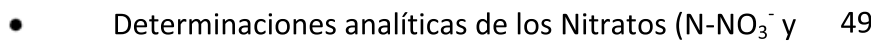
$\mathrm{N}-\mathrm{NO}_{2}{ }^{-}$)

- La influencia del fruto en el balance hormonal 50

- Capítulo 3.- Influencia del fruto en la floración 51

- Capítulo 4.- El control del fruto sobre su propio desarrollo 53

- Capítulo 5.- Influencia del fruto en el desarrollo radicular y el 53 transporte de carbohidratos. La maduración.

- Análisis estadístico de los resultados.

\section{Resultados}

1. Características morfológicas y fisiológicas del cv. 'Piera'

1.1. Características morfológicas.

1.2.Características fisiológicas

2. Influencia del fruto en la brotación y el desarrollo vegetativo.

2.1. Eliminación y/o aislamiento temporal de los frutos. Estudio individual de la panícula.

2.2. Influencia de la semilla.

2.3. Eliminación de los frutos. Estudio al árbol completo.

2.4. La influencia del fruto en el reparto de carbohidratos.

3. Influencia del fruto en la floración

4. El control del fruto sobre su propio desarrollo 
5. Influencia del fruto en el desarrollo radicular y el transporte de carbohidratos. La maduración. 



\section{Resúmenes}





\section{Resumen}

Este estudio aborda la acción del fruto como órgano de control del desarrollo del árbol frutal en el níspero japonés (Eriobotrya japonica (Thunb) Lindl.). Para ello se establecieron 4 niveles de comparación: dos cultivares, 'Algerie' y 'Piera', el primero con un comportamiento típico en Clima Mediterráneo, el segundo de brotación, floración, fructificación y maduración recurrentes a lo largo del año; árboles jóvenes (3 años de edad), cultivados en maceta, capaces de florecer y fructificar adecuadamente; árboles adultos en cultivo con frutos y sin ellos, eliminados en sus primeras fases de desarrollo; brotes con panícula, brotes sin ella y brotes con ésta aislada temporalmente mediante un anillado en su base. Se evaluó la brotación y la floración, el desarrollo radicular, el desarrollo del fruto, y el contenido nutricional, carbohidratos de transporte, consumo y de reserva, fracciones nitrogenadas, $\mathrm{N}-\mathrm{NO}_{3}{ }^{-}, \mathrm{N}-\mathrm{NH}_{4}{ }^{+} \mathrm{y}$ N-proteico, y el contenido hormonal, AIA, ABA y zeatina, en los diferentes órganos de la planta. Los resultados indican que el árbol no inicia la brotación hasta que el fruto es recolectado y que su ausencia acelera el desborre de las yemas y el posterior desarrollo de los brotes y promueve la floración. Del mismo modo, la presencia del fruto restringe severamente el crecimiento radicular y, con ello, el aporte de hormonas a la parte aérea de la planta. Se demuestra, asimismo, que el fruto controla su propio desarrollo a través de un fenómeno de competencia nutricional con el resto de frutos de la panícula y que, a través de su interacción con el desarrollo del resto de órganos de crecimiento activo del árbol, controla el proceso de su maduración. El resultado final es que 1) la actividad fotosintética está modulada por la demanda del principal sumidero de la planta, el fruto, y que ésta, en gran medida, está regulada por la semilla que cuando completa su crecimiento cesa la demanda de carbohidratos por parte de éste; 2 ) la floración está controlada por el fruto, que restringe significativamente la brotación anticipada de las yemas axilares e inhibe la formación de flores en éstas panículas y en las principales; 3 ) el crecimiento y la actividad de las raíces se ralentizan marcadamente cuando el fruto alcanza su máximo tamaño, lo que queda demostrado por la reducción de su longitud, el descenso en la densidad de puntos mitóticos de sus tricloblastos, la reducción del transporte de azúcares desde las hojas, medido a través de la exposición de éstas a una atmósfera de ${ }^{13} \mathrm{C}$, la reducción del transporte desde las raíces al fruto, determinado por la acumulación de almidón y la fracción $\mathrm{N}-\mathrm{NH}_{4}{ }^{+}$, y la drástica reducción de la síntesis y transporte hormonal desde la raíz a la copa y los frutos, y 4) la acumulación de carbohidratos, junto con la reducción de la concentración de $\mathrm{N}-\mathrm{NH}_{4}{ }^{+}$y de zeatina, facilitan la maduración del fruto que es, de este modo, controlada por su propia actividad. 



\section{Abstract}

The aim of this work is to study the role of the fruit controlling tree development in loquat (Eriobotrya japonica Lindl.). As approach, we established four levels of comparison: 1) two varieties, 'Algerie' y 'Piera', the former presenting a typical behaviour under Mediterranean Climate, the latter is an everflowering variety giving rise to several vegetative and floral flushes a year, which develop several fruit generations that develop and mature appropriately; 2) young trees ( 3 years old), growing in pots, capable of flowering and set suitably; 3 ) mature trees with their fruits and without fruits thinned by hand at early stage of development; and 4) flowering shoots, shoots with detached panicle and shoots with panicle isolated panicle by means of bark ringing. Sprouting and flowering intensity, root development, fruit development, both reducing and transport carbohydrates, starch, nitrogen fractions, $\mathrm{N}^{-\mathrm{NO}_{3}}$, $\mathrm{N}-\mathrm{NH}_{4}{ }^{+}$y N-proteinaceous, and hormonal content, IAA, ABA, and zeatin, in different developing organs, were evaluated. Results suggest that sprouting takes place once the fruit is harvested, hence bud break and shoots development takes place in its absence and also flowering. In the same way, root growth and root activity are hardly reduced by fruit, thus reducing hormones transport to the canopy. Results also show a self-controlled fruit development through a nutritional competitive process among panicle-developing fruits and interacting with tree organs in active growth stage, thus harmonizing colour break and maturation. In brief: 1) fruit sink activity modulates photosynthesis since carbohydrates demand is largely depending on its development, mainly the seeds, and once the seeds complete the growth carbohydrates demand progressively cut off.; 2) Fruit reduces flowering by reducing premature bud break and number of flowers per panicle both of premature and current shoots; 3 ) Root growth and root activity slow down as fruit grows, giving rise to a shorter roots, a reduction in tubular outgrowths from trichloblast cells, a reduction of carbohydrates from the canopy, measured by a reduction of ${ }^{13} \mathrm{C}$ transported after ${ }^{13} \mathrm{CO}_{2}$ leaves exposure, and a reduced transport from the roots to the fruit, showed by root starch accumulation, and a reduced $\mathrm{N}^{-\mathrm{NH}_{4}}{ }^{+}$and hormones concentrations; and 4) sugars accumulation and reduced concentration of $\mathrm{N}-\mathrm{NH}_{4}{ }^{+}$ and zeatin make easy the maturation process, being, thus, self-controlled by fruit. 



\section{Resum}

Aquest estudi aborda l'acció del fruit com a òrgan de control del desenvolupament de l'arbre fruital en la nespra japonesa (Eriobotrya japonica (Thunb) Lindl.). Per a realitzar-ho es varen establir 4 nivells de comparació: dos cultivars, 'Algerie' i 'Piera', el primer d'ells amb un comportament típic de la climatologia Mediterrània, el segon amb brotació, floració, fructificació i maduració del fruit recorrents al llarg de l'any; arbres joves (3 anys d'edat) cultivats amb test capaços de florir i fructificar adequadament; arbres adults cultivats al camp amb fruits i sense ells, eliminats a les primeres etapes del seu creixement, brots amb panicula, brots sense ella i amb aquesta ailllada temporalment per l'anellat de la seua base. Es varen avaluar la brotació, la floració, el desenvolupament de les arrels, el desenvolupament del fruit, i el contingut nutricional, sucres de transport, de consum i de magatzematge, fraccions nitrogenades, $\mathrm{N}-\mathrm{NO}_{3}{ }_{3}^{-}, \mathrm{N}-\mathrm{NH}_{4}{ }^{+}$i N-proteic, i el contingut hormonal, AIA, ABA i zeatina, en els diferents òrgans de la planta. Els resultats indiquen que l'arbre no inicia la seua brotació fins que no es recull el fruit i que la seua absència accelera el desborrament de les seues gemmes $\mathrm{i}$ el posterior creixement dels brots i promou la floració. Igualment, la presència restringeix severament el creiximent del fruit, i amb això, l'aportació d'hormones a la part aèria de la planta. Així mateix, es demostra que el fruit controla el seu propi desenvolupament mitjançant un fenomen de competència per nutrients amb la resta de fruits de la panicula i que mitjançant la seua interacció amb el desenvolupament de la resta d'òrgans amb creiximent actiu de l'arbre, controla el mecanisme de la seua maduració. El resultat final es que: 1) l'activitat fotosintètica està regulada per la demanda del principal embornal de la planta, el fruit, i que aquesta, majoritàriament està regulada per la llavor que, quan acaba el seu creixement, finalitza la demanda del fruit per carbohidrats; 2) la floració està controlada pel fruit, que restringeix significativament la brotació anticipada de les gemmes axil.lars i inhibeix la formació de flors en aquestes inflorescències i en les principals; 3) el creixement i l'activitat de les arrels es ralentitza marcadament quan el fruit aconsegueix el seu tamany màxim, la qual cosa queda demostrada per la reducció de la seua llargària, el descens en el nombre dels seus punts mitòtics procedents dels tricoblastes, la reducció del transport de sucres des de les fulles, medit per l'exposició d'aquestes a una atmòsfera de ${ }^{13} \mathrm{C}$, la reducció del transport des de les arrels fins al fruit, determinat per l'acumulació de midó i de la fracció $\mathrm{N}_{-} \mathrm{NH}_{4}{ }^{+} \mathrm{i}$ la dràstica reducció de la síntesi i transport d’hormones des de l'arrel fins la part aéria de la planta, i 4)

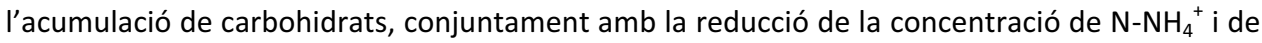
zeatina, faciliten la maduració del fruit que és, d'aquesta manera, controlada per la seua propia activitat. 

Introducción 



\section{INTRODUCCIÓN}

\section{1.- Origen y difusión de la especie}

La primera mención de la existencia del níspero japonés (Eriobotrya japonica Lindl, familia Rosaceae) data del Sur de China, en el valle del río Daduhe, donde se originó, contrariamente a lo que había descrito Lindley, quien lo consideró originario de Japón, hasta el punto de darle el término japonica a la especie (Zhang et al., 1990). Hay que remontarse a 1690 para encontrar la primera descripción de esta especie por parte del botánico alemán Kaempfer. Probablemente éste llegó a Europa en 1784 con algunos ejemplares que se plantaron en el jardín botánico de París, según algunos procedentes de las islas Mauricio, donde la especie había sido introducida, según otros, por los jesuitas directamente de Cantón. Tres años después se encontró, en Inglaterra, y a mediados de 1800 ya estaba presente en las colecciones públicas y privadas de Sicilia, en el Levante español (en la ciudad de Sagunto, introducido por el capitán Roig), Malta, Argelia, Grecia y Turquía. En 1867 fue introducido en Florida y en 1870 en California donde su cultivo no ha tenido auge (Lin et al., 1999).

\section{2.- Distribución geográfica e importancia económica}

Actualmente, el níspero japonés se cultiva en áreas localizadas entre los paralelos $25^{\circ}$ y $38^{0}$ Norte y Sur, por tanto, en una franja del mundo relativamente estrecha. Dos son los polos más importantes: ChinaJapón y la Cuenca Mediterránea. En otras zonas su cultivo con fines comerciales es esporádico y los árboles se encuentran mayoritariamente en los jardines con fines ornamentales. Los primeros países del Mediterráneo que se interesaron por el cultivo intensivo de este frutal fueron Italia, Argelia y España.
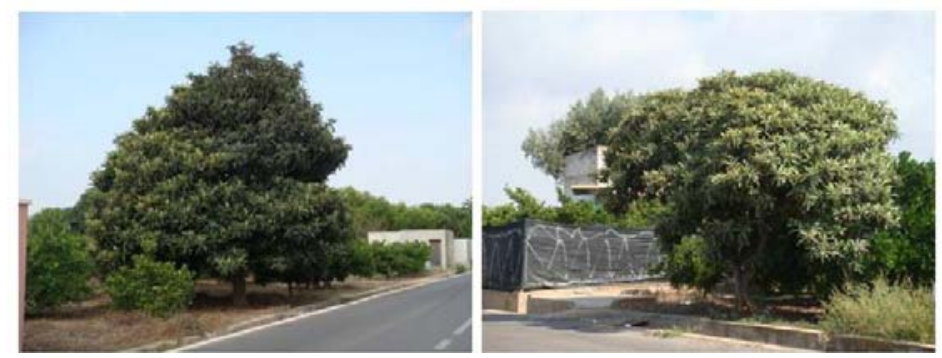

En los países mediterráneos es frecuente ver el níspero japonés en parcelas familiares para el consumo doméstico de sus frutos.

En Italia el cultivo se afianzó en Sicilia, sobre todo en la costa de la provincia de Palermo, pero actualmente está en recesión a causa de los elevados costes de producción (Espinosa et al., 1997). En Argelia hubo mucho interés por este cultivo durante el periodo colonial francés, pero desde la independencia del país su cultivo ha ido en decadencia. En España, actualmente la zona de mayor interés se encuentra en la 
Comunidad Valenciana, en la provincia de Alicante, con cerca del 59\% del total de la producción, seguida de Andalucía con el 39\% y, a mucha distancia, Murcia, Cataluña y Baleares. España es hoy el primer país productor de níspero japonés en el Mediterráneo y el primer exportador del mundo (con algo más del 70\%
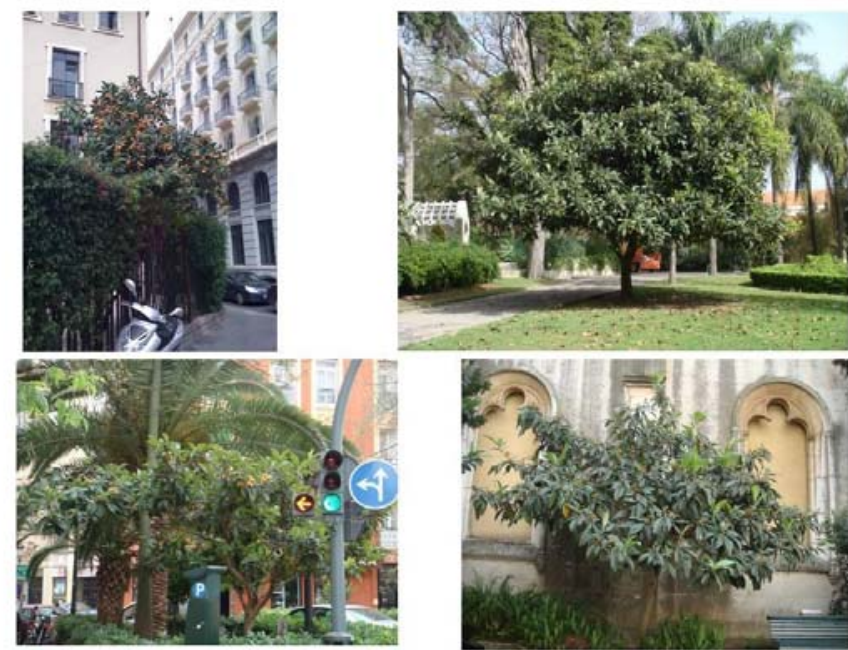

El uso ornamental del níspero japonés es valorado en todo el mundo. de su producción), siendo el principal país importador de la producción española Italia, que absorbe cerca del $18 \%$ de la exportación. Ningún otro país de la Cuenca Mediterránea sigue, por el momento, los pasos de España en rentabilidad y técnicas culturales avanzadas, causas del progreso de su cultivo en el último decenio, a pesar de lo cual, tanto la extensión y la producción se han reducido en los últimos años. Actualmente existen, aproximadamente, 2.836 ha en plantación, de las que sólo 2.768 están en cultivo, 33 de las cuales en régimen de secano y las 2735 restantes en regadío. La producción total de 36.467 t se distribuye en 1883 t y $13126 \mathrm{t}$, en condiciones de secano y regadío, respectivamente. El precio medio percibido por los agricultores en los últimos años ha oscilado entre los 80 cts/kg y $1 € /$ kg (MAPA 2007).

A pesar de estos avances que sitúan a España como el segundo país productor del mundo, China sigue manteniéndose en primer lugar y su cultivo continúa expandiéndose de modo sostenido, hasta haberse duplicado en los últimos diez años (Lin, 2007).

Sorprende encontrar a Pakistán en tercer lugar, aunque con una producción muy heterogénea y de baja calidad, con variedades locales procedentes de semilla, pero con un plan de mejora varietal que se inició con la introducción de la variedad japonesa 'Tanaka', de la que hoy existen poco más de 100 ha y se exportan pequeñas cantidades a los países del golfo.

Japón, por el contario, al igual que Israel, ha entrado desde hace tiempo en una situación estacionaria y se advierten signos de ligero descenso.

Un país en crecimiento, en cambio, es Turquía, en el que su cultivo se extiende, sobre todo, a lo largo de la costa mediterránea, hasta llegar a la costa del Mar Egeo y del Mar Negro. 


\section{3.- Características generales del ciclo vegetativo}

El nípero japonés (Eriobotrya japonica Lindl.) pertence a la subtribu Pyrinae, de la familia Rosaceae, junto a otras especies como el manzano, el peral o el membrillero (Philips et al., 1991; Potter et al., 2005; 2007). Esta especie florece en otoño, cuaja y desarrolla sus frutos durante el invierno y madura en primavera.

Durante el invierno puede iniciarse el desborre de algunas yemas principales, que no adquiere importancia hasta después de la recolección, momento a partir del cual crece rápidamente al mismo tiempo que se inicia la brotación anticipada de algunas yemas formadas el mismo año, hasta detenerse por las altas temperaturas del verano. Después de la parada estival, los brotes retoman su crecimiento.

La floración, que se inicia en otoño puede prolongarse, en función de las condiciones climáticas, el cultivar y el patrón, hasta el invierno, lo cual indica que en esta especie no hay reposo invernal ni acumulación de horas frío. Se desconoce la acumulación de horas de calor requerida durante los meses previos para llegar a la antesis.

El desarrollo radicular del níspero japonés, contrariamente a lo que ocurre en otras especies frutales, es coincidente con el desarrollo vegetativo.

\section{4.- Brotación y crecimiento vegetativo}

El níspero japonés, en los climas templados, presenta inicialmente tres periodos diferentes de desborre de sus yemas a lo largo del año que, finalmente, acaban reduciéndose a dos brotaciones claramente diferenciadas. La más importante se desarrollo durante la primavera.

Esta brotación se origina a partir de yemas de reemplazo de brotes vegetativos y de yemas laterales de ramos fructíferos, en ambos casos del año anterior y, por tanto, yemas principales, cuyos brotes crecen a lo largo del verano, interrumpidos durante un corto periodo de tiempo por las elevadas temperaturas, conocido como parada estival, tras el cual reanudan su crecimiento hasta principios de otoño, finalizando con la diferenciación floral de la mayor parte de ellos (Hueso y Cuevas, 2003). Le sigue en importancia la brotación de verano, que se inicia antes de la parada estival a partir de yemas laterales de los brotes del año en crecimiento (yemas anticipadas) originando brotes anticipados que crecen de la misma forma que los principales, pero a mayor velocidad. La brotación de primavera origina, por tanto, brotes largos con hojas grandes, conocidos como principales, que no sólo aportan las inflorescencias y las yemas que iniciarán la brotación del año siguiente, sino que contribuyen a la producción de sustancias de reserva, carbohidratos y sustancias nitrogenadas. La de verano, por el contrario, es más débil y su crecimiento tan rápido dificulta que sus yemas, que brotaron anticipadamente, adquieran la madurez suficiente para 
desarrollar brotes de calidad el año siguiente (Agustí y Reig, 2006). La brotación de otoñó apenas tiene importancia.

En climas cálidos, como para otras muchas especies, el número de brotaciones que se dan a lo largo del año es múltiple y la actividad vegetativa de la planta no cesa. Algunos mutantes de níspero japonés como el cv. 'Piera' también pueden comportarse de esta manera aunque se cultiven en condiciones de clima templado (Reig y Agustí, 2007).

\section{5.- Floración}

El níspero japonés florece en panículas de forma piramidal de entre 18 y $40 \mathrm{~cm}$ de longitud, compuestas por un eje principal sobre el que se insertan de 5 a 10 racimos de consistencia no leñosa, formados a su vez, por un número variable de flores y racimos secundarios que agrupan un total de entre 70 y 100 flores (Agustí y Reig, 2006) o incluso hasta más de 100 (Lin et al., 1999).

Presenta una floración centrípeta, típica de las Rosáceas, con un desarrollo inicial de las flores basales de los racimos progresivamente hacia el ápice de la panícula. El tiempo necesario para que todas las flores de ésta estén en antesis oscila entre 2 y 4 semanas, según las condiciones climáticas (Rodríguez, 1983), por eso la duración y la época de floración en los climas templados varía desde mediados de septiembre, para los cultivares más precoces, hasta finales de diciembre, para los más tardíos (Martínez-Calvo et al., 2000a), con un desfase de seis meses en el hemisferio sur.

La floración va precedida de la inducción y diferenciación florales que, en condiciones climáticas templadas, ocurren en el mes de junio la primera y entre agosto y septiembre la segunda, más o menos 4 meses antes de la antesis, dependiendo de los cultivares y condiciones fisiológicas del árbol (Liu et al., 2007). La defoliación y el estudio histológico de los ápices en desarrollo permiten situar la iniciación floral en el hemisferio norte, por tanto, en estas fechas (Fatta del Bosco, 1961). Los brotes de verano, es decir, los que brotan anticipadamente,diferencian más tarde sus panículas que los de primavera, sin embargo, la antesis de sus flores tiene lugar en el mismo periodo y sus flores acaban siendo más pequeñas y producen frutos de baja calidad.

Las flores son hermafroditas, olorosas, blancas y pequeñas $(12-20 \mathrm{~mm})$. Están formadas por 5 sépalos y 5 pétalos, 15-25 estambres libres (Robertson et al., 1991) y entre 2 y 5 estigmas y estilos libres que se unen basalmente a un ovario ínfero poco profundo (Rohrer et al., 1994) con 5 carpelos, cada uno de los cuales puede albergar hasta 2 óvulos. 


\section{6.- Cuajado y desarrollo del fruto}

En el níspero japonés no existe unión de los canales estilares, lo cual influye directamente en el cuajado final, sobre todo cuando existen problemas de polinización (Sheffield et al., 2005), y presenta efectos directos en la variabilidad de las producciones y en la distribución de las semillas que afectan, finalmente, a la calidad de los frutos (Williams et al., 1993).

Aunque inicialmente se pensaba que esta especie era mayoritariamente autocompatible y que sólo algunas de sus variedades eran parcial o completamente autoincompatibles, estudios recientes de su biología floral demuestran que las flores de la mayoría de las variedades de níspero japonés cultivadas en España, adquieren un sistema de incompatibilidad gametofítico (GSI) en los estados previos a su antesis (Carrera, 2009). Recientemente se ha demostrado que el cv. 'Algerie', el más difundido en España, presenta un elevado pocentaje de autoincompatibilidad (Cuevas et al., 2003). Por eso, en condiciones óptimas de polinización, el porcentaje de cuajado de esta especie no es muy elevado, y alcanza entre el $10 \%$ y el $15 \%$ de las flores inicialmente formadas. Y esa es la razón de que el cultivo intensivo del níspero japonés haya traído consigo problemas de cuajados erráticos en algunas zonas, y de que la presencia de polinizadores mejore sustancialmente, en estos casos, el rendimiento del cultivo (Kan et al., 1986; Martínez-Calvo et al., 2000b; Karadeniz, 2002; Cuevas et al., 2003a). La identificación del sistema de incompatibilidad que opera en esta especie, así como sus formas alélicas, permitirán una correcta implantación del cultivo, evitando, de esta manera, los mencionados cuajados erráticos producidos por la presencia de polen incompatible.

Al igual que en el manzano (Williams, 1966) o membrillero (Kaufmane y Rumpunen, 2002) la fecundación en el níspero japonés ocurre varios días después de su polinización. La llegada de los tubos polínicos al óvulo de esta especie, y con ello el inicio de la fructificación, comienza a partir de la primera semana tras la polinización, siendo completa entre la primera y segunda semana (Carrera, 2009). Todas estas especies se caracterizan por tener una corta fase progámica, si se comparan con otras especies frutales, como el melocotonero, en el que la fecundación se observa a las tres semanas de su polinización (Herrero y Arbeloa, 1989; Arbeloa y Herrero, 1991).

La tasa de crecimiento del fruto del níspero japonés es muy lenta durante las seis semanas siguientes al cuajado (Fase I) (Ateyyeh y Qrunfleh, 1998), a ésta le sigue una fase de división celular (fase II) que se prolonga durante 4 semanas; finalmente, en primavera, tiene lugar una etapa en la que la tasa de crecimiento aumenta espectacularmente y el fruto crece a gran velocidad hasta completar su tamaño final (fase III). De este modo, y de acuerdo con Blumenfeld (1980), su curva de crecimiento no es sigmoidal, como le correspondería a un fruto de pepita, sino exponencial. Algunos autores, sin embargo, indican que los frutos crecen siguiendo el modelo sigmoidal simple característico de los pomos (Rodríguez, 1983; Cuevas et al., 2003b). 
En climas templado-cálidos, a los que el cultivo de esta especie se adapta perfectamente, el crecimiento del fruto se inicia a finales de otoño-principios de invierno y la cosecha se inicia a mediados de primavera. Las diferencias en tamaño del fruto entre variedades son consecuencia de diferencias en su tasa de crecimiento y no en su periodo de crecimiento.

La evolución de los componentes del fruto durante el crecimiento sigue pautas diferentes. Por una parte, en las primeras fases, el peso seco de la pulpa es superior al de la semilla, pero con el tiempo esta situación se invierte y en la maduración, el peso seco de la semilla es superior al de la pulpa. En esta fase la partición de materia seca entre pulpa y semilla es del $45 \%$ y $55 \%$, respectivamente. En términos de peso fresco, la pulpa siempre pesa más que la semilla, particularmente a partir del cambio de color del fruto y en la madurez, que representa prácticamente el $80 \%$ del peso fresco del fruto. La comparación entre el peso seco ( $\approx 6 \mathrm{~g})$ y fresco $(\approx 30 \mathrm{~g})$ totales de un fruto medio del cv. 'Algerie' pone en evidencia la contribución del agua al crecimiento de los frutos.

En resumen, los principales cambios tienen lugar durante los últimos 45 días de crecimiento del fruto, cuando éste acumula el $85 \%$ del peso fresco y el $80 \%$ del peso seco. El agua se acumula casi exclusivamente en la pulpa (90\%) y la materia seca se reparte en un $37 \%$ para ésta y un $73 \%$ para la semilla. Y como consecuencia de todo ello, durante este periodo la pulpa reduce a la mitad el porcentaje de su materia seca mientras que la semilla lo duplica (Gariglio et al., 2002).

\subsection{El control hormonal del crecimiento del fruto}

En la Fase I, el ovario inicia la división celular y, aunque la tasa de crecimiento del fruto es baja, los niveles de ácido indolacético (AIA), ácido abscísico (ABA) y citoquininas son máximos. Estos cambios hormonales son seguidos durante la fase de división celular (fase II) por un descenso progresivo del contenido en $A B A$, que alcanza su nivel mínimo, y un incremento progresivo de la producción de etileno, que alcanza su máximo contenido, y que luego decrece gradualmente. Al final de este estado de desarrollo, el AIA y las citoquininas alcanzan un segundo pico en su contenido en el fruto. Durante la fase III, de rápido crecimiento del fruto, las concentraciones de AIA y de citoquininas alcanzan sus mínimos valores, la de ABA aumenta de nuevo, y se encuentra un segundo pico en la producción de etileno (Ding and Zhang, 1988; Ye, 1988).

La producción de giberelinas (GAs) en las semillas inmaduras y en el pericarpo del níspero fue estudiada por Yuda (1987), Yuda et al (1992), Koshioka et al. (1988) y Kraft-Klaunzer y Mander (1992). Las giberelinas $\mathrm{GA}_{9}, \mathrm{GA}_{15}, \mathrm{GA}_{19}, \mathrm{GA}_{20}, \mathrm{GA}_{24}, \mathrm{GA}_{25}, \mathrm{GA}_{29}, \mathrm{GA}_{35}, \mathrm{GA}_{44}, \mathrm{GA}_{48}, \mathrm{GA}_{50}, \mathrm{GA}_{61}, \mathrm{GA}_{80}$ y $\mathrm{GA}_{84}$ y otras 5 GAs no identificadas (seguramente derivados de las $G_{A}$ y $G_{35}$ ), fueron encontradas en las fracciones biológicamente activas extraídas de semillas inmaduras. De todas ellas, las más abundantes fueron la $\mathrm{GA}_{35} \mathrm{Y}$ las 5 GAs no identificadas. 


\subsection{El control nutricional del crecimiento del fruto}

La acumulación de azúcares en el fruto es parcialmente responsable del reclamo de agua por el fruto y la relación del K con el transporte de agua por la planta podría, también, estar relacionado con el fenómeno. Dado el papel relevante del agua en el tamaño final del fruto, la concentración de azúcares y de K en la pulpa, junto con la acción hormonal, pueden ser responsables de su crecimiento.

El azúcar más abundante en la pulpa del fruto durante su crecimiento es el sorbitol con un $60 \%$ del total de azúcares. Le siguen en importancia la fructosa y la glucosa, con un contenido entre el $15 \%$ y el $33 \%$, dependiendo del momento, y la sacarosa, cuyo contenido fluctúa ampliamente, representando entre el 5\% y el $45 \%$, según la época (Gariglio et al., 2002). Estos cambios en el contenido de azúcares detectados en los tejidos del fruto no se corresponden, sin embargo, con los de las hojas. De hecho, en el momento en que se registra la máxima tasa de crecimiento del fruto, los niveles foliares de azúcares muestran una tendencia alcista. La respuesta, por tanto, está desfasada y la disminución del contenido de azúcares observada en las hojas en pleno invierno ocurre dos semanas antes de que se presente el primer pico de aumento en la tasa de crecimiento del fruto. Igualmente, se observa una disminución de la concentración de azúcares en las hojas 15 días después del cambio de color del fruto. Por lo tanto, el contenido de azúcares en las hojas parece disminuir en respuesta a un aumento de la demanda de asimilados por parte del fruto, con un retraso en la respuesta de unos 15 días (Gariglio et al., 2002). Un aspecto a destacar lo constituye el hecho de que durante los últimos 15 días de crecimiento del fruto éste acumula el 90\% de los azúcares, siendo la sacarosa el más predominante (Hirai, 1980).

La concentración de azúcares en la semilla de este frutos se mantiene prácticamente constante hasta que éste inicia su rápido crecimiento, momento en el que lo aumenta notablemente para disminuirlo progresivamente después hasta que el fruto cambia de color. También en este caso, el azúcar predominante en la semilla, durante todo el período de crecimiento del fruto, es el sorbitol, que fluctúa su contenido entre el $45 \%$ y el $60 \%$ del total de los azúcares, disminuyendo en el momento de la maduración hasta el 40\%. En el fruto del níspero japonés, la acumulación de almidón, solamente tiene lugar en la semilla (Gariglio et al., 2002).

La concentración de elementos minerales en la pulpa desciende durante el desarrollo del fruto alcanzando los valores más bajos en el momento de la maduración. Después del cuajado, el $\mathrm{N}$ es el macronutriente que se encuentra en mayor concentración en la pulpa, seguido del K, Ca, Mg y P. El Fe y el Cu son los micronutrientes más abundantes en la pulpa del fruto, seguidos del $\mathrm{Zn}$ y del Mn (Gariglio y Agustí, 2005). Los cambios en la concentración de elementos minerales observados en la pulpa del fruto del níspero japonés durante su crecimiento son debidos, mayoritariamente, a un proceso de dilución más que a su metabolización. De acuerdo con los resultados de Gariglio y Agustí (2005), durante este proceso el 
elemento mineral que más desciende en su concentración es el $\mathrm{Cu}$, con un 90\%, seguido del $\mathrm{Fe}, \mathrm{Ca}, \mathrm{Zn}, \mathrm{Mn}$, $\mathrm{N}$ y K cuyas concentraciones descienden un $80 \%, 75 \%, 73 \%, 66 \%, 65 \%$ y $40 \%$, respectivamente.

\section{7.- Maduración}

Existe controversia en el comportamiento del fruto del níspero japonés durante su maduración en el árbol y la prolongación de la vida del fruto para clasificarlo como climatérico o no-climatérico. Mientras algunos autores indican la ausencia de un incremento de la respiración y de un pico en la producción de etileno tanto en el árbol como tras su recolección y concluyen que el níspero japonés es un fruto no-climatérico (Blumenfeld, 1980; Zheng et al 1993; Hamauzu et al., 1997; Ding et al, 1998; Kader, 2002; González et al., 2004), otros encuentran producción de etileno a lo largo de todo el periodo de desarrollo del fruto (Gariglio et al., 2002) y picos en la producción de etileno y de la tasa respiratoria en etapas precoces de la maduración (Hirai, 1980; Chachin et al, 1990; Gariglio et al., 2002; Amorós et al., 2003), lo que induce a algunos a concluir que el níspero japonés es un fruto climatérico (Amorós et al., 2003). Ninguno de los trabajos citados estudia la evolución de los enzimas que reblandecen los tejidos, pectinmetilesterasa y poligalacturonasa, y su dependencia de la producción de etileno, y este factor es decisivo para determinar el tipo de maduración de este fruto.

En el níspero japonés, la coloración del fruto avanza progresivamente desde la zona estilar a la peduncular. Por otra parte, el descenso de la acidez libre de la pulpa no se halla coordinado con el incremento en el contenido de SST. Mientras la primera desciende tras el cambio de color del fruto, el incremento en la concentración de los segundos sólo se inicia cuando la piel ha perdido prácticamente todas las clorofilas (González et al., 2004). Esta falta de coordinación entre la maduración externa e interna no es privativa del níspero japonés y ha sido descrita también para otras especies frutales. El ácido málico es el más importante en contenido de los cuatro analizados (Serrano et al., 2004), con valores entre $0.5 \%$ y $2.7 \%$ de materia fresca, dependiendo del cv., seguido del ácido succínico, con un contenido 10 veces más bajo $(0.05 \%$ y $0.30 \%)$, y el ácido cítrico $(0.01 \%$ - $0.14 \%)$; los menores contenidos son para el ácido ascórbico $(<0.01 \%-0.08 \%)$.

Durante la maduración del fruto, son la sacarosa, la fructosa y la glucosa los azúcares más abundantes, seguidos por el sorbitol. De acuerdo con Gariglio et al. (2002), a lo largo de la etapa de maduración y, teniendo en cuenta el cambio de peso del fruto, en sólo 15 días se acumula más del 80 \% del total de los azúcares. 


\section{8.- El papel del fruto en la planta}

La presencia del fruto en un árbol frutal aumenta la eficiencia fotosintética de sus hojas. En efecto, los estudios de productividad llevados a cabo en el manzano indican que la cantidad de carbohidratos transportada a los frutos es mayor, en peso, que la que supone la supresión del desarrollo vegetativo inducida por ellos. Además, determinaciones directas utilizando ${ }^{14} \mathrm{CO}_{2}$ demuestran que los frutos actúan como potentes sumideros, y que son éstos los responsables del transporte de fotoasimilados (Ft) desde las hojas a ellos mismos, sobre todo durante la fase lineal de su crecimiento (Faust, 1989).

La capacidad fotosintética del árbol es más que suficiente, en la mayoría de las especies frutales, para asegurar una cosecha abundante y la fotosíntesis puede convertirse en un factor limitante sólo en unos pocos casos de cosechas muy elevadas, con competencia muy acusada entre órganos, y/o cuando se presentan fenómenos de estrés o defoliaciones importantes por razones diversas.

En términos generales, por tanto, el potencial fotosintético en los frutales se halla bajo dos tipos de control, el medioambiental, que afecta indirectamente al desarrollo de las hojas, y el de la demanda de los sumideros.

\subsection{El fruto y su relación con la brotación y la floración}

La presencia de los frutos reduce el desarrollo vegetativo, al menos en manzanos, melocotoneros y cítricos. Así, en el manzano, aunque la cosecha detiene, literalmente, el desarrollo radicular, el desarrollo vegetativo es reducido hasta en un 30\% (en peso seco) en relación con los árboles sin cosecha. Lenz (1986) demostró que ello se debe a que el fruto reduce el transporte de fotoasimilados hacia las yemas y las partes vegetativas del árbol, sin embargo, la falta de correlación entre el contenido de carbohidratos y el porcentaje de brotación de las yemas indica que aquel es decisivo sólo para atender el proceso.

El proceso de acumulación y utilización de las reservas se repite cíclicamente en las plantas. La importancia de las reservas para la brotación y la floración en las especies caducifolias es obvia, ya que estos procesos tienen lugar al inicio de la primavera, cuando no hay superficie fotosintética y la absorción de nutrientes está limitada por las bajas temperaturas. En otras palabras, el almacenamiento de carbohidratos es necesario para iniciar la brotación y posterior crecimiento tras la latencia (Dowler y King, 1966; Keller y Loescher, 1989).

Por otra parte, la importancia de las reservas nitrogenadas para la brotación y el crecimiento vegetativo del melocotonero, así como para el desarrollo de sus frutos, está fuera de duda (Taylor, 1967;). Es más, las alteraciones en la reducción de $\mathrm{NH}_{3}-\mathrm{NH}_{4}^{+}$y su relación con la floración se han demostrado en cítricos (Monselise et al., 1981) y en melocotonero como respuesta a la presencia del fruto (Reig et al., 2006). 
En la mayoría de frutales caducifolios, el inicio del desarrollo del fruto coincide con el periodo de inducción floral, observándose una relación directa e inversa entre los frutos en desarrollo y las flores formadas (Lavee, 1996; Bubán y Faust, 1982). En el manzano (Bubán y Faust, 1982) y en el pistachero (Crane et al., 1973) se ha demostrado que son las semillas de los frutos las que inhiben la producción de las yemas reproductivas. La presencia de éstas, generalmente, mejora la persistencia del fruto en el árbol, evitando su caída, lo que se debe a un incremento en la producción de reguladores del desarrollo y, con ello, a una más intensa actividad sumidero de los frutos (Monselise y Goldschmidt, 1982) que estimula la movilización de compuestos fotosintétizados hacia el fruto en desarrollo.

De entre todas las hormonas vegetales, las giberelinas son las más influyentes en el proceso de floración (Pharis y King, 1985; Okuda, 2000) ya que: (1) la aplicación de ácido giberélico (AG) durante el periodo de inducción floral interfiere en éste e inhibe parcialmente la floración de la primavera siguiente (Painter y Stembridge, 1972; Jourdain y Clanes, 1987; Byers et al., 1990; Southwick et al., 1995), y (2) la actividad de las giberelinas se correlaciona positivamente con el efecto del fruto sobre la floración siguiente (Goren y Goldschmidt, 1970; Erner et al., 1976; García-Luis et al., 1986). En el manzano, el AG se emplea para inhibir los estadíos primarios de las yemas florales (Luckwill, 1970). En los cítricos un tratamiento de AG durante la época de inducción floral reduce hasta un $50 \%$ la floración de la primavera siguiente, especialmente las inflorescencias sin hojas, dependiendo de la concentración (Monselise y Halevy,1964; Davenport, 1983; Guardiola et al., 1977). En el albaricoquero (Southwick et al., 1995b), en el melocotonero (Painter y Stembridge, 1972) y en el ciruelo (González-Rossia et al., 2006), su aplicación ha logrado una respuesta similar y se ha propuesto como una técnica de aclareo indirecto de frutos en especies del género Prunus (González-Rossia et al., 2007).

Un aspecto de interés se presenta al eliminar los frutos y realizar aplicaciones de ácido giberélico. En estos casos se ha observado una intensidad de floración similar a la encontrada en los árboles con frutos, lo que demuestra que las giberelinas exógenas pueden sustituir el efecto inhibitorio del fruto y ser parte del mecanismo de control de la floración de muchas especies, como por ejemplo los cítricos (Goldschmidt y Monselise, 1972; Guardiola et al., 1982), al mismo tiempo que sugiere que la acción inhibidora de la floración por parte de los frutos es a través de las giberelinas (Martínez-Fuentes, 2010).

A ello contribuye el hecho de que el contenido en giberelinas es mayor en las hojas de brotes con frutos que en las hojas de brotes sin frutos (Koshita et al., 1999), y dada la importancia de la presencia de hojas para el desarrollo de yemas reproductivas demostrado en diferentes especies frutales como el mango (Reece et al., 1949), el manzano (Harley et al., 1932), el olivo (Hackett y Hartmann, 1964), el níspero japonés (Fatta del Bosco, 1961) y los cítricos (Ayalon y Monselise, 1960), su papel en la floración debe ser, además de receptor de estímulos ambientales, hormonal y nutricional. Se ha sugerido, también, que la presencia del fruto podría reducir la sensibilidad de las yemas a las condiciones inductivas, o incrementar la exigencia en condiciones inductivas de la floración (Albrigo y Galán, 2004). 
En experimentos realizados con segmentos de tallo de vid, Mullins y Rajasekaran (1981) demostraron que los primordios vegetativos son sumideros más potentes de citoquininas que los primordios florales, y que una limitación en la disponibilidad de éstas significaría una reducción en el desarrollo de yemas reproductivas, hasta el punto de que descensos bruscos de su nivel causan la caída de racimos (Mullins 1980). Otros autores, sin embargo, trabajando con el olivo no han encontrado este efecto de las citoquininas en la formación de yemas reproductivas (Badr y Hartma, 1972).

El ácido abscísico puede reducir la intensidad de floración mediante la reducción del desarrollo de inflorescencias sin hojas en los cítricos (Davenport 1990), aunque se ha encontrado una relación positiva entre el contenido endógeno de ácido abscísico en árboles de limonero inducidos a florecer mediante estrés hídrico (Raveh, 2008). Por otra parte, el hecho de que la aplicación de ABA localizada a las yemas en época de inducción floral reduzca la intensidad de la floración del mandarino Satsuma (García-Luis et al., 1986) impide atribuir a esta sustancia un papel regulador de la floración.

En el manzano, las auxinas producidas en las semillas se desplazan desde éstas hasta las inflorescencias (Luckwill, 1957; Grochowska, 1968). Este movimiento es más intenso en un cultivar alternante, como el 'Laxton Superb', que en otros de comportamiento regular, como el 'Cox Orange Pippin' (Hoad, 1978). Además, se han observado niveles más bajos de auxinas en los brotes en los que se diferencian flores durante el año off que en los que no las diferencian (Grochowska, 1964). Por otra parte, Verreynne y Lovatt (2009) encontraron niveles más elevados de ácido indolacético en las yemas de árboles de mandarino 'Pixie' en año on, que en las yemas de árboles en año off. Asimismo, se consiguió incrementar la floración en plantones de pomelo mediante la aplicación de un inhibidor del transporte de auxinas, el TIBA (Kessler et al., 1959). Todo ello sugiere que el ácido indolacético puede influir en el proceso de floración directa o indirectamente, aunque su efecto específico todavía es incierto (Okuda, 2000).

El rayado de ramas da lugar a la acumulación de carbohidratos en la zona superior del corte (Cohen, 1981) y por tanto, a un reparto más ventajoso de carbohidratos (Wallerstein et al., 1974;1978), consiguiendo estimular la floración del ciclo siguiente (Goldschmidt et al., 1985, Agustí et al., 1992). La posibilidad de que el rayado ejerza su acción a través de un mecanismo hormonal ha sido también señalada (Rivas et al., 2007). La variaciones en el transporte (Monselise, 1979) y acumulación de auxinas (Dann et al., 1985), giberelinas (Wallerstein et al., 1973; Cutting y Lyne, 1993) y citoquininas (Cutting y Lyne, 1993) tras el rayado invita a pensar en un control hormonal del efecto provocado por éste, aunque su mecanismo todavía se desconoce. Un aspecto de interés es el efecto combinado del rayado y la presencia del fruto en la floración de los árboles de mandarino 'Murcott' con elevada cosecha (Goldschmidt et al., 1985). A pesar del efecto del rayado promoviendo la floración, la presencia del fruto consigue anular su acción. Así, el rayado provocó una acumulación de carbohidratos en las hojas y brotes situados por encima de la zona de incisión en los árboles off, pero en los árboles on la elevada demanda de carbohidratos por parte de los 
frutos en desarrollo evitó su acumulación (Goldschmidt et al., 2003).Si ésta es la razón por la cual los frutos anulan el efecto del rayado, se desconoce.

\subsection{El fruto y su competencia por el desarrollo}

El reparto de carbohidratos entre los diferentes órganos del árbol depende marcadamente de su capacidad sumidero. De acuerdo con el modelo de Landsberg (1980), ésta se ordena de manera decreciente entre frutos, brotes, hojas y raíces. La ganancia en peso seco de cada uno de ellos y, por tanto, el reparto de fotoasimilados, es claramente favorable a los frutos en desarrollo. Es más, una elevada cosecha tiene un efecto de memoria en el árbol, de modo que el (los) año(s) siguiente(s) reduce su producción, y la explicación debe estar en la reducción de los carbohidratos acumulados en las raíces, puesto que las hojas, en muchas especies, se pierden en otoño. Este fenómeno de competencia se da en todas las especies frutales y es responsable de la relación inversa normalmente encontrada entre el número de frutos por árbol o inflorescencia y el tamaño final de los mismos. Esta relación entre el reparto de carbohidratos y el número de frutos por brote que beneficia al fruto cuanto menor es el número de los que inician el desarrollo, es la razón por la que la reducción del número de éstos se presente como una técnica muy útil para mejorar su tamaño final. El aumento de la concentración de azúcares se ha demostrado como factor responsable del aumento del tamaño del fruto en diferentes especies, como melocotonero (Genard et al., 1991), manzano (Archbold, 1992), cítricos (Agustí et al.,2002) y níspero japonés (Gariglio et al., 2003).

El aclareo manual de frutos es empleado en fruticultura en especies con deficiencias en su tamaño final y en variedades cuya exigencia comercial así lo recomienda. En melocotoneros y nectarinas se elimina alrededor del $60 \%$ de los frutos inicialmente formados, dejando entre 2 y 5 frutos por ramo mixto, según la longitud de éste. En el níspero japonés, se elimina parte de la panícula en plena floración y se aclaran los frutos cuajados dejando entre 3 y 5 en función de las dimensiones de la misma. En otras especies de frutales, de hueso y de pepita, también se practica con frecuencia.

El aclareo químico de frutos, por el contrario, en la mayoría de las especies frutales, es de difícil aplicación y apenas se utiliza en la práctica. Sin embargo, la inhibición parcial de la floración mediante la aplicación de AG en la época de inducción floral de los melocotoneros y nectarinas (Southwick et al., 1995) y del ciruelo japonés (González-Rossia et al., 2007), reduce el número de flores y, como consecuencia de ello, hasta en un $50 \%$ los costes de aclareo manual. La reducción temprana del número de yemas florales y el estímulo del desarrollo vegetativo por la acción del AG, maximizan la capacidad del árbol para aumentar el tamaño del fruto (Weinberg, 1941). Dadas las estructuras florales del níspero japonés, el aclareo químico de frutos en desarrollo mediante la aplicación de ácido naftalenacético (ANA) también es posible (Agustí et al., 2000). Esto es lógico, ya que el aborto del ovario es uno de los mecanismos por los que se ha explicado 
la acción de esta auxina sobre el aclareo de frutos en el manzano (Luckwill, 1953). Tanto en los árboles aclarados a mano, como en los tratados con ANA, el aumento del peso individual de los frutos compensa su pérdida y la cosecha no se ve alterada o aumenta ligeramente. Ello enfatiza el papel de la competencia por carbohidratos entre frutos en desarrollo como factor capaz de determinar su tamaño final (Nitsch, 1950).

La mejora del tamaño de los frutos también puede lograrse mejorando su disponibilidad de carbohidratos mediante el rayado o anillado de ramas. Esta técnica se ha mostrado eficaz en los cítricos (Furr et al., 1945), cerezos y ciruelos (Agustí et al., 1997), en melocotoneros y nectarinas (Agustí et al., 1998) y en el níspero japonés (Agustí et al., 2005). El momento de realización del rayado es de gran importancia, ya que si se lleva a cabo de forma anticipada aumenta el cuajado de frutos, repercutiendo negativamente sobre el tamaño de éstos o aumentando las necesidades de aclareo, mientras que si se retrasa a etapas avanzadas de la fase de engrosamiento celular pierde, progresivamente, eficacia (Agustí et al., 1998).

Otro modo de facilitarle al fruto la captación de carbohidratos es aumentando su capacidad sumidero. Ello puede lograrse con la aplicación de auxinas de síntesis (Schiaparelli et al., 1995; Agustí et al., 1997). La respuesta de los frutos con semilla a la aplicación de reguladores del crecimiento se puede explicar teniendo en cuenta que el tamaño final de los frutos no sólo depende de la competencia entre frutos u otros órganos en crecimiento, sino de la capacidad por atraer los asimilados (De Jong y Walton, 1989). En frutales de hueso la aplicación de auxinas de síntesis refuerza esta actividad y mejora el tamaño del fruto por un efecto directo sobre su desarrollo (Agustí et al., 1997), constituyendo, por lo tanto, una técnica eficaz para aumentar el tamaño final del fruto. El tratamiento también logra una anticipación en la entrada en color del fruto, permitiendo anticipar la recolección. En el caso del níspero japonés, la única sustancia hormonal que ha mostrado, hasta hoy, efectos agronómicamente recomendables es el éster butilglicólico del ácido 2,4-diclorofenoxipropiónico (2,4-DP) (Agustí et al., 2003).

\subsection{El fruto y el desarrollo radicular}

El reparto de carbohidratos en el árbol se halla fuertemente influido por los sumideros en desarrollo, de modo que el desarrollo reproductivo, vegetativo y radicular compiten entre sí (Gifford y Evans, 1987; Ho et al., 1989; Patrick, 1989). Los estudios de productividad indican que la cantidad de carbohidratos transportados a los frutos en crecimiento es mayor, en peso, que la transportada a cualquier otro órgano, de modo que las determinaciones directas utilizando ${ }^{14} \mathrm{CO}_{2}$ demuestran que los frutos actúan como potentes sumideros responsables del transporte de fotoasimilados desde las hojas a ellos mismos.

Las raíces son sumideros débiles que se ven fuertemente afectadas por la presencia de otros órganos en desarrollo. De hecho, su crecimiento sólo tiene lugar cuando se recolectan los frutos o cesa el desarrollo vegetativo, por eso, los árboles altamente productivos suelen tener un sistema radicular poco desarrollado. 
Ello, sin embargo, no es general en todas las especies y así en el cerezo la presencia de los frutos no condiciona el desarrollo vegetativo ni radicular.

Pero el crecimiento de las raíces también depende de las disponibilidades hídricas y nutricionales y está controlado hormonalmente. El estrés hídrico trae como consecuencia el cese del desarrollo radicular, lo que algunos autores relacionan con una restricción del aporte de giberelinas a la copa. Sin embargo, Layne et al. (1986) observaron que melocotoneros maduros sometidos a condiciones de escasez de agua desarrollaban más raíces. La primera respuesta a una sequía controlada fue el incremento de los brotes y yemas, así como una reducción en la asimilación del carbono (Flore et al., 1994).

Por otra parte, la actividad foliar es indispensable para nutrir adecuadamente a las raíces de metabolitos y hormonas. De hecho, la evolución del desarrollo radicular a lo largo del año es antifásica con la de los brotes vegetativos en la mayoría de las especies, de modo que cuando éstos se desarrollan más intensamente, la formación de nuevas raíces disminuye, apuntando a un cierto gardo de competencia entre la copa y la raíz. La ausencia de frutos permite, por una parte, el desarrollo vegetativo y, por otra, la acumulación de reservas en las raíces que suministrarán el poder reductor necesario para que reduzcan los nitratos a amonio y éste, finalmente, forme parte de aminoácidos. Así pues, el carbono asimilado se reparte entre la síntesis de carbohidratos y la de aminoácidos. Es por ello que durante la incorporación del $\mathrm{NH}_{4}{ }^{+}$en aminoácidos la demanda de carbohidratos por parte de la raíz es muy elevada y el árbol debe satisfacerla para utilizar el nitrógeno de manera eficiente. Priestley (1972) y Catlin y Priestley (1976) concluyeron que el árbol produce suficientes carbohidratos para la utilización del $\mathrm{N}$ y que su disponibilidad sólo se ha mostrado insuficiente en el proceso por un efecto derivado del crecimiento de los frutos.

\subsection{Su interacción con la maduración}

El cambio de color de los frutos es un proceso característico de la maduración de la mayor parte de los frutos. La degradación de unos pigmentos y la síntesis y acumulación de otros es, sin embargo, variable, cuantitativa y cualitativamente, con ellos.

En los cítricos, la separación entre la corteza y la pulpa, no conectadas vascularmente entre sí, contribuye a que la maduración de ambos tejidos esté regulada por mecanismos diferentes. La hipótesis de Huff sobre la coloración de estos frutos está basada en el transporte de carbohidratos, nitrógeno y hormonas al fruto en combinación con las condiciones climáticas. Mientras la temperatura permite el desarrollo de las raíces, las hormonas sintetizadas en ellas y el nitrógeno absorbido y reducido por ellas son transportados al fruto, previniéndolo del cambio de color; a ello contribuye el desarrollo competitivo de los nuevos brotes por carbohidratos, que exigen compartir el reparto de los fotoasimilados. Cuando bajan las temperaturas, el desarrollo radicular cesa y, por tanto, se detienen la síntesis hormonal y la absorción de nitrógeno y su transporte hacia el fruto. Como el desarrollo vegetativo también se detiene, los 
fotoasimilados son transportados mayoritariamente a los frutos, todo lo cual promueve la conversión de cloroplastos en cromoplastos y, por tanto, la pérdida de color verde de la corteza del fruto, la síntesis de carotenoides y, finalmente su coloración típica (Huff, 1983; 1984; Agustí, 2003; Iglesias et al., 2007). Un estudio semejante no se ha realizado en otras especies frutícolas.

A la vista de estos antecedentes, la capacidad sumidero del fruto en desarrollo parece suficientemente potente para competir con otros órganos en desarrollo $y$, en gran medida, vencer. $Y$ hacerlo en competencia con todos ellos a la vez. Los estudios aquí expuestos son, en su totalidad, parciales, relacionando el crecimiento del fruto con un aspecto concreto de un órgano particular en desarrollo, y no existe ningún estudio que aborde la influencia del fruto en crecimiento sobre el desarrollo global del árbol y sus órganos, esto es, sobre la actividad de sus yemas, la brotación y la floración, el propio desarrollo de los frutos y el crecimiento y la actividad radiculares. Esta Tesis Doctoral es un intento de ello, de modo que pretende contribuir al conocimiento del desarrollo global del árbol frutal bajo el punto de vista nutricional y hormonal, y teniendo como eje conductor el papel protagonista influyente del fruto, y la especie Eriobotrya japonica como objetivo general. 


\section{OBJETIVO}

En esta Tesis Doctoral se estudia el desarrollo del fruto del níspero japonés bajo el punto de vista nutricional y hormonal, teniendo como objetivo la siguiente Hipótesis de Trabajo:

En el níspero japonés, el fruto, a través de su capacidad sumidero, restringe la brotación y el desarrollo vegetativo, reproductivo y radicular en beneficio propio; el fruto también controla su propio crecimiento en competencia con otros órganos de la planta, sobre todo frutos, y armoniza el tiempo y el proceso de su propia entrada en color y maduración.

\section{OBJECTIVE}

The aim of this $\mathrm{PhD}$ Thesis is to study loquat fruit development under nutritional and hormonal point of view, according to the following Hypothesis:

In loquat, fruit sink capacity reduces bud break and vegetative and reproductive shoot development and also reduces root growth and root activity to its own advantage; fruit controls its own size as well through a competition for carbohydrates among developing organs, mainly fruits, and harmonizes colour break and maturation processes. 


\section{Materiales y métodos}





\section{Materiales y métodos.}

\section{1.- Material vegetal}

Los experimentos se realizaron en plantaciones comerciales de níspero japonés (Eriobotrya japonica Lindl.), cvs. Algerie, Piera, Golden Nugget y San Filipparo bajo condiciones normales de cultivo, con riego localizado y fertirrigación.

Los árboles adultos de entre 20 y 25 años de edad estaban injertados sobre patrón franco, podados en forma de vaso, con un marco de plantación de entre 4 × 3m y 4 × 5m dependiendo de la parcela, y localizados en Callosa d'En Sarrià (Alicante, España, $38^{\circ} 39^{\prime} \mathrm{N}$; $00^{\circ} 07^{\prime} \mathrm{W}$ ), Palermo (Sicilia, Italia, $38^{\circ} 04^{\prime} \mathrm{N} ; 13^{\circ} 25^{\prime} \mathrm{E}$ ) y Trapani (Sicilia, Italia, $37^{\circ} 41^{\prime} \mathrm{N}$; $12^{\circ} 47^{\prime} \mathrm{E}$ )

Para los experimentos de desarrollo radicular también se utilizaron árboles jóvenes en producción de los cvs 'Algerie' y 'Piera', de 3 años de edad. Algunos de ellos se cultivaron en macetas de plástico transparente, de $40 \mathrm{~cm}$ de diámetro, que se introdujeron, a su vez, dentro de macetas de plástico negro de mayor diámetro y que finalmente se cubrieron con bolsas de plástico negro hasta conseguir la completa oscuridad. Otros se plantaron directamente en macetas de plástico negro. Todos ellos localizados en una parcela de la Escuela Técnica Superior de Ingenieros Agrónomos de la Universidad Politécnica de Valencia $\left(39^{\circ} 33^{\prime} \mathrm{N}\right.$; $00^{\circ} 34^{\prime} \mathrm{W}$ ), disponían de condiciones normales de riego localizado, fertilización y control fitosanitario.

\section{2.- Experimentos}

\section{Capítulo 1.- Características morfológicas y fenológicas del cv. Piera.}

De la parcela experimental de la Cooperativa de Callosa d’En Sarrià se siguió semanalmente el comportamiento fisiológico de 5 árboles adultos del cv. Piera, paralelamente al de su parental el cv. Algerie. Se caracterizaron, por una parte, la naturaleza de sus yemas y se siguió, por otra, la evolución de algunas de ellas a lo largo de todo el ciclo vegetativo, estableciendo un cronograma que englobaba las diferentes generaciones de flores, en sus respectivas épocas de iniciación y diferenciación floral, de antesis, de desarrollo de frutos y de recolección.

Aleatoriamente se muestrearon 10 brotes reproductivos de cada árbol y cultivar, y se detallaron comparativamente las características morfológicas de sus hojas (peso, longitud, anchura, número y profundidad de los dientes del borde de la hoja, número de nervios, longitud del peciolo y color del haz) y de los granos de polen (dimensiones del eje polar y 
ecuatorial y la longitud del mesocolpo), para lo que se utilizó un microscopio electrónico de barrido (SEM). Una muestra de granos de polen se montó sobre el portaobjetos del SEM y se cubrió con una capa de oro en un dispositivo Polaron E-6100. Las observaciones se realizaron con un escáner de microscopía electrónica JEOL JSM-5410

Se midieron las dimensiones de sus panículas (forma y estructura) y se contaron y pesaron sus flores individuales. Se recolectaron las diferentes generaciones de frutos, se pesaron y de los frutos maduros se determinaron sus características de firmeza, concentración de sólidos solubles totales (SST), acidez y color. La firmeza se determinó con un penetrómetro FT-011 (Facchini, Italia) utilizando una varilla de $1.5 \mathrm{~mm}$ de diámetro. Para determinar la concentración de SST se utilizó un refractómetro digital (Atago, Tokio, Japón). La acidez libre se valoró con $\mathrm{NaOH} 0.1 \mathrm{~N}$ utilizando fenolftaleína como indicador. El color se midió determinando las coordenadas $a$ y $b$ de Hunter, utilizando un Minolta Chroma Meter CR-300 (Osaka, Japón).

\section{Capítulo 2.- Influencia del fruto en la brotación y el desarrollo vegetativo.}

\section{- Eliminación y/o aislamiento temporal de los frutos.}

Se seleccionaron 5 árboles adultos de níspero japonés cv. Algerie próximos al cv. Piera y de volúmenes parecidos. De cada uno de ellos se seleccionaron al azar 12 brotes reproductivos con un número de frutos prácticamente idéntico. A 4 de ellos se les eliminaron las panículas enteras cuando sus frutos estaban en el estado fenológico 701 de la escala BBCH, a otros 4 se les anilló la panícula en el mismo estado fenológico, eliminando un anillo de $2 \mathrm{~cm}$ de anchura de corteza con un bisturí y los restantes se dejaron como controles (Época I). Esto mismo se repitió 1 mes más tarde en otros 12 brotes reproductivos diferentes de los mismos árboles, cuando los frutos ya habían alcanzado el estado fenológico 703 de la escala BBCH (Época II).

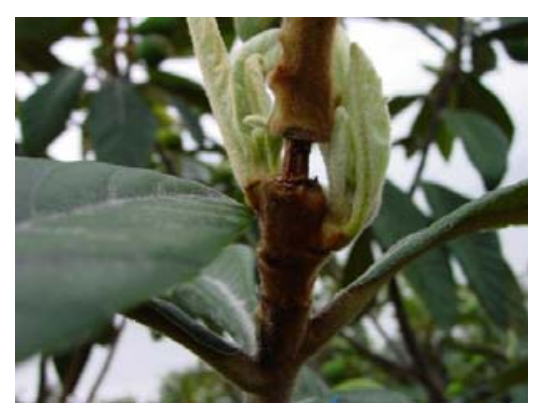

Anillado de un brote mixto del cv. Algerie
De cada uno de ellos se evaluó regularmente, durante 5 años consecutivos, hasta el momento de la antesis, el número de brotes principales y anticipados, así como su longitud y el número de sus hojas. En los brotes anillados y en los controles, además se midió el diámetro de sus frutos hasta la recolección y las características de sus frutos maduros (firmeza, SST, acidez y color), del mismo modo descrito en el apt. anterior. 


\section{- Influencia de la semilla}

Cinco árboles adultos de níspero japonés cv. Algerie se trataron con $100 \mathrm{mg} \mathrm{I}^{-1}$ de ácido giberélico (AG), tres veces en preantesis (estados 504, 506 y 508 de la escala BBCH), para promover la partenocarpia y se dejaron otros 5 árboles sin tratar como controles. Posteriormente se seleccionaron 4 brotes reproductivos con todos sus frutos partenocárpicos de cada árbol y otros 4 brotes de cada árbol control.

De cada uno de ellos se evaluó hasta el momento de la antesis, el número de brotes principales y anticipados, su longitud y el número de hojas y el diámetro de sus frutos hasta el momento de su recolección.

El experimento se repitió durante 2 años consecutivos.

\section{- Eliminación de los frutos. Estudio al árbol completo.}

Sse seleccionaron 8 árboles adultos, en cultivo, del cv. Algerie de cosecha y volumen de copa aparentemente iguales. A 4 de ellos se les eliminaron todos sus frutos manualmente en el estado fenológico 702 de la escala $\mathrm{BBCH}$, mientras que a los 4 restantes se les dejaron todos hasta su recolección. A los primeros los llamamos SF y a los segundos CF. Al igual que en experimentos anteriores se seleccionaron, completamente al azar, 4 brotes de cada árbol a los que se les midió regularmente hasta el momento de la antesis, el número de brotes principales y anticipados, así como su longitud y el número de sus hojas.

\section{- La influencia del fruto en el reparto de carbohidratos.}

De todos los brotes marcados y descritos anteriormente, excepto de los partenocárpicos, se tomaron muestras de sus hojas, floema y frutos, cuando los hubo, para el análisis de carbohidratos. En los brotes anillados se muestreó por separado el floema de la parte de arriba del anillado del de la parte de abajo. En el caso de los árboles CF y SF, además se muestrearon sus raíces. Al menos 4 brotes por árbol y $200 \mathrm{~g}$ de raíz se tomaron por muestra. Además, se analizó por separado el almidón de las hojas de estos brotes.

Estos muestreos se realizaron periódicamente atendiendo a los estados fenológicos de los brotes seleccionados, que fueron los siguientes:

- Estado fenológico 702 de la escala BBCH: Aproximadamente 30 días después de la eliminación de las primeras panículas, de los primeros anillados y la realización de los segundos. El equivalente en los CF y SF al estado fenológico 703 de la misma escala. 
- Estado fenológico 704 de la escala BBCH: 30 días después de la eliminación de las segundas panículas y segundos anillados. El correspondiente al 705 en los árboles CF y SF.

- Estado fenológico 705- 706 o 707 (CF y SF) de la escala BBCH: pleno crecimiento exponencial de los frutos.

- Estado fenológico 709 de la escala BBCH: cuando los alcanzaron el 90\% de su tamaño final.

- Estado fenológico 801 de la escala BBCH: en el momento del cambio de color del fruto.

- Estado fenológico 809 de la escala BBCH: en el momento de la maduración. Cuando el fruto está apto para su recolección y consumo.

- Estado fenológico 325 de la escala BBCH: pleno desarrollo vegetativo.

En el texto se hace referencia a un estado fenológico 809+ inexistente, pero que quiere indicar frutos que han sobrepasado incluso su periodo de senescencia y se hallan próximos a la momificación.

Un experimento basado en la completa defoliación de los brotes reproductivos del níspero japonés cv. Algerie se realizó con el fin de evaluar el efecto de la ausencia de hojas en el reparto de carbohidratos, y su influencia sobre la brotación y floración siguientes. Para ello se seleccionaron 8 brotes reproductivos de cada uno de los 5 árboles utilizados en el experimento de la eliminación y/o aislamiento temporal del fruto. A 4 de ellos se les eliminaron las hojas en el estado fenológico 701 de la escala $\mathrm{BBCH}$ y a los restantes en el estado 703 de la misma escala. La brotación de estos brotes se evaluó como se ha descrito anteriormente y el floema y los frutos de éstos también se muestrearon para su posterior análisis de carbohidratos.

- Determinaciones analíticas de carbohidratos.

De las muestras tomadas en el campo se separaron sus tejidos (hojas, floema, xilema, frutos,...), se congelaron inmediatamente con $\mathrm{N}$ líquido, se transportaron al laboratorio a baja temperatura $\left(\approx 5^{\circ} \mathrm{C}\right)$ y se liofilizaron.

Partiendo de $100 \mathrm{mg}$ de tejido vegetal liofilizado y molido, se procedió a su extracción. A cada muestra se le añadieron $1 \mathrm{ml}$ de etanol al $80 \%$ y $100 \mu \mathrm{l}$ de una solución con $60 \mathrm{mg} \mathrm{ml}^{-1}$ de D- manitol (Sigma-Aldrich), un compuesto hidrocarbonado no existente en los tejidos vegetales del níspero japonés, y que fue usado como estándar interno para corregir las posibles pérdidas de los azúcares durante el proceso de extracción y purificación de los mismos. 
Tras homogeneizar la muestra se calentó en un baño termostatizado a 85 으 durante 5 minutos. El homogeneizado se centrifugó a $12.000 \mathrm{rpm}$ durante 10 minutos en una centrífuga Pselecta meditronic -BL y el sobrenadante se recogió en un tubo eppendorf. La extracción se repitió dos veces más. El sobrenadante resultante fue evaporado en condiciones de vacío en un Speed-vac (Savant ${ }^{\circ}$ ) a $40 \circ \mathrm{C}$, hasta obtener un volumen de $0.5 \mathrm{ml}$.

El extracto vegetal se purificó mediante un filtrado a través de dos columnas de resina. La resina catiónica "Dowex" 50Wx8-100 (Acros organics) disuelta en $\mathrm{HCl} 2 \mathrm{~N}$, y la aniónica "Dowex" 1x4-100 (Fluka chemie GMBH) mesh, disuelta en $\mathrm{Na}_{2} \mathrm{CO}_{3} 1 \mathrm{M}$. Antes de su utilización las resinas se llevaron a un pH entre 4,5-5 (Mehouachi et al., 1995) para la resina catiónica y un $\mathrm{pH}$ entre 7,5-8 para la resina aniónica mediante sucesivos lavados con agua Milli-Q.

La muestra se hizo pasar por filtros de nylon de 0,45 $\mu \mathrm{m}$ y un cartucho C-18. La muestra purificada se evaporó en un Speed-Vac hasta obtener un residuo sólido de azúcares que, posteriormente se disolvió en $100 \mu \mathrm{l}$ de una agua $\mathrm{mQ}$.

Para la determinación de carbohidratos presentes en el material vegetal, se inyectaron $20 \mu \mathrm{l}$ de esta solución en un HPLC (High Performance Liquid Cromatography) Spectra System ${ }^{\circledR}$, equipado con un refractómetro diferencial R150, una bomba de vacío P2000 y un sistema de procesamiento de datos Chrom Quest para Windows NT. La columna utilizada fue del tipo Waters $^{\mathrm{TM}}$ Sugar-PAK ${ }^{\mathrm{TM}}$ I adaptada a una precolumna del tipo Sugar-Pak ${ }^{\mathrm{TM}}$ ॥ Guard-Pak ${ }^{\mathrm{TM}}$. EI

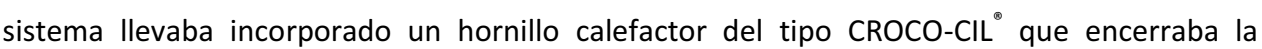
columna del HPLC y alcanzaba una temperatura de 85으, El disolvente utilizado fue agua Milli$\mathrm{Q}$, a un flujo de $0.5 \mathrm{ml} / \mathrm{min}$.

Los azúcares obtenidos se identificaron por comparación del tiempo de retención con muestras de patrones puros y se cuantificaron por extrapolación con una curva de calibración elaborada con concentraciones conocidas de cada azúcar. Se utilizó un factor de corrección dependiente de la recuperación de D-Manitol y los resultados se expresaron en gramos de azúcar por 100 gramos de materia seca.

Para la determinación de almidón, el residuo sólido obtenido después de la extracción de azúcares con etanol, se diluyó con agua miliQ hasta un volumen de $6 \mathrm{ml}$. El material se esterilizó en autoclave ( $\mathrm{P}$ selecta) durante $2 \mathrm{~h}$ a $130^{\circ} \mathrm{C}$ y a una presión entre 1.2 y 1.5 bares. Los tubos autoclavados se centrifugaron a 4500 rpm en una centrífuga P Selecta Meditronic BL y se enrasó el volumen de agua de cada tubo hasta aproximadamente $2 \mathrm{ml}$.

Posteriormente se añadieron $0.2 \mathrm{ml}$ de fucosa de concentración $30 \mathrm{mg} / \mathrm{ml}, 0.5 \mathrm{ml}$ de una solución tampón de acetato sódico a PH 4.5 ( $40 \%$ ácido acético $0.2 \mathrm{M}$ y $60 \%$ acetato sódico 0.2 M ) y $1 \mathrm{ml}$ de solución de enzima amiloglucosidasa de Rhizopus mold (Sigma Química) de concentración $60 \mathrm{mg} / \mathrm{ml}$. 
Se dejó actuar el enzima durante $2 \mathrm{~h}$ en un baño a 55으, para hidrolizar el almidón a glucosa, agitando de vez en cuando con el agitador del baño. Se centrifugó durante 30 min a 4500 rpm para recoger el sobrenadante en tubos de vidrio Pirex-18.

Se evaporó el agua en un Speed Vac (Savant Holbrook, NY) hasta sequedad. A continuación se añadió $1 \mathrm{ml}$ de agua MilliQ a cada tubo y, finalmente se centrifugaron durante 20 minutos a 12000 rpm en una centrífuga P-selecta Meditronic-BL.

Posteriormente se filtró el conjunto con un cartucho C-18 y con uno de $0.45 \mu \mathrm{m}$. Se inyectaron $20 \mu \mathrm{l}$ de esta solución en el HPLC, cuyas características se detallaron en apartado anterior, para cuantificar la glucosa liberada. Los resultados se expresaron en mg de glucosa liberada por g de materia seca

\section{- La influencia del fruto en la movilización de fracciones nitrogenadas}

Los mismos brotes que se muestrearon aleatoriamente en los árboles con todos los frutos (CF) y sin ninguno de ellos (SF) para la determinación de los carbohidratos, se utilizaron para el análisis de las fracciones nitrogenadas.

- Determinaciones analíticas del Nitrógeno Proteico y Nitrógeno Amoniacal $\left(\mathrm{N}_{-} \mathrm{NH}_{4}^{+}\right)$.

La extracción de las fracciones de nitrógeno proteico y nitrógeno amoniacal se basó en la metodología propuesta por Maquieira et al. (1980). Se pesaron $0.5 \mathrm{~g}$ de muestra liofilizada y molida a la que se le añadieron $10 \mathrm{ml}$ de ácido tricloro acético frío al 5\% (TCA 5\%-T6399 SIGMA-ALDRICH) para precipitar la fracción proteica. La suspensión se agitó durante 15 min en un agitador magnético múltiple marca RO5 IKA-WERKE, a continuación se le añadieron $30 \mathrm{ml}$ de TCA $5 \%$ y se introdujo en nevera a 4ㅇ C durante 15 minutos

Después se procedió al filtrado mediante un embudo con papel de filtro (Schleicher y Shvell, de $90 \mathrm{~mm}$ ) recogiendo la muestra en un matraz. Se realizó un lavado del recipiente en el que estaba la muestra con $10 \mathrm{ml}$ de TCA 5\% frío, pasándolo también a través del filtro, y luego se lavó el embudo tres veces con $10 \mathrm{ml}$ de TCA 5\% frío. Después del último lavado se dejó escurrir el residuo durante 15 minutos, aproximadamente.

El conjunto del residuo sólido y el papel de filtro se introdujeron en un tubo de digestión Tecator (Foss, Hoagans, Sweden). Al tubo se le añadieron $3 \mathrm{~g}$ de una mezcla de catalizadores compuesta por sulfato potásico $\left(\mathrm{K}_{2} \mathrm{SO}_{4}\right)(\mathrm{SIGMA})$, sulfato cúprico $\left(\mathrm{CuSO}_{4}\right) 99 \%(\mathrm{SiGMa})$ y Selenio (Se) metal, polvo purísimo (Panreac), en una proporción de 10:1:0.1, respectivamente; además se añadieron $10 \mathrm{ml}$ de ácido sulfúrico 96\% (Panreac 131058) y $10 \mathrm{ml}$ de peróxido de 
hidrógeno 35\% (Scharlau HI 0138, Reagent grade). El tubo Tecator se introdujo en el digestor a 450 $\mathrm{C}$ durante 30 minutos. Posteriormente se añadieron $50 \mathrm{ml}$ de agua destilada a cada tubo y se destilaron en un destilador Foss Kjeltec 2200 Auto Destillation, en corriente de vapor durante 4 minutos, utilizando $\mathrm{NaOH} 40 \%$ como alcalinizante, agua destilada y una solución ácido bórico indicador (ácido bórico $2 \%$, rojo de metilo, verde de bromocresol; Laboratorio MALAB). El destilado se valoró con ácido clorhídrico $0.1 \mathrm{~N}$, factor 1 . Paralelamente se valoró un ensayo como blanco.

El porcentaje de nitrógeno proteico se calculó de acuerdo con la siguiente ecuación:

\section{$\% \mathrm{NP}=\underline{\mathrm{ml} \mathrm{HCl} \times \text { factor del } \mathrm{HCl} \times \text { normalidad del } \mathrm{HCl} \times 100 \times 14}$ \\ $1000 \times$ peso muestra original $(\mathrm{g})$}

Se tomó una alícuota de $10 \mathrm{ml}$ de las muestras guardadas en nevera y usando un muestreador automático 5027 Sampler del equipo Fiastar 5000 Analyzer equipado con el cassette del ión amonio $\left(\mathrm{N}-\mathrm{NH}_{4}{ }^{+}\right)$, siguiendo la metodología propuesta por Raigón et al. (1992) y Foss Tecator $\mathrm{AB}(2000)$ se determinó la concentración de $\mathrm{N}-\mathrm{NH}_{4}{ }^{+}$

El amoníaco es arrastrado y disuelto por el Reactivo 2, con el cuál reacciona produciendo un cambio de color que se cuantifica por espectrofotometría a una longitud de onda de $590 \mathrm{~nm}$. Los reactivos utilizados fueron:

Carrier: Agua mQ.

Reactivos: $\mathrm{NaOH}$ 0.5M (Reactivo 1) y solución indicadora (Sulfanilamida Reactivo 2). La solución indicadora se preparó diluyendo $10 \mathrm{ml}$ de la solución madre indicadora (Indicator Stock Solution) en $500 \mathrm{ml}$ de agua $\mathrm{mQ}$. La solución madre indicadora se preparó disolviendo $1 \mathrm{~g}$ de amonio indicador con $10 \mathrm{ml}$ de $\mathrm{NaOH} 0.01 \mathrm{M}$ y $10 \mathrm{ml}$ de etanol $95 \%$ y finalmente enrasando hasta $200 \mathrm{ml}$ con agua $\mathrm{mQ}$.

El equipo requiere realizar una calibración previa a cada análisis para la cual se prepararon los siguientes patrones de calibración a distintas concentraciones en $\mathrm{mg}^{-1}: 0,0.1,0.3,0.7,1,1.5$, 2 y 4, a partir de la Standard Stock Solution $1000 \mathrm{mg} \mathrm{I}^{-1} \mathrm{NH}_{4}^{+}$(SSS) y de la Interim Stock Solution $20 \mathrm{mgl}^{-1} \mathrm{NH}_{4}^{+}$(ISS).

Determinaciones analíticas de los Nitratos $\left(\mathrm{N}-\mathrm{NO}_{3}^{-}\right.$y $\left.\mathrm{N}-\mathrm{NO}_{2}^{-}{ }^{-}\right)$.

La extracción de las fracciones de nitrógeno nitrato y nitrito se basó en la metodología propuesta por Beljaars et al. (1994) y FOSS Tecator AB (2001). Se pesaron $0.5 \mathrm{~g}$ de muestra previamente liofilizada y molida, posteriormente se le añadieron $50 \mathrm{ml}$ de agua $\mathrm{mQ}$. La suspensión se agitó durante $30 \mathrm{~min}$ en un agitador magnético múltiple marca RO5 IKA-WERKE 
y se filtró mediante un embudo y papel de filtro de $90 \mathrm{~mm}$ (Schleicher y Shvell). El filtrado se recogió en un matraz del cual se tomó una alícuota de $10 \mathrm{ml}$ que se introdujo en un tubo de ensayo directamente en el muestreador automático 5027 Sampler del equipo Fiastar 5000 Analyzer equipado con el cassette correspondiente a la determinación del ion ( $\left.\mathrm{N}-\mathrm{NO}_{3}{ }^{-}\right)$y $(\mathrm{N}-$ $\mathrm{NO}_{2}^{-}$) siguiendo la metodología propuesta por Foss Tecator $\mathrm{AB}$ (2001). El cassette de $\mathrm{NO}_{3}^{-}$y $\mathrm{NO}_{2}{ }^{-}$incluye una columna de reducción de cadmio, cuya finalidad es reducir todos los nitratos a nitritos, y una membrana de diálisis para purificar la muestra. Los nitritos reaccionan con la sulfanilamida (Reactivo 2) y el NED (Reactivo 3) generando un coloración rojo púrpura que se mide con un espectrofotómetro a una longitud de onda de $540 \mathrm{~nm}$. Los reactivos utilizados en este análisis son:

\section{Carrier: Agua $\mathrm{mQ}$}

Reactivos: $\mathrm{NH}_{4} \mathrm{Cl}$ a pH 8.5 (Reactivo 1), sulfanilamida (Reactivo 2) y NED (Reactivo 3).

El equipo requiere una calibración previa a cada análisis para la cual se prepararon los patrones de calibración a distintas concentraciones en $\mathrm{mg}^{-1}: 0,0.10,0.25,0.50,0.75,1,2,4 \mathrm{a}$ partir de la Standard Stock Solution $1000 \mathrm{mg} \mathrm{I}^{-1} \mathrm{NO}_{3}^{-}$(SSS) y de la Interim Stock Solution 100 $\mathrm{mg} \mathrm{I}^{-1} \mathrm{NO}_{3}^{-}$(ISS).

\section{- La influencia del fruto en el balance hormonal}

A partir de 100 mg de muestra liofilizada y molida se realizó la extracción de ácido abscísico (ABA), ácido indolacético (AIA) y zeatina, con $2 \mathrm{ml}$ de metanol al $80 \%$. Se agitó varias veces y se dejó durante 24 horas en agitación a 4 ํㅡ. Posteriormente se centrifugó en frío (4ํㅡ) a 13000 rpm durante 10 min y se recogió el sobrenadante en un tubo de ensayo silanizado.

El residuo sólido se diluyó en $1 \mathrm{ml}$ de metanol al 100\%, se agitó varias veces y se dejó reposar durante $60 \mathrm{~min}$. Se volvió a centrifugar en frío $(4$ 으) a $13000 \mathrm{rpm}$ durante $10 \mathrm{~min}$ y el sobrenadante se añadió al anterior.

Se filtró el conjunto a un nuevo tubo de ensayo silanizado mediante filtros de $0.45 \mu$ y 0.22 $\mu$ y se evaporó en un Speed-Vac hasta sequedad. Se re-suspendió con metanol para su purificación con cartuchos C-18 y HPLC (Agustí et al., 2007). Las fracciones del HPLC se metilaron y se inyectaron 1-2 $\mu \mathrm{l}$ de muestra en un cromatógrafo de gases Varian Star $3400 \mathrm{CX}$ acoplado a un espectofotómetro de masas Varian Saturn de $85 \mathrm{kPa}$ de presión y $200^{\circ} \mathrm{C}$ de temperatura para su separación. El ABA, AIA y zeatina se cuantificaron en base a los estándares internos que se añadieron a los extractos según el contenido endógeno que se encontró en la mayoría de las muestras. Se añadieron diferentes cantidades de $\left[{ }^{2} \mathrm{H}_{6}\right]-A B A$, $\left[{ }^{2} \mathrm{H}_{6}\right]$-AIA y $\left[{ }^{2} \mathrm{H}_{5}\right]$-zeatina a las muestras como estándares internos y cada una de las hormonas 
se identificaron en base a los iones que se monitorearon por reacción múltiple siguiendo las masas moleculares y el método descrito por Agustí et al. (2007) y Domingo et al. (2009). La cuantificación de cada una de ellas se hizo por referencia a la curva de calibración elaborada con concentraciones conocidas.

\section{Capítulo 3.- Influencia del fruto en la floración}

De todos los brotes descritos en el apartado anterior, se evaluaron en el momento de la antesis, el número de flores de las panículas principales y anticipadas, así como el número de brazos de cada una de ellas. Los análisis puntuales de carbohidratos, fracciones nitrogenadas y hormonas se realizaron del mismo modo que en el apartado anterior.

De las mismas plantaciones de níspero japonés cv. Algerie en las que se realizaron los experimentos anteriores, se selecionaron 25 árboles de cosecha aparentemente similar y de cada uno de ellos se seleccionaron 8 panículas con el mismo número de frutos. Desde el momento del aclareo manual, cuando los frutos tenían el $10 \%$ de su tamaño final, hasta su senescencia, se fueron eliminando periódicamente la totalidad de los frutos de las panículas seleccionadas, de las que el otoño siguiente se evaluó la brotación y floración del modo descrito anteriormente. Las fechas en las que se eliminaron los frutos fueron las siguientes:

- Diciembre: Estado fenológico 701 de la escala BBCH. Momento del aclareo manual.

- Enero: Estado fenológico 702 de la escala BBCH.

- Febrero: Estado fenológico 703 de la escala BBCH.

- Principios de Marzo: Estado fenológico 705 de la escala BBCH. Pleno desarrollo exponencial del fruto.

- Finales de Marzo: Estado fenológico 707 de la escala BBCH. Pleno desarrollo exponencial del fruto.

- Principios de Abril: Estado fenológico 709 de la escala BBCH. El fruto alcanzó el 90\% de su tamaño final.

- Finales de Abril: Estado fenológico 809 de la escala BBCH. Momento de la maduración y recolección

- Junio: Estado fenológico 809+ de la escala BBCH. Frutos completamente senescentes, casi momificados.

Paralelamente se siguió la evolución del crecimiento del fruto para lo cual se determinó periódicamente su diámetro y peso fresco y seco medio. 
- Otros experimentos basados en aplicaciones en diferentes épocas de ácido giberélico (AG) se realizaron en el níspero japonés con el fin de evaluar su efecto sobre la brotación y floración siguientes.

Estos experimentos se llevaron a cabo en árboles adultos de los cvs. 'Algerie' y 'San Filipparo'cultivados bajo condiciones de cultivo similares en Callosa d'En Sarrià, Alicante,

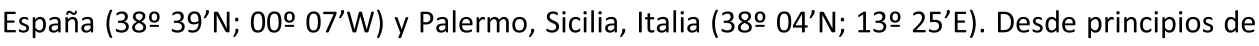
mayo (tras la recolección) hasta mediados de septiembre (próximo a la diferenciación del ápice), se aplicaron, quincenalmente, $150 \mathrm{mg} \mathrm{l}^{-1}$ de AG (Arabelex-L; 1.6\% w/v; Aragro; Madrid) pulverizando los árboles con tanque a una presión de 25-30 atm hasta goteo con el fin de determinar la (s) época(s) de mayor sensibilidad.

A principios de junio y de septiembre se aplicaron concentraciones crecientes $(0$, $50,100,150$ y $200 \mathrm{mg} \mathrm{l}^{-1}$ ) de AG con el fin de determinar la concentración óptima.

- En un experimento adicional se pulverizaron directamente con 0, 50, 100, 150, 200 y 250 $\mathrm{mg}^{-1}$ de $A G$, los ápices próximos a su diferenciación, de 25 brotes seleccionados al azar en cada árbol, que recibieron un total de $5 \mathrm{ml}$ de $A G$ cada uno. En todos los casos se añadió un agente tensoactivo (alkyl polyglycol eter) a una concentración de $0.01 \%$. El diseño de los experimentos fue de 4 bloques al azar con 4 repeticiones de un árbol cada una y el experimento se repitió durante 4 años en árboles diferentes.

En el momento de la floración, estado fenológico 507 de la escala BBCH (Martínez-Calvo et al. 1999), se evaluaron el número total de brotes vegetativos y reproductivos, distinguiendo las panículas principales de las anticipadas, en cada árbol. Los resultados se expresaron por $\mathrm{m}^{3}$ de copa con el fin de homogeneizar los volúmenes de los diferentes árboles y años. Se seleccionaron aleatoriamente 5 brotes principales de cada árbol a los que se les evaluó el número de hojas y de flores. El número total de flores por $\mathrm{m}^{3}$ de copa se calculó multiplicando directamente el número medio de flores de las panículas por el número de panículas por $\mathrm{m}^{3}$ de copa.

En el momento del aclareo, estado fenológico 701 de la escala BBCH (Martínez-Calvo et al. 1999), se calculó el porcentaje de cuajado contando el número de frutos de cada panícula de las que se habían contado los frutos, y en el momento de la recolección se evaluó la cosecha (kg) de cada árbol y el diámetro medio del fruto.

- En otro experimento complementario se seleccionaron 75 brotes de los cvs. 'Algerie' y 'Golden Nugget' repartidos aleatoriamente entre 5 árboles adultos de cada cultivar en campos de Callosa d'En Sarrià. A 25 de ellos se les eliminó completamente el ápice en la época de inducción floral (mediados de junio), a otrs 25 se les eliminó más tarde, en etapas próximas a 
su diferenciación (finales de agosto) y los restantes se dejaron como controles. Esto mismo se repitió en árboles adultos de los cvs. 'Algerie' y 'San Filipparo' en campos de Palermo.

En el momento de la antesis de cada uno de ellos se evaluó el número de brotes desarrollados y su naturaleza (vegetativos o reproductivos), el número de hojas y flores de cada brote y el número de hojas viejas, las del brote al que se le eliminó el ápice. A partir de estos valores se determinó el porcentaje de brotes vegetativos y reproductivos para cada uno de los tratamientos.

Se tomaron al azar muestras de los ápices y del floema de 5 nuevos brotes vegetativos y reproductivos que se desarrollaron a partir del brote principal al que se le eliminó su ápice en junio o agosto, inmediatamente antes de completarse la diferenciación floral, para el análisis de ABA y AIA que se siguió el protocolo anteriormente descrito.

\section{Capítulo 4.- El control del fruto sobre su propio desarrollo.}

Árboles adultos del cv. Algerie, cultivados en Callosa d'En Sarriá, fueron aclarados manualmente cuando el fruto alcanzó un diámetro medio de $1 \mathrm{~cm}$ (estado fenológico 702 de la escala $\mathrm{BBCH}$ ), dejando 1, 2, 3, 4, 5,... frutos por panícula, dejando los árboles control sin aclarar ( $\geq 9$ frutos/panícula). De cada tratamiento se realizaron 6 repeticiones distribuidas en 6 bloques al azar.

De cada uno de los tratamientos se hizo un seguimiento del crecimiento del fruto, determinándose su diámetro y pesos fresco y seco a partir de 30 frutos por árbol. De los tratamientos aclarados a 1, 3, 5 frutos por panícula y no aclarados (control) se realizó un seguimiento del contenido en carbohidratos. La semilla, se separó, se peso, se secó y de ella se determinaron carbohidratos y almidón. Estos se analizaron siguiendo el protocolo descrito en el apt. 2.

Capítulo 5.- Influencia del fruto en el desarrollo radicular y el transporte de carbohidratos. La maduración.

El experimento se llevó a cabo en árboles jóvenes de los cvs. 'Algerie' y 'Piera' cultivados en macetas transparentes y oscurecidas del modo descrito en el apt. 1. Cuando las raíces alcanzaron la superficie de la maceta, se evaluó, semanalmente, sobre una planilla transparente, el número de nuevas raíces formadas y su crecimiento en longitud $(\mathrm{cm})$. Cada semana se marcaron sobre la planilla las mediciones con un color diferente y las mediciones se expresaron como la tasa de crecimiento radicular diario $\left(\mathrm{mm} \mathrm{dia}^{-1}\right)$ calculada como: 
Tcd: $\Sigma$ longitud de todas las raíces desarrolladas en la semana $(\mathrm{mm}) / №$ total de raíces formadas 7 (días)
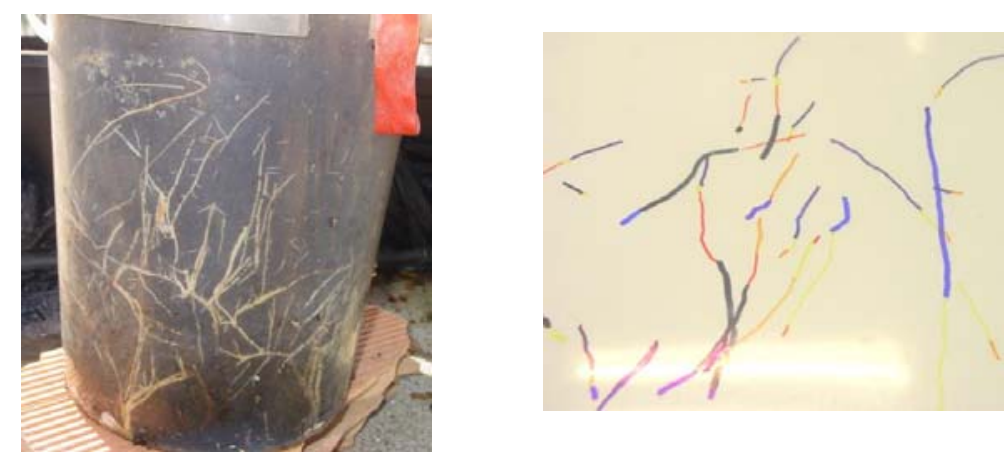

Raíces en crecimiento asomando a la superficie de la maceta transparente utilizada para su cultivo (izqda.) y transparencia con el seguimiento de su crecimiento (dcha.).

La actividad radicular también se evaluó indirectamente midiendo el número de puntos mitóticos de las raíces. Para ello, se muestrearon 15 raíces jóvenes de, aproximadamente, 5 $\mathrm{cm}$ de longitud de 5 árboles adultos del cv. Algerie que se lavaron, tiñeron y posteriormente evaluaron de acuerdo a la metodología descrita por Canellas et al (2002).

Paralelamente se siguió la evolución del crecimiento de los frutos midiendo su diámetro hasta su maduración. Se determinaron las características de maduración interna y externa de la misma manera que en los apartados anteriores.

En los estados fenológicos 702, 706, 709, 809 y 325 de la escala BBCH, se muestraron raíces, xilema, floema, frutos y hojas de ambos cultivares para el análisis de carbohidratos, fracciones nitrogenadas y hormonas como se ha descrito anteriormente. Paralelamente también se muestrearon todos estos órganos en los mismos estados fenológicos, además del 704, 801 y 339 de la escala $\mathrm{BBCH}$, en árboles adultos de los mismos cultivares para los mismos análisis.

Con el fin de estudiar el movimiento de los carbohidratos en los distintos órganos de la planta, se recurrió al empleo del ${ }^{13} \mathrm{C}$ como trazador. Para ello, se utilizaron árboles jóvenes del cv. Algerie, cultivados en maceta, en Palermo y Callosa, bajo condiciones de manejo similares. De ellos se seleccionaron 3 brotes en los estados fenológicos 703, 708, 801 y 809 de la escala $\mathrm{BBCH}$, se introdujeron en una cámara de plástico, dejando fuera los frutos, exponiéndolos a una atmósfera de ${ }^{13} \mathrm{CO}_{2}$ siguiendo el método descrito por Volpe et al. (2008). Este experimento de repitió durante 2 años consecutivos. 
A los 4 y 7 días de la aplicación del isótopo marcado de ${ }^{13} \mathrm{C}$ a los brotes, se muestrearon sus hojas, sus frutos, una porción del floema de la parte más basal del brote situado entre 40-50 $\mathrm{cm}$ de la rama expuesta, y sus raíces para el análisis del isótopo.

La relación isotópica ${ }^{13} \mathrm{C} /{ }^{12} \mathrm{C}$ se determinó por espectrometría de masas de relaciones isotópicas (IRMS, Delta Plus, Thermo Finnigan, Bremen, Alemania) en el gas carbónico procedente de la combustión completa de las muestras vegetales llevada a cabo en un analizador elemental (NC 2500, Thermo Finnigan). Para ello, se pesaron de 0,10 a 0,50 mg de materia seca según el tipo de órgano, previamente liofilizada y triturada, en cápsulas de estaño de $5 \times 9 \mathrm{~mm}$ (Eurovector, Milán, Italia) que se sellaron para su posterior análisis en el analizador elemental siguiendo la metodología de Martínez-Alcántara (2010). La comparación con una referencia calibrada frente a la referencia internacional V-PDB (Belemnite Viena Pee-Dee) permite calcular el contenido en carbono 13 en la escala relativa de $\delta^{13} \mathrm{C}(\%)$. Los valores de $\delta$ $13 \mathrm{C}$ se expresan en función del patrón interno como se explica a continuación:

[0 ${ }^{13} C_{\text {muestra/ref }} \%=\left(R_{\text {muestra }} / R_{\text {ref }}-1\right) \times 1000$

donde $R_{\text {muestra }}$ y $R_{\text {ref }}$ son respectivamente las relaciones isotópicas $\left({ }^{13} C /{ }^{12} C\right)$ de la muestra y del dióxido de carbono utilizado como patrón.
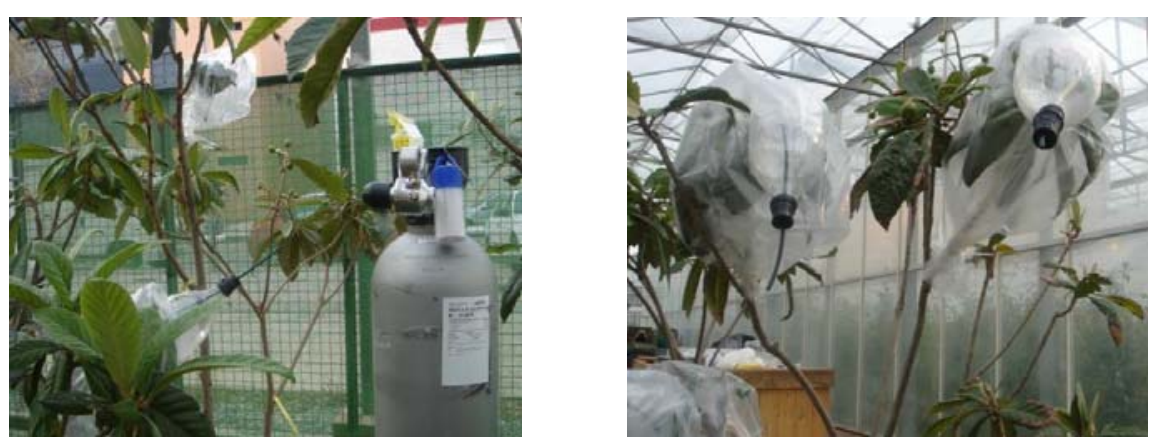

Vistas del dispositivo utilizado para la exposición de las hojas a una atmósfera de ${ }^{13} \mathrm{CO}_{2}$.

\section{- Análisis estadístico de los resultados}

A los resultados obtenidos se les aplicó el análisis de la varianza o de la regresión, con un nivel de confianza $P \leq 0.05$. Para la separación de las medias se aplicó el test de Student-NewmanKeuls. A los valores porcentuales se les aplicó la transformación arcsen ( $\mathrm{V} p$ ) para normalizar la muestra. 



\section{Resultados}





\section{Características morfológicas y fenológicas del cv. Piera en relación a su parental 'Algerie’.}

El cv. Piera de níspero japonés se originó por mutación gemaria espontánea de un árbol del cv. Algerie, en Callosa d’En Sarriá (Alicante, España).

\subsection{Características morfológicas.}

Aparentemente, el árbol del cv. Piera de níspero japonés no se distingue de su parental, el cv. Algerie. Cuando se forma en vaso, con un tronco único sobre el que se apoyan 3-5 ramas principales, y su riego, fertilización y poda son comunes, el árbol alcanza hasta 2.5-3.0 m de altura y mantiene su tendencia a la verticalidad característica de la especie. Su porte, tamaño de copa y color de la madera son idénticos al cv. Algerie. La resistencia de las ramas, la disposición de las hojas y su ramificación, tampoco presentan diferencias aparentes con su parental.

Las hojas del cv. Piera son pubescentes, más en el envés que en el haz, como las del cv. Algerie. Su peso y longitud son significativamente inferiores a los de éste, pero su anchura no difiere significativamente (Tabla 1.1). El número de dientes de las hojas del cv. Piera es inferior $(22.1 \pm 0.9)$ al de las hojas del cv. Algerie $(26.5 \pm 1.8)$, aunque sin alcanzar la significación estadística. Su profundidad (1.1 $\mathrm{mm}$ y $1.2 \mathrm{~mm}$, respectivamente) tampoco difiere estadísticamente (Tabla 1.1).

Tabla 1.1. Características de las hojas de los cvs. 'Piera' y 'Algerie' de níspero japonés. Cada valor es la media de 5 muestras de 10 hojas cada una.

\begin{tabular}{lccc}
\hline & Piera & Algerie & Significación \\
\hline Peso $(\mathrm{g})$ & $3.00 \pm 0.15$ & $3.80 \pm-0.21$ & $P \leq 0.05$ \\
Longitud $(\mathrm{cm})$ & $19.60 \pm 0.32$ & $21.80 \pm 0.53$ & $P \leq 0.05$ \\
Anchura $(\mathrm{cm})$ & $6.20 \pm 0.13$ & $6.70 \pm 0.24$ & n.s. \\
№ de dientes & $22.1 \pm 0.9$ & $26.5 \pm 1.8$ & n.s. \\
Profundidad dientes $(\mathrm{mm})$ & $1.10 \pm 0.09$ & $1.20 \pm 0.12$ & n.s. \\
№ de nervios & $25.6 \pm 0.5$ & $27.1 \pm 0.5$ & n.s. \\
Longitud del peciolo $(\mathrm{mm})$ & $0.60 \pm 0.07$ & $0.70 \pm 0.06$ & n.s. \\
Color del haz (unidades SPAD) & $58.50 \pm 1.29$ & $60.40 \pm 1.08$ & n.s. \\
\hline
\end{tabular}

Las hojas de esta especie presentan una nerviadura reticulada y muy pronunciada, particularmente el nervio central. Todos los nervios, que resaltan por el envés, están también recubiertos de abundante pelo. En el cv. Piera ambas características resultan indistinguibles del cv. Algerie. Tampoco difieren en el número de nervios secundarios $(25.6 \pm 0.5$ y $27.1 \pm 0.5$, respectivamente) ni en la longitud del peciolo (Tabla 1.1). 
El color de las hojas, medido en unidades SPAD, no difirió entre ambos cultivares (Tabla 1.1.), siendo de una tonalidad verde oscura por el haz, y más claras y sin brillo por el envés.

Las panículas del cv. Piera son iguales a las del cv. Algerie en forma y estructura. Su número de flores, aunque ligeramente inferior en el cv. Piera, no difiere estadísticamente, y el peso individual de las mismas tampoco (Tabla 1.2.).

Tabla 1.2. Características de las flores de los cvs. 'Piera' y 'Algerie' del níspero japonés. Cada valor es la media de 25 panículas distribuidas en 5 árboles. No existen diferencias significativas entre medias.

\begin{tabular}{lll}
\hline & Piera & Algerie \\
\hline No. de flores/panícula & $21.1 \pm 5.1$ & $25.0 \pm 2.8$ \\
Peso seco /flor (g) & $72.3 \pm 0.5$ & $73.7 \pm 0.2$ \\
\hline
\end{tabular}

Esta especie, y en las condiciones de Clima Mediterráneo, posee yemas vegetativas, que desarrollan solo hojas, y yemas mixtas, que desarrollan hojas durante la primavera y el verano $y$, al final de éste, diferencian una panícula terminal. Ambos tipos de yemas están presentes en el cv. Piera. Estas yemas se inician a partir de la yema terminal o de las yemas axilares del ramo del año anterior. Tampoco en este aspecto existen diferencias entre ambos cultivares. Pero el cv. Piera posee yemas de flor que se desarrollan en las axilas de las hojas (Fotg. 1.1) y este sí es un aspecto diferencial de este cultivar, ya que el cv. Algerie, del que procede, carece de yemas de flor en las condiciones de Clima Mediterráneo.
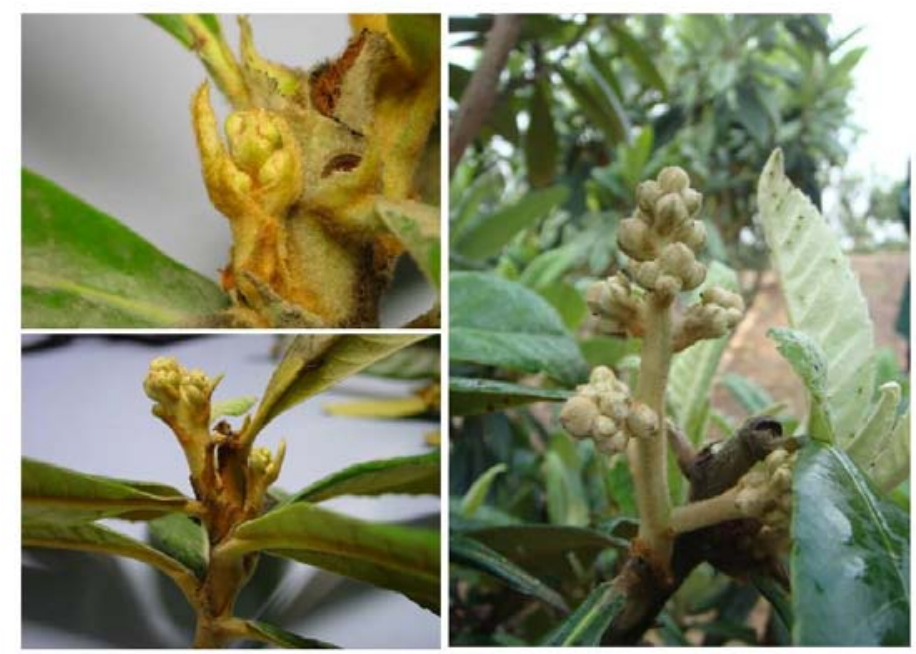

Fotg. 1.1. Yemas de flor en tres estados de desarrollo en el cv. 'Piera'. En éstas la panícula se diferencia en el mismo momento de la brotación. 
El grano de polen de esta especie es tricolpado (Fotg. 1.2), de forma alargada y sección aproximadamente circular cuando está hidratado. Nuestros estudios no encontraron diferencias significativas en el tamaño medio del grano de polen de los cvs. 'Piera' y 'Algerie' (Tabla 1.3; Fotg. 1.2), si bien el eje polar del primero fue ligeramente inferior al del segundo. Como consecuencia de ello la relación eje polar/eje ecuatorial del cv. Piera fue ligeramente inferior (Tabla 1.3). La ausencia de diferencias significativas en estos parámetros hace que los granos de polen de ambos cvs. sean prácticamente iguales.

Tabla 1.3. Características morfométricas de los granos de polen de los cvs. 'Piera' y 'Algerie' de níspero japonés. Cada valor es la media de 15 granos de polen. Valores obtenidos a partir de microfotografías de crio- SEM.

\begin{tabular}{lllll}
\hline Cultivar & $\begin{array}{l}\text { Eje polar } \\
(\mu \mathrm{m})\end{array}$ & $\begin{array}{l}\text { Eje ecuatorial } \\
(\mu \mathrm{m})\end{array}$ & $\begin{array}{l}\text { Ratio } \\
\text { E.polar/E.ecuatorial }\end{array}$ & $\begin{array}{l}\text { Longitud del } \\
\text { mesocolpo }(\mu \mathrm{m})\end{array}$ \\
\hline Piera & $33.7 \pm 2.1$ & $21.7 \pm 1.4$ & $1.55 \pm 0.10$ & $12.2 \pm 1.1$ \\
Algerie & $36.6 \pm 2.3$ & $22.6 \pm 1.5$ & $1.62 \pm 0.11$ & $12.2 \pm 1.1$ \\
\hline
\end{tabular}
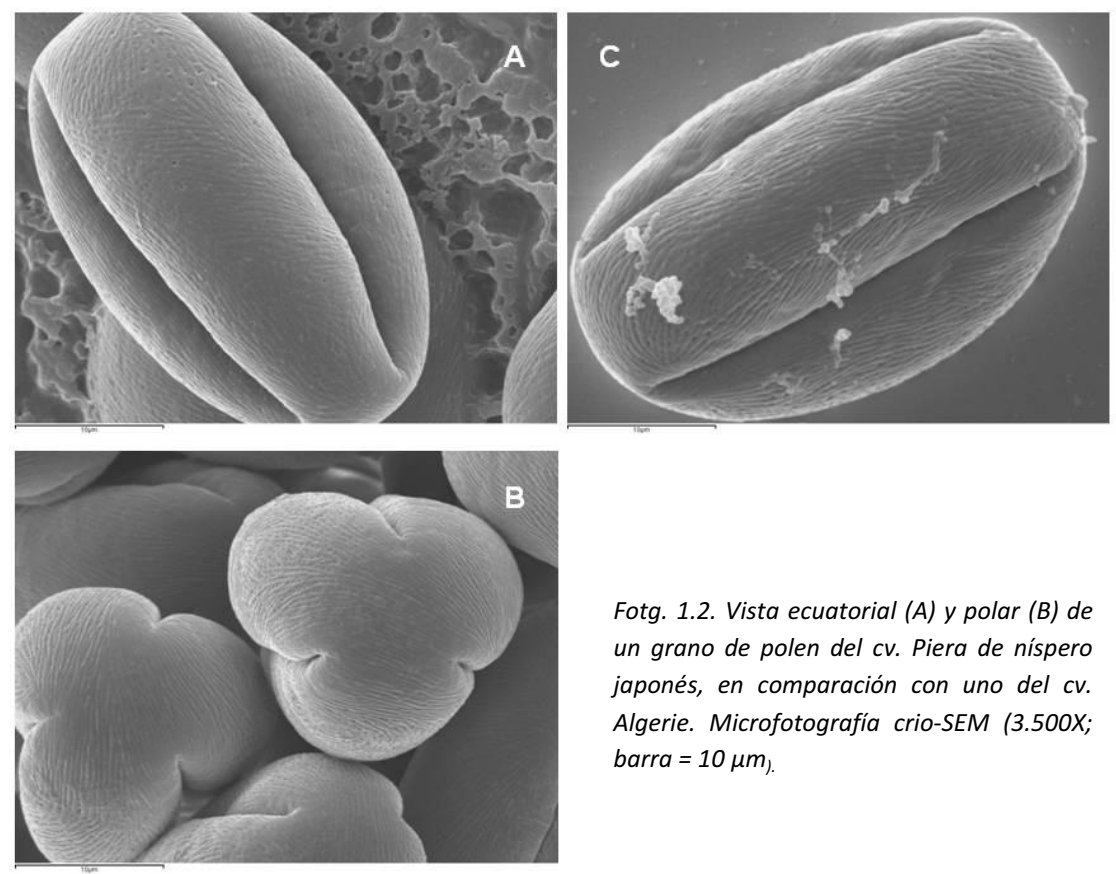

Fotg. 1.2. Vista ecuatorial (A) y polar (B) de un grano de polen del cV. Piera de níspero japonés, en comparación con uno del cV. Algerie. Microfotografía crio-SEM (3.500X; barra $=10 \mu \mathrm{m}$.

La superficie de la exina del grano de polen de esta especie es estriada, pero sin ninguna regularidad, y se hallan sobre ella numerosos poros (Fotg. 1.3). Aunque es posible apreciar 
diferencias en la orientación de las estrías cuando se examinan detalladamente la superficie de los mesocolpos de los granos de polen de ambos cultivares, éstas no son suficientes para clasificarlos de acuerdo con ellas.
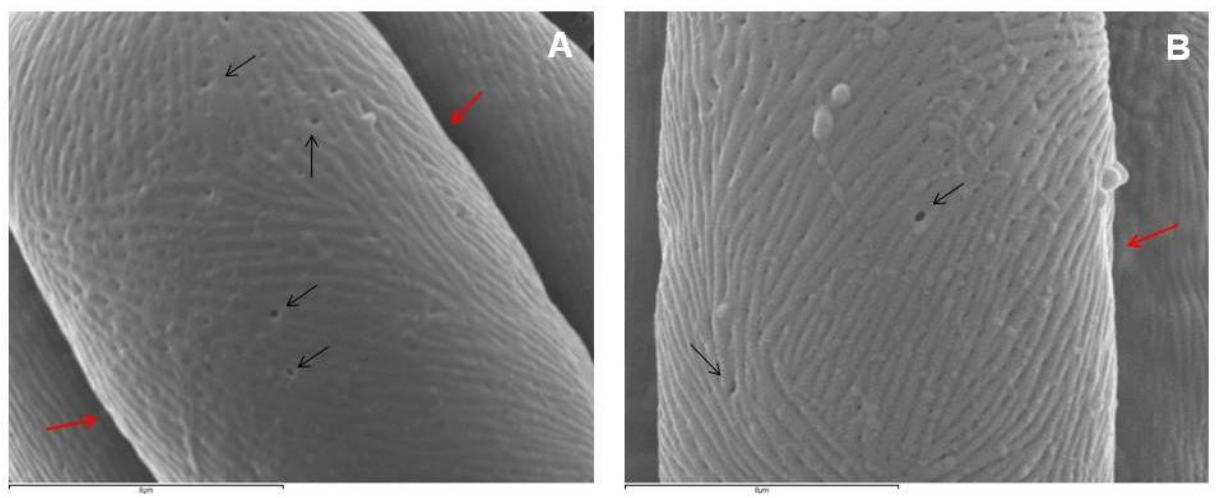

Fotg. 1.3. Superficie de un mesocolpo de un grano de polen del cv. Piera (A) y del cv. Algerie (B) de níspero japonés. Las estrías de ambos cultivares no presentan diferencias distinguibles. Los poros se han marcado con flechas negras. Las flechas rojas señalan los colpos.

\section{2. Características fisiológicas.}

De acuerdo con nuestros resultados, el desarrollo vegetativo y de las panículas del cv. Piera no difiere del que presenta el cv. Algerie, pero sí lo hace en cuanto a la época, ya que es capaz de desarrollar brotes vegetativos y panículas continuamente a lo largo de todo el año, con diferente intensidad dependiendo de la época.

En condiciones de cultivo y de Clima Mediterráneo, el níspero japonés brota de modo generalizado tras la recolección, en primavera, florece a finales de verano o principios de otoño, dependiendo de la temperatura del año y del cultivar, y el fruto cuaja en otoño, se desarrolla durante el invierno y madura y se recolecta en primavera. Este es el caso del cv. Algerie, en el que solo se identifica una floración anual (ver generación I de la Fig. 1.1).

Sin embargo, y bajo las mismas condiciones climáticas, nuestros resultados demuestran que el cv. Piera repite el proceso doce veces al año, esto es, brota, florece, cuaja sus frutos, los madura y pueden ser recolectados 12 veces al año (Fig. 1.1). Tomando como referencia el cv. Algerie, el cv. Piera tiene una brotación coincidente con él (brotación I, diagrama 1 de la Fig. 1.1.), idéntica en comportamiento y fechas, cuya diferenciación floral tiene lugar a principios de septiembre y la floración se extiende desde mediados de dicho mes hasta bien entrado octubre; sus frutos se desarrollan desde finales de octubre hasta principios de mayo y se 
recolecta a partir de esas fechas (Fig. 1.1, 2, 3 y 4). Quince días después, aproximadamente, el cv. Piera inicia una segunda brotación, de comportamiento similar a la primera, cuya diferenciación floral tiene lugar la segunda quincena de octubre y cuya floración se extiende desde mediados de septiembre hasta finales de octubre, coincidiendo y confundiéndose con la de la generación I, de modo que sus frutos se desarrollan coincidiendo, también, con los de la primera generación, recolectándose junto con ellos (Fig. 1.1.). Esta coincidencia en los procesos de floración, desarrollo del fruto, maduración y recolección de los frutos de ambas generaciones, I y II, permite agruparlas en un único grupo de floración que hemos denominado Grupo A.

Las generaciones III y IV brotan junto con la I y la II (Fig. 1.1.; 1), pero lo hacen a partir de yemas de flor, por lo que diferencian sus flores al mismo tiempo que brotan, esto es, en mayo (Fig. 1.1; 2). A ellas le sigue la generación $\mathrm{V}$, que brota también en mayo, a finales de este mes, y desde mediados de junio hasta principios de julio brotan, sucesivamente a intervalos de 1012 días, aproximadamente, otras tres generaciones, VI, VII y VIII (Fig. 1.1; 1), y todas, como las anteriores, a partir de yemas de flor que diferencian sus flores mientras brotan (Fig. 1.1; 2). La floración de estas seis generaciones se solapa en el tiempo, abarcando desde principios de mayo, cuando se inicia la brotación de la generación III, hasta mediados de julio, con la floración de la generación VIII, y sus frutos se desarrollan conjuntamente desde principios mediados de julio hasta la segunda quincena de septiembre (Fig. 1.1; 3), recolectándose todos juntos a finales de septiembre (Fig. 1.1; 4). Estas seis generaciones (de la III a la VIII), coincidentes en la época de floración, desarrollo del fruto, maduración, y recolección, conforman un segundo grupo de floración del cv. Piera al que hemos denominado Grupo B (Fig. 1.1).

A mediados de agosto se inicia una nueva brotación (generación IX; Fig. 1.1; 1), también a partir de yemas de flor que siguen un desarrollo conjunto con las generaciones I y II y forma parte, por tanto, del Grupo A de floración. El desarrollo del fruto es deficiente y no alcanza los mínimos exigibles para ser recolectado. Esta generación, por tanto, carecería de interés de no ser por el hecho de iniciarse en una época de latencia de esta especie que, por consiguiente, no presenta el cv. Piera.

Finalmente, desde principios de enero y hasta mediados de febrero se inicia la brotación de otras tres generaciones, X, XI y XII (Fig. 1.1; 1), también a partir de yemas de flor. Éstas, por tanto, también diferencian sus yemas mientras brotan (Fig. 1.1; 2). Al igual que en los casos anteriores, la floración de estas tres generaciones se solapa y se confunde en una sola desde principios de enero a finales de febrero, iniciándose el desarrollo de sus frutos casi conjuntamente y abarcando un periodo de tiempo desde mediados de febrero a finales de 
mayo (Fig. 1.1; 3), época en la que se recolectan a la vez los de las tres generaciones (Fig. 1.1; 4). Constituyen el Grupo $C$ de las generaciones anuales de flores del cv. Piera.

Es de destacar que, de acuerdo con la evolución presentada de las doce generaciones del cv. Piera, en algunas épocas del año es posible ver sobre el mismo árbol varias de ellas en diferentes estados de desarrollo. En nuestro estudio, el caso más espectacular se presentó a mediados de enero, cuando eran visibles en el mismo árbol las últimas flores en pre-antesis de la generación XII, flores en antesis de la XI, los primeros frutos recién cuajados de la generación $\mathrm{X}$, y frutos en estados avanzados de desarrollo de las generaciones I y II (ver Fig. 1.1; 3) (Fotg. 1.4 A). Del mismo modo, a mediados de septiembre coexistían en un mismo árbol flores en pre-antesis y antesis de la generación I, frutos en estados iniciales del desarrollo de la generación IX, y frutos maduros del Grupo B de floración (ver Fig. 1.1) (Fotg. 1.4 B).

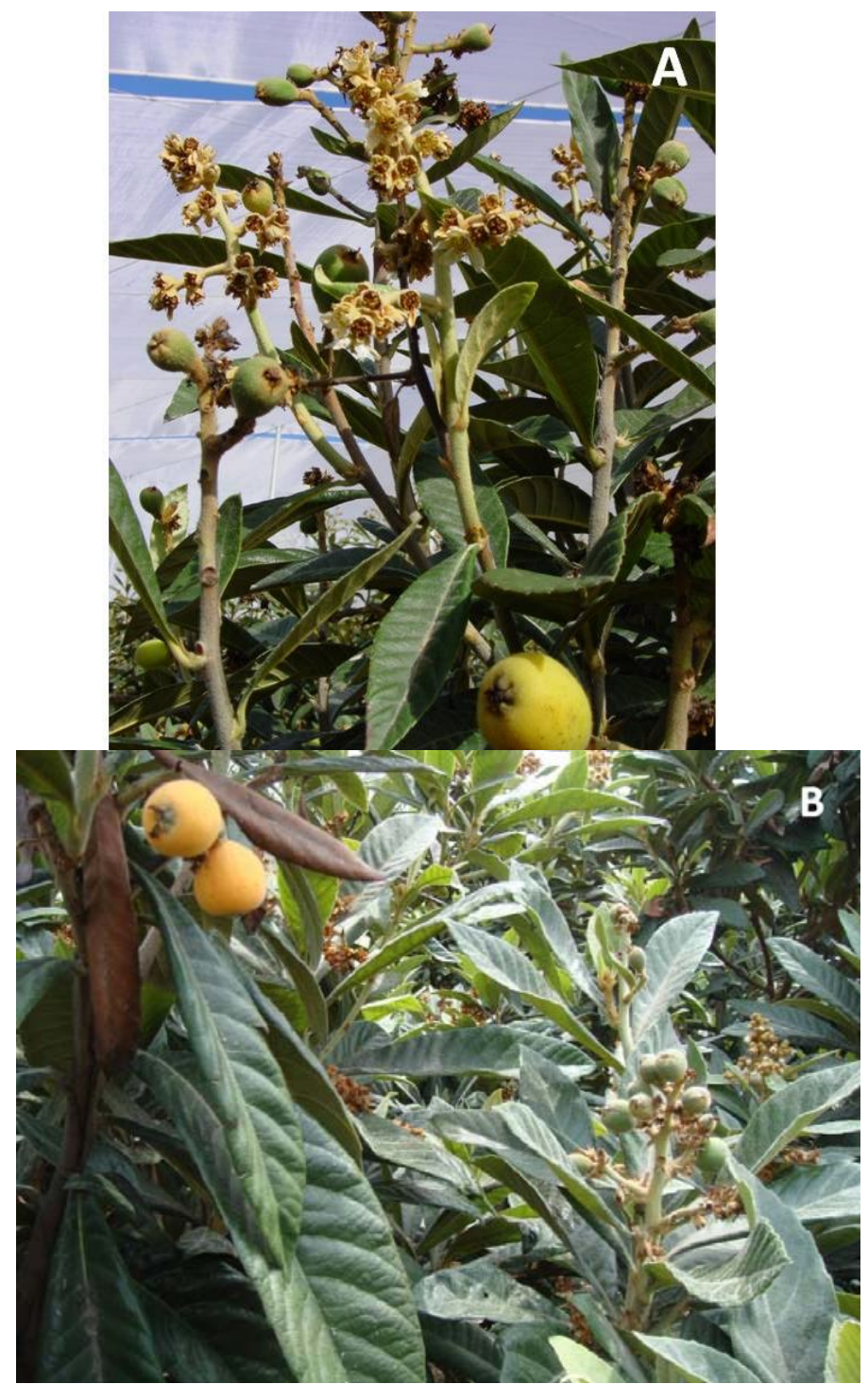

Fig. 1.4. Coexistencia de distintas estructuras reproductivas de las generaciones de flores I, II, $X, X I$ y XII (A) y de las generaciones I y III a IX (B) del cv. Piera del níspero japonés. Las fotografías fueron tomadas el 14 de enero (A) y el 18 de septiembre (B). 
A principios de la primavera, periodo del año en que se detuvo la diferenciación de flores del cv. Piera, el desarrollo vegetativo fue más intenso (datos no presentados). Es de destacar que en dicha época coexistía el desarrollo de frutos de seis generaciones, las del Grupo A y las del Grupo C (Fig. 1.1; 3).

Los frutos de la generación del Grupo A del cv. Piera alcanzaron un peso seco similar (57 g) al de los frutos del cv. Algerie (59 g) (Tabla 1.4) y su firmeza fue, asimismo, similar. Las diferencias en la concentración de sólidos solubles totales, ligeramente inferior en el cv. Piera $\left(6.7^{\circ} \mathrm{Brix}\right)$ que en el cv. Algerie $\left(8.5^{\circ} \mathrm{Brix}\right)$, y en la acidez libre, ligeramente superior $(1.4 \%$ y $1.0 \%$, respectivamente), no alcanzaron la significación estadística en nuestros estudios (Tabla 1.4). La coloración de los frutos, expresada en coordenadas Hunter, fue prácticamente idéntica en los frutos de ambos cultivares (Tabla 1.4).

Tabla 1.4. Características del fruto maduro del Grupo A de flores del cv. Piera y del fruto de la generación coincidente del cv. Algerie. Valores correspondientes a la media de todos los frutos desarrollados en 20 ramos distribuidos en 4 árboles de cada cultivar. No existen diferencias significativas entre cvs. para ninguna de las variables analizadas.

\begin{tabular}{lll}
\hline & Piera & Algerie \\
\hline Grupo de floración & \multicolumn{1}{l}{ A } & -- \\
Peso seco (g) & $59.3 \pm 3.5$ & $57.2 \pm 3.8$ \\
Maduración interna & & \\
Firmeza (N) & $13.9 \pm 1.2$ & $14.0 \pm 1.8$ \\
SST ( ${ }^{\circ}$ Brix) & $6.7 \pm 1.4$ & $8.5 \pm 0.3$ \\
Acidez libre (\%) & $1.4 \pm 0.1$ & $1.0 \pm 0.1$ \\
Coloración & & \\
$a$ & $6.9 \pm 1.1$ & $6.8 \pm 0.9$ \\
$b$ & $28.6 \pm 1.1$ & $28.1 \pm 0.3$ \\
$a / b$ & $0.23 \pm 0.05$ & $0.23 \pm 0.03$ \\
\hline
\end{tabular}

Pero los frutos de este Grupo A del cv. Piera sí presentaron un peso seco medio significativamente más alto (59.3 g) que el de los frutos del Grupo B (38.7 g) y éstos, a su vez, superior a los del Grupo C (9.8 g) (Tabla 1.5). Del mismo modo, la firmeza de los frutos del Grupo A fue superior a la de los del Grupo B (Tabla 1.5). Los parámetros de la maduración interna (SST y acidez libre) no mostraron diferencias significativas atribuibles al grupo de floración (Tabla 1.5). La coloración roja (coordenada a de Hunter) de los frutos del Grupo B fue significativamente más intensa que la de los frutos de los Grupos A y C, pero la coloración amarilla (coordenada $b$ de Hunter) no mostró diferencias significativas entre los frutos de los diferentes Grupos de floración (A, B y C); consecuentemente, la relación $a / b$ fue significativamente menor en los Grupos A y $C$ que en el Grupo B, pero sin diferencias significativas entre sí (Tabla 1.5). 
Tabla 1.5. Características del fruto maduro de las generaciones del cv. Piera de níspero japonés pertenecientes a los Grupos de floración $A, B$ y $C$. Valores correspondientes a la media de todos los frutos desarrollados en 20 ramos distribuidos en 4 árboles.

\begin{tabular}{lcll}
\hline & $\mathrm{A}$ & $\mathrm{B}$ & $\mathrm{C}$ \\
\hline Peso seco (g) & $59.3 \pm 3.5 \mathrm{a}$ & $38.7 \pm 3.3 \mathrm{~b}$ & $9.8 \pm 0.7 \mathrm{c}$ \\
Maduración interna & & & \\
$\quad$ Firmeza (N) & $13.9 \pm 1.2 \mathrm{a}$ & $5.6 \pm 0.3 \mathrm{~b}$ & -- \\
$\quad$ SST ('Brix) & $6.7 \pm 1.4$ & $4.5 \pm 1.1$ & -- \\
$\quad$ Acidez libre (\%) & $1.4 \pm 0.1$ & $1.1 \pm 0.1$ & -- \\
Coloración & & & \\
$a$ & $6.9 \pm 1.1 \mathrm{ab}$ & $10.6 \pm 0.5 \mathrm{a}$ & $5.3 \pm 0.9 \mathrm{~b}$ \\
$b$ & $28.6 \pm 1.1$ & $27.5 \pm 0.3$ & $26.2 \pm 0.3$ \\
$a / b$ & $0.23 \pm 0.05$ & $0.41 \pm 0.02$ & $0.20 \pm 0.04$ \\
\hline
\end{tabular}

Letras distintas en una misma fila indican diferencias significativas $(P \leq 0.05)$. 


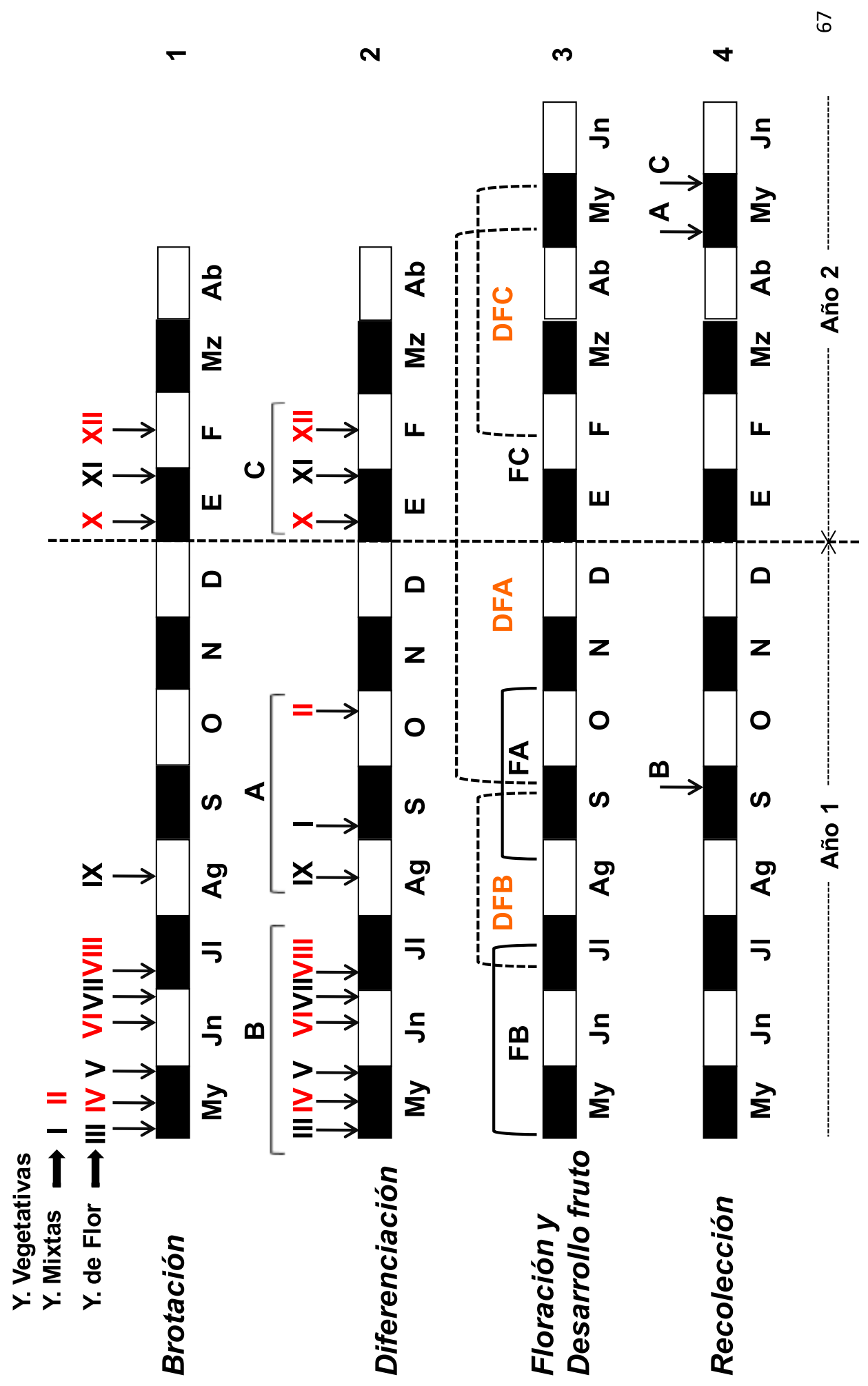





\section{2.- INFLUENCIA DEL FRUTO EN LA BROTACIÓN Y EL DESARROLLO VEGETATIVO.}

\subsection{Eliminación y/o aislamiento temporal de los frutos. Estudio individual de la panícula.}

La eliminación de todos los frutos de la panícula en el estado 701 de la escala BBCH (despuntado I) o en el estado 703 (despuntado II), aumentó significativamente el número de brotes principales al final del crecimiento vegetativo respecto de los controles que mantuvieron todos los frutos en la panícula hasta la recolección. Mientras los ramos control desarrollaron 2.2 brotes, por término medio, los despuntados desarrollaron 3.2 y 2.7 , respectivamente (Fig. 2.1). La respuesta fue inmediata y a los 30 días de la eliminación de los frutos el $100 \%$ de los brotes despuntados I y II habían iniciado el desborre con 2.3 y 1.8 brotes en desarrollo, respectivamente, mientras que la brotación de los controles se retrasó hasta 25 días después de la recolección, con 0.6 brotes por brote despuntado. En el momento de la recolección, 80 y 40 días después de la eliminación de los frutos en los despuntados I y II, respectivamente, los brotes ya presentaban 2.4 y 2.2 nuevos brotes en crecimiento que aunque no difirieron significativamente entre ellos, sí lo hicieron con el control, que todavía no había iniciado el desborre (Fig. 2.1).

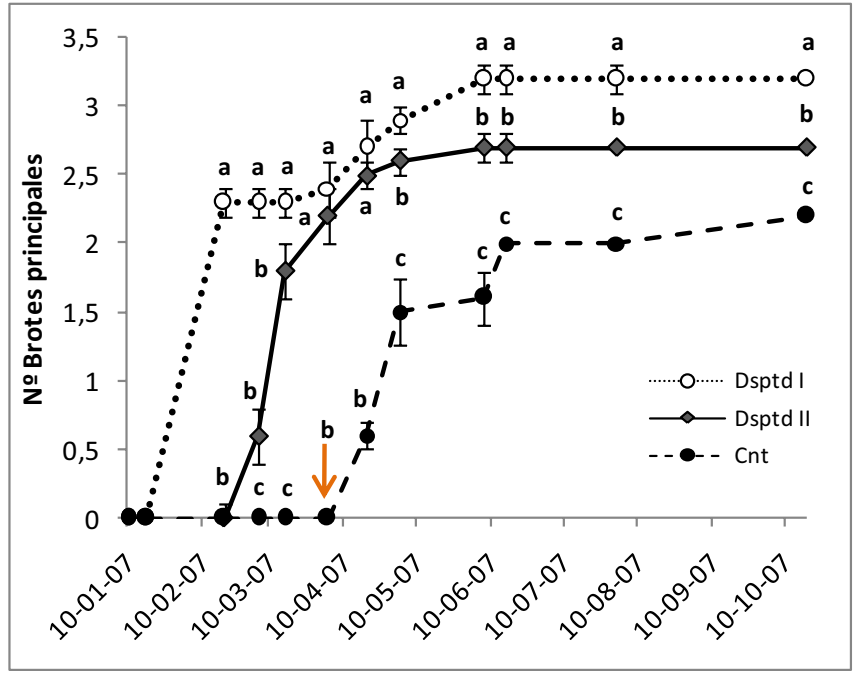

Fig. 2.1.- Efecto de la época de eliminación del fruto en la evolución de la brotación de las yemas del níspero japonés cv. 'Algerie'. Cada valor es la media de 20 brotes repartidos en cinco árboles. Las barras verticales indican el ES. La flecha indica el momento de la recolección. Despt l: frutos elininados en el estado fenológico 701 de la escala BBCH; Desptd II: frutos eliminados en el estado fenológico 703 de la escala BBCH; Cnt: Frutos presentes hasta la recolección. Letras diferentes para una misma fecha indican diferencias significativas $(P \leq 0.05)$. 
El número de brotes anticipados por brote principal también aumentó significativamente al final del crecimiento vegetativo con la eliminación de los frutos. Mientras los brotes control desarrollaron 1 brote anticipado, por término medio, los despuntados I y II desarrollaron 1.4 y 2.0, respectivamente, al mismo tiempo que anticiparon el desborre de sus yemas (Fig. 2.2). Así, en el momento de la recolección, los brotes despuntados I y II ya tenían 1.5 y 0.8 brotes anticipados, respectivamente, pero en los controles la brotación era inexistente y no se inició hasta 65 días después en que empezaron a mostrarse los primeros indicios (Fig. 2.2).

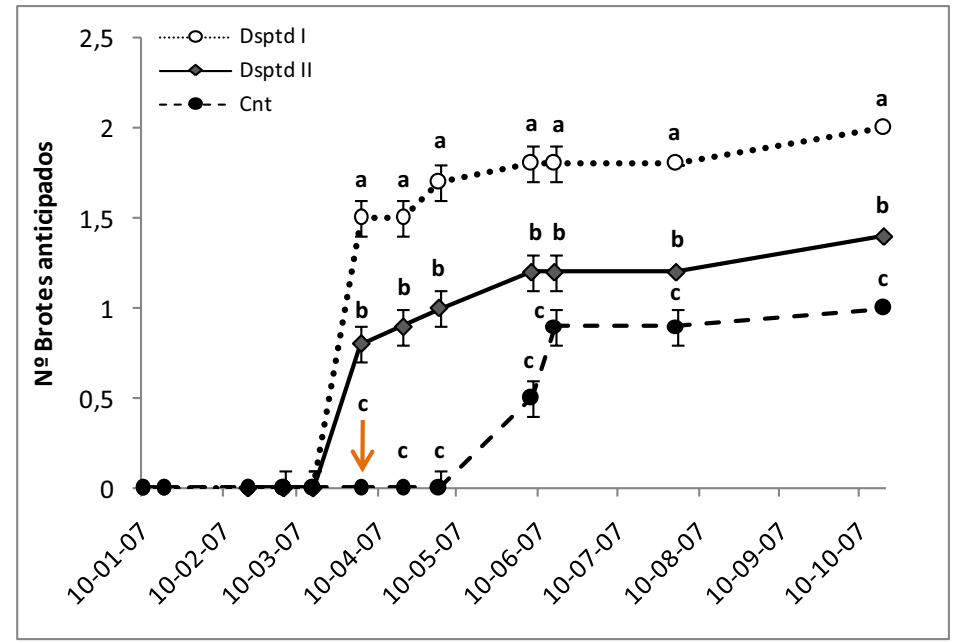

Fig. 2. 2.- Efecto de la época de eliminación del fruto en la evolución de la brotación de las yemas anticipadas del níspero japonés cv. 'Algerie'. Cada valor es la media de 20 brotes repartidos en cinco árboles. Las barras verticales indican el ES. La flecha indica el momento de la recolección. Clave de tratamientos como en la Fig. 2.1. .Letras diferentes para una misma fecha indican diferencias significativas $(P \leq 0.05)$.

La longitud final de los brotes, tanto principales como anticipados, también se vió afectada por la presencia del fruto. La diferencia en longitud de los brotes principales entre los que se despuntaron en ambas épocas y los controles se mantuvo durante todo el periodo estudiado. Esta diferencia fue más notable a partir de los 65 días de la recolección, cuando la longitud de los brotes era de $14.7,10.3$ y $9.4 \mathrm{~cm}$, respectivamente; al final del periodo de estudios (9 meses después del despuntado I) la longitud de los brotes era de 28.5, 25.3 y $23.8 \mathrm{~cm}$, respectivamente (Fig. 2.3). También en este momento el número final de hojas fue significativamente mayor en los brotes que permanecieron más tiempo sin los frutos (12.6) que en los que los mantuvieron hasta su recolección (11), que no difirieron respecto de los que 
se despuntaron más tarde (10.5). Los brotes despuntados en etapas más precoces del desarrollo del fruto se mostraron más sensibles a la acción del fruto y a los 30 días de su eliminación habían crecido $0.8 \mathrm{~cm}$ más que los que se despuntaron más tarde (Fig. 2.3; los controles aún no habían iniciado su crecimiento (Fig. 2.2).

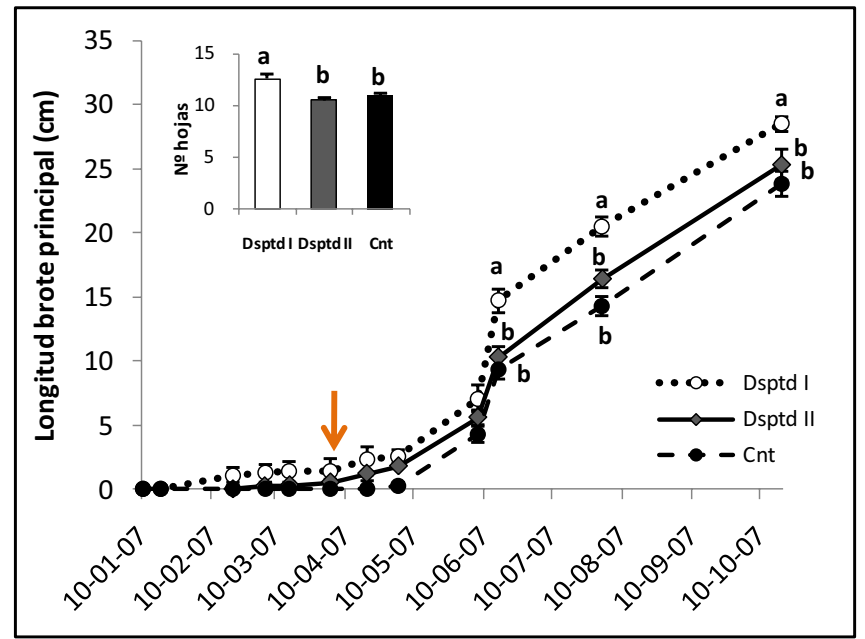

Fig. 2. 3.- Efecto de la época de eliminación del fruto en el crecimiento de los brotes principales y su número de hojas del níspero japonés cv. 'Algerie'. Cada valor es la media de 20 brotes repartidos en cinco árboles. Las barras verticales indican el ES. La flecha indica el momento de la recolección. Clave de tratamientos como en la Fig. 2.1. .Letras diferentes para una misma fecha indican diferencias significativas $(P \leq 0.05)$.

Los brotes anticipados también alcanzaron una mayor longitud final con la ausencia de los frutos. Éstos fueron tanto más largos cuanto menos tiempo estuvieron bajo la influencia de los frutos, aunque sólo los procedentes de los brotes despuntados I, que crecieron 5.3 y $7.6 \mathrm{~cm}$ más que los de los brotes despuntados II y los controles, respectivamente, consiguieron alcanzar la significación estadística al finalizar su crecimiento (Fig. 2.4). Estas diferencias ya eran evidentes 15 días después de la recolección cuando los brotes de los despuntados I medían prácticamente el doble que los brotes de los despuntados II mientras en los controles ni siquiera habían logrado iniciar el desborre (Fig. 2.4). A partir de este momento y hasta el final del crecimiento vegetativo, como en los casos anteriores, en los despuntados en etapas más precoces del desarrollo del fruto que habían iniciado antes el desborre, sus brotes anticipados crecieron significativamente más que en el resto de tratamientos. Los brotes anticipados procedentes de los brotes despuntados II se situaron a lo largo de todo el periodo 
estudiado en una posición intermedia, pero sin alcanzar diferencias significativas con los controles (Figs. 2.3 y 2.4) pero no en su longitud final (Figs. 3 y 4). Los resultados más destacados se obtuvieron, por tanto, cuando se eliminaron los frutos en estados más precoces del desarrollo (estado 701 de la escala $\mathrm{BBCH}$ ) o, lo que es lo mismo, cuanto menos tiempo permanecieron los frutos en los brotes.

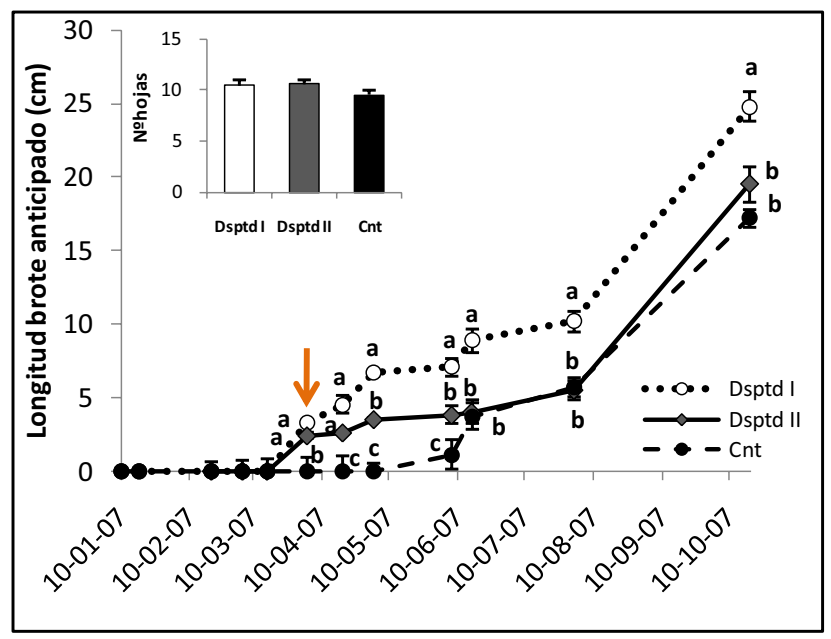

Fig. 2. 4.- Efecto de la época de eliminación del fruto en el crecimiento y el número de hojas de los brotes anticipados del níspero japonés cv. 'Algerie'. Cada valor es la media de 20 brotes repartidos en cinco árboles. Las barras verticales indican el ES. La flecha indica el momento de la recolección. Clave de tratamientos como en la Fig. 2.1. Letras diferentes para una misma fecha indican diferencias significativas $(P \leq 0.05)$.

Sin embargo, a los 75 días de la eliminación de los frutos, los brotes principales de los controles parecían haber crecido más que los despuntados I y II, que no mostraban diferencias entre sí (Fig. 2.5). Esto sería así de no tener en cuenta las fechas, ya que para una misma fecha (16 de junio), pleno crecimiento vegetativo, los brotes principales de los despuntados I y II medían 14.7 y $10.3 \mathrm{~cm}$, respectivamente, frente a los $9.4 \mathrm{~cm}$ de los controles (Fig. 2.3). Aunque prácticamente no se apreciaron diferencias significativas en la longitud de los brotes anticipados al compararlos para esa misma fecha, en pleno desarrollo vegetativo, los despuntados I fueron significativamente más largos, con $8.9 \mathrm{~cm}$, que los despuntados II y los controles, que fueron prácticamente iguales con 4.0 y $3.7 \mathrm{~cm}$, respectivamente (Fig. 2.4). Este comportamiento, por el contrario, no se observó al comparar el número de brotes principales ni anticipados (Fig. 2.5). 

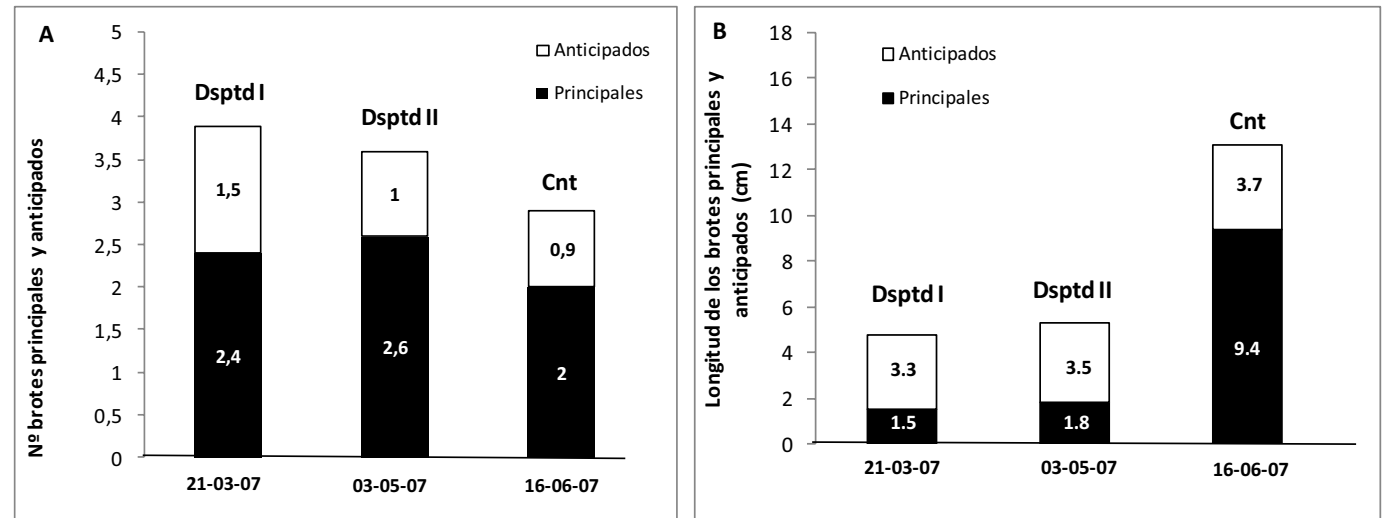

Fig. 2.5.- Efecto de la época de eliminación del fruto sobre el número de brotes principales y anticipados (A) y su longitud (B). Valores obtenidos 75 días después de las fechas de despuntado o de la recolección en el caso de los controles. Cada valor es la media de 20 brotes repartidos en cinco árboles. Letras diferentes indican diferencias significativas $(P \leq 0.05)$. Clave de tratamientos como en la Fig. 2.1.

Resultados similares en cuanto al número y longitud de los brotes se obtuvieron 120 días después de haber eliminado los frutos (Fig. 2.6). En este caso, la diferencia en la longitud de los brotes principales de los despuntados I y II fue menor (20.5 y $16.4 \mathrm{~cm}$, respectivamente) qué la registrada a los 75 días al compararlos para la misma fecha de los controles ( 1 de agosto), pero mayores, en ambos casos, que los controles (14.3 cm) (Fig. 2.3).
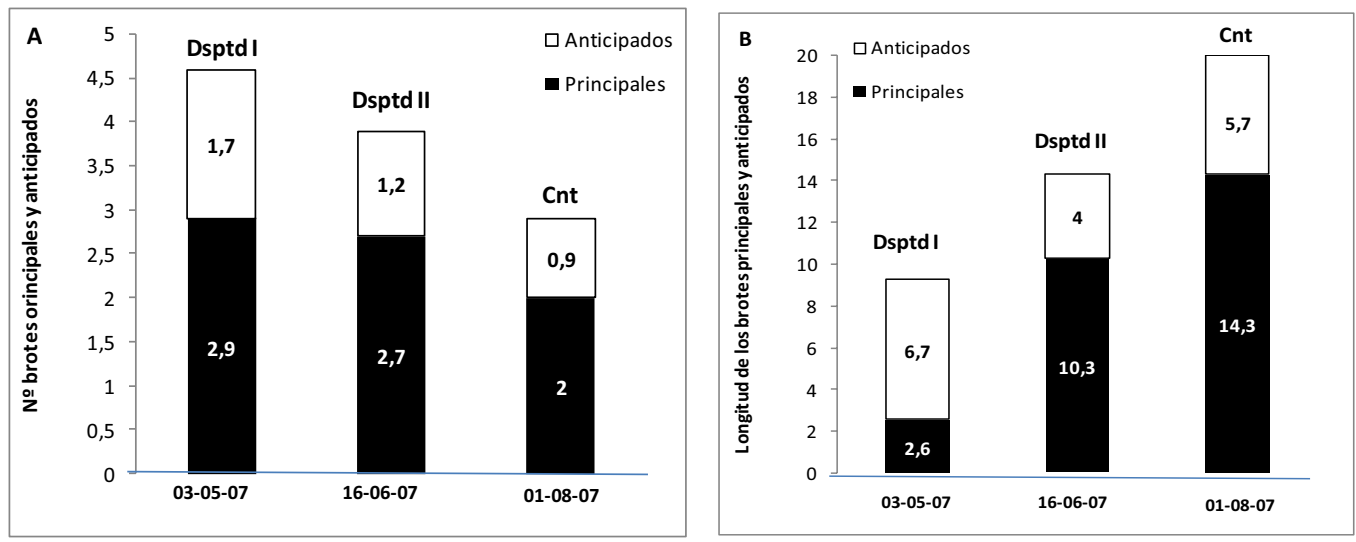

Fig. 2.6.- Efecto de la época de eliminación del fruto sobre el número de brotes principales y anticipados (A) y su longitud (B). Valores obtenidos a los 120 días de la eliminación de los frutos de cada fecha de despuntado y de los controles. Cada valor es la media de 20 brotes repartidos en cinco árboles. Letras diferentes indican diferencias significativas $(P \leq 0.05)$. Clave de tratamientos como en la Fig. 2.1. 
Cuando los frutos en vez de eliminarse totalmente, se aislaron temporalmente del resto del brote mediante un anillado en la base de la panícula, en las mismas épocas en que se realizaron los despuntados, los resultados en el comportamiento de la brotación fueron similares a los descritos para el despuntado. Aumentaron, por una parte, el número de brotes principales y anticipados (Figs. 2.7 y 2.8) y, por otra, la longitud final de ambos brotes (Figs. 2.9 y 2.10). En el caso de los brotes principales, solo se consiguieron diferencias significativas a los pocos días de haber realizado el anillado, independientemente de la época en que se realizara (Fig. 2.7). Quince días después de la recolección y hasta el final del periodo estudiado, las diferencias perdieron la significación estadística. El número de brotes principales en los anillados I y II y los controles finalmente desarrollados fue de $2.1,1.9$ y 2, respectivamente. Los resultados más relevantes se obtuvieron a los 30 días de realizados los anillados, ya que mientras la brotación en los controles era nula, los anillados I y II presentaban 0.6 y 0.5 brotes principales en crecimiento, respectivamente (Fig. 2.7).

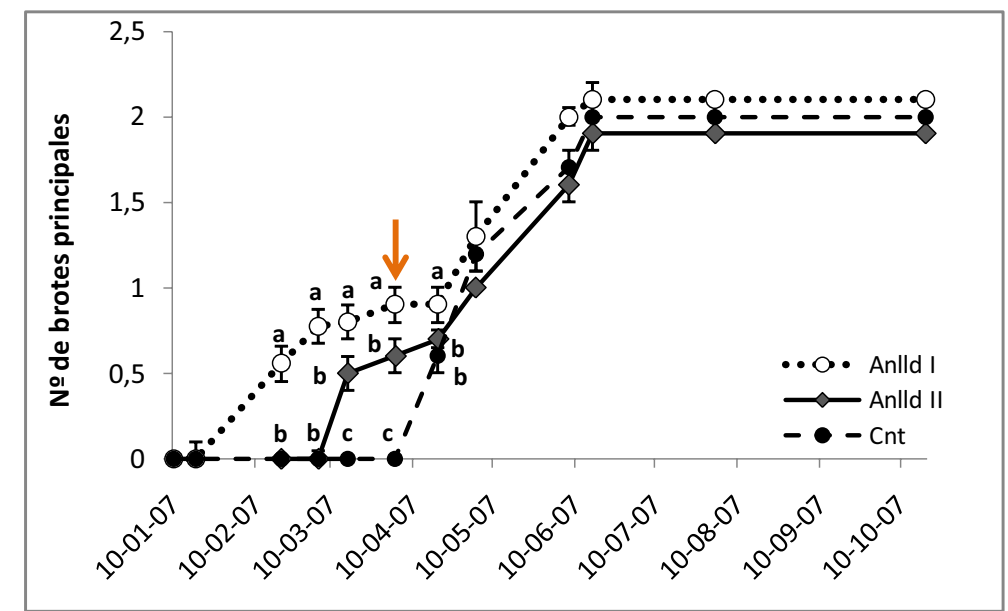

Fig. 2.7.- Influencia del aislamiento temporal del fruto en la evolución de la brotación de las yemas del níspero japonés cv. 'Algerie'. Cada valor es la media de 20 brotes repartidos en cinco árboles. Las barras verticales indican el ES. La flecha indica el momento de la recolección. Anlld I: panícula anillada en el estado 701 de la escala BBCH; Anlld II: panícula anillada en el estado 703 de la escala BBCH; Cnt: panícula no anillada. .Letras diferentes para una misma fecha indican diferencias significativas $(P \leq 0.05)$.

Algo parecido ocurrió con la brotación anticipada, aunque en este caso la respuesta fue más lenta y tuvieron que transcurrir entre 80 y 50 días desde la realización de los anillados I y II, respectivamente, o, lo que es lo mismo, esperar hasta el momento de la recolección o 15 días después, en cada caso, para encontrar diferencias significativas entre los tratamientos (Fig. 
2.8). Estas diferencias se hicieron más notables a los 30 días de la recolección, cuando los controles no habían brotado y los anillados I y II ya presentaban 0.7 y 0.3 brotes anticipados, respectivamente, por cada brote principal. Sin embargo, 35 días después, los anillados II y los controles igualaron su respuesta hasta el final de periodo en el que sólo los anillados I consiguieron mantener las diferencias, de hasta 0.4 brotes anticipados más por brote principal (Fig. 2.8).

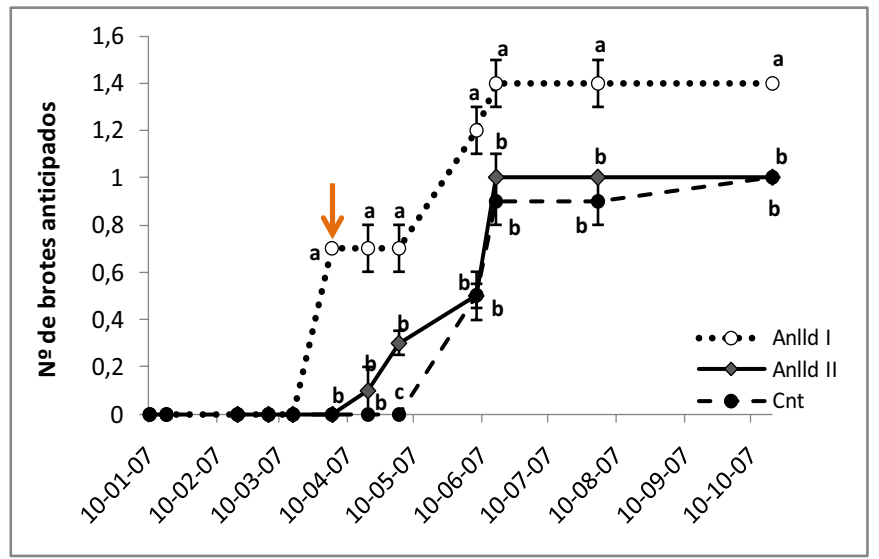

Fig. 2. 8.- Influencia del aislamiento temporal del fruto en la evolución de las yemas de brotación anticipada del níspero japonés cv. 'Algerie'. Cada valor es la media de 20 brotes repartidos en cinco árboles. Las barras verticales indican el ES. La flecha indica el momento de la recolección.Clavede tratamientos como en la Fig. 2.7. .Letras diferentes para una misma fecha indican diferencias significativas ( $P \leq 0.05)$.

El crecimiento de los brotes, principales y anticipados, siguió pautas de comportamiento similares, y parecidas a las encontradas cuando se eliminaron todos los frutos mediante el despuntado. Los brotes principales de los anillados I y II crecieron más que los controles, y al final del periodo su longitud era de 29.8, 26.5 y $24.8 \mathrm{~cm}$, respectivamente (Fig. 2.9). Sólo los brotes originados por el anillado I consiguieron alcanzar la significación estadística, que mantuvieron durante todo el periodo estudiado. Aunque también se encontraron diferencias significativas entre los anillados II y los controles, a favor de los primeros, en algunos momentos puntuales del desarrollo vegetativo, finalmente los controles consiguieron igualar su longitud (Fig. 2.9). Los primeros indicios de crecimiento en los controles se detectaron a los 15 días de haber realizado la recolección, momento en el que los brotes de los anillados I y II ya medían 2.2 y $0.5 \mathrm{~cm}$, respetivamente (Fig. 2.9). Estos resultados demuestran, una vez más, la acción del fruto retrasando la brotación y restringiendo el posterior crecimiento de los brotes. 


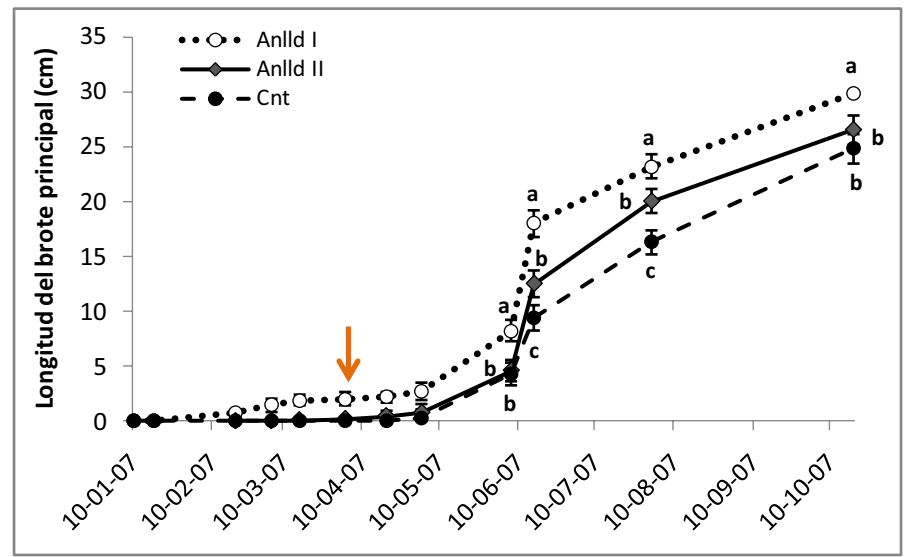

Fig. 2.9.- Influencia del aislamiento temporal del fruto en el crecimiento de los brotes principales del níspero japonés cv. 'Algerie'. Cada valor es la media de 20 brotes repartidos en cinco árboles. Las barras verticales indican el ES. La flecha indica el momento de la recolección. Clave de tratamientos como en la Fig. 2.7. .Letras diferentes para una misma fecha indican diferencias significativas ( $P \leq 0.05)$.

Una respuesta similar se obtuvo en el crecimiento de los brotes anticipados, si bien en este caso los procedentes de brotes anillados I se mostraron más sensibles. Ya en el momento de la recolección las diferencias habían alcanzado la significación estadística, que se mantuvo hasta el final del periodo estudiado (Fig. 2.10). En ese momento estos brotes medían $20 \mathrm{~cm}$ y los anillados II y los controles 16.9 y $17.2 \mathrm{~cm}$, respectivamente (Fig. 2.10). Los anillados II se comportaron prácticamente igual que los controles a lo largo de todo el ciclo, si bien consiguieron anticipar su crecimiento un mes, aproximadamente (Fig. 2.10).

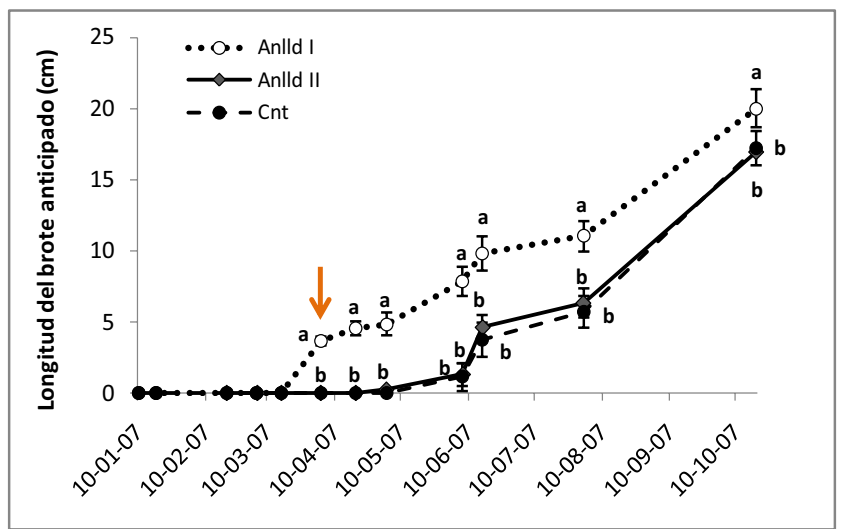

Fig. 2.10.- Influencia del aislamiento temporal del fruto en el crecimiento de los brotes anticipados del nispero japonés cv. 'Algerie'. Cada valor es la media de 20 brotes repartidos en cinco árboles. Las barras verticales indican el ES. La flecha indica el momento de la recolección. Clave de tratamientos como en la Fig. 2.7. .Letras diferentes para una misma fecha indican diferencias significativas $(P \leq 0.05)$. 
Al comparar los resultados de los brotes anillados y despuntados, se observó que, en general, la respuesta fue más eficaz cuando se eliminaron los frutos del brote que cuando se aislaron temporalmente hasta la cicatrización de los anillados (Fig. 2.11). Tanto es así que a los 30 días de la eliminación de los frutos, independientemente de la época, el 100\% de los brotes despuntados ya habían iniciado la brotación, mientras que de los brotes anillados I y II tan sólo lo habían conseguido el $33 \%$ y el $20 \%$, respectivamente. La eliminación o aislamiento temporal de los frutos en ambas épocas I y II produjo un estímulo de la brotación de las yemas principales y anticipadas. Treinta días después de la eliminación o del aislamiento de los frutos, el número de brotes principales en los brotes despuntados y en los anillados, e independientemente de la época, fue significativamente mayor, 1.8 y 0.6 en los despuntados y anillados I y 2.3 y 0.5 en los despuntados y anillados II, respectivamente, que en los controles, que no habían mostrado, todavía, indicios de brotación (Fig. 2.11). Las diferencias en el número de brotes principales desarrollados fueron máximas en el momento de la recolección de los controles cuando ambos despuntados, I y II, tenían 2.3 y 2.5 brotes principales en desarrollo, respectivamente, los anillados 0.9 y 0.6 , y los controles aún no habían iniciado la brotación. Mientras en los brotes despuntados en ambas épocas estas diferencias se mantuvieron hasta el final del periodo estudiado, los anillados en ambas épocas y los controles no difirieron entre sí desde, aproximadamente, los 15 y 30 días posteriores a la recolección, respectivamente (Fig. 2.11).
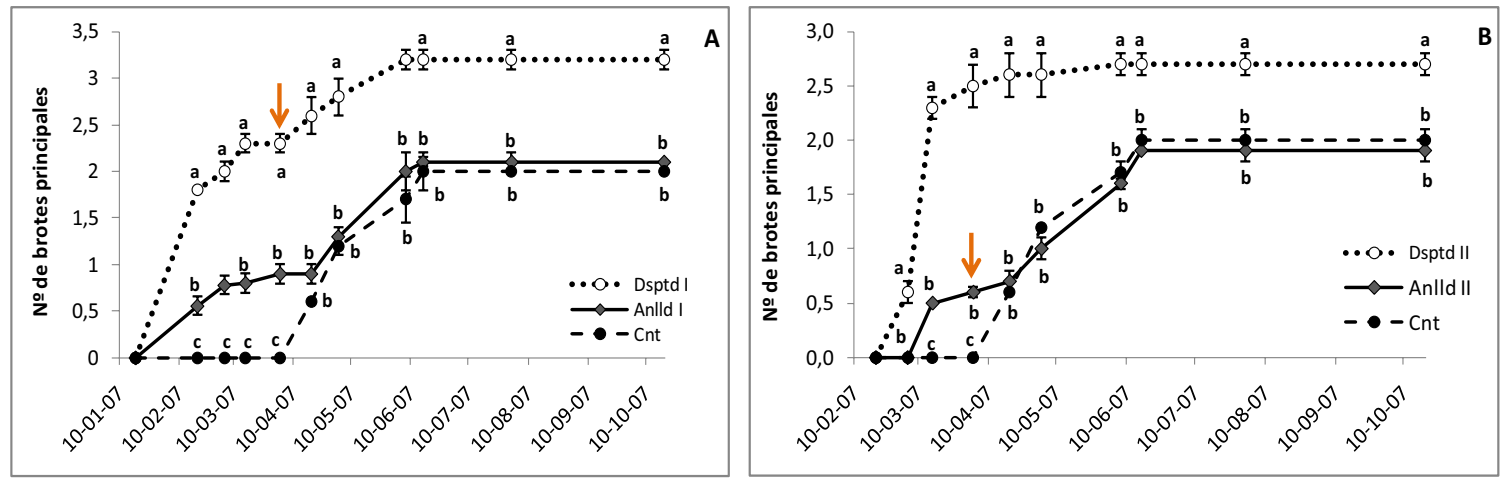

Fig. 2.11.- Influencia de la presencia del fruto hasta su recolección y de su eliminación o aislamiento temporal en el estado 701 (A) y 703 (B) de la escala $B B C H$, sobre la brotación de las yemas principales del níspero japonés cv. 'Algerie'. Cada valor es la media de 20 brotes distribuidos en cinco árboles. Las barras verticales indican el ES y la flecha el momento de la recolección. Dsptd I y II: frutos eliminados en los estados fenológicos 701 y 703 de la escala BBCH; Anlld I y II: brotes anillados en los estados fenológicos 701 y 703 de la escala BBCH; Cnt: Panícula no anillada. .Letras diferentes para una misma fecha indican diferencias significativas $(P \leq 0.05)$. 
Una respuesta similar se obtuvo sobre la brotación de las yemas anticipadas, si bien en este caso hubo que esperar más tiempo para detectar las primeras diferencias debidas a los tratamientos, esto es, hasta el momento de la recolección para la primera época del tratamiento ó 15 días después en el caso de la segunda (Fig. 2.12), lo que refleja una mayor sensibilidad a éstos en las primeras fases de crecimiento del fruto. Como consecuencia de ello, los brotes despuntados o anillados en la primera época tuvieron antes un mayor número de brotes anticipados ( 1.5 y 0.7 brotes, respectivamente) (Fig. $2.12 \mathrm{~A}$ ), que los correspondientes a la segunda época del tratamiento ( 0.8 y 0.1 brotes) (Fig. 2.12 B); los controles no mostraron ningún indicio de brotación en las dos épocas en que se realizaron las determinaciones. Este efecto perduró hasta el final del periodo estudiado, de manera que seis meses más tarde, al final del crecimiento vegetativo, el número total de brotes desarrollados en cada uno de los tratamientos de la primera época fue significativamente mayor (2.0 y 1.4 brotes) (Fig. $2.12 \mathrm{~A}$ ) que cuando se hicieron en la segunda (1.4 y 1.0 brotes) (Fig. 2.12 B) y que los controles, que sólo tuvieron 1.0 brote (Fig. 2.12 A y B). Asimismo, únicamente los tratamientos realizados durante la primera época consiguieron mantener las diferencias significativas a lo largo de todo el ciclo vegetativo. En efecto, 60 días después de la recolección, en pleno crecimiento vegetativo, los anillados en la segunda época y los controles igualaron su respuesta, mientras que los despuntados en la primera presentaron mayor número de brotes anticipados, aunque significativamente menor a los conseguidos por este mismo tratamiento en la primera época (Fig. 2.12).

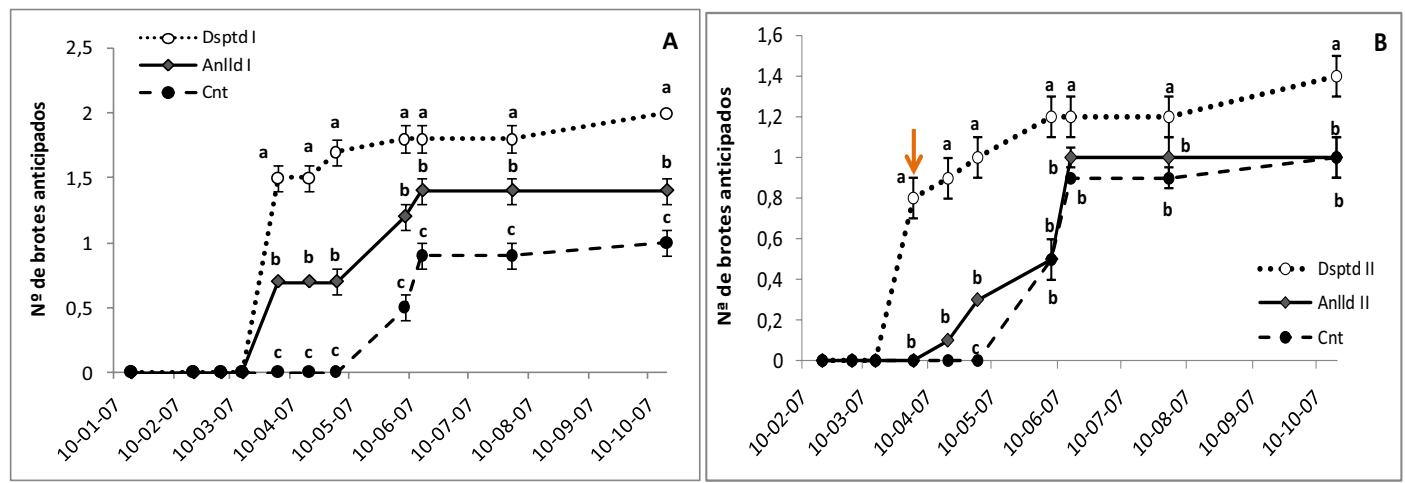

Fig. 2.12.- Influencia de la presencia del fruto hasta su recolección y de su eliminación o aislamiento temporal, en los estados fenológicos 701 (A) y 703 (B) de la escala $B B C H$, sobre la brotación de las yemas anticipadas del níspero japonés cv. Algerie. Cada valor es la media de 20 brotes distribuidos en cinco árboles. Las barras verticales indican el ES y la flecha el momento de la recolección. Clave de tratamientos como en la Fig. 2.11. Letras diferentes para una misma fecha indican diferencias significativas (PS0.05). 
La eliminación de los frutos o su aislamiento temporal también estimuló el desarrollo vegetativo. En el momento de la recolección, 80 días después de la descarga de los frutos o de su aislamiento, la longitud de sus brotes principales y anticipados ya era significativamente mayor que la de los controles, que todavía no habían iniciado el crecimiento (Fig. 2.13). Estas diferencias se mantuvieron en todas las fechas estudiadas $y$, al final del crecimiento vegetativo, los brotes principales de los despuntados y anillados crecieron, por término medio, 4.0 y $5.0 \mathrm{~cm}$ más, respectivamente, que los controles (Fig. $2.13 \mathrm{~A}$ ), lo que supone un incremento entre el $12.9 \%$ y el $16.7 \%$ de la longitud final. Los brotes anticipados también fueron más largos y crecieron hasta $7.6 \mathrm{~cm}(24.5 \%)$ y $2.8 \mathrm{~cm}(9.4 \%)$ más, respectivamente, que los controles (Fig. 2.13 B). Sin embargo, en general, y salvo para el caso de los brotes anticipados al final del crecimiento vegetativo, los tratamientos se mostraron igual de eficaces durante todo el ciclo estudiado, por lo que la eliminación de los frutos no mejoró la respuesta respecto de su aislamiento temporal (Fig. 2.13). Resultados similares, pero menos relevantes, se obtuvieron cuando los tratamientos se realizaron en etapas más avanzadas del desarrollo del fruto.
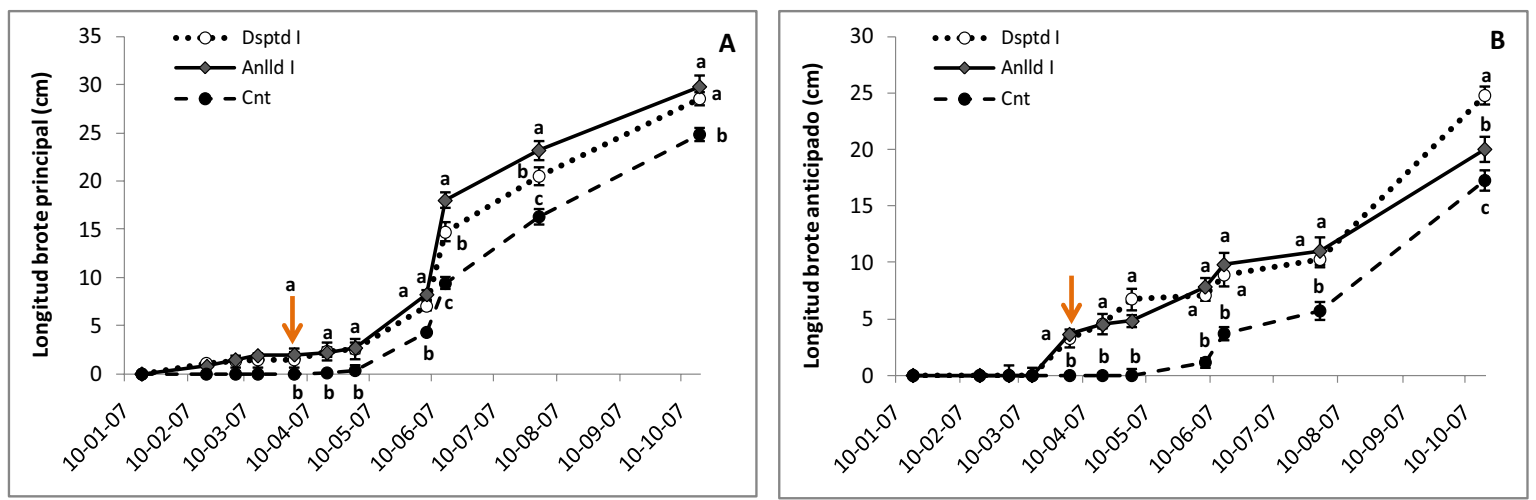

Fig. 2.13.- Influencia de la presencia del fruto hasta su recolección y de su eliminación o aislamiento temporal en el estado fenológico 701 de la escala $B B C H$, sobre el crecimiento de los brotes principales(A) y anticipados(B) del nispero japonés cv. 'Algerie'. Cada valor es la media de 20 brotes distribuidos en cinco árboles. Las barras verticales indican el ES y la flecha el momento de la recolección. Dsptd I: frutos eliminados; Anlld I: frutos aislados mediante anillado; Cnt: frutos presentes hasta la recolección. Letras diferentes para una misma fecha indican diferencias significativas $(P \leq 0.05)$.

Como consecuencia del aislamiento temporal de los frutos el crecimiento de éstos se resintió. Independientemente de la época de anillado, los frutos de estos brotes fueron significativamente más pequeños que los controles a lo largo de todo el periodo de su 
crecimiento. Los frutos de los brotes anillados prácticamente detuvieron su crecimiento en los días inmediatos a su aislamiento, que retomaron posteriormente con la cicatrización del anillado, aproximadamente 60 días después de la realización del mismo (Fig. 2.14). En el momento de la maduración estas diferencias fueron más acusadas, siendo el diámetro y el peso fresco final alcanzado por los controles de $41.5 \mathrm{~mm}$ y $53 \mathrm{~g}$, y el de los anillados I y II de $32.0 \mathrm{~mm}$ y $31.5 \mathrm{~g}$ y $31.0 \mathrm{~mm}$ y $30.0 \mathrm{~g}$, respectivamente, no mostrándose diferencias significativas entre ambos tratamientos (Fig. 2.14). El peso fresco de la semillas también fue significativamente mayor en los controles (3.2 g) que en los anillados I y II (2.2 y $2.0 \mathrm{~g}$, respectivamente), sin verse modificado el número de las mismas. No se encontraron diferencias significativas entre los tratamientos en la concentración de sólidos solubles totales del zumo del fruto (11.1 ${ }^{\circ}$ Brix); los procedentes de brotes anillados fueron más ácidos pero sin llegar a la significación ( $1 \%$ y $0.9 \%$ frente a $0.7 \%$ de los controles) y significativamente más firmes (7.3 y $7.6 \mathrm{~N}$ frente a $6.8 \mathrm{~N}$ de los controles).

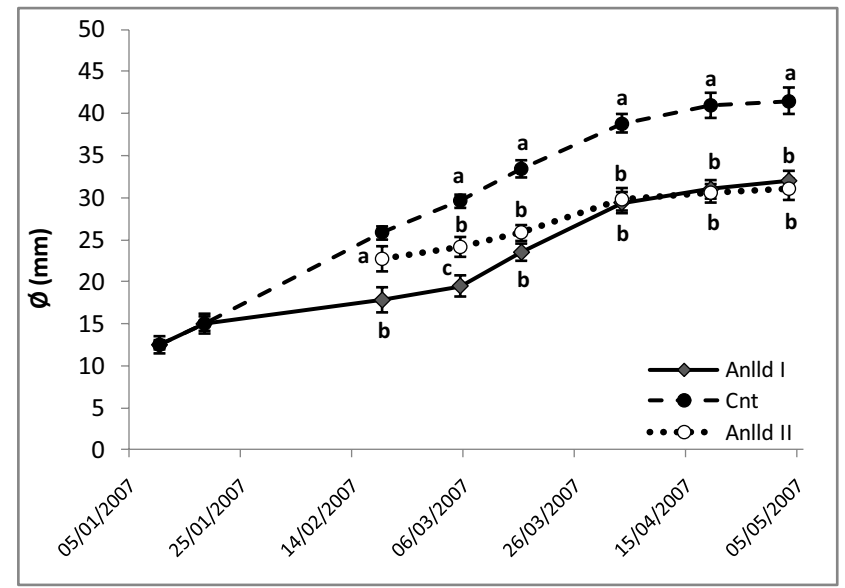

Fig. 2.14.- Influencia del aislamiento temporal del fruto sobre su crecimiento en el níspero japonés cv. 'Algerie'. Cada valor es la media de 20 frutos por árbol distribuidos en cinco árboles. Las barras verticales indican el ES. Clave de tratamientos como en la Fig. 2.1. .Letras diferentes para una misma fecha indican diferencias significativas $(P \leq 0.05)$.

\subsection{Influencia de la semilla}

La presencia de frutos partenocárpicos en el brote, o lo que es lo mismo, la ausencia de semillas en los frutos, modificó los parámetros de la brotación de un modo similar a lo obtenido con la eliminación o aislamiento temporal de los frutos del brote. En los brotes con frutos partenocárpicos también se anticipó la brotación y se consiguieron mayor número de brotes, tanto principales como anticipados, y de mayor longitud, ambos, que en los controles, en los dos años consecutivos estudiados (Tabla 2.1). Mientras en los controles no se detectó 
ningún indicio de desborre durante todo el tiempo en el que el fruto estuvo presente en el brote, en los partenocárpicos, 1 mes antes de su recolección, el $75 \%$ de las yemas, aproximadamente, ya lo habían conseguido. Por otra parte, las diferencias en número y en longitud fueron más relevantes en el caso de los brotes anticipados que en el de los principales en los dos años que duró el experimento. Así, por ejemplo, al final del crecimiento vegetativo, en el primer año de estudio, la ausencia de semillas en los frutos aumentó en 0.8 el número de éstos que, además, midieron $10.5 \mathrm{~cm}$ más que los controles y tuvieron mayor número de hojas (Tabla 2.1). Aunque la respuesta en el incremento del número de brotes principales fue menos sensible que en el caso de los brotes anticipados, también en éstos se alcanzó la significación estadística, de modo que la ausencia de semillas en los frutos promovió su crecimiento, y acabaron midiendo $11.4 \mathrm{~cm}$ más que los controles, pero con el mismo número de hojas (Tabla 2.1). En este caso, por tanto, el efecto también alcanzó a la longitud de los entrenudos de los brotes principales que se redujo por la presencia de las semillas en los frutos. La repetición del tratamiento el año siguiente produjo los mismos efectos sobre el desarrollo vegetativo, si bien mostrando diferencias cuantitativas importantes, lo que es consecuencia de la variabilidad climática entre años para una misma zona de cultivo (Tabla 2.1).

Tabla 2.1.- Influencia de la presencia (control) o ausencia de semillas en los frutos (partenocárpicos) sobre las características de la brotación principal y anticipada del níspero japonés cv. 'Algerie' al final del crecimiento vegetativo. Cada valor es la media de 20 brotes repartidos en cinco árboles. Letras distintas en una misma columna y para un mismo año indican diferencias significativas $(P \leq 0.05)$.

\begin{tabular}{|l|c|c|c|c|c|c|}
\cline { 2 - 7 } \multicolumn{1}{c|}{} & \multicolumn{9}{c|}{ Año 1 } \\
\cline { 2 - 7 } \multicolumn{1}{c|}{} & \multicolumn{2}{c|}{ № Brotes } & \multicolumn{2}{c|}{ Longitud (cm) } & \multicolumn{2}{c|}{ № Hojas } \\
\hline Tratamiento & Principales & Anticipados & Brote Principal & Brote Anticipado & Brote Principal & Brote Anticipado \\
Partenocárpico & $2.4 \mathrm{a}$ & $1.6 \mathrm{a}$ & $25.7 \mathrm{a}$ & $15.8 \mathrm{a}$ & 9.3 & $6.4 \mathrm{a}$ \\
Control & $2 \mathrm{~b}$ & $0.8 \mathrm{~b}$ & $14.3 \mathrm{~b}$ & $5.3 \mathrm{~b}$ & 9 & $4.8 \mathrm{~b}$ \\
\hline & \multicolumn{7}{|c|}{ Año 2 } & $2.8 \mathrm{a}$ & 6.4 & $1.3 \mathrm{a}$ \\
\hline Partenocárpico & $2.1 \mathrm{a}$ & $0.4 \mathrm{a}$ & $7.9 \mathrm{a}$ & $0.1 \mathrm{~b}$ & 6.2 & $0.1 \mathrm{~b}$ \\
\hline Control & $1.4 \mathrm{~b}$ & $0.1 \mathrm{~b}$ & $4.5 \mathrm{~b}$ & &
\end{tabular}

Las pautas de crecimiento en un fruto con semillas (control) y sin semillas (partenocárpico) fueron similares a lo largo de todo el periodo de crecimiento del fruto; no obstante, las diferencias encontradas en su cinética durante las primeras fases del crecimiento se acentuaron a medida que el fruto aumentaba de tamaño, hasta alcanzar valores máximos al final de su crecimiento, cuando el diámetro de los frutos con semillas fue significativamente mayor (45.9 mm) (Fig. 2.15 A) que el de los frutos sin semillas (28.7 mm) (Fig. 2.15 B). Estos aspectos se estudian en mayor profundidad en el Capítulo 4. Un efecto contrario, sin embargo, 
se observó en el crecimiento vegetativo, ya que los nuevos brotes que estuvieron bajo la influencia de los frutos partenocárpicos midieron $11.4 \mathrm{~cm}$ más que los que lo estuvieron bajo la de los frutos con semillas (Fig. 2.15). Pero tanto en frutos partenocárpicos como no partenocárpicos los nuevos brotes no iniciaron su crecimiento en longitud hasta que el fruto alcanzó su tamaño final, poniéndose también así de manifiesto la competencia existente entre el crecimiento de los frutos y el de los brotes, a favor de los primeros (Fig. 2.15).
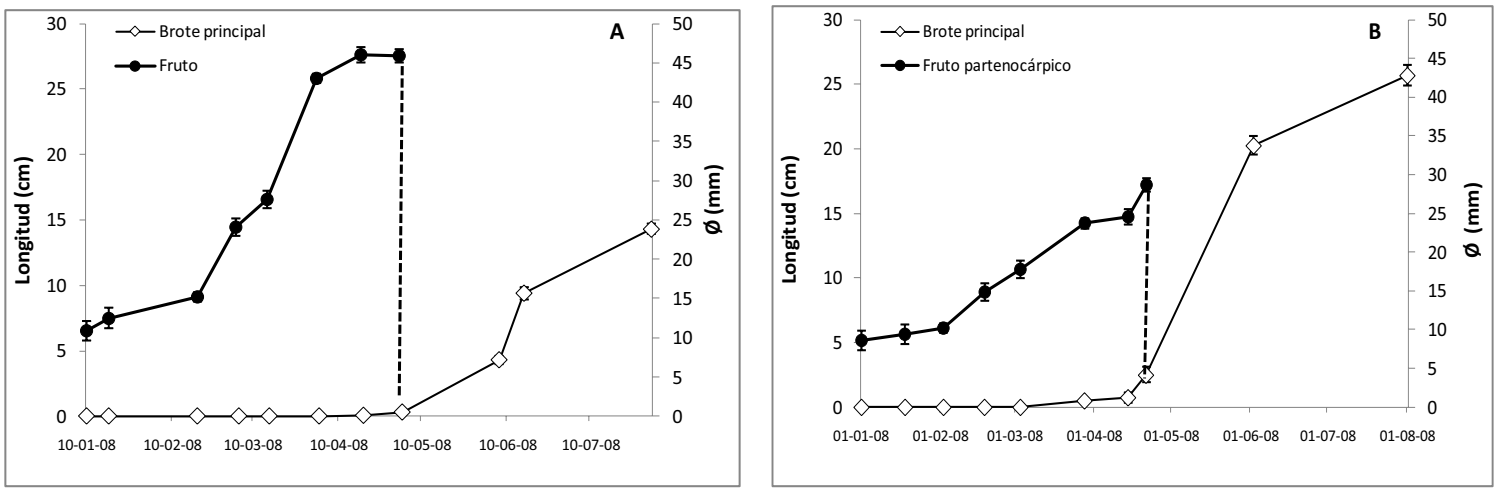

Fig. 2.15.- Influencia de la presencia (A) o ausencia (B) de semillas en los frutos, sobre el tamaño final del fruto y el crecimiento de los brotes principales desde las primeras fases del crecimiento del fruto hasta el final del desarrollo en el níspero japonés cv. 'Algerie'. Cada valor es la media de 20 frutos y 20 brotes repartidos en cinco árboles. Las barras verticales indican el ES.

\subsection{Eliminación de los frutos. Estudio del árbol completo.}

La ausencia de frutos, esto es, la eliminación de todos los frutos de un árbol, reveló, como en casos anteriores, un adelanto en la brotación y un estímulo del desarrollo vegetativo cuando se comparó con la presencia de frutos, esto es con la de árboles que conservaron todos sus frutos hasta la maduración. Así, en nuestras condiciones climáticas, la brotación espontánea de un árbol en condiciones de cultivo y soportando la totalidad de los frutos comienza a partir de yemas axilares tras la recolección o en etapas muy próximas a ella, y al final del crecimiento vegetativo es capaz de desarrollar, por término medio, 2 nuevos brotes principales (de los que surgirán los brotes anticipados) que, posteriormente, diferenciarán panículas en sus extremos; la nueva brotación de yemas axilares reiniciará el ciclo vegetativo. Con la eliminación de todos los frutos del árbol esta brotación no sólo se anticipó en, aproximadamente, 35 días, sino que, además, aumentó significativamente durante todo el periodo de crecimiento del fruto hasta 
que, una vez completado el mismo, se mantuvo prácticamente estable hasta el final del crecimiento vegetativo, perdiendo entonces las diferencias con respecto a los árboles que mantuvieron todos sus frutos hasta la recolección (Fig. 2.16).

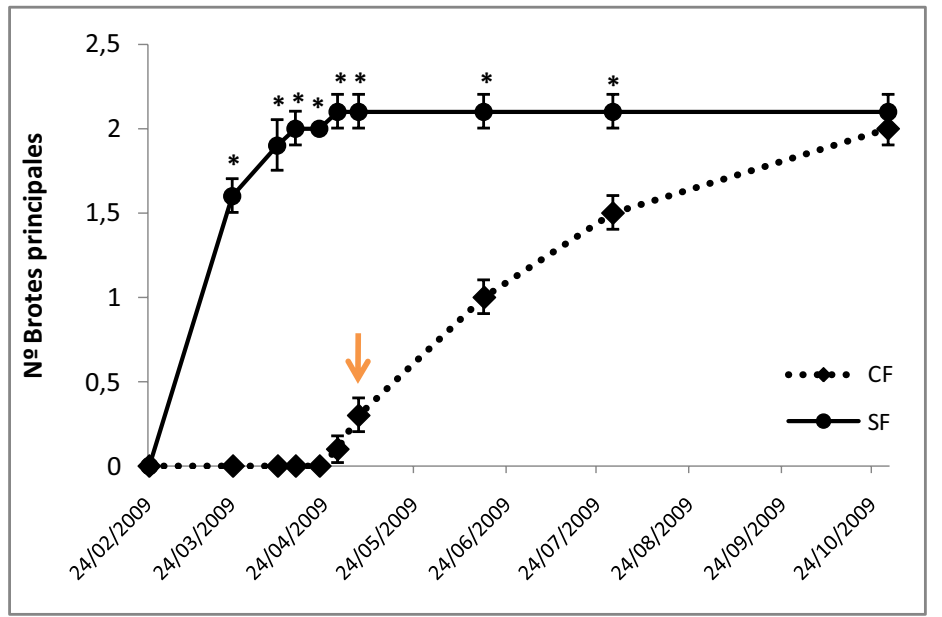

Fig. 2.16.- Influencia del fruto sobre la evolución de la brotación de las yemas del níspero japonés cv. 'Algerie'. Cada valor es la media de 20 brotes repartidos en cinco árboles. Las barras verticales indican el ES. La flecha indica el momento de la recolección. CF: árboles con todos sus frutos hasta el momento de la recolección; SF: árboles a los que se les eliminaron todos los frutos en el estado fenológico 701 de la escala BBCH. * indica diferencias significativas ( $P \leq 0.05$ ) para un mismo estado fenológico.

La longitud de los brotes principales en los árboles que mantuvieron todos sus frutos hasta la recolección fue significativamente menor a lo largo de todo el periodo estudiado que la de aquellos a los que se les eliminaron todos al inicio de su desarrollo. La respuesta fue inmediata, y a los 30 días de la descarga de los frutos, los brotes en éstos árboles ya medían $0.6 \mathrm{~cm}$, mientras que en los árboles con todos los frutos todavía no se había iniciado la brotación. Cuatro meses más tarde, en pleno crecimiento vegetativo, los resultados muestran más claramente el efecto derivado de la presencia de los frutos. En efecto, entre las dos fechas estudiadas, los brotes de los árboles sin frutos habían crecido $12.2 \mathrm{~cm}$ frente a los $4.3 \mathrm{~cm}$ de los árboles con todos los frutos (Fig. 2.17), mostrándose, de nuevo, una reducción del desarrollo vegetativo debida a la presencia de los frutos. Desde la anterior observación hasta el final del crecimiento vegetativo los brotes de los árboles sin frutos crecieron 
significativamente más $(20.5 \mathrm{~cm})$ que los brotes de los árboles que mantuvieron todos sus frutos hasta el momento de la recolección $(6.9 \mathrm{~cm}$ ) (Fig. 2.17). Este efecto, sin embargo, no alcanzó al número de hojas formadas en estos brotes, que fue prácticamente el mismo, pero sí a la longitud de los entrenudos, que se vio reducida por la presencia de los frutos (Fig. 2.17).

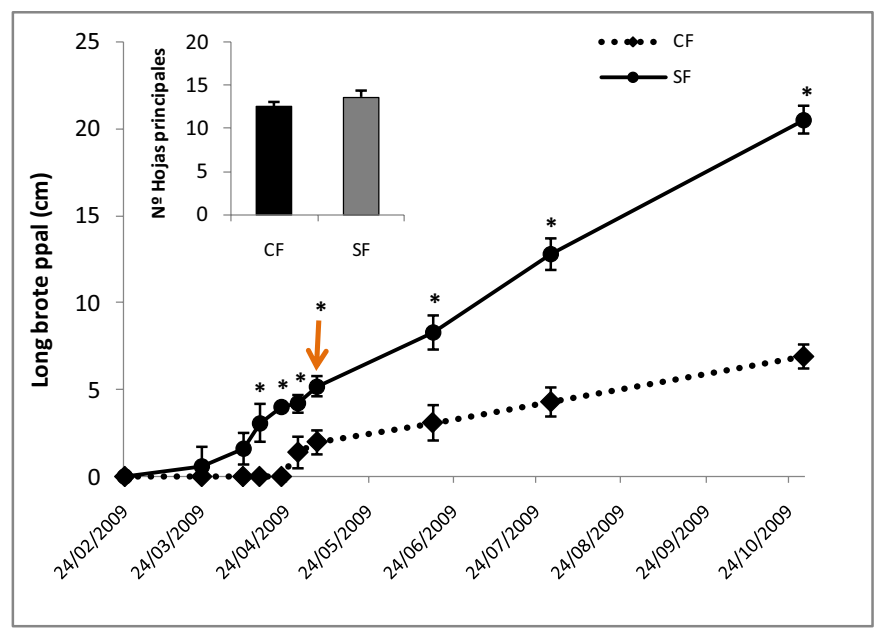

Fig. 2.17. Influencia del fruto sobre el crecimiento de los brotes principales y de su número de hojas en el níspero japonés cv. 'Algerie'. Cada valor es la media de 20 brotes repartidos en cinco árboles. Las barras verticales indican el ES. La flecha indica el momento de la recolección. Clave de tratamientos como en la Fig. 2.16. * indica diferencias significativas ( $P \leq 0.05$ ) para un mismo estado fenológico.

De igual modo, la ausencia de los frutos favoreció la anticipación de la brotación de las yemas que iniciaron antes el desborre y presentaron, al final del crecimiento vegetativo, 1.4 brotes anticipados más, por término medio, que los árboles que mantuvieron todos los frutos hasta el momento de su recolección (Tabla 2.2). En este caso, las yemas anticipadas fueron más sensible al fruto y el aumento registrado en el número de brotes totales alcanzó la significación estadística, a diferencia de lo observado en los brotes principales (Fig. 2.16). La longitud de los brotes anticipados y el número de hojas que desarrollaron también disminuyeron como consecuencia de la presencia de los frutos en el árbol (Tabla 2.2). Estas diferencias, que ya se apreciaron al inicio del crecimiento vegetativo, cuando en los árboles que habían perdido antes todos sus frutos los brotes anticipados medían $6.3 \mathrm{~cm}$ y tenían 3 hojas y en los que los habían perdido hacía sólo 1 mes ni siquiera había indicios de desborre, se mantuvieron durante todo el crecimiento vegetativo, y al final de éste alcanzaron su máxima intensidad, de modo que en los primeros los brotes anticipados fueron significativamente más 
largos (13.5 cm más) y con mayor densidad foliar ( 8.8 hojas más) que en los segundos (Tabla 2.2).

Tabla 2.2.- Influencia de la presencia del fruto sobre el número y las características de los brotes anticipados del níspero japonés cv. 'Algerie'. Cada valor es la media de 20 brotes repartidos en cinco árboles. Clave de tratamientos como en la Fig. 2.16. Letras distintas en una misma columna indican diferencias significativas $(P \leq 0.05)$.

\begin{tabular}{|c|c|c|c|}
\cline { 2 - 4 } \multicolumn{1}{c|}{} & \multicolumn{3}{c|}{ BROTES ANTICIPADOS } \\
\hline Tratamiento & No brotes & Longitud $(\mathrm{cm})$ & No hojas \\
\hline CF & $1,3 \mathrm{a}$ & $4,5 \mathrm{a}$ & $5,9 \mathrm{a}$ \\
\hline SF & $2,7 \mathrm{~b}$ & $18.0 \mathrm{~b}$ & $14,7 \mathrm{~b}$ \\
\hline
\end{tabular}

Resulta interesante destacar la localización de los brotes anticipados. Éstos siempre se encontraron en la mitad basal del brote principal, es decir, fueron las yemas más alejadas del ápice principal las responsables de brotar lateralmente formando, de esta manera, los nuevos brotes anticipados en desarrollo. Este comportamiento se presentó de manera general en todos los árboles estudiados, independientemente del número de frutos que tuvieran y del tiempo que permanecieran. Por eso, los árboles que estuvieron sin frutos desde el momento del aclareo tuvieron al final del crecimiento vegetativo, o lo que es lo mismo, aproximadamente 8 meses después de la descarga, 2.1 brotes principales por ramo principal que crecieron $20.5 \mathrm{~cm}$ y desarrollaron 13.6 hojas (Figs. 2.16 y 2.17 y Tabla 2.2), y en los que, por término medio, desde la novena hoja contada desde el ápice del brote principal, se originaron los 2.7 brotes anticipados de $18 \mathrm{~cm}$ y 14.7 hojas (Tabla 2.2). Sin embargo, cuando los frutos permanecieron en el árbol hasta su recolección, los 2 brotes principales desarrollados al final del crecimiento vegetativo, en este caso, aproximadamente 5 meses después de la descarga, midieron $6.9 \mathrm{~cm}$ y desarrollaron 12 hojas, encontrándose también en este caso los 1.3 brotes anticipados, de $4.5 \mathrm{~cm}$ y 5.9 hojas, originados a partir de las yemas situadas en las axilas de las hojas más basales, concretamente desde la 6a contada desde el ápice. Aunque no se encontró ninguna relación entre la longitud o el número final de hojas en el brote principal y el número de brotes anticipados desarrollados, de nuestros resultados se deduce que es necesario que el brote principal haya desarrollado un mínimo de hojas, más de 5, para que haya brotes anticipados. De este modo, ambas brotaciones, principal y anticipada, presentan una estrecha relación, por lo que cualquier variación en los brotes principales puede explicar la variación encontrada en las características de los brotes anticipados. 
La presencia del fruto, por tanto, no alteró el número de brotes principales, pero sí la longitud de sus entrenudos, reduciéndola, y el número de los anticipados sobre los que, además, modificó el orden de brotación y redujo su longitud, el número de entrenudos y la longitud de éstos. El efecto del fruto sobre el desarrollo vegetativo es, por tanto, decisivo.

\subsection{La influencia del fruto en el reparto de carbohidratos}

En nuestros experimentos la presencia de los frutos apenas alteró el contenido en carbohidratos de transporte en el floema, que fue, prácticamente, constante a lo largo del tiempo de estudio (Fig. 2.19). Únicamente se detectó un marcado descenso de la concentración en el momento de máximo crecimiento del fruto (estado 709 de la escala $\mathrm{BBCH}$ ), coincidente a su vez, con un marcado descenso de las temperaturas. Tras restablecerse éstas, la concentración de azúcares de transporte aumentó rápidamente, recuperándose los valores iniciales que perduraron hasta el final del ciclo vegetativo. Los brotes sin frutos (despuntados) fueron menos sensibles a los cambios térmicos, de modo que mantuvieron prácticamente estable su concentración en todos los estados fenológicos estudiados (Fig. 2.19). Por ello, no se encontraron diferencias significativas entre los tratamientos hasta el estado fenológico $709 \mathrm{BBCH}$, atribuibles más a un efecto indirecto del descenso de las temperaturas sobre el desarrollo del fruto que al propio crecimiento de éste. Aunque este hecho puntual afectó por igual a todos los tratamientos, que vieron reducida significativamente su concentración en las dos épocas estudiadas, sus efectos secundarios difirieron considerablemente. Mientras en los brotes despuntados durante la primera época (despuntado I) la concentración de azúcares de transporte 15 días después del descenso de temperaturas era significativamente más baja que en el resto de los tratamientos (Fig. $2.19 \mathrm{~A}$ ), en los brotes depuntados más tarde (despuntado II) la concentración era la misma (Fig. 19 B). Las diferencias de los despuntados I con el resto de los tratamientosse perdieron con el trancurso del tiempo, contrariamente a lo observado para los despuntados II, de manera que en pleno crecimiento vegetativo mientras la concentración de azúcares de transporte en los primeros era similar en todos ellos, en los segundos la concentración fue significativamente mayor en los brotes sin frutos (Fig. 2.19B). 

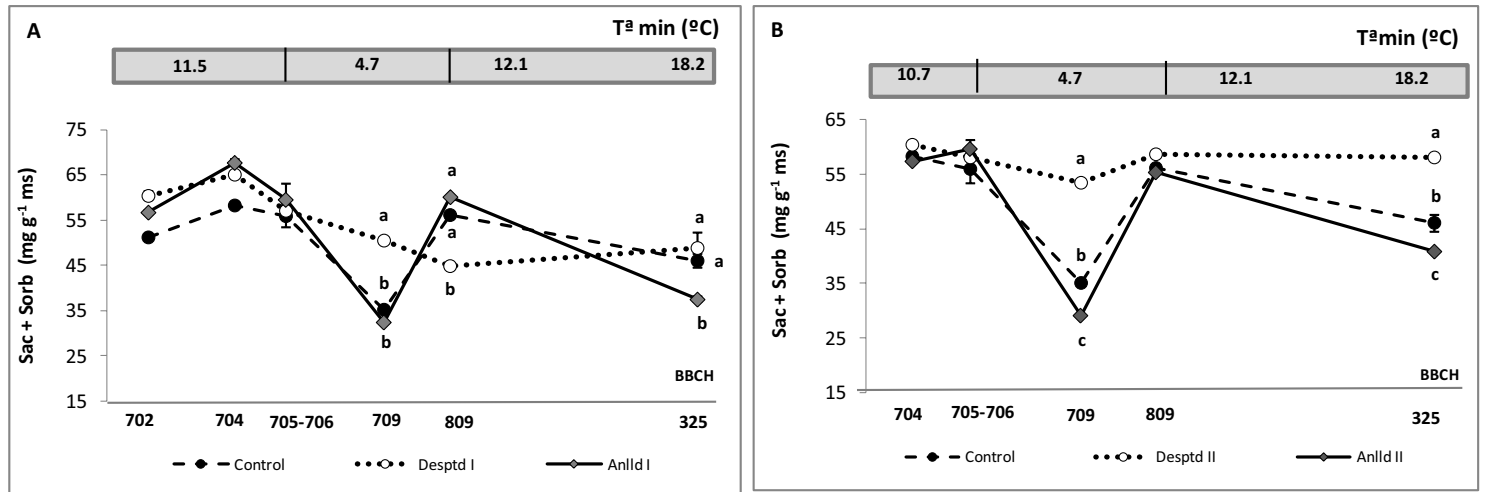

Fig. 2.19.- Influencia de la presencia del fruto hasta su recolección y de su eliminación o aislamiento temporal en el estado 701 (A) y 703 (B) de la escala BBCH, en la evolución del contenido en carbohidratos de transporte (sacarosa + sorbitol) en el floema de los brotes mixtos del níspero japonés cv. 'Algerie' a lo largo del ciclo vegetativo. Cada valor es la media de cuatro árboles. En una barra horizontal se indican las temperaturas medias a lo largo del periodo de estudio. Estados fenológicos representados en el eje de abscisas según la escala BBCH Las barras verticales indican el ES. Clave de tratamientos como en la Fig. 2.11. Letras diferentes indican diferencias significativas $(P \leq 0.05)$ para un mismo estado fenológico.

Al seguir la evolución de la concentración de estos carbohidratos en el tejido floemático que quedó por encima y por debajo de los correspondientes anillados, se observó un comportamiento paralelo en ambos a lo largo del periodo estudiado e independiente del momento en que se hicieron, pero significativamente superior en el primero (Fig. 2.20). Esta evolución reveló un aumento progresivo de la concentración a ambos lados del anillado a lo largo del periodo de crecimiento del fruto y hasta su maduración, interrumpido por el descenso térmico ya señalado, estabilizándose posteriormente hasta el final del ciclo vegetativo. La concentración conjunta de sacarosa y sorbitol en la parte superior del anillado alcanzó valores significativamente superiores (hasta $44.6 \mathrm{mg} \mathrm{g}^{-1} \mathrm{~ms}$ ) en los brotes anillados en la primera época (estado $701 \mathrm{BBCH}$; Fig. $2.20 \mathrm{~A}$ ) que en la segunda (estado 703 BBCH; Fig. 2.20 B) (hasta $34.2 \mathrm{mg} \mathrm{g}^{-1} \mathrm{~ms}$ ); sin embargo, en la parte inferior la concentración alcanzada fue, prácticamente, la misma en cualquier momento del desarrollo para ambas épocas de anillado (35- $55 \mathrm{mg} \mathrm{g}^{-1} \mathrm{~ms}$ ) (Fig. 2.20). Estos resultados, en su conjunto, ponen de manifiesto la influencia del estado de desarrollo del fruto sobre la movilización de carbohidratos. 

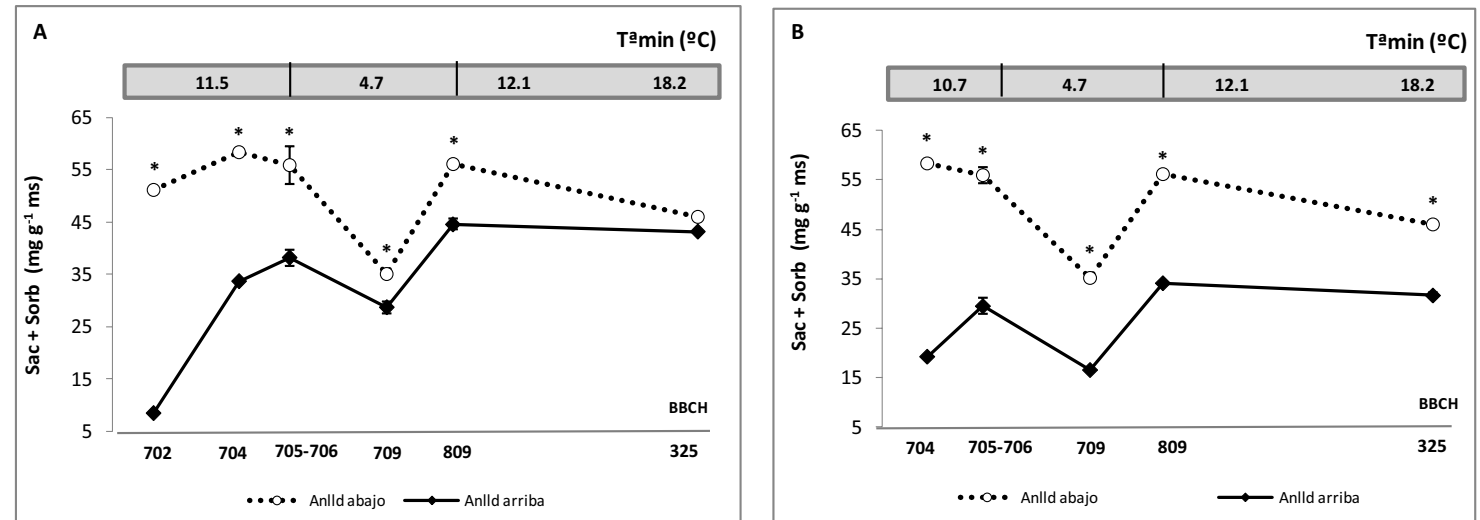

Fig. 2.20.- Influencia del aislamiento temporal del fruto en el estado 701 (A) y 703 (B) de la escala BBC, en la evolución del contenido en carbohidratos de transporte (sacarosa + sorbitol) en el tejido floemático de la parte superior e inferior del anillado de los brotes mixtos del níspero japonés cv. 'Algerie' a lo largo del ciclo vegetativo. Cada valor es la media de cuatro árboles. En una barra horizontal se indican las temperaturas medias a lo largo del periodo de estudio. Las barras verticales indican el ES. El eje de abscisas representa los estados fenológicos según la escala BBCH. Clave de tratamientos como en la Fig. 2.11. * indica diferencias significativas $(P \leq 0.05)$ para un mismo estado fenológico.

La concentración conjunta de azúcares reductores (glucosa y fructosa) en el tejido floemático, aumentó significativamente en las primeras fases de crecimiento del fruto hasta alcanzar valores máximos en el momento en que éste había alcanzado más de la mitad de su tamaño final, estados 705-706 BBCH (ver control en la Fig. 2.21). En los brotes despuntados, la evolución a lo largo de dicho periodo fue paralela a la de los controles, si bien el máximo señalado fue más acusado en los brotes que tenían frutos $\left(27.1 \mathrm{mg} \mathrm{g}^{-1} \mathrm{~ms}\right)$ que en los que se les había eliminado en cualquiera de las dos fechas (20.6 $\mathrm{mg} \mathrm{g}^{-1} \mathrm{~ms}$ ) (Fig. 2.21). Al completar el fruto su crecimiento, la concentración de éstos azúcares descendió significativamente hasta valores mínimos en el momento de la maduración, tras la cual aumentó de nuevo espectacularmente, coincidiendo con el inicio del periodo de crecimiento vegetativo, hasta valores entre 19 y $22 \mathrm{mg} \mathrm{g}^{-1} \mathrm{~ms}$ para todos los tratamientos. Para estos azúcares y, al igual que para los de transporte, el brusco descenso de la concentración registrado en el momento de máximo crecimiento del fruto, (709 $\mathrm{BBCH}$ ), coincidió con el descenso acusado de las temperaturas ya señalado. En los brotes anillados la concentración de ambos azúcares se mantuvo prácticamente estable durante todo el periodo estudiado. En general, y salvo para los momentos de mayor demanda de 
carbohidratos por parte del fruto, esto es, desde que éste alcanzó el 50\% de su tamaño final y hasta que maduró, las diferencias entre los diferentes tratamientos no alcanzaron la significación estadística, no difiriendo, por tanto, entre sí, los brotes que mantuvieron sus frutos hasta la recolección, de los que se les eliminaron o aislaron durante las primeras fases de su crecimiento. Este comportamiento fue similar en las dos épocas en las que se realizaron los tratamientos (Fig. 2.21). Debe destacarse la importancia cuantitativa de los azúcares de transporte en el tejido floemático frente al resto de azúcares; así, el sorbitol, dependiendo del tratamiento y del estado fenológico, alcanzó valores medios entre 25 y $60 \mathrm{mg} \mathrm{g}^{-1} \mathrm{~ms}$ mientras que la glucosa y la fructosa nunca superaron los 18 ó $22 \mathrm{mg} \mathrm{g}^{-1} \mathrm{~ms}$, respectivamente. Resulta interesante el distinto comportamiento de los brotes despuntados y anillados hasta el momento de la maduración del fruto, siendo que en ambos la presencia del fruto fue eliminada (en el caso de los segundo, al menos, hasta la cicatrización del anillado); resulta igualmente interesante el paralelismo, ya indicado, entre los brotes con frutos y los brotes sin frutos.
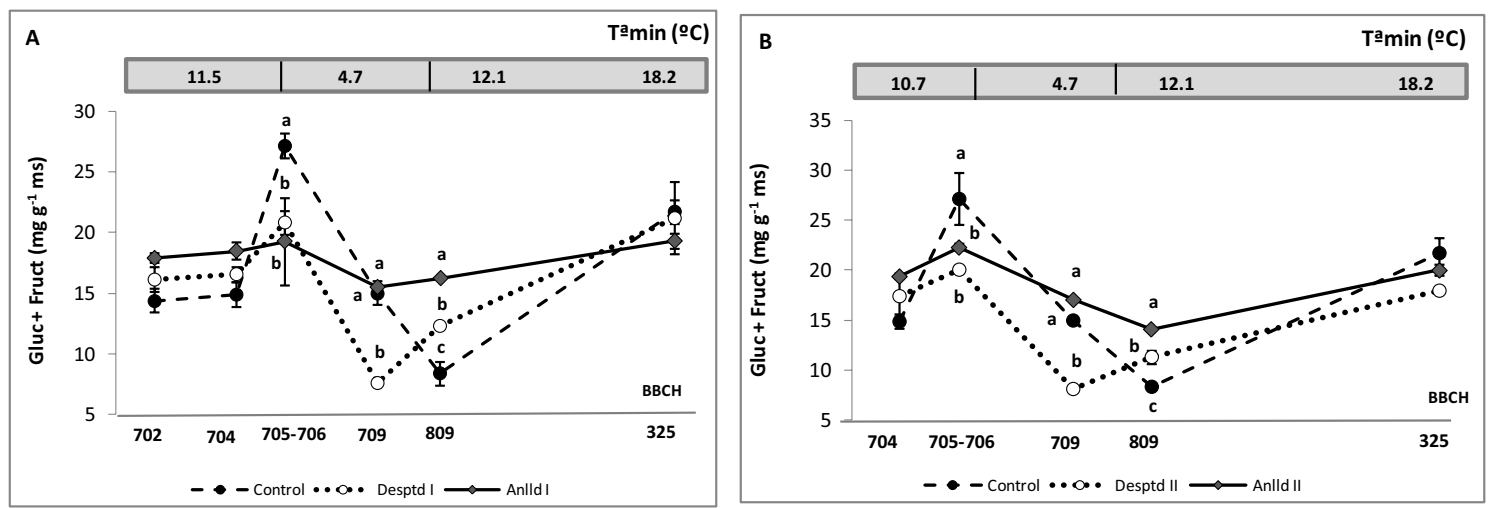

Fig. 2.21.- Influencia de la presencia del fruto hasta su recolección y de su eliminación o aislamiento temporal en el estado 701 (A) y 703 (B) de la escala BBC, en la evolución del contenido en carbohidratos de consumo (glucosa + fructosa) en el floema de los brotes mixtos del níspero japonés cv. 'Algerie' a lo largo del ciclo vegetativo. Cada valor es la media de cuatro árboles. En una barra horizontal se indican las temperaturas medias a lo largo del periodo de estudio. El eje de abscisas representa los estados fenológicos según la escala BBCH. Las barras verticales indican el ES.

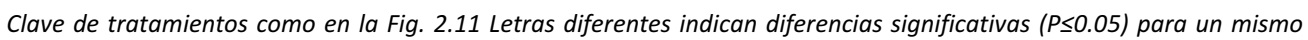
estado fenológico. 
Al analizar por separado la evolución de estos carbohidratos en el tejido floemático que quedó por encima y por debajo de los correspondientes anillados (Fig. 2.22), el comportamiento fue similar al encontrado en los azúcares de transporte (Fig. 2.20), siendo significativamente más elevada la concentración conjunta de glucosa y fructosa en la zona superior del anillado a lo largo de todo el periodo estudiado e independientemente del momento en que se realizaran los tratamientos (Figs. 2.22). Sin embargo, el descenso en la concentración de estos azúcares fue más prolongado en el tiempo que el de los azúcares de transporte, contrastando los valores más bajos de la concentración de glucosa y fructosa en el floema a ambos lados del anillado, en el momento de la maduración (mínimos en el caso del despuntado II), con la de sacarosa y sorbitol que era máxima. El efecto puntual de la bajada de las temperaturas durante la fase final del crecimiento del fruto afectó cuantitativamente más a los azúcares de transporte, que vieron reducida su concentración, por término, medio entre 9.5 y $13 \mathrm{mg} \mathrm{g}^{-1} \mathrm{~ms}$ en la parte superior y entre 27.1 y $30.5 \mathrm{mg} \mathrm{g}^{-1} \mathrm{~ms}$ en la parte inferior del anillado en las dos épocas del tratamiento, respectivamente (Fig. 2.20), que a los reductores, que sólo la vieron reducida entre 3.4 y $4.4 \mathrm{mg}$ $\mathrm{g}^{-1} \mathrm{~ms}$ y 3.8 y $5.2 \mathrm{mg} \mathrm{g}^{-1} \mathrm{~ms}$, respectivamente (Fig. 2.22). La recuperación a ambos lados del anillado de los niveles de sacarosa y sorbitol tras el descenso térmico fue más rápida que la de los de glucosa y fructosa; como consecuencia de ello, mientras en los primeros en el momento de la maduración los niveles ya se habían reestablecido, en los segundos hubo que esperar hasta que el desarrollo vegetativo ya se hubiera iniciado (Figs. 2.20 y 2.22 ).
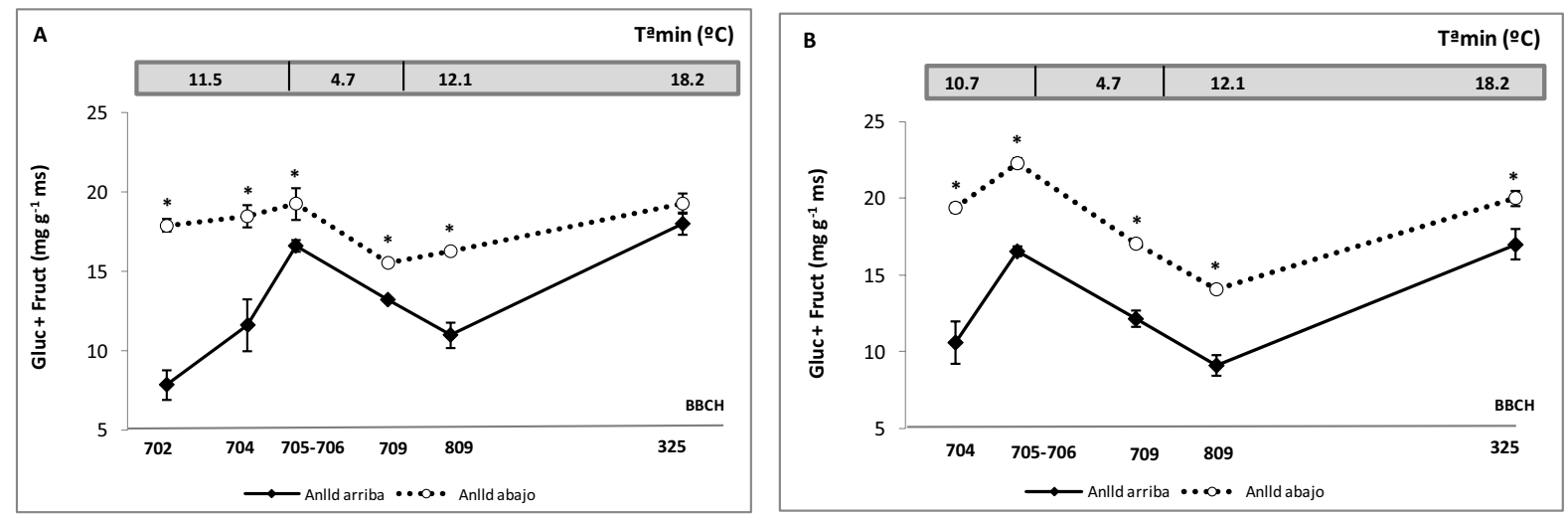

Fig. 2.22.- Influencia del aislamiento temporal del fruto en el estado 701 (A) y 703 (B) de la escala BBCH en la evolución del contenido en carbohidratos de consumo (glucosa + fructosa) en el floema de la parte superior e inferior del anillado de los brotes mixtos del níspero japonés cv. 'Algerie' a lo largo del ciclo vegetativo. Cada valor es la media de cuatro árboles. En una barra horizontal se indican las temperaturas medias a lo largo del periodo de estudio. El eje de abscisas representa los estados fenológicos según la escala BBCH. Las barras verticales indican el ES. Clave de tratamientos como en la Fig. 2.11. * indica diferencias significativas $(P \leq 0.05)$ para un mismo estado fenológico. 
La eliminación o aislamiento temporal del fruto también afectó la concentración foliar de carbohidratos. Así, a los 30 días de los primeros tratamientos, el contenido en azúcares de transporte en las hojas de los brotes despuntados o anillados, fue significativamente mayor, 98.9, $82.9 \mathrm{mg} \mathrm{g}^{-1} \mathrm{~ms}$, que cuando los frutos permanecieron en el brote hasta su recolección, 66.3 $\mathrm{mg} \mathrm{g}^{-1} \mathrm{~ms}$ (Fig. 2.23 A). Esta acumulación de sorbitol y sacarosa detectada en las hojas, como consecuencia de la eliminación o aislamiento de los frutos, se repitió para la segunda época de tratamientos estudiada (Fig. 2.23 B), y aunque en ambos casos fue superior cuando los frutos se eliminaron que cuando se aislaron, sólo en la primera época se alcanzó la significación estadística. Posteriormente, hubo un descenso generalizado de estos azúcares hasta el momento de la maduración y si bien en ese momento las hojas de los brotes sin frutos experimentaron un incremento significativo en su concentración para ambas fechas de despuntado, sufrieron un descenso posterior, en pleno desarrollo vegetativo, hasta igualar al resto de los tratamientos (Fig. 2.23).
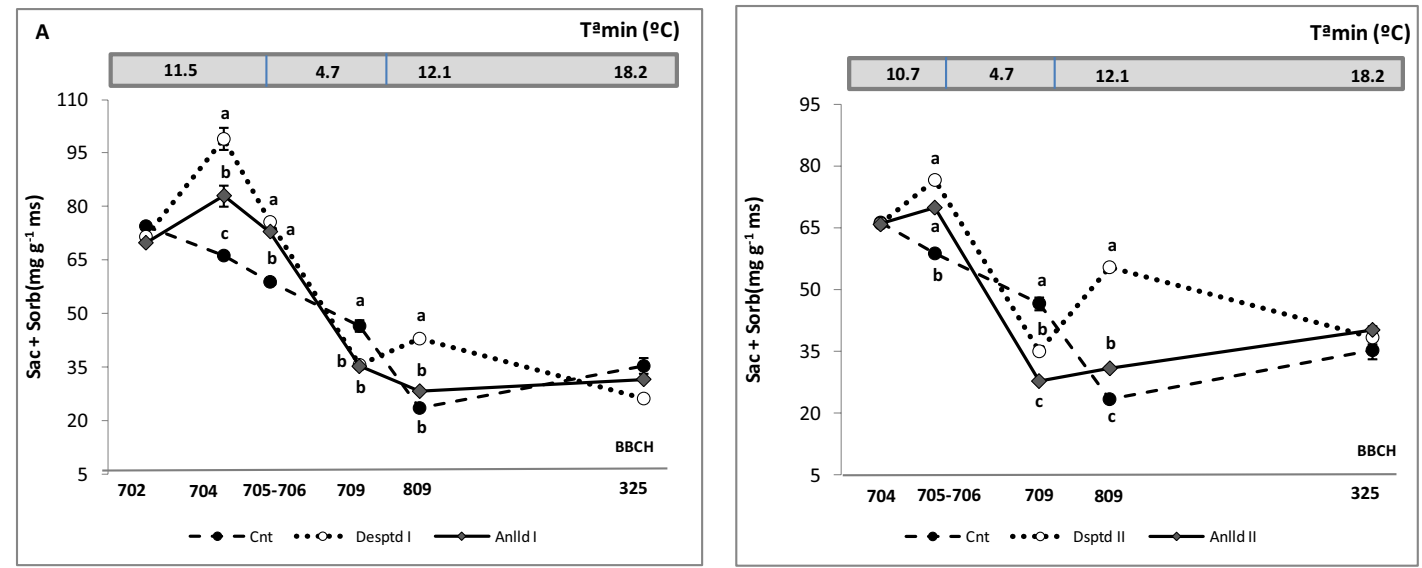

Fig. 2.23.- Influencia de la presencia del fruto hasta su recolección y de su eliminación o aislamiento temporal en el estado 701 (A) y 703 (B) de la escala BBCH en la evolución del contenido en carbohidratos de transporte (sacarosa + sorbitol) en las hojas de los brotes mixtos del níspero japonés cv. 'Algerie' a lo largo del ciclo vegetativo. Cada valor es la media de cuatro árboles. En una barra horizontal se indican las temperaturas medias a lo largo del periodo de estudio. El eje de abscisas representa los estados fenológicos según la escala BBCH. Las barras verticales indican el ES. Clave de tratamientos como en la Fig. 2.11.

Algo diferente se vio al estudiar la evolución del contenido en azúcares reductores de estas hojas. En este caso, el análisis de glucosa y fructosa en su conjunto, en las hojas de los controles y de los despuntados, independientemente de la época en que éstos se hicieran, revela un aumento progresivo de su concentración hasta valores máximos en pleno crecimiento del fruto o de los 
brotes, según el caso, seguido de un ligero descenso significativamente más pronunciado en los brotes que no tenían frutos que en el momento de la maduración alcanzaron valores mínimos de 7.5 (Fig. $2.23 \mathrm{~A}$ ) y $8.5 \mathrm{mg} \mathrm{g}^{-1} \mathrm{~ms}$ (Fig. 2.23 B) en la primera y segunda época de los tratamientos, respectivamente, frente a los $16.7 \mathrm{mg} \mathrm{g}^{-1} \mathrm{~ms}$ de los controles (Fig. $2.23 \mathrm{~A} \mathrm{y} \mathrm{B).} \mathrm{El} \mathrm{pico} \mathrm{máximo}$ alcanzado en las hojas de los controles durante el crecimiento de sus frutos fue significativamente superior (23.1 $\mathrm{mg} \mathrm{g}^{-1} \mathrm{~ms}$ ) al de los despuntados en ambas épocas durante el crecimiento de sus brotes (18.4 o $15.5 \mathrm{mg} \mathrm{g}^{-1} \mathrm{~ms}$, respectivamente) (Fig. $2.23 \mathrm{~A}$ y B), mostrando la relación directa que existe entre la intensidad fotosintética de las hojas exigida por la capacidad sumidero de los frutos o de los nuevos brotes en desarrollo, mayor en los primeros. Tras la recolección, el contenido de estos azúcares en los controles continuó descendiendo atenuadamente durante el crecimiento vegetativo, a diferencia de los despuntados en los que aumentó hasta superar el del resto de los tratamientos cuando éstos se hicieron en la primera época (Fig. $2.23 \mathrm{~A}$ ), o igualándolo cuando se hicieron en la segunda (Fig. 2.23 B); solamente en el primer caso se alcanzó la significación estadística. Cuando los frutos se aislaron del brote con el anillado, la evolución de la concentración de glucosa y fructosa a lo largo de todo el ciclo estudiado fue prácticamente idéntica para las dos épocas del anillado estudiadas (Fig. 2.23 A y B). En este caso también se detectó un descenso progresivo en el contenido de éstos azúcares desde, aproximadamente, 30 días después de la realización de los correspondientes anillados hasta el momento de la maduración, lo que indica una mayor demanda por parte de los frutos al restablecerse su conexión con el resto del brote por la aparente cicatrización del anillado (Fig. 2.24).
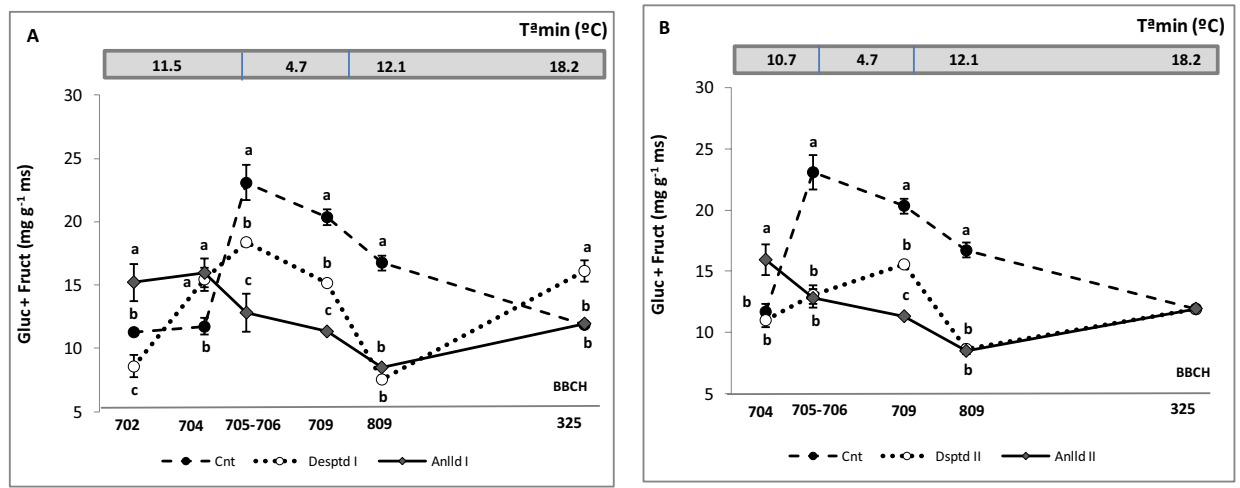

Fig. 2.24.- Influencia de la presencia del fruto hasta su recolección y de su eliminación o aislamiento temporal en el estado 701 (A) y 703 (B) de la escala BBCH en la evolución del contenido en carbohidratos reductores (glucosa + fructosa) en las hojas de los brotes mixtos del níspero japonés cv. 'Algerie' a lo largo del ciclo vegetativo. Cada valor es la media de cuatro árboles. En una barra horizontal se indican las temperaturas medias a lo largo del periodo de estudio. El eje de abscisas representa los estados fenológicos según la escala BBCH. Las barras verticales indican el ES. Clave de tratamientos como en la Fig. 2.11. 
La acumulación de sacarosa y sorbitol detectada en las hojas de los brotes despuntados y anillados, a los 30 días de la eliminación o aislamiento de los frutos (estados 701 y 703 de la escala BBCH) (Fig. 2.23), se confirmó al estudiar la evolución del contenido en almidón de éstas. Al igual que en lo observado para los azúcares de transporte, a los 30 días de la realización de los tratamientos el contenido en almidón de estas hojas aumentó significativamente, respecto del control, hasta valores máximos de 33.7 y $31.9 \mathrm{mg} \mathrm{g}^{-1} \mathrm{~ms}$ en los despuntados y anillados de la primera época (Fig. 2.25 A) y 28.8 y $25.8 \mathrm{mg} \mathrm{g}^{-1} \mathrm{~ms}$ en los de la segunda (Fig. 2.25 B), respectivamente, frente a los 18.7 ó $24.7 \mathrm{mg} \mathrm{g}^{-1} \mathrm{~ms}$ de los controles (Fig. $2.25 \mathrm{~A}$ y B). Dicha acumulación se perdió 15 días más tarde cuando, en pleno crecimiento del fruto o de los brotes, según el caso, el contenido en este carbohidrato de reserva descendió significativamente hasta niveles iniciales, igualándose con el control al final del periodo estudiado. El contenido en almidón de las hojas de los brotes que no tenían frutos fue ligeramente superior a los que los tenían aislados, pero en ningún caso se llegó a la significación estadística. La presencia del fruto hasta su recolección, por el contrario, no modificó su concentración en las hojas que mantuvieron prácticamente constante su actividad en todos los estados fenológicos estudiados, si bien con un ligero descenso tras la recolección, en pleno crecimiento vegetativo, que no alcanzó la significación estadística (Fig. 2.25).

Esta diferencia en la movilización de las reservas observada en nuestros experimentos, indica que mientras existió demanda, la actividad fotosintética en las hojas fue contínua y éstas no acumularon almidón porque los azúcares sintetizados rápidamente se exportaron, mayoritariamente al fruto, para satisfacer sus requerimientos energéticos. Sin embargo, con la eliminación o aislamiento del principal sumidero, el fruto, las hojas, ante la falta puntual de demanda, acumularon parte de los azúcares sintetizados en forma de almidón que más tarde hidrolizarían al reestablecerse la demanda por la cicatrización del anillado o la presencia de los nuevos brotes en desarrollo, según el caso. Esto indica que la ausencia del fruto altera la actividad fotosintética de las hojas y que éstas rápidamente se autoregulan en función de los requeremientos energéticos exigidos. 

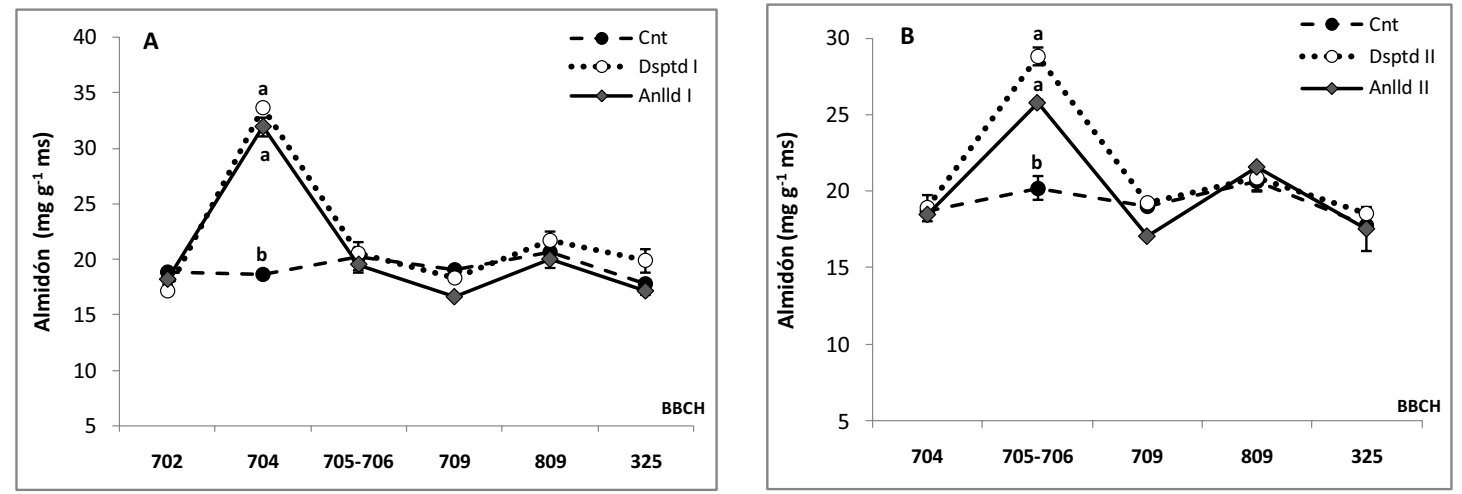

Fig. 2.25.- Influencia de la presencia del fruto hasta su recolección y de su eliminación o aislamiento temporal en el estado 701 (A) y 703 (B) de la escala BBCH en la evolución de la concentración de almidón en las hojas de los brotes mixtos del níspero japonés cv. 'Algerie' a lo largo del ciclo vegetativo. Valores expresados como la concentración de glucosa liberada después de una reacción enzimática con amiloglucosidasa. Cada valor es la media de cuatro árboles. El eje de abscisas representa los estados fenológicos según la escala BBCH. Las barras verticales indican el ES. Clave de tratamientos como en la Fig. 2.11.

Al estudiar la evolución del contenido en carbohidratos de los frutos, se observó que en las dos épocas de anillado estudiadas, los azúcares de consumo inmediato aumentaban progresivamente a lo largo del crecimiento del fruto hasta valores máximos en el momento de la maduración (Fig. 2.26 A), contrariamente a los de transporte, que disminuían conforme el fruto crecía, aunque aumentando marcadamente durante la maduración (Fig. 2.26 B). Si bien el comportamiento a lo largo de todo el ciclo, en los tres tratamientos estudiados y en todos los azúcares analizados, fue prácticamente idéntico, a los 30 días de haber aislado los frutos del resto del brote, e independientemente de la época en que se hiciera, su contenido en azúcares reductores y de transporte ya era significativamente menor que el de los frutos de los controles, y así se mantuvo hasta el momento de la maduración en el que desaparecieron las diferencias (Fig. $2.26 \mathrm{~A}$ y B). Cuando los frutos se aislaron en etapas más precoces de su desarrollo, esto es en el estado $701 \mathrm{BBCH}$, su contenido en glucosa y fructosa fue menor durante todo el periodo de crecimiento y hasta la maduración, que cuando se aislaron más tarde, en el estado 703 BBCH, pero en ningún caso se alcanzó la significación estadística (Fig. 2.26 A). En los azúcares de transporte, sin embargo, sucedió lo contrario, aunque sólo en los estados de máximo crecimiento de los frutos se encontraron diferencias significativas entre ambos anillados; estas diferencias se perdieron con la maduración (Fig. 2.26 B). Es de destacar la importancia cuantitativa de los azúcares reductores durante el crecimiento del fruto pero, sobre todo, en el momento de la maduración que llegaron incluso a cuadruplicar su valor en comparación con los 
de transporte. A pesar del aumento generalizado de la concentración de sacarosa y sorbitol en los frutos durante la maduración, ésta fue significativamente menor que la de glucosa y fructosa para esa misma fecha, y ello con independencia del tratamiento. Así, por ejemplo, mientras en los frutos de los controles el contenido en azúcares de tansporte, en el momento de la maduración, era de $78 \mathrm{mg} \mathrm{g}^{-1} \mathrm{~ms}$ (Fig.26 B), el de azúcares reductores, para esa misma fecha, era de $489.8 \mathrm{mg} \mathrm{g}^{-1} \mathrm{~ms}$ (Fig. $26 \mathrm{~A}$ ).
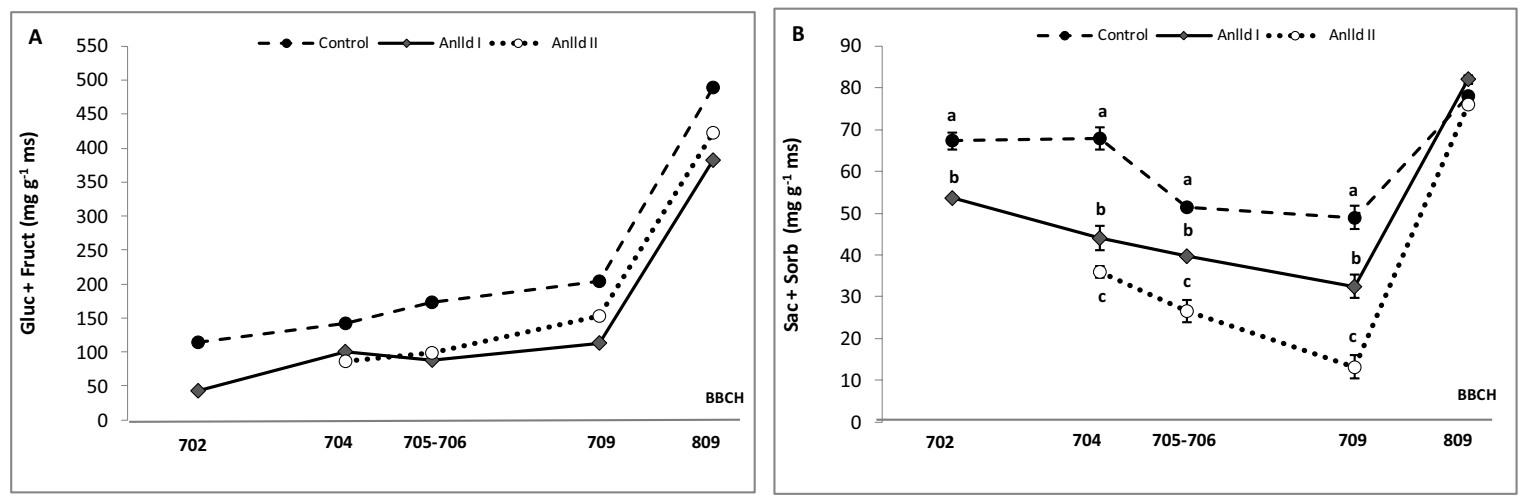

Fig. 2.26.- Influencia de la presencia del fruto hasta su recolección y de su aislamiento temporal en el estado 701) y 703 de la escala $\mathrm{BBCH}$ en la evolución del contenido en carbohidratos reductores, glucosa + fructosa (A), y de transporte, sacarosa + sorbitol (B), en los frutos del níspero japonés cv. 'Algerie. Cada valor es la media de cuatro árboles. Las barras verticales indican el ES. El eje de abscisas representa los estados fenológicos según la escala BBCH. Clave de tratamientos como en la Fig. 2.11.

La eliminación de las hojas del brote en las mismas épocas en que se realizaron el resto de los tratamientos, es decir, en los estadíos 701 y 703 de la escala BBCH, disminuyó significativamente el contenido en azúcares de transporte del floema respecto del resto de los tratamientos a lo largo de todo el ciclo vegetativo e independientemente de la época manteniendo, no obstante, un comportamiento paralelo al de ellos (Fig. 2.27). La respuesta fue inmediata y a los 30 días de la defoliación ya se observaban estas diferencias en la concentración de sacarosa y sorbitol de estos brotes, que se mantuvieron prácticamente estables a lo largo de todo el periodo de estudio. Este comportamiento fue común para las dos épocas en que se defoliaron los brotes, y aunque la concentración de estos azúcares en el floema fue siempre inferior cuando se eliminaron las hojas en el estado 701 que en el 703 de la escala $\mathrm{BBCH}$, nunca se alcanzó la significación estadística, salvo en el momento de la recolección en que los primeros tenían la 
mitad de la concentración (26.3 $\mathrm{mg} \mathrm{g}^{-1} \mathrm{~ms}$ ) (Fig. $2.27 \mathrm{~A}$ ) que los segundos (42.8 $\mathrm{mg} \mathrm{g}^{-1} \mathrm{~ms}$ ) (Fig.

$2.27 \mathrm{~B})$.
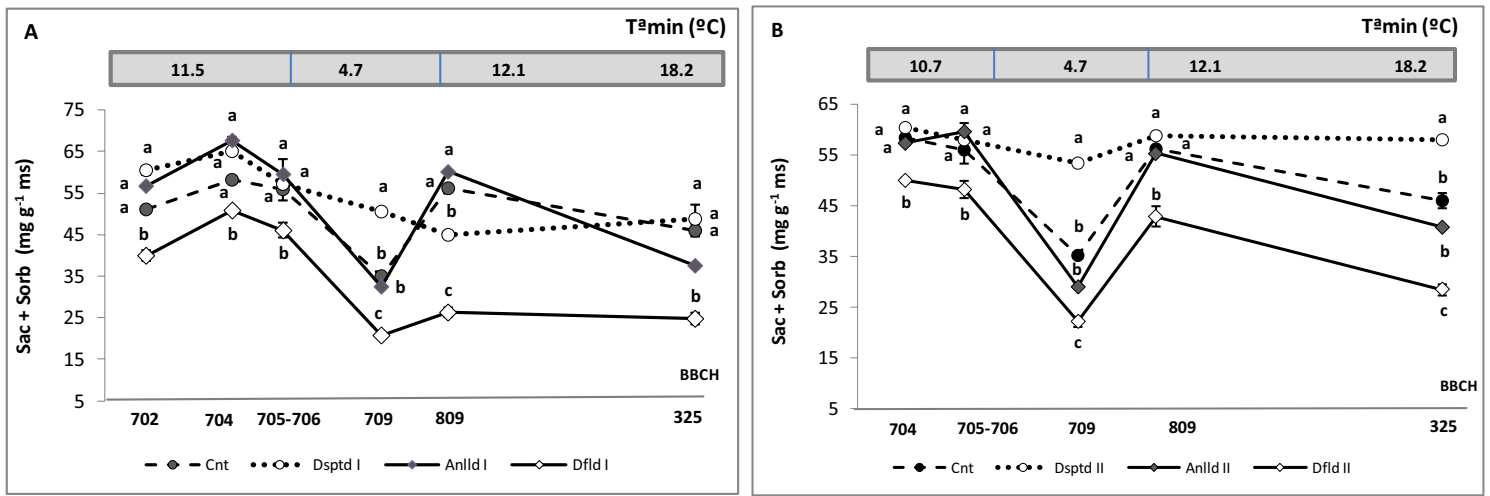

Fig. 2.27.- Influencia de la presencia del fruto hasta su recolección y de su aislamiento temporal y de la eliminación de las hojas del brote en el estado 701(A) y 703 (B) de la escala BBCH en la evolución del contenido en carbohidratos de transporte (sacarosa + sorbitol) en los tejidos floemáticos de los brotes mixtos de níspero japonés cv. 'Algerie' a lo largo del ciclo vegetativo. Cada valor es la media de cuatro árboles. Las barras verticales indican el ES. El eje de abscisas representa los estados fenológicos según la escala BBCH. Dfld I: eliminadas las hojas del brote en el estado701 de la escala BBCH; Dfld II: eliminadas las hojas del brote en el estado703 de la escala BBCH. Clave del resto de tratamientos como en la Fig. 2.11

Algo parecido se encontró al estudiar el contenido en azúcares reductores de los tejidos floemáticos de estos brotes, si bien la respuesta no fue tan clara. Aunque en general el contenido fue significativamente menor a lo largo del tiempo en las dos épocas de defoliación analizadas, no siempre se alcanzó la significación estadística e incluso en algunos momentos puntuales llegó a ser mayor. Concretamente, a los 30 días de la eliminación de las hojas, independientemente de la época en que se hiciera, el contenido en glucosa y fructosa en los tejidos floemáticos de estos brotes fue significativamente superior, hasta 11.8 y $9.8 \mathrm{mg} \mathrm{g}^{-1} \mathrm{~ms}$ más por término medio, que el resto de los tratamientos de la época I y II, respectivamente (Fig. 2.28). De nuestros resultados se deduce que, a pesar de la independencia de panículas existente en esta especie, la ausencia de hojas en el brote que soporta la panícula, y, por tanto, la restricción de carbohidratos al fruto, podría verse compensada por el aporte de éstos desde las hojas de otras panículas, regulando el efecto la propia capacidad sumidero del fruto de la panícula áfila. Otra evidencia de la alta capacidad sumidero de los frutos de estos brotes es que, a pesar de la ausencia de sus hojas, en el momento de máximo crecimiento de éstos (entre los 
estados 705 y 709 de la escala $\mathrm{BBCH})$, el contenido en glucosa y fructosa de sus tejidos floemáticos fue significativamente superior al de los que no tenían frutos aunque tuvieran hojas

(Fig. 2.28).
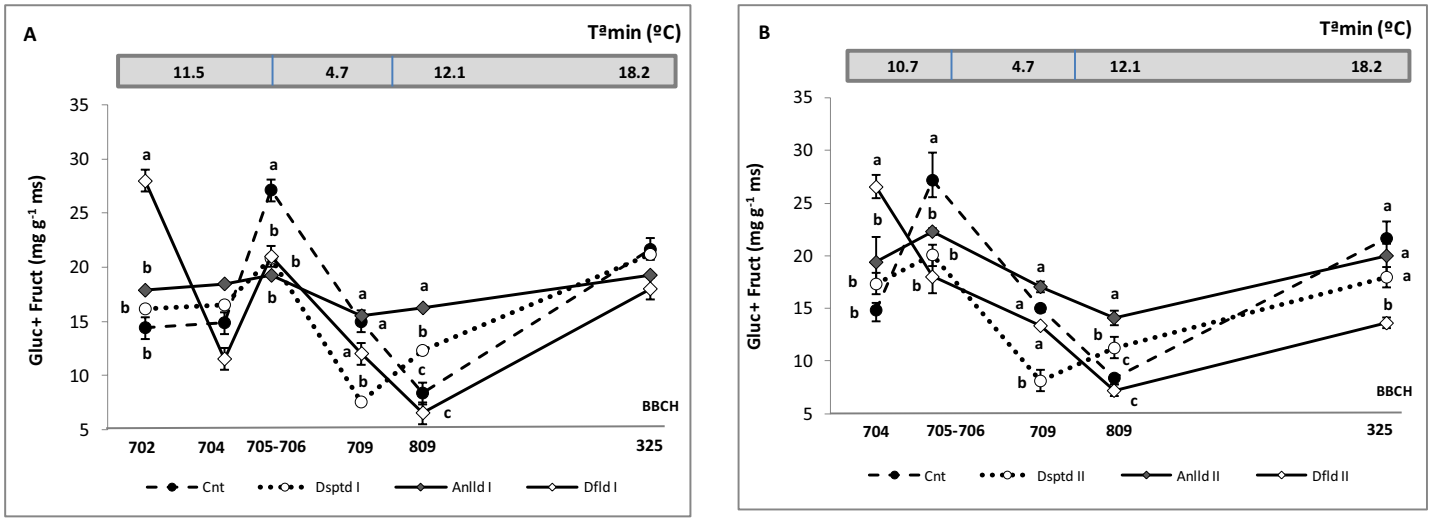

Fig. 2.28.- Influencia de la eliminación de las hojas del brote en el estado 701(A) y 703 (B) de la escala BBCH, en la evolución del contenido en carbohidratos reductores (glucosa + fructosa) en los tejidos floemáticos de los brotes mixtos de níspero japonés cv. 'Algerie' a lo largo del ciclo vegetativo. Cada valor es la media de cuatro árboles. El eje de abscisas representa los estados fenológicos según la escala BBC. Las barras verticales indican el ES. Clave del de tratamientos como en la Fig. 2.27

Como consecuencia de la ausencia de hojas, la brotación al final del crecimiento vegetativo fue significativamente reducida, en número de brotes, principales y anticipados, y en longitud de éstos (Tabla 2.3), respecto de los tratamientos de despunte y anillado e independientemente de las dos épocas estudiadas. Así, mientras los brotes defoliados en la primera y segunda época tenían, al final del crecimiento vegetativo, 1.2 y 1.3 brotes principales, respectivamente, el resto de los tratamientos, es decir, los brotes anillados en la primera y segunda época, los despuntados en ambas épocas y los controles, tenían para la misma fecha, un $61.9 \%$ y $47.3 \%$, un $75 \%$ y $62.9 \%$, y un $60 \%$ y $50 \%$ más de brotes, respectivamente (ver figuras 2.1 y 2.7 ). El efecto de la ausencia de las hojas también alcanzó a la longitud de estos brotes que, al final del crecimiento vegetativo, midieron 20.3 y $3.6 \mathrm{~cm}$ menos que los anillados I y II, 19 y $2.4 \mathrm{~cm}$ menos que los despuntados I y II y 14.3 y $0.9 \mathrm{~cm}$ menos que los controles de ambas fechas (ver figuras 2.3 y 2.9). El efecto de la defoliación sobre el crecimiento del brote fue, por tanto, significativamente más pronunciado cuando las hojas se eliminaron en la primera que en la segunda época, por lo que cuanto más tiempo estuvo sometido el brote inicial a la ausencia de 
hojas menos crecieron sus nuevos brotes, lo que pone de manifiesto las elevadas exigencias energéticas de estos brotes durante su crecimiento.

Algo parecido ocurrió con la brotación anticipada de ambas épocas que también se vio significativamente reducida en número y longitud por la ausencia de hojas al final del crecimiento vegetativo (Tabla 2.3). En este caso y, para el mismo orden de tratamientos seguido en los brotes principales, el incremento en el número de brotes anticipados en los que se mantuvieron las hojas fue del $71.4 \%$ y $50 \%$ en los anillados, del $80 \%$ y $64.2 \%$ en los despuntados o del $60 \%$ y $50 \%$ en los controles (ver figuras 2.2 y 2.8 ). El crecimiento de los brotes anticipados también fue reducido por la ausencia de hojas que al final de su crecimiento midieron 8.0 y 6.9 $\mathrm{cm}$, según se defoliaran en la primera o segunda época, mientras que los brotes que mantuvieron sus hojas hasta el final del ciclo midieron, 20 y $16.9 \mathrm{~cm}$ en el caso de los anillados I y II, 24.8 y 19.5 en los despuntados de las mismas fechas y $17.2 \mathrm{~cm}$ en el caso de los controles (ver figuras 2.4 y 2.10). Nuestros resultados ponen de relevancia la importancia que los carbohidratos tienen en el desborre y posterior crecimiento de los brotes.

Tabla 2.3.- Influencia de la eliminación de las hojas del brote en el estado 701 (Defoliado I) y 703 de la escala $\mathrm{BBCH}$ (Defoliado II) sobre las características de la brotación principal y anticipada del níspero japonés cv. 'Algerie' al final del crecimiento vegetativo. Cada valor es la media de 20 brotes repartidos en cinco árboles. Letras distintas en una misma columna indican diferencias significativas $(P \leq 0.05)$.

\begin{tabular}{|c|c|c|c|c|}
\hline & \multicolumn{2}{|c|}{ № brotes } & \multicolumn{2}{c|}{ Longitud (cm) } \\
\hline Tratamiento & Principales & Anticipados & Principales & Anticipados \\
Defoliado I & $1,2 \mathrm{a}$ & $0,4 \mathrm{a}$ & $9,5 \mathrm{a}$ & $8,0 \mathrm{a}$ \\
Defoliado II & $1,3 \mathrm{a}$ & $0,5 \mathrm{a}$ & $22,9 \mathrm{~b}$ & $6,9 \mathrm{a}$ \\
Control & $2,2 \mathrm{~b}$ & $1,0 \mathrm{~b}$ & $23,8 \mathrm{~b}$ & $17,6 \mathrm{~b}$ \\
\hline
\end{tabular}

Pero la eliminación de las hojas también alteró marcadamente el crecimiento de los frutos que, en el momento de la recolección, fueron significativamente más pequeños que los controles, tanto en diámetro como en peso fresco y seco. Estas diferencias fueron más marcadas cuanto más tiempo permanecieron los frutos sin las hojas, es decir, cuando éstas se eliminaron en estados más precoces del desarrollo del fruto (estadíos 701 ó 703 de la escala $\mathrm{BBCH}$ ). Como consecuencia, en el momento de la recolección los diámetros de los frutos, de los controles y defoliados en la primera y segunda época fueron, respectivamente, $42.6 \mathrm{~cm}, 30.0$ $\mathrm{cm}$, y $38.3 \mathrm{~cm}$, los pesos frescos $53.0 \mathrm{~g}, 31.2 \mathrm{~g}$ y $42.0 \mathrm{~g}$, respectivamente, y los pesos secos $8.4 \mathrm{~g}$, 5.0 g y $6.1 \mathrm{~g}$, respectivamente. Este efecto también alcanzó significativamente al crecimiento de las semillas que en el momento de la recolección pesaron $3.5 \mathrm{~g}$, $2.5 \mathrm{~g}$ y $2.6 \mathrm{~g}$, respectivamente. De las características de la maduración de estos frutos solamente en la acidez se encontraron 
concentraciones significativamente más altas; los frutos de los brotes que perdieron sus hojas, en cualquiera de las dos épocas ensayadas, tuvieron una acidez más alta $(1.0 \%$ y $0.8 \%$, respectivamente) que los controles (0.5\%).

Al analizar el contenido en carbohidratos de la piel y de la pulpa de los frutos en su conjunto a lo largo de todo su periodo de crecimiento y hasta la maduración, se observó una evolución similar para los azúcares de transporte y reductores entre los que tenían todas o ninguna de las hojas en el brote, si bien ligeramente superior en los primeros (Fig. 2.29). Estas diferencias también se hicieron visibles al poco tiempo de la defoliación, como ya ocurrió en el tejido floemático, de modo que a los 30 días de la eliminación de las hojas, cuando el fruto tenía el 10\% de su tamaño final, la concentración de azúcares reductores y de transporte en estos frutos era de 50.7 y 58.0 $\mathrm{mg} \mathrm{g}^{-1} \mathrm{~ms}$, mientras que en los controles era de 113.8 y $67.3 \mathrm{mg} \mathrm{g}^{-1} \mathrm{~ms}$, respectivamente (Fig. 2.29). Menos efectiva se mostró la defoliación en etapas más avanzadas del desarrollo del fruto cuando para el mismo tiempo desde la eliminación de las hojas las diferencias con los controles eran prácticamente inexistentes (Fig. 2.29). A pesar de ello, se encontró una relación inversa entre el tiempo en que los frutos permanecieron en la panícula sin las hojas y su concentración de carbohidratos, de modo que los defoliados durante la segunda época mostraron una concentración intermedia de azúcares de transporte y reductores en todas la fechas estudiadas, como ya se apreció en sus correspondientes tejidos floemáticos (ver figuras 2.27 y 2.28 ).
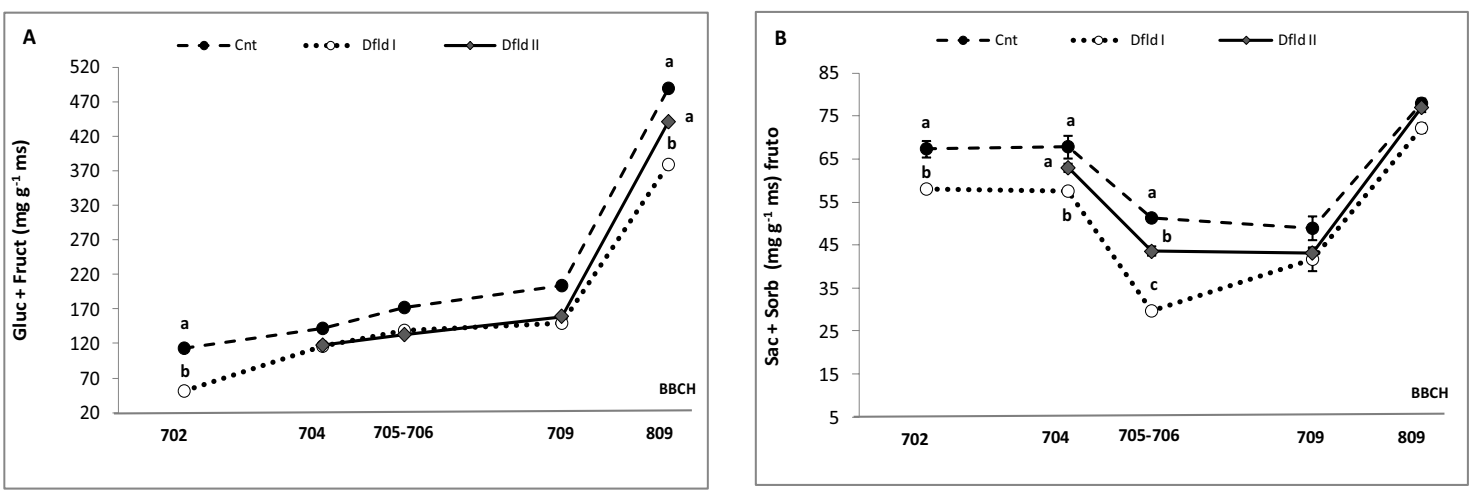

Fig. 2.29.- Influencia de la eliminación de las hojas del brote en el estado 701 y 703 de la escala BBCH en la evolución del contenido en carbohidratos reductores, glucosa + fructosa (A), y de transporte, sacarosa + sorbitol (B), en los frutos de níspero japonés cv. 'Algerie'. Cada valor es la media de cuatro árboles. Las barras verticales indican el ES El eje de abscisas representa los estados fenológicos según la escala BBC. Dfld I: eliminadas las hojas del brote en el estado 701 de la escala BBCH; Dfld II: eliminadas las hojas del brote en el estado703 de la escala BBCH; Cnt: hojas presentes hasta su senescencia. 
Sin embargo, la presencia de todos los frutos de un árbol hasta su recolección, en comparación con su eliminación total cuando éstos tenían el 20\% de su tamaño final, sí alteró significativamente el contenido en carbohidratos de los tejidos floemáticos de estos árboles y, por tanto, su reparto. La evolución del contenido en carbohidratos de transporte en el floema de los árboles con todos sus frutos, reveló un descenso progresivo de su concentración durante el crecimiento del fruto, más pronunciado en las últimas fases de su crecimiento, que prosiguió hasta valores mínimos en el cambio de color (estado 801 de la escala BBCH) (Fig. 2.30). A partir de ese momento, aumentó significativamente durante la maduración hasta alcanzar los valores iniciales en pleno desarrollo vegetativo (estado $325 \mathrm{BBCH}$ ). Por el contrario, en el floema de los árboles que no tenían ningún fruto apenas se modificó su contenido (Fig.2.30); no obstante, un aumento proporcional al grado de desarrollo de los nuevos brotes en crecimiento, seguido de un ligero descenso hasta el final del periodo estudiado, y coincidente con el inicio de la brotación anticipada, resultó evidente (Fig. 2.30). Hasta que el fruto alcanzó el $70 \%$ de su tamaño final, el contenido conjunto de sacarosa y sorbitol en los árboles que conservaban todos sus frutos fue significativamente superior, prácticamente el doble, que el de los árboles sin frutos, igualándose para dicho estado (707 de la escala BBCH) (Fig. 2.30). A partir de este momento y hasta el final del periodo estudiado, la tendencia fue completamente divergente entre ambos grupos de árboles. Así, mientras en las etapas finales del crecimiento del fruto (709 y $801 \mathrm{BBCH}$ ), la concentración de sacarosa y sorbitol en el floema de los árboles sin frutos aumentó ligeramente hasta valores máximos de $46.3 \mathrm{mg} \mathrm{g}^{-1} \mathrm{~ms}$, en los que los tenían todos disminuyó hasta valores mínimos de $24.6 \mathrm{mg} \mathrm{g}^{-1} \mathrm{~ms}$. Posteriormente, en los primeros el contenido en estos azúcares disminuyó ligeramente hasta valores mínimos de $29.8 \mathrm{mg} \mathrm{g}^{-1}$ ms en pleno desarrollo vegetativo, en los segundos aumentó espectacularmente hasta valores máximos de 67.2 $\mathrm{mg} \mathrm{g}^{-1} \mathrm{~ms}$ (Fig. 2.30). Estas diferencias encontradas en el comportamiento de los azúcares de transporte a lo largo del tiempo, entre árboles con frutos y árboles sin frutos pero con brotes en desarrollo (ver Fig. 2.16), refleja la importancia que el tipo de sumidero tiene en la movilización de carbohidratos. Prueba de ello es el descenso continuo de sacarosa y sorbitol registrado en los árboles con frutos durante el crecimiento de éstos, no detectado en los árboles sin frutos durante el crecimiento de sus brotes. 


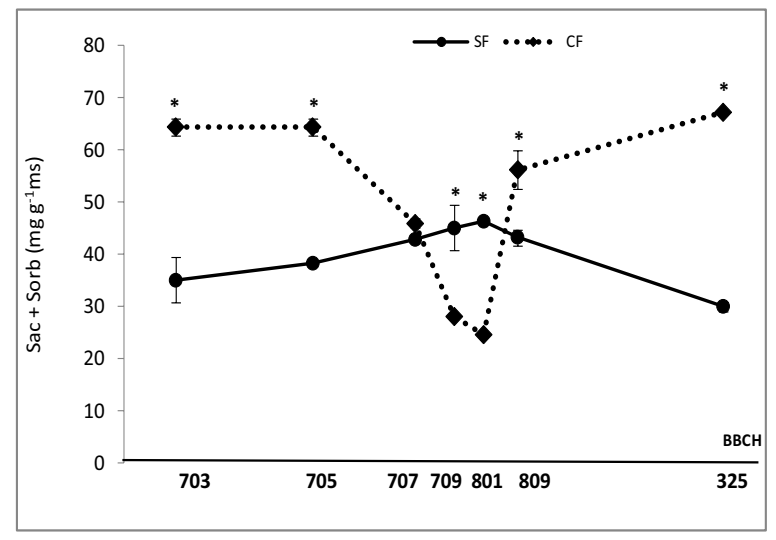

Fig. 2.30.- Influencia de la eliminación de todos los frutos del árbol en el estado fenológico 702 de la escala BBCH (SF) y de su presencia hasta la recolección (CF), en la evolución de la concentración de carbohidratos de transporte (sacarosa + sorbitol) en los tejidos floemáticos de los brotes mixtos del níspero japonés cv. 'Algerie' a lo largo del ciclo vegetativo. Cada valor es la media de cuatro árboles. Las barras verticales indican el ES. El eje de abscisas representa los estados fenológicos según la escala $B B C H . *$ indica diferencias significativas $(P \leq 0.05)$ para un mismo estado fenológico.

La descarga de todos los frutos del árbol al inicio de su crecimiento también alteró el contenido de los azúcares reductores. El efecto fue tan rápido que a los 15 días de la eliminación de los frutos ya se observaron diferencias significativas entre los tratamientos (Fig. 2.31). Al igual que en los azúcares de transporte, la concentración de glucosa y fructosa en los tejidos floemáticos de los árboles que tenían todos sus frutos disminuyó progresivamente a lo largo de todo el periodo de crecimiento del fruto hasta el cambio de color (Figs. 2.30 y 2.31). El descenso más significativo tuvo lugar cuando el fruto pasó de tener el $30 \%$ de su tamaño final al 50\%, cuyos valores fueron de 32 y $18.3 \mathrm{mg} \mathrm{g} \mathrm{gs}^{-1} \mathrm{~ms}$ respectivamente. Entre estas dos fechas, la evolución de estos azúcares en los tejidos floemáticos de los árboles sin frutos apenas se alteró, mateniéndose su concentración, a partir de ese momento y hasta que los frutos completaron su crecimiento (estado $709 \mathrm{BBCH}$ ), muy parecida entre ambos grupos de árboles. En el momento en el que en los árboles con frutos éstos cambiaron de color se detectó un pico máximo en los árboles sin fruto, ausente en los primeros, en los que, por el contrario, siguió disminuyendo (Fig. 2.31). La presencia de todos los frutos de un árbol hasta su recolección consiguió una mayor concentración de glucosa y fructosa en sus tejidos floemáticos a lo largo de todo el ciclo estudiado, excepto en el momento del cambio de color. El aumento espectacular registrado en los árboles sin fruto en este momento no consiguió superar el valor máximo alcanzado por los árboles con fruto al inicio de su crecimiento (Fig. 2.31). Debe destacarse la importancia cuantitativa de los azúcares de transporte frente a los reductores en estos tejidos. Así, 
cuando el fruto tenía el $30 \%$ de su tamaño final, el contenido en sacarosa y sorbitol en el floema de los árboles que tenían frutos era de $64.4 \mathrm{mg} \mathrm{g}^{-1} \mathrm{~ms}$ (Fig. 2.30), mientras que el de glucosa y fructosa era justo la mitad, $32 \mathrm{mg} \mathrm{g}^{-1} \mathrm{~ms}$ (Fig. 2.31). Del mismo modo, y en ese mismo momento, en los árboles que descargaron todos sus frutos al inicio de su crecimiento, el contenido en sacarosa y sorbitol era de $35.8 \mathrm{mg} \mathrm{g}^{-1} \mathrm{~ms}$ frente a los $15.1 \mathrm{mg} \mathrm{g}^{-1} \mathrm{~ms}$ de glucosa y fructosa (Figs. 2.30 y 2.31).

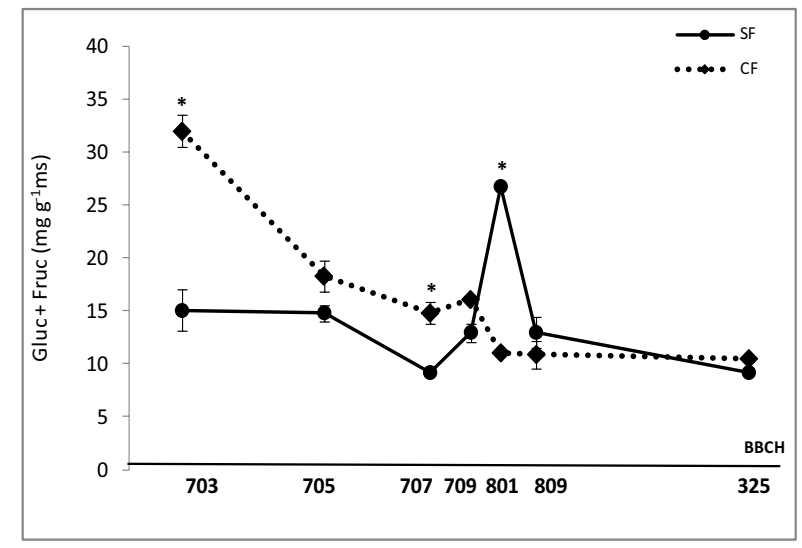

Fig. 2.31.- Influencia de la eliminación de todos los frutos del árbol en el estado fenológico 702 de la escala $B B C H$ (SF) y de su presencia hasta la recolección (CF), en la evolución de la concentración de carbohidratos reductores (glucosa + fructosa) en los tejidos floemáticos de los brotes mixtos del níspero japonés cv. 'Algerie' a lo largo del ciclo vegetativo. Cada valor es la media de cuatro árboles. Las barras verticales indican el ES. El eje de abscisas representa los estados fenológicos según la escala $B B C H .{ }^{*}$ indica diferencias significativas $(P \leq 0.05)$ para un mismo estado fenológico.

La completa eliminación de los frutos del árbol apenas modificó la evolución del contenido en cabohidratos de las hojas, si bien con diferencias puntuales de interés. La evolución en la concentración de sacarosa y sorbitol en éstas a lo largo del tiempo fue prácticamente similar, independientemente de la presencia o ausencia de los frutos en el árbol. En ambos casos hubo un aumento generalizado de estos azúcares durante el crecimiento de los frutos o brotes, según el caso, seguido de un descenso progresivo de la concentración en etapas próximas a la maduración o antes, en el caso de los árboles sin frutos, y este, a su vez, de aumento posterior con el crecimiento vegetativo hasta valores de 87.5 ó $63.9 \mathrm{mg} \mathrm{g}^{-1} \mathrm{~ms}$, en función de si los árboles tenían o no frutos en el momento de la recolección, respectivamente. También el aumento en los azúcares de transporte detectado en las primeras fechas, como consecuencia del crecimiento de los frutos, desde que éstos tenían el 30\% de su tamaño final (estado 703 $\mathrm{BBCH}$ ) hasta que lo completaron (estado $709 \mathrm{BBCH}$ ), fue significativamente superior $(48.6 \%)$ 
que el registrado por el crecimiento de los nuevos brotes (29.5\%), poniéndose de manifiesto, de nuevo, la mayor capacidad sumidero de los frutos respecto de los brotes jóvenes, reclamándoles mayores cantidades de carbohidratos a las hojas (Fig. 2.32). Por ello, al comparar paralelamente la evolución de estos azúcares en las hojas y en los tejidos floemáticos de estos árboles, se observó que mientras el fruto crecía, el contenido en sacarosa y sorbitol aumentaba en las primeras (Fig. 2.32) y disminuía en los segundos (Fig. 2.30). Sin embargo, en estas mismas fechas, el crecimiento de los nuevos brotes provocado por la eliminación de todos los frutos del árbol, apenas alteró el contenido de estos azúcares de transporte en ambos tejidos (Figs. 2.30 y 2.32 ).

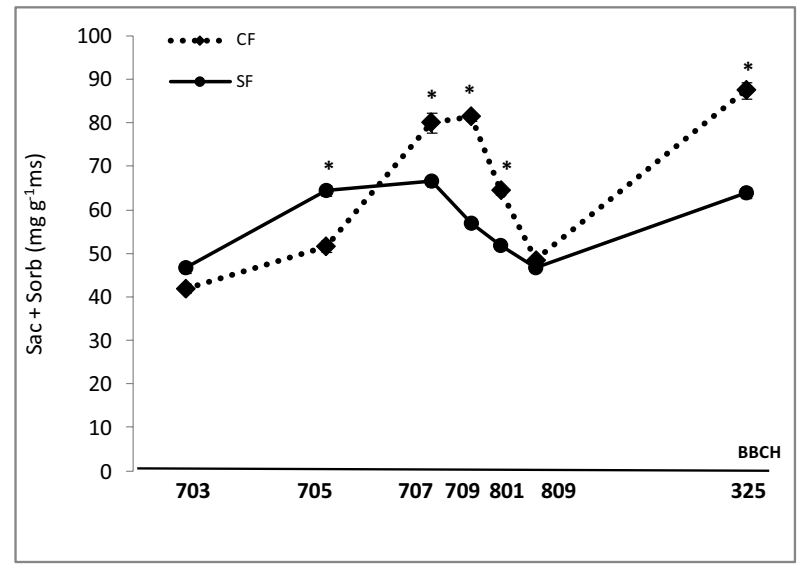

Fig. 2.32.- Influencia de la eliminación de todos los frutos del árbol en el estado fenológico 702 de la escala $B B C H$ (SF) y de su presencia hasta la recolección (CF), en la evolución de la concentración de carbohidratos de transporte (sacarosa + sorbitol) en las hojas de los brotes mixtos del níspero japonés cv. 'Algerie' a lo largo del ciclo vegetativo. Cada valor es la media de cuatro árboles. Las barras verticales indican el ES. El eje de abscisas representa los estados fenológicos según la escala $B B C H$. * indica diferencias significativas ( $P \leq 0.05)$ para un mismo estado fenológico.

El análisis conjunto de la concentración de glucosa y fructosa en las hojas de los árboles que tuvieron todos sus frutos hasta la recolección y en las de los que se les eliminaron todos al inicio de su desarrollo, mostró una evolución idéntica a lo largo del ciclo vegetativo, pero desplazada en el tiempo. Así, el significativo aumento detectado hacia el final del crecimiento del fruto y el posterior descenso en etapas próximas a la maduración, tuvo lugar una semana antes, aproximadamente, en los árboles sin frutos (Fig. 2.33), consecuencia de la diferencia en el ritmo de crecimiento de sus respectivos sumideros, frutos o brotes. Es por ello que sólo en 
estos dos momentos, en el estado 709 y 801 de la escala $\mathrm{BBCH}$, se encontraron diferencias significativas entre los tratamientos. Así, en el primero de estos estados, los árboles sin frutos ya habían alcanzado el pico máximo con valores de $17.6 \mathrm{mg} \mathrm{g}^{-1} \mathrm{~ms}$, mientras los árboles con frutos todavía seguían aumentando su concentración, alcanzando el valor máximo, $18.3 \mathrm{mg} \mathrm{g}^{-1}$ ms, 7 días después con el cambio de color de los frutos (estado $801 \mathrm{BBCH}$ ). En este momento en los primeros la concentración foliar de azúcares reductores ya había descendido hasta 10.6 $\mathrm{mg} \mathrm{g}^{-1} \mathrm{~ms}$ (Fig. 2.33). La respuesta de las hojas a la eliminación de todos los frutos del árbol fue tan rápida que, a los 15 días de la descarga, las hojas de estos árboles ya tenían $2.1 \mathrm{mg} \mathrm{g}^{-1} \mathrm{~ms}$ más de glucosa y fructosa que las de aquellos que tenían todos sus frutos (Fig. 2.33). En los azúcares de transporte, sin embargo, hubo que esperar hasta 1 mes más tarde para detectar estas diferencias (Fig. 2.32). El aumento significativo detectado posteriormente (hasta el estado fenológico $705 \mathrm{BBCH}$ ) en los árboles con frutos, ausente en los árboles sin frutos (Fig. 33), indica que dicho efecto tuvo una corta duración y que las hojas reaccionaron inmediatamente a las exigencias de los frutos en desarrollo. Por eso, mientras el fruto estuvo creciendo y hasta que cambió de color, la concentración de estos azúcares reductores en las hojas de los árboles con frutos fue siempre superior a la de los árboles sin frutos (Fig. 2.33).

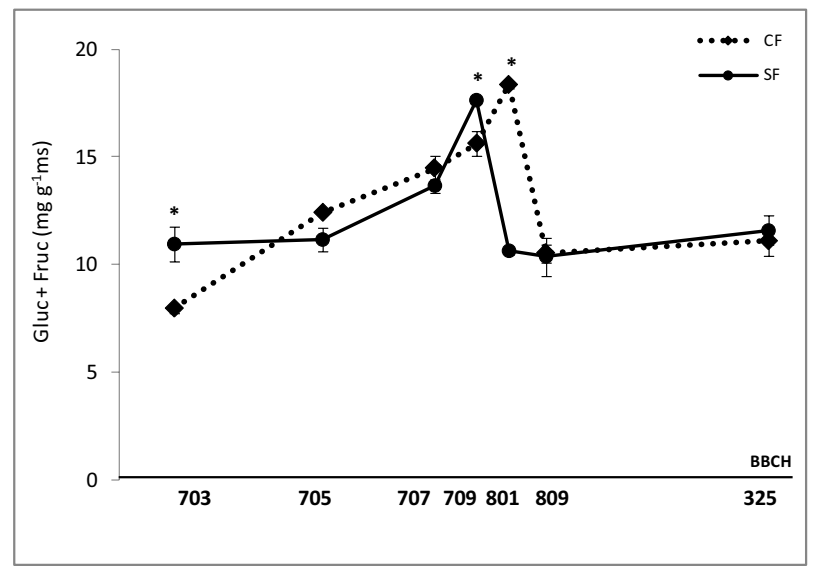

Fig. 2.33.- Influencia de la eliminación de todos los frutos del árbol en el estado fenológico 702 de la escala BBCH (SF) y de su presencia hasta la recolección (CF), en la evolución de la concentración de carbohidratos reductores (glucosa + fructosa) en las hojas de los brotes mixtos del níspero japonés cv. 'Algerie' a lo largo del ciclo vegetativo. Cada valor es la media de cuatro árboles. Las barras verticales indican el ES. El eje de abscisas representa los estados fenológicos según la escala $\mathrm{BBCH} .{ }^{*}$ indica diferencias significativas $(P \leq 0.05)$ para un mismo estado fenológico. 
Estos resultados indican que el suministro de carbohidratos desde las hojas se ajusta, en gran medida, a las exigencias de los sumideros. En este sentido, los frutos son sumideros más potentes que los brotes vegetativos jóvenes, y, además, difieren espacial y temporalmente a lo largo de la vida del árbol. Como consecuencia de ello, al completar los sumideros su crecimiento, y con ello su demanda por carbohidratos, el contenido foliar de éstos decreció significativamente (ver figuras 2.32 y 2.33 ). Este desequilibrio fuente-sumidero generado tuvo un efecto directo sobre la movilización de los carbohidratos a favor de los primeros, como lo demuestra el contenido foliar de almidón. Cuando los frutos completaron su crecimiento (709 $\mathrm{BBCH}$ ) o los nuevos brotes pasaron a ser fuentes directas de carbohidratos, el contenido de almidón en las hojas de los árboles que tenían todos o ninguno de sus frutos fue prácticamente el mismo (100 y $106 \mathrm{mg} \mathrm{g}^{-1} \mathrm{~ms}$, respectivamente) (Fig. 2.34). Sin embargo, 7 días después, aproximadamente, cuando los frutos de los primeros ya habían cambiado de color (estado $801 \mathrm{BBCH}$ ) o ya se había iniciado la brotación anticipada en los segundos, dicho contenido fue significativamente superior en los árboles con frutos (141.9 $\mathrm{mg} \mathrm{g}^{-1} \mathrm{~ms}$ ) que en los sin frutos (76.3 $\mathrm{mg} \mathrm{g}^{-1} \mathrm{~ms}$ ). Este aumento de la concentración de almidón detectada en las hojas de los árboles con frutos (41.9 $\mathrm{mg} \mathrm{g}^{-1} \mathrm{~ms}$ ), ausente por el contrario en las de los árboles sin frutos, demuestra que es una consecuencia directa de la falta de demanda por parte de los sumideros, esto es, de la ausencia de frutos en crecimiento (Fig. 2.34).

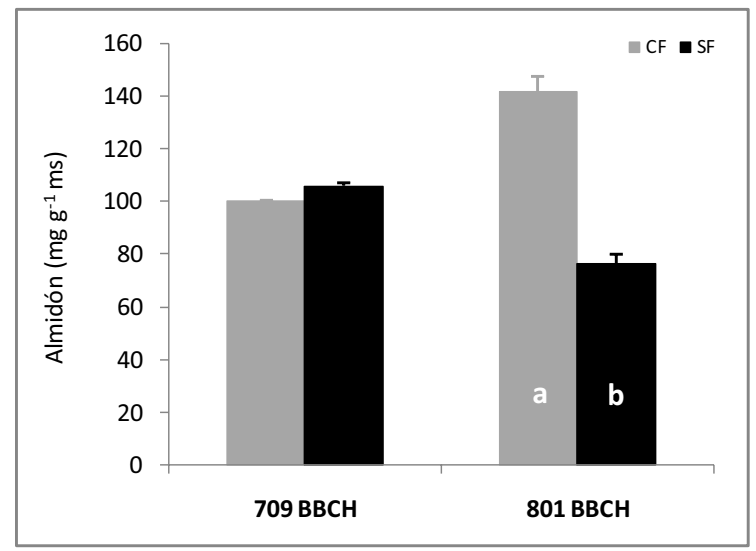

Fig 34.- Influencia de la eliminación de todos los frutos del árbol en el estado fenológico 702 de la escala BBCH (SF) y de su presencia hasta la recolección (CF), en la concentración de almidón en las hojas de los brotes mixtos del níspero japonés cV. 'Algerie' al final de su crecimiento. Valores expresados como la concentración de glucosa liberada. Cada valor es la media de cuatro árboles. Las barras verticales indican el ES. El eje de abscisas representa los estados fenológicos según la escala $B B C H$. 
Al estudiar la evolución del contenido en carbohidratos en la piel y la pulpa de los frutos en su conjunto, se observó que los azúcares de consumo inmediato aumentaban progresivamente a lo largo del crecimiento del fruto hasta valores máximos en el momento de la maduración (Fig. 2.35 A), contrariamente a los de transporte, que se mantenían prácticamente constantes conforme el fruto crecía, hasta que al final de su crecimiento aumentaron marcadamente, también durante la maduración (Fig. 2.35).

Es de destacar la importancia cuantitativa en estos tejidos de los azúcares reductores frente a los de transporte durante el crecimiento del fruto pero, sobre todo, en el momento de la maduración, momento en el que su concentración fue hasta 6 veces superior a la de los azúcares de transporte (Fig. 2.35). Los cambios en el contenido de azúcares de transporte en las hojas y en el floema de los árboles sometidos a la carga completa de sus frutos, son consecuencia directa del reparto regido por el fruto. De esta manera, y en nuestros experimentos, desde que el fruto alcanzó la mitad de su tamaño final hasta que maduró, y como consecuencia de ello, su contenido en las hojas aumentó (Fig. 2.32), consecuencia de su demanda, al mismo tiempo que disminuyó en el floema (Fig. 2.30), porque se transportaba al fruto, donde se acumulaba de manera coordinada con su ritmo de crecimiento (Fig. 2.35 B).
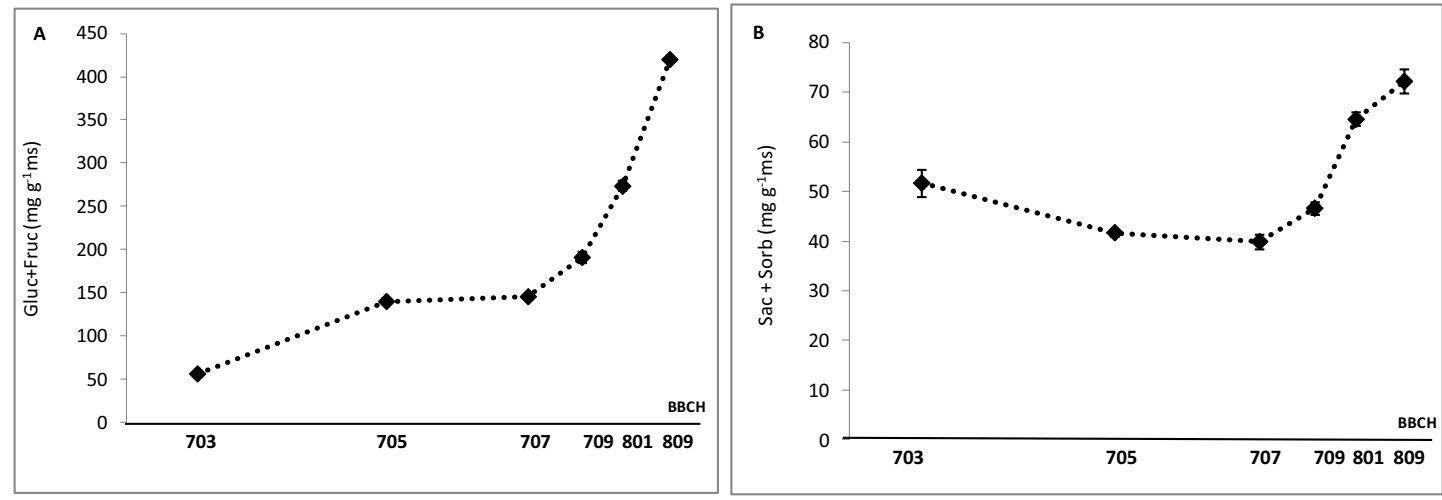

Fig. 2.35.- Influencia de la presencia de todos los frutos de un árbol de níspero japonés cv. 'Algerie' hasta su recolección, en la evolución de su contenido en carbohidratos reductores, glucosa + fructosa (A), y de transporte, sacarosa + sorbitol (B).Cada valor es la media de cuatro árboles. Las barras verticales indican el ES. El eje de abscisas representa los estados fenológicos según la escala $\mathrm{BBCH}$. 
En resumen, la influencia del fruto en el reparto de carbohidratos en el árbol fue prácticamente la misma con independencia del número de éstos, como se demuestra en nuestros estudios a la panícula individual o al árbol completo. La descarga o carga totales de un árbol no consiguió un mayor impacto en el balance de los azúcares estudiados que el conseguido con la descarga parcial de frutos mediante la eliminación o aislamiento de algunas panículas, ya que la distribución de éstos estuvo siempre regulada por el crecimiento de los frutos. Así se demuestra, de nuevo, la independencia de panículas en el árbol y la ausencia de una correlación significativa entre el número total de frutos por árbol y su tamaño final, en beneficio de la significación cuando se estudia por panícula.

\section{5.- La influencia del fruto en la movilización de las fracciones nitrogenadas.}

La concentración de nitratos en las hojas se mantuvo constante hasta que el fruto alcanzó la mitad de su tamaño, aumentando significativamente a continuación hasta un $85.2 \%$ cuando ya tenía el $70 \%$ de su tamaño final y descendiendo, prácticamente hasta los niveles iniciales, cuando completó su crecimiento (Fig. 2.36). Con el cambio de color y posterior maduración del fruto el contenido en nitratos aumentó de nuevo, aunque un $20 \%$ menos que en el caso anterior, descendiendo ligeramente a medida que se aproximaba la brotación (Fig. 2.36A). Los resultados no fueron modificados por la presencia o ausencia de frutos, de modo que no se encontraron diferencias significativas entre los tratamientos, excepto en el momento del cambio de color del fruto, que el contenido foliar de nitratos en los árboles que no tenían frutos fue significativamente superior (139.1 $\left.\mu \mathrm{g}^{-1} \mathrm{~ms}\right)$ al de aquellos en los que los frutos estuvieron presente hasta su recolección (49.5 $\mu \mathrm{g} \mathrm{g}^{-1}$ ms) (Fig. 2.36A). La evolución de la concentración de amonio, sin embargo, sí se vio marcadamente alterada por la presencia de los frutos en todas las fechas analizadas. Así, los árboles que mantuvieron todos sus frutos hasta la recolección presentaron una acumulación foliar de esta fracción nitrogenada desde que el fruto cambió de color hasta que maduró, en claro contraste con aquellos a los que se les habían eliminado todos los frutos en las primeras fases del desarrollo (Fig. 2.36B). Esta diferencia alcanzó la significación estadística, y así cuando en las hojas de los árboles con frutos la concentración de amonio en el cambio de color y maduración era de 57 y $62.6 \mu \mathrm{g} \mathrm{g}^{-1} \mathrm{~ms}$, respectivamente, en los árboles sin frutos era de 21.9 y $14.7 \mu \mathrm{g} \mathrm{g}^{-1} \mathrm{~ms}$ (Fig. 2.36B). Tras la recolección y con el inicio de la brotación vegetativa, en los árboles sin frutos la concentración se mantuvo constante y en los árboles con frutos fue prácticamente inexistente. 

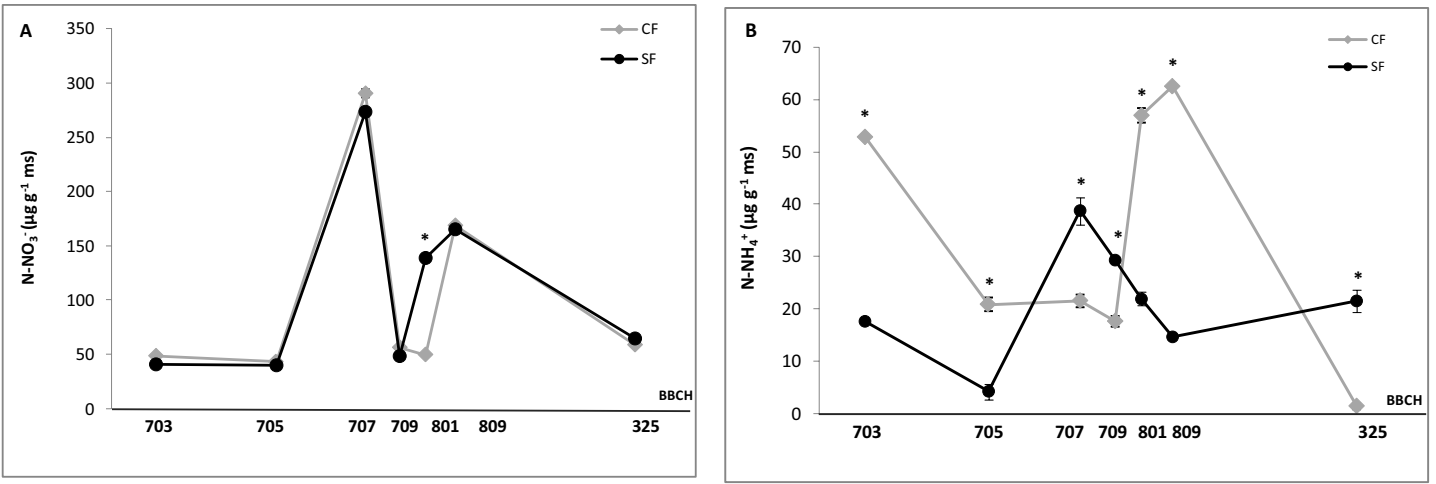

Fig. 2.36.- Influencia de la eliminación de todos los frutos del árbol en el estado fenológico 702 de la escala BBCH (SF) y de su presencia hasta la recolección (CF), en la evolución de la concentración de las fracciones nitrogenadas, $\mathrm{N}-\mathrm{NO}_{3}{ }^{-}(\mathrm{A})$ y $\mathrm{N}$ $\mathrm{NH}_{4}{ }^{+}(B)$, en las hojas de los brotes mixtos del níspero japonés cv. 'Algerie' a lo largo del ciclo vegetativo. Cada valor es la media de cuatro árboles. Las barras verticales indican el ES. El eje de abscisas representa los estados fenológicos según la escala $B B C H .{ }^{*}$ indica diferencias significativas $(P \leq 0.05)$ para un mismo estado fenológico.

La acumulación de amonio en las hojas de los árboles sin frutos, por otra parte, se adelantó 20 días respecto a la de los árboles con frutos. En pleno desarrollo del fruto, desde que éstos tenían el $70 \%$ de su tamaño final hasta que lo completaron, la concentración en los primeros fue un $44.5 \%$ y 40.1\% superior a la de los segundos, respectivamente; a pesar de ello estos valores máximos no alcanzaron los máximos registrados en los árboles con frutos (Fig. 2.36B). También en este caso la respuesta de las hojas a la descarga de todos los frutos fue inmediata, y a los 15 días de la misma ya se observaban diferencias significativas: las hojas de los árboles a los que se le habían eliminado todos sus frutos tenían $35.2 \mu \mathrm{g} \mathrm{g}^{-1} \mathrm{~ms}$ menos amonio que las hojas de los que los tenían todos, y así se mantuvieron hasta 1 mes después cuando todavía tenían $16.7 \mu \mathrm{g} \mathrm{g}^{-1} \mathrm{~ms}$ menos (Fig. 2.36B). Debe destacarse la importancia cuantitativa de la concentración foliar de nitratos frente a la de amonio. Así, mientras la de los primeros alcanzó valores entre 250 y $300 \mu \mathrm{g} \mathrm{g}^{-1} \mathrm{~ms}$, la de amonio nunca superó los $70 \mu g^{-1}$ (Fig. 2.36).

La evolución de la concentración de nitrógeno proteico en las hojas de estos mismos árboles estuvo marcadamente alterada por la presencia de los frutos hasta que éstos completaron su crecimiento. Durante todo este tiempo, la concentración de N-proteico en las hojas de los árboles que no tenían frutos fue significativamente superior a la de aquellos que los tuvieron todos hasta su recolección (Fig. 2.37). Las mayores diferencias se obtuvieron 1 mes después de la eliminación de los frutos, cuando en los árboles con frutos éstos ya habían alcanzado la mitad de su tamaño final; en ese momento, mientras el contenido de $\mathrm{N}$-proteico en las hojas de los árboles sin frutos era máximo 
(16.3 $\left.\mathrm{mg} \mathrm{g}^{-1} \mathrm{~ms}\right)$, el de de los árboles con frutos era mínimo (11.6 $\mathrm{mg} \mathrm{g}^{-1} \mathrm{~ms}$ ). Estas diferencias se mantuvieron en estados fenológicos posteriores, pero mientras dicho contenido descendia progresivamente en los primeros aumentaba en los segundos, hasta igualarse con el cambio de color y durante el crecimiento vegetativo (Fig. 2.37). Debe destacarse la importancia cuantitativa del nitrógeno proteico frente a las fracciones de nitratos o amonio. Así, mientras en éste se alcanzaron valores máximos de $16000 \mu \mathrm{g} \mathrm{g}^{-1} \mathrm{~ms}$, en la de nitratos y amonio nunca se superaron los 300 y $70 \mu \mathrm{g} \mathrm{g}$

1 , respectivamente (Fig. 2.36). El contenido en esta fracción representó, por tanto, entre el $95 \%$ y el 98\% del nitrógeno total de las hojas y la concentración de éste, por tanto, no estuvo influida por la del resto de las fracciones nitrogenadas estudiadas, esto es, nitratos y amonio.

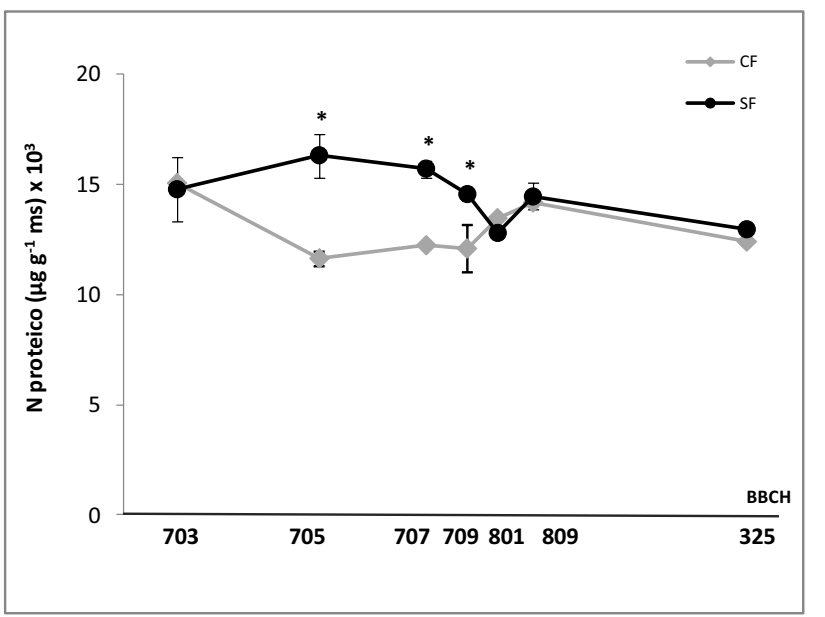

Fig. 2.37.- Influencia de la eliminación de todos los frutos del árbol en el estado fenológico 702 de la escala $B B C H$ (SF) y de su presencia hasta la recolección (CF), en la evolución de la concentración de $N$ proteico, en las hojas de los brotes mixtos del níspero japonés Cv. 'Algerie' a lo largo del ciclo vegetativo. Cada valor es la media de cuatro árboles. Las barras verticales indican el ES. El eje de abscisas representa los estados fenológicos según la escala $B B C H . \quad *$ indica diferencias significativas $(P \leq 0.05)$ para un mismo estado fenológico.

El contenido foliar de estas tres fracciones nitrogenadas siguió una evolución lógica cuando se estudiaron de manera conjunta. Así, el bajo contenido de nitratos detectado en las hojas de los árboles que tenían todos sus frutos, en el momento en que éstos dejaron de crecer, coincidió con un descenso en la concentración de amonio y, como consecuencia de ello, los niveles de nitrógeno proteico fueron mínimos (Figs. 2.36 y 2.37). De estos resultados se deduce que el efecto del fruto alcanzó a la actividad de la enzima nitrato-nitrito reductasa, alterando, de este modo, el mecanismo de reducción de los nitratos. Aunque en los árboles que no tenían frutos se observó un comportamiento similar, en este caso en el momento en que los brotes desarrollados pasaron a ser fuentes de carbohidratos, los efectos provocados por estos sumideros en el metabolismo de las fracciones nitrogenadas no fueron tan potentes. La acumulación de $\mathrm{N}_{-} \mathrm{NH}_{4}{ }^{+}$detectada en las hojas de 
los árboles con frutos en etapas próximas a la maduración, ausente en los árboles que no los tenían, resalta nuestros resultados anteriores.

En nuestros experimentos, la concentración de nitrógeno amoniacal en el floema de los árboles sin frutos, fue superior a la de los controles, durante el periodo de crecimiento del fruto, excepto en la primera fecha del análisis y sólo hasta que el fruto alcanzó practicamente su tamaño final. Posteriormente, 60 días después el contenido en ambos tipos de árboles se igualó; y en pleno crecimiento vegetativo, la concentración en el floema de los árboles sin frutos volvió a ser significativamente mayor (Fig. 2.38 A). La descarga absoluta de los frutos provocó las mayores diferencias a los 15 días de efectuada, momento en el que la concentración de amonio en el floema de estos árboles era la mitad que la de los que no habían perdido ningún fruto. Aunque ambos tipos de árboles alcanzaron los valores máximo y mínimo en los mismos estados fenológicos, 707 y 325 de la escala $\mathrm{BBCH}$, respectivamente, en los dos casos los árboles sin frutos tuvieron un $50 \%$ más de amonio que los árboles con frutos (Fig. $2.38 \mathrm{~A}$ ).

El nitrógeno proteico, sin embargo, no vio alterada su evolución por la acción del fruto que, prácticamente, fue idéntica para todos los árboles a lo largo del periodo estudiado. Aunque el contenido de esta fracción nitrogenada fue siempre superior en el floema de los árboles sin frutos, como en el caso del amonio, el descenso más acusado en su concentración (53.7\%) durante el estado fenológico 709 de la escala BBCH, hizo que éste fuera, ocasionalmente, menor ( $3.2 \mathrm{mg} \mathrm{g}^{-1} \mathrm{~ms}$ ) que el de los árboles con frutos (4.8 $\mathrm{mg} \mathrm{g}^{-1} \mathrm{~ms}$ ), que sólo la redujeron un 19.3\%. (Fig. 2.38 B). Ni siquiera la mayor reducción de la concentración, como consecuencia de la ausencia de los frutos, consiguió diferencias significativas respecto a los árboles con la carga completa que también la experimentaron. Tras la recolección, y con ello la descarga completa de los árboles que tuvieron todos sus frutos hasta ese momento, la concentración de nitrógeno proteico en el floema de éstos aumentó significativamente hasta igualarse con la de los árboles sin frutos (Fig. 2.38 B). A pesar de la ausencia de diferencias significativas por la presencia o ausencia de frutos en el contenido proteico floemático, cuando estos niveles se estudiaron comparativamente en cada estado fenológico sí alcanzaron la significación estadística. Así, por ejemplo, cuando los frutos estaban cambiando de color, el floema de estos árboles tenía $1.2 \mathrm{mg} \mathrm{g}^{-1} \mathrm{~ms}$ más que una semana antes, cuando aquellos tenían el 90\% de su tamaño final (Fig. 2.38 B). La comparación del contenido de las dos fracciones nitrogenadas, amonio y proteico, en el floema de los árboles con frutos, por una parte, y sin frutos, por otra, mostró una evolución coherente con el metabolismo de estas sustancias en todas las fechas analizadas, excepto en el cambio de color de los frutos en el que el contenido en amonio descendió y el proteico aumentó (Fig. 2.38). 

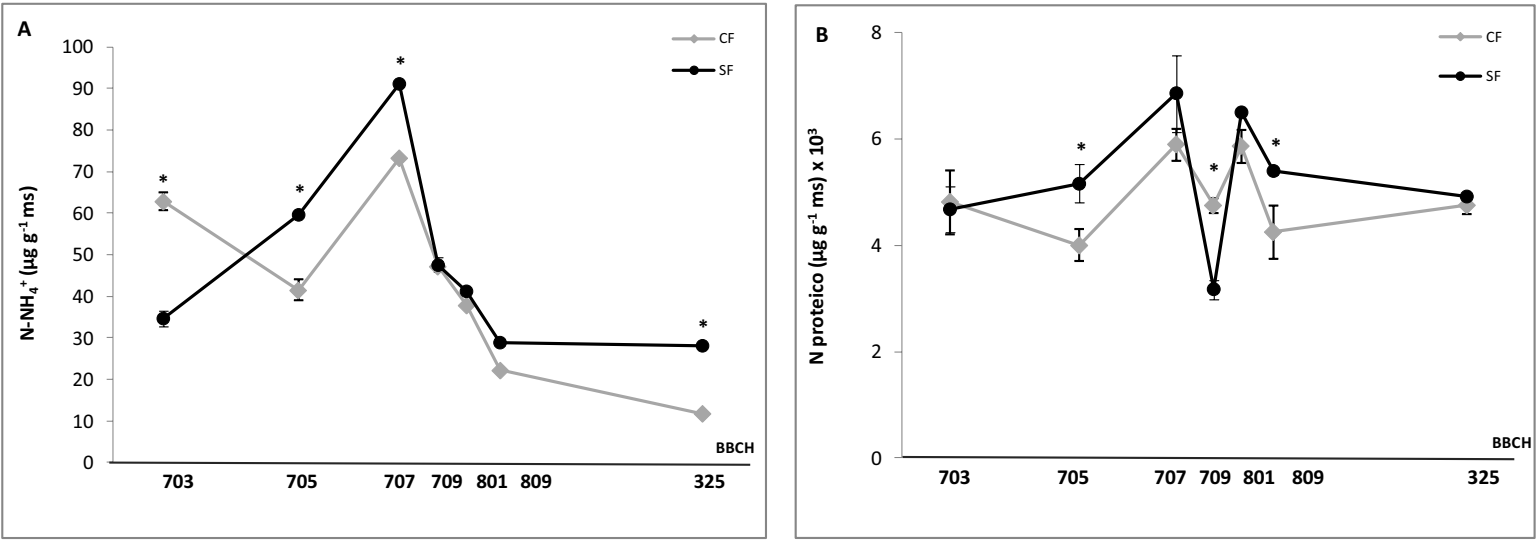

Fig 38. - Influencia de la eliminación de todos los frutos del árbol en el estado fenológico 702 de la escala BBCH (SF) y de su presencia hasta la recolección (CF), en la evolución de la concentración de $\mathrm{N}-\mathrm{NH}_{4}^{+}(A)$ y $\mathrm{N}$ proteico (B), en el floema de los brotes mixtos del níspero japonés CV. 'Algerie' a lo largo del ciclo vegetativo. Cada valor es la media de cuatro árboles. Las barras verticales indican el ES. El eje de abscisas representa los estados fenológicos según la escala $B B C H .{ }^{*}$ indica diferencias significativas (P $\left.\leq 0.05\right)$ para un mismo estado fenológico.

El contenido en $\mathrm{N}^{-\mathrm{NO}_{3}}{ }^{-}$y $\mathrm{N}-\mathrm{NH}_{4}{ }^{+}$de la piel y la pulpa de los frutos en su conjunto, aumentó progresivamente durante el crecimiento del fruto hasta que éste alcanzó su tamaño final, descendiendo posteriormente con el cambio de color y hasta su maduración. Este incremento fue más pronunciado para la fracción $\mathrm{N}_{-} \mathrm{NO}_{3}{ }^{-}$que para la fracción $\mathrm{N}-\mathrm{NH}_{4}{ }^{+}$, y al final del crecimiento del fruto, mientras las primera había aumentando en un $71.5 \%$ su contenido, la segunda sólo lo hizo en un $24 \%$. Por el contrario, fue la concentración de amonio la que descendió más bruscamente cuando los frutos cambiaron de color y durante su maduración, de 362.8 a $103.4 \mu \mathrm{g} \mathrm{g}^{-1} \mathrm{~ms}$, mientras que la de nitratos pasó 48.6 a $32.4 \mu \mathrm{g} \mathrm{g}^{-1} \mathrm{~ms}$ (Fig. 2. 39 A y B). Debe destacarse la mayor importancia cuantitativa del $\mathrm{N}-\mathrm{NH}_{4}{ }^{+}$frente a la de $\mathrm{N}-\mathrm{NO}_{3}{ }^{-}$; así, mientras los primeros alcanzaron valores máximos entre 350 y $400 \mu \mathrm{g} \mathrm{g}^{-1} \mathrm{~ms}$, los segundos apenas superaron los $50 \mu \mathrm{g} \mathrm{g}^{-1} \mathrm{~ms}$.

El contenido de nitrógeno proteico, por el contrario, descendió progresivamente durante todo el periodo de crecimiento del fruto alcanzando el mínimo valor con la maduración del fruto (Fig. 2.39 C). En este caso, el mayor descenso proteico fue durante las primeras fases de crecimiento del fruto, de modo que cuando éste alcanzó el $70 \%$ de su tamaño final (estado 707 de la escala BBCH) su concentración era, aproximadamente, la mitad de la registrada en el momento en que el fruto había crecido un $30 \%$ de su tamaño final (estado $703 \mathrm{BBCH}$ ). A partir de este momento, con $6.3 \mathrm{mg} \mathrm{g}^{-1} \mathrm{~ms}$ 
de nitrógeno proteico, el contenido en esta fracción nitrogenada descendió ligeramente hasta alcanzar $4.2 \mathrm{mg} \mathrm{g}^{-1}$ en el momento de su maduración (Fig. 2.39 C).
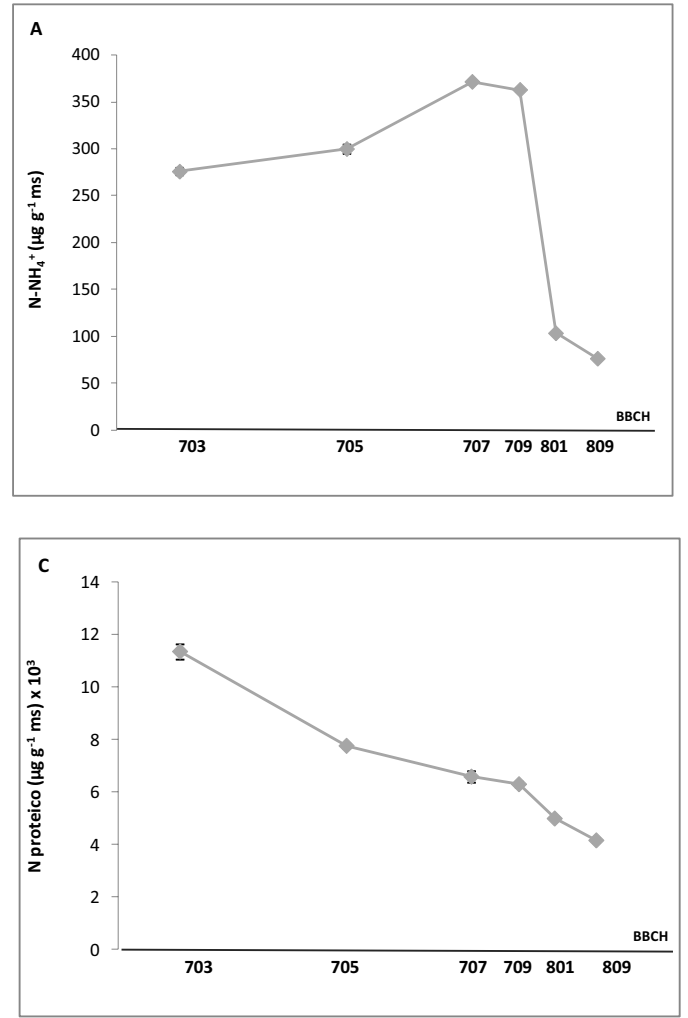

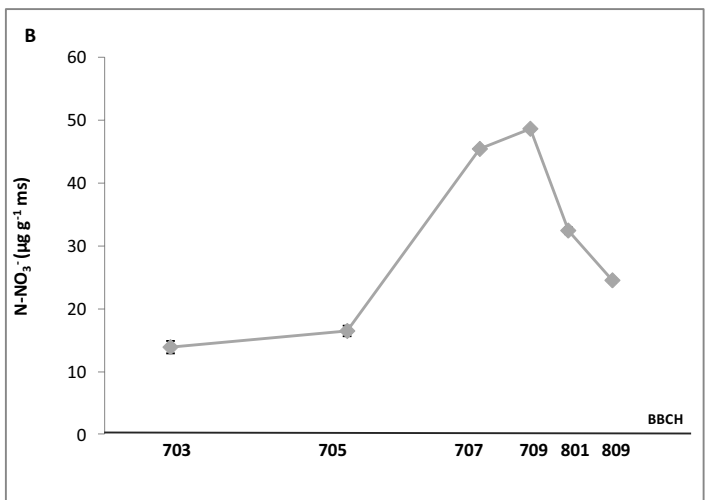

Fig. 2.39.- Influencia de la presencia de todos los frutos de un árbol de níspero japonés cv. 'Algerie' hasta su recolección, en la evolución de su concentración en $\mathrm{N}-\mathrm{NH}_{4}^{+}(\mathrm{A}), \mathrm{N}-\mathrm{NO}_{3}^{-}$(B) y $\mathrm{N}$ proteico (C). Cada valor es la media de cuatro árboles. Las barras verticales indican el ES. El eje de abscisas representa los estados fenológicos según la escala $\mathrm{BBCH}$. Clave de tratamientos como en la Fig 2.30.

\section{6.- La influencia del fruto en el balance hormonal.}

El contenido endógeno de hormonas en la planta se vio alterado por la presencia de los frutos, como demuestran las diferencias significativas entre la concentración de AIA de los árboles sin frutos y los que mantuvieron todos sus frutos hasta la recolección (Fig. 2.40). En ambos casos esta auxina aumentó su concentración en las primeras fechas de análisis, pero manteniendo los valores más elevados en los segundos, es decir, en los que brotaron menos (Tabla 2.2) y más tarde (Fig. 2.17). Cuando el fruto alcanzó el estado fenológico 705 de la escala BBCH la concentración de AIA en el floema de los árboles sin frutos era de $57,9 \mathrm{ng} \mathrm{g}^{-1} \mathrm{~ms}$, la de los árboles con frutos era de 80,9 $\mathrm{ng} \mathrm{g}^{-1}$ ms. A partir de este momento, mientras los primeros aumentaron en un $61,3 \%$ su concentración, los segundos la mantuvieron prácticamente constante hasta la maduración de sus frutos y el desarrollo 
vegetativo (Fig. 2.40). El contenido de auxinas en el floema de los árboles con frutos fue, por tanto, significativamente superior al de los árboles sin frutos durante todo el ciclo vegetativo, excepto en el estado fenológico 709 de la escala BBCH (Fig. 2.40), correspondiente al máximo señalado más arriba. El efecto de la descarga de los frutos en el contenido de auxinas del árbol fue tan rápido que, a los 15 días de la misma, ya se detectaban las primeras diferencias significativas entre los tratamientos (Fig. 2.40).

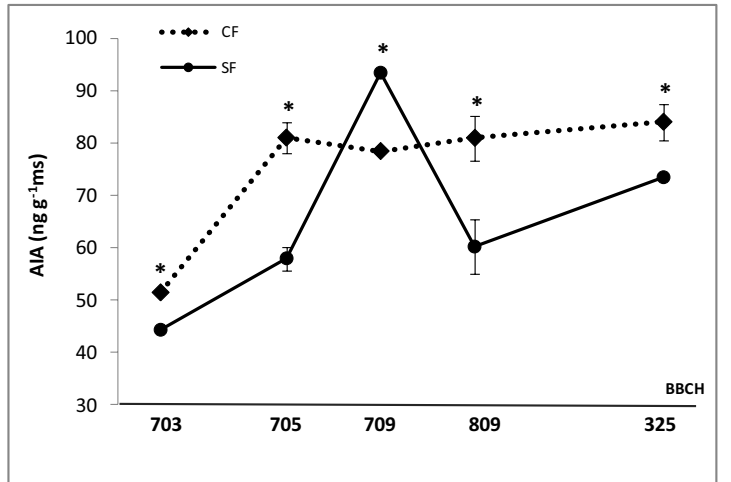

Fig. 2.40.- Influencia de la eliminación de todos los frutos del árbol en el estado fenológico 702 de la escala BBCH (SF) y de su presencia hasta la recolección (CF), en la evolución del contenido de AIA en el floema de los brotes mixtos del níspero japonés cv 'Algerie'. Cada valor es la media de cuatro árboles. Las barras verticales indican el ES. EI eje de abscisas representa los estados fenológicos según la escala $\mathrm{BBCH}$. * indica diferencias significativas $(P \leq 0.05)$ para un mismo estado fenológico.

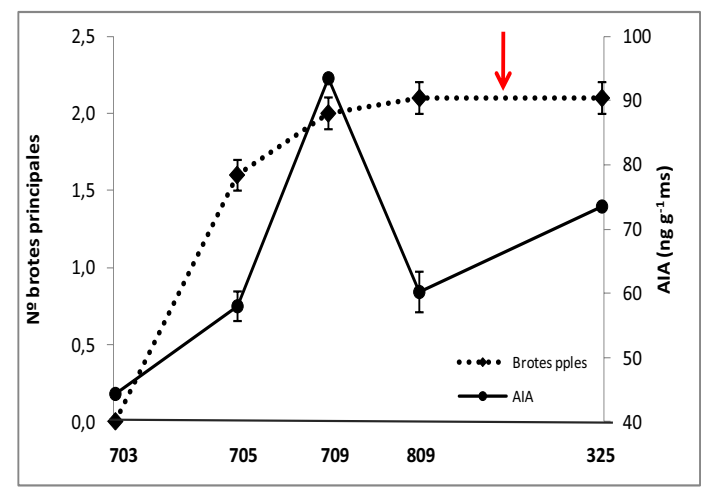

Fig. 2.41.- Evolución del contenido en AIA del floema de árboles de níspero japonés cv. 'Algerie' sin frutos y la brotación de sus yemas. Cada valor es la media de cuatro árboles. Las barras verticales indican el ES y la flecha el inicio de la brotación anticipada. El eje de abscisas representa los equivalentes estados fenológicos según la escala BBCH a los árboles que tenían todos sus frutos en el momento de la recolección. * indica diferencias significativas $(P \leq 0.05)$ para un mismo estado fenológico.

Un comportamiento similar se observó en la evolución del contenido de ABA y de Zeatina en el floema de estos mismos árboles. El máximo encontrado para el AIA en los árboles sin frutos en el momento en que el número de brotes emitidos ya era el definitivo (Fig. 2.41) y el descenso posterior hasta valores de la concentración similares a los del inicio del desarrollo del fruto (estado $703 \mathrm{BBCH}$ ) se repitió para estas dos fitohormonas en los mismos estados fenológicos (Fig. $2.42 \mathrm{~A}$ y B). El descenso citado, sin embargo, fue más acusado para el ABA que disminuyó su concentración un $10 \%$ más, aproximadamente, que el AIA y la zeatina. Hasta que el fruto alcanzó la mitad de su tamaño final, o lo que es lo mismo, cuando ya habían brotado más de la mitad de las yemas principales en el caso de los árboles sin frutos (ver figura 2.41), la concentración de ABA y Zeatina en el floema se 
mantuvo constante con valores mínimos, muy próximos entre sí, de $39.1 \mathrm{ng} \mathrm{g} \mathrm{g}^{-1} \mathrm{~ms}$ (Fig. 2.42), mientras que la del AIA aumentó en un 23.5\%, hasta alcanzar valores superiores a $55 \mathrm{ng} \mathrm{g}^{-1} \mathrm{~ms}$ (Fig. 2.40). En pleno crecimiento vegetativo, cuando se estaba iniciando la brotación anticipada en los árboles sin frutos (ver figura 2.41), las concentraciones en el floema de AIA, ABA y Zeatina aumentaron en un $18 \%, 37 \%$ y $46.5 \%$, respectivamente, llegando en este último caso a superar la de los árboles con frutos e incluso alcanzar su valor máximo (Figs. 2.40 y 2.44 A y B). Pero lo relevante es que, en dicho periodo, la concentración de AIA en el floema de los árboles sin frutos era menor y la zeatina mayor que en los árboles con frutos, facilitando así la mayor y más precoz brotación de los primeros frente a los segundos. Más claro resulta este efecto al comparar la evolución del ratio AIA/zeatina, más bajo para los árboles sin frutos a lo largo de todo el periodo estudiado (Fig. 2.43). El descenso de este ratio se relaciona con la brotación, y viceversa, explicándose de este modo las diferencias en la brotación encontrada entre los árboles con y sin frutos (Fig. 2.17 y Tabla 2.2).Estos resultados ponen de manifiesto la estrecha relación que existe entre el contenido hormonal del árbol en etapas próximas a la brotación y el inicio del desborre de las yemas.
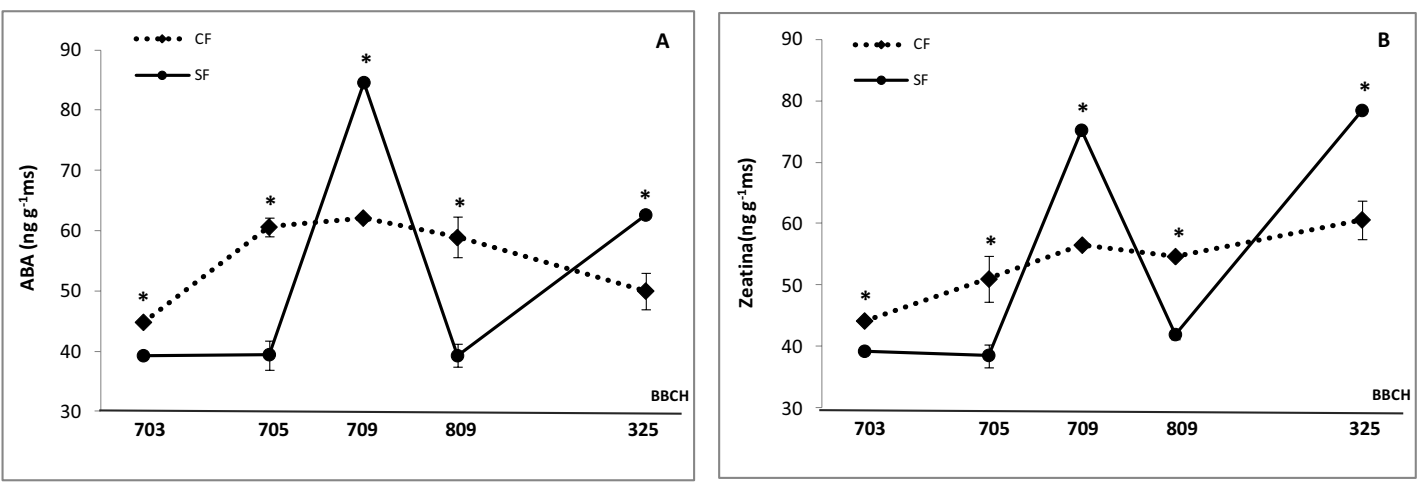

Fig. 2.42.- Influencia de la eliminación de todos los frutos del árbol en el estado fenológico 702 de la escala BBCH (SF) y de su presencia hasta la recolección (CF), en la evolución la concentración de ABA (A) y Zeatina (B) en el floema de los brotes mixtos del níspero japonés cv 'Algerie'. Cada valor es la media de cuatro árboles. Las barras verticales indican el ES. El eje de abscisas

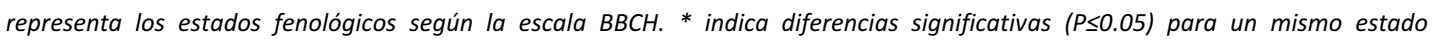
fenológico.

La evolución del contenido hormonal en el floema de los árboles con fruto fue, a partir de que éste adquiriera el $50 \%$ de su tamaño final, prácticamente constante para las tres fitohormonas analizadas. Más estables fueron los contenidos del ABA y la Zeatina, que hasta que el fruto alcanzó la mitad de su tamaño final sólo aumentaron su concentración en 15.8 y 6.8 ng $\mathrm{g}^{-1} \mathrm{~ms}$, 
respectivamente, que los del AIA, que lo hizo en $29.8 \mathrm{ng} \mathrm{g}^{-1} \mathrm{~ms}$ y alcanzó la significación estadística (Figs. 2.40 y $2.42 \mathrm{~A}$ y B). Tras la recolección la concentración de este último apenas se modificó, mientras que la de ABA disminuyó ligeramente y la de zeatina aumentó (Figs. 2.40 y $2.42 \mathrm{~A}$ y B). A diferencia de los árboles sin frutos en los que todas Las fitohormonas alcanzaron la máxima concentración en el mismo estado fenológico, esto es, el equivalente al estado 709 de la escala $\mathrm{BBCH}$, los árboles con frutos lo alcanzaron, en el caso del AIA y la Zeatina, durante el crecimiento vegetativo, con valores de 84 y $60.6 \mathrm{ng} \mathrm{g}^{-1} \mathrm{~ms}$, respectivamente, y en el caso del ABA cuando el fruto completó su crecimiento, con valores de $62.1 \mathrm{ng} \mathrm{g}^{-1} \mathrm{~ms}$ (Figs. 2.40 y $2.42 \mathrm{~A}$ y B).

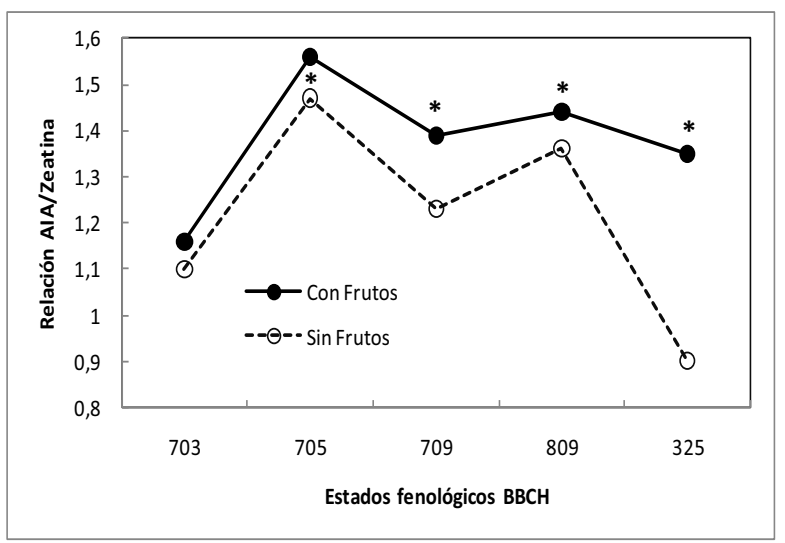

Fig. 2.43.- Influencia de la presencia del fruto en el árbol sobre la evolución del ratio AlA/zeatina en el floema de árboles de níspero japonés cv. 'Algerie'. Cada valor es la media de cuatro árboles. Las barras verticales indican el ES. El eje de abscisas representa los estados fenológicos según la escala $\mathrm{BBCH} .{ }^{*}$ indica diferencias significativas $(P \leq 0.05)$ para un mismo estado fenológico.

El contenido en $A B A$ y Zeatina en el conjunto de la piel y la pulpa del fruto descendió progresivamente con el crecimiento del fruto hasta valores mínimos en la maduración (Fig. 2.44). El AIA, sin embargo, tras un descenso progresivo de su concentración hasta el momento en que el fruto completó su crecimiento (estado 709 de la escala BBCH), aumentó significativamente un $37.2 \%$ su concentración (Fig. 2.44 A). Aunque las tres fitohormonas estudiadas partieron de valores máximos en el mismo estado fenológico, 703 de la escala $\mathrm{BBCH}$, la concentración de AIA fue significativamente superior a la de ABA (Fig. 2.44 B) y Zeatina (Fig. 2.44 C), con valores de 163.4, 82.5 y $65.4 \mathrm{ng} \mathrm{g}^{-1} \mathrm{ms,}$ respectivamente, lo que resalta la importancia cuantitativa de las auxinas respecto de las otras dos fitohormonas. Sin embargo, fue el AIA el que más bruscamente disminuyó su contenido cuando al final del crecimiento del fruto su concentración se había reducido un $11.3 \%$ y un $7.3 \%$ más que la del ABA y la de la Zeatina, respectivamente, para ese mismo estado fenológico (Fig. 2.44). 

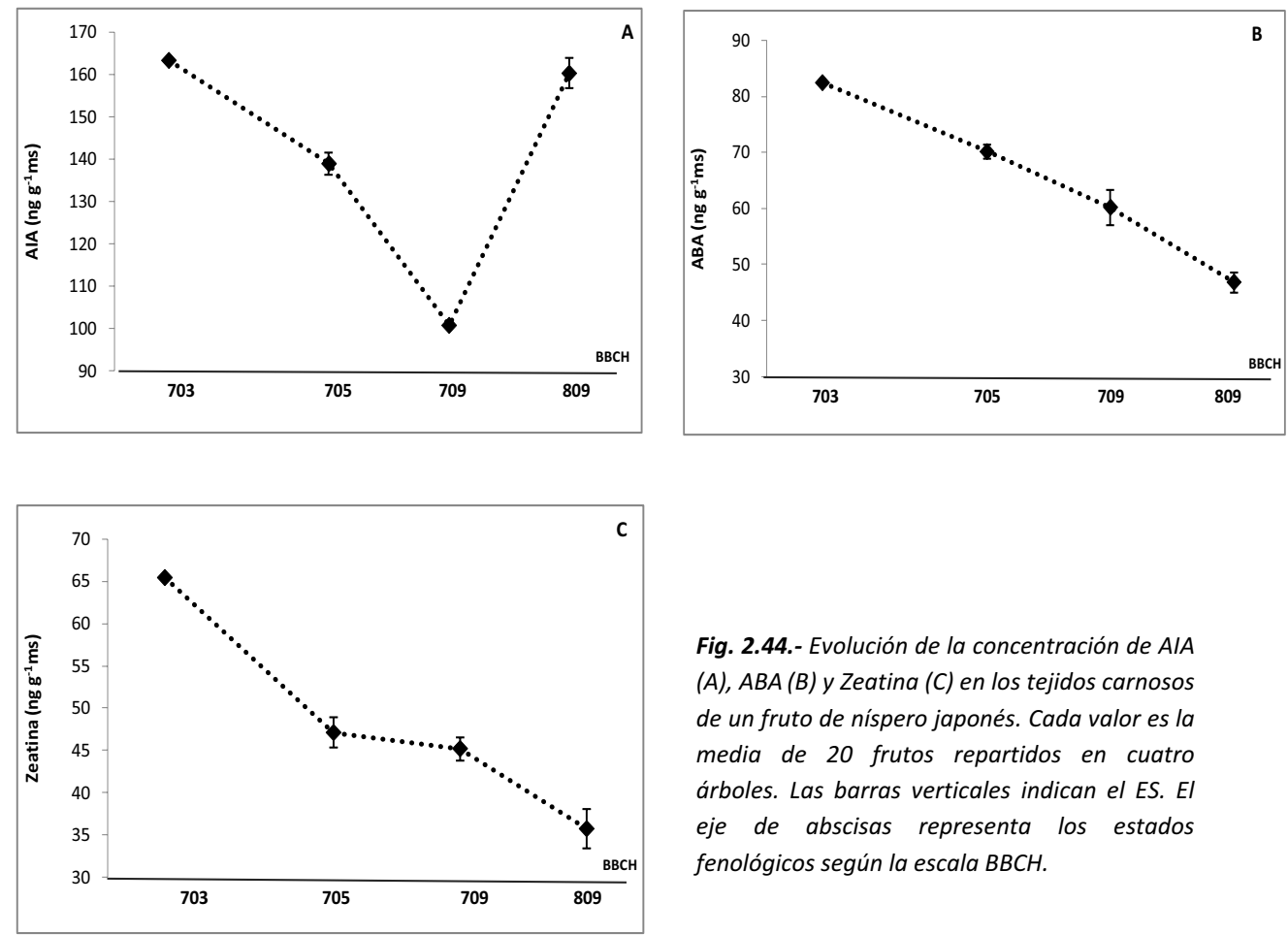

Fig. 2.44.- Evolución de la concentración de AIA (A), $A B A(B)$ y Zeatina (C) en los tejidos carnosos de un fruto de níspero japonés. Cada valor es la media de 20 frutos repartidos en cuatro árboles. Las barras verticales indican el ES. EI eje de abscisas representa los estados fenológicos según la escala $\mathrm{BBCH}$.

La comparación de la concentración de estas fitohormonas en el floema de los árboles con frutos (Figs 2.40 y 2.42) y en los frutos (Fig. 2.44), reveló una evolución completamente divergente. Mientras en el floema aumentó hasta la maduración, en los frutos disminuyó, con la excepción del AIA ya señalada. El mayor contenido de estas sustancias en el fruto cuando éste iniciaba su crecimiento (Fig. 2.44), un 50.5\%, 24.8\% y $13.6 \%$ más de AIA, ABA y Zeatina, respectivamente, que en el floema cuando éste alcanzó sus valores máximos en el momento de la maduración (Figs. 2.40 y $2.42 \mathrm{~A}$ y B), indica la alta capacidad de síntesis hormonal del fruto durante las primeras fases del desarrollo de su embrión.

En resumen, las alteraciones observadas en el contenido hormonal de los árboles que tuvieron todos sus frutos hasta la recolección y los que se descargaron completamente al inicio de su desarrollo, lo fueron por causas diferentes. Mientras en los primeros las diferencias detectadas, por ejemplo en la evolución del AIA, fueron consecuencias directas del crecimiento de los frutos y su posterior maduración, en los segundos lo fueron por causa de la brotación de las yemas y el posterior desarrollo de sus brotes. La dependencia del desarrollo de los sumideros, esto es, del crecimiento de los frutos, por una parte, y del desborre de las yemas y crecimiento de los brotes, principales y 
anticipados, por otra, respecto de la concentración de AlA fue clara, y puso de manifiesto la importancia que estos reguladores del desarrollo tienen en el control de ambos procesos (Fig. 2.45).
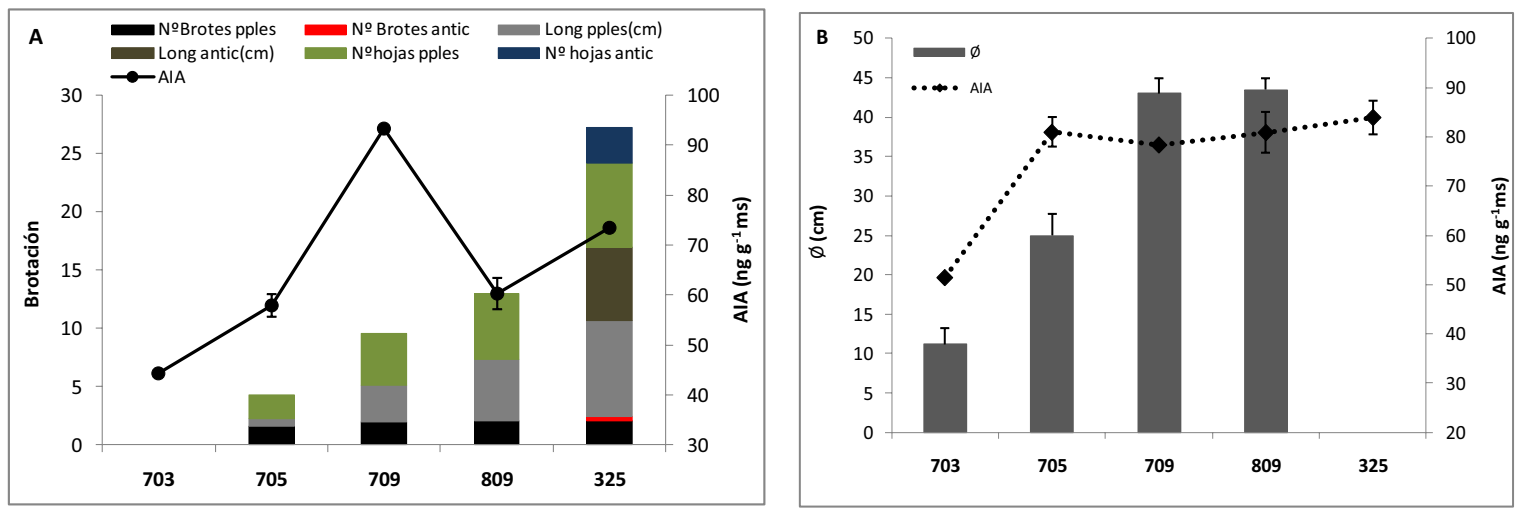

Fig. 2.45.- Evolución del contenido floemático de AlA en los árboles de níspero japonés cv. 'Algerie' a los que se les eliminaron todos sus frutos en el estado fenológico 702 de la escala $B B C H$ (A) y en los que los mantuvieron todos hasta su recolección (B), durante el desborre y crecimiento de los brotes y a lo largo del crecimiento y maduración de los frutos, respectivamente. Cada valor es la media de cuatro árboles. Las barras verticales indican el ES. El eje de abscisas representa los equivalentes estados fenológicos según la escala BBCH. En el panel A, los estados fenológicos son los equivalentes a los de los árboles con frutos. Pples $=$ principlaes; antic $=$ anticipados. 



\section{3.- INFLUENCIA DEL FRUTO EN LA FLORACIÓN.}

La presencia del fruto redujo significativamente el número de flores totales del árbol en el momento de la antesis. Este efecto fue la consecuencia indirecta, por una parte, de la reducción de la brotación (ver capítulo 2, sección 2.3), y directa, por otra, de la reducción del número de flores de las panículas principales y anticipadas. La respuesta fue la misma tanto cuando se estudió sobre la panícula individual eliminando los frutos en los estados fenológico 701 (despuntado I) y 703 (despuntado II) de la escala BBCH, como cuando se hizo sobre el árbol completo, con la eliminación de todos sus frutos en las primeras fases de su desarrollo. Así, la descarga parcial de los frutos del árbol, eliminando los de algunas panículas cuando éstos medían $22.8 \mathrm{~mm}$ (despuntado II), aumentó en un $20.2 \%$ el número de flores de las panículas principales que surgieron de estos brotes, respecto de los controles que mantuvieron los frutos hasta su recolección (Tabla 3.1). Algo parecido ocurrió con las panículas anticipadas que también vieron reducidas sus flores por la presencia de los frutos. En este caso, los brotes nuevos surgidos de los brotres despuntados dieron lugar a brotes anticipados con una media, en el momento de la antesis, de 117.7 flores, frente a las 79.9 que tuvieron las panículas de los brotes anticipados de los controles (Tabla 3.1). Este incremento de un $32.1 \%$ de la floración anticipada alcanzó la significación estadística, como ya se observó en el número de estos brotes al final de su crecimiento (ver Fig. 2.12 B). Resulta interesante destacar la importancia que el tiempo de permanencia del fruto en el brote tiene sobre la floración. Así, los brotes control que estuvieron 75 días más que los brotes despuntados bajo la influencia de sus frutos, presentaron, en el momento de la antesis, un $18.5 \%$ menos de panículas principales que, además, tuvieron 32.4 flores menos y un $28.6 \%$ menos de brotes anticipados, con 37.8 flores menos que los brotes despuntados en el estado fenológico 703 de la escala BBCH (Tabla 3.1). Resultados similares se obtuvieron cuando las panículas se eliminaron en estados más precoces del desarrollo del fruto, esto es, en la época I de nuestros estudios (datos no presentados).

Tabla 3.1.- Influencia de la presencia del fruto en la panícula (control) y en el árbol completo (con frutos) hasta su recolección y de su eliminación de la panícula (despuntado II) y del árbol (sin frutos), sobre la floración del níspero japonés Cv. 'Algerie'. Cada valor es la media de 20 brotes repartidos en cinco árboles. Letras distintas en una misma columna indican diferencias significativas $(P \leq 0.05)$.

\begin{tabular}{llllc}
\hline TRATAMIENTO & Días tras la eliminación & $\varnothing(\mathrm{mm})$ & № flores/panícula ppal & № flores/panícula anticipada \\
\hline Despuntado II & 240 & 22,8 & $159,9 \mathrm{a}$ & $117,7 \mathrm{a}$ \\
Control & 165 & 41,5 & $127,5 \mathrm{~b}$ & $79,9 \mathrm{~b}$ \\
& & & & \\
Sin frutos & 240 & 18,5 & $160,2 \mathrm{a}$ & $114,1 \mathrm{a}$ \\
Con frutos & 135 & 38,3 & $141,4 \mathrm{~b}$ & $78,8 \mathrm{~b}$ \\
\hline
\end{tabular}


El estudio del árbol completo, dejando en unos árboles todos sus frutos y eliminándolos en su totalidad en otros, tuvo la misma respuesta que los árboles que se aclararon parcialmente despuntando algunas de sus panículas. Así, en nuestras condiciones climáticas, las panículas principales y anticipadas de un árbol en condiciones de cultivo y soportando la totalidad de sus frutos, tuvieron 141.4 y 78.8 flores, respectivamente, mientras que la eliminación de todos ellos las elevó, significativamente, hasta 160.2 y 114.1 flores, respectivamente (Tabla 3.1). La diferencia de 105 días más de permanencia de los frutos en unos árboles que en otros fue razón suficiente para que la intensidad de floración en los primeros fuera significativamente menor que en los segundos. También en este caso, al estudiar la respuesta del árbol completo a la presencia de los frutos se observó que el efecto de éstos sobre la floración fue más destacado en las panículas anticipadas que en las principales, de modo que mientras las primeras redujeron el número de sus flores en un 31\%, las segundas apenas lo hicieron en un 12\%. La similitud en los resultados de los árboles que se descargaron, total o parcialmente, demuestra que la acción directa del fruto sobre la floración de la panícula es la misma con independencia del número de frutos que tenga el árbol, lo que indica, de nuevo, la autonomía de la panícula para florecer.

Nuestros resultados indican que la presencia de los frutos hasta su recolección reduce significativamente el número de flores totales del árbol el ciclo siguiente, como consecuencia directa de la reducción del número de flores en sus panículas principales y anticipadas. La intensidad de este efecto dependió del tiempo que sus frutos permanecieron en el árbol, indicando una clara relación inversa entre ambas variables. Por eso, la eliminación de todos los frutos de la panícula, desde los primeros estados de su desarrollo y hasta 45 días después de su maduración, cuando éstos estaban completamente senescentes, afectó de manera diferente a la floración total del árbol en el momento de su antesis. En efecto, la reducción del número de flores de ambas panículas (principal y anticipada), fue mayor cuanto más tiempo estuvieron los frutos presentes en el árbol, o lo que es lo mismo, cuando éstos se eliminaron en estados más avanzados de su desarrollo. Pero no fue, prácticamente hasta que éstos alcanzaron su tamaño final (estado fenológico 709 de la escala BBCH), cuando estas diferencias consiguieron la significación estadística, que mantuvieron hasta al final del periodo estudiado (Fig. 3.1). Así, el número de flores de las panículas principales descendió ligeramente desde 167.7 hasta 138.9 a medida que el fruto se mantenía en el árbol mientras aumentaba en $10.1 \mathrm{~g}$ su peso fresco y alcanzaba, de esta manera, el estado fenológico 707 de la escala BBCH (Fig. 3.1 A). Pero más pronunciada fue esta reducción cuando tan sólo 20 días después estos frutos 
ya habían cudruplicado su peso fresco y alcanzado el estado fenológico 709 de la escala BBCH; cuando se eliminaron los frutos en ese momento, las panículas principales tuvieron en el momento de la antesis del ciclo siguiente 117.9 flores, un $12.7 \%$ menos que cuando el fruto se había eliminado en el estado fenológico anterior (707 de la escala BBCH) o un $29.7 \%$ menos que el primero de ellos (701 BBCH) (Fig. 3.1 A). Un retraso mayor en la eliminación de los frutos, cuando éstos estaban maduros (estado $809 \mathrm{BBCH}$ ) o completamente senescentes (809+ $\mathrm{BBCH}$ ), la redujo en un $33.2 \%$ y un $40.1 \%$, respectivamente. El máximo efecto derivado de la presencia de los frutos sobre la floración de las panículas principales fue, por tanto, para estados fenológicos posteriores al 809 de la escla $\mathrm{BBCH}$, es decir, cuando éstos ya estaban completamente senescentes y tanto su pulpa como sus semillas habían disminuido en $5.4 \mathrm{~g} \mathrm{y}$ $0.2 \mathrm{~g}$, respectivamente, sus pesos frescos respecto a su estado de plena madurez. Los mismos resultados se obtuvieron al estudiar el efecto de la eliminación de los frutos en distintos estados de su desarrollo sobre el número de flores de las panículas anticipadas. En este caso la reducción de la floración conseguida por la presencia de los frutos en el árbol hasta los estados fenológicos 709, 809 y 809+ de la ecala BBCH, fue más drástica. Así, la permanencia de los frutos en el árbol hasta su senescencia redujo el número de flores de sus panículas anticipadas en un 65.3\% (Fig. 3.1 B). Éstas últimas fueron, por tanto, más sensibles a la acción del fruto que las panículas principales de las que se originaron, al igual que ocurrió con la reducción del número de brotes principales y anticipados por acción de la presencia de los frutos (ver Fig. 2.16 y Tabla 2.2). Debe destacarse, no obstante, la importancia cuantitativa de las flores de las panículas principales frente a las de las anticipadas, que siempre fueron significativamente superiores en número con independencia del estado fenológico en el que se eliminaron los frutos, llegando en alguno de ellos a ser hasta 4 veces superiores (Fig. 3.1 A y B). La presencia de los frutos en el árbol hasta que éstos completaron su crecimiento (estado $709 \mathrm{BBCH}$ ), maduraron $(809 \mathrm{BBCH})$ o entraron en senescencia $(809+\mathrm{BBCH})$, redujo el número total de flores en el brote de 236.8 a 163.9, 140 y 124.4, respectivamente (Fig 3.1 C), alcanzado los resultados la significación estadística en los tres casos. 

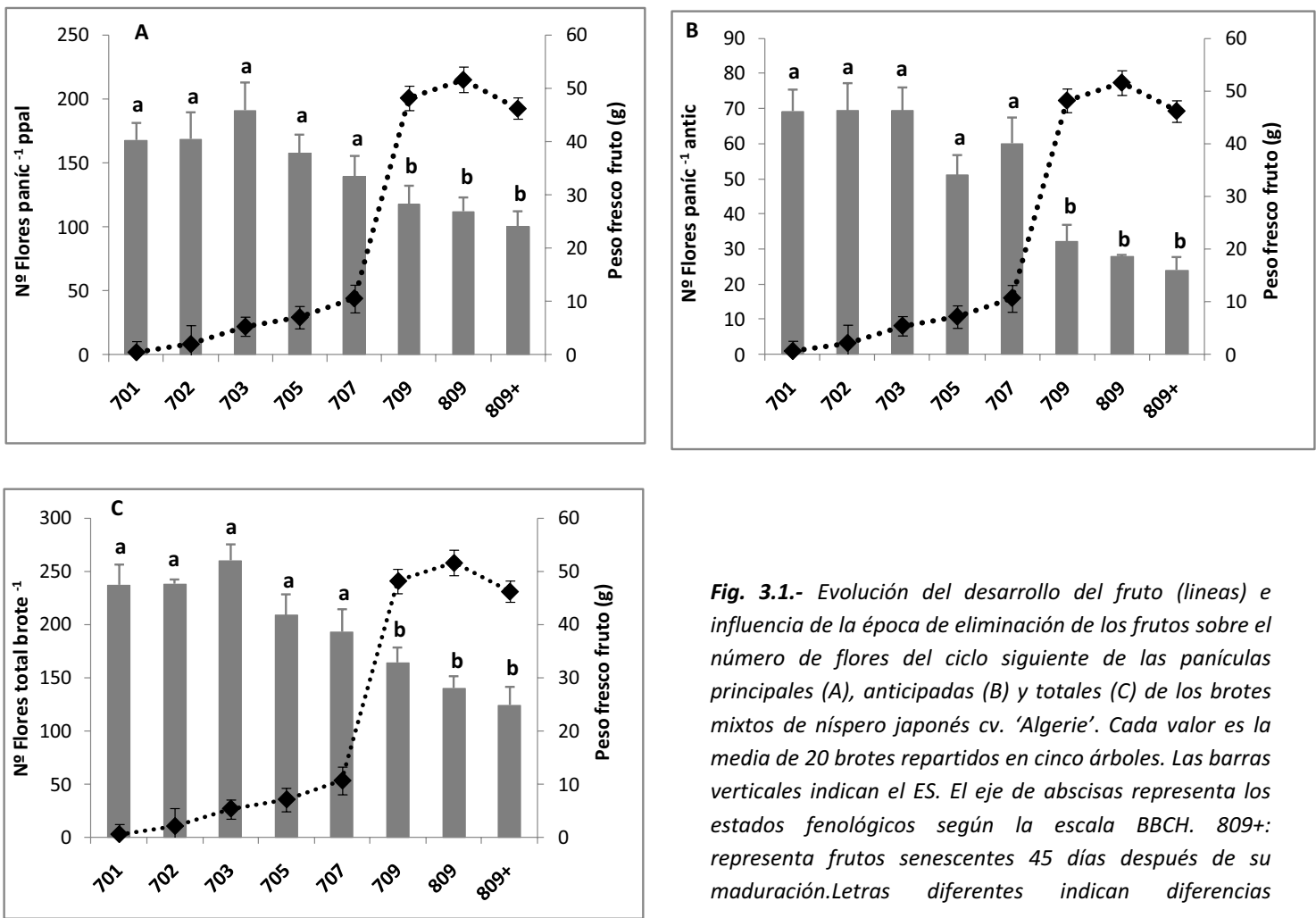

Fig. 3.1.- Evolución del desarrollo del fruto (lineas) $e$ influencia de la época de eliminación de los frutos sobre el número de flores del ciclo siguiente de las panículas principales $(A)$, anticipadas $(B)$ y totales $(C)$ de los brotes mixtos de níspero japonés cv. 'Algerie'. Cada valor es la media de 20 brotes repartidos en cinco árboles. Las barras verticales indican el ES. El eje de abscisas representa los estados fenológicos según la escala BBCH. 809+: representa frutos senescentes 45 días después de su maduración.Letras diferentes indican diferencias

El contenido en carbohidratos reductores durante el periodo de inducción floral apenas se alteró por la presencia de los frutos. Su eliminación del brote al inicio de su crecimiento no modificó la concentración de estos azúcares en las hojas y en el floema respecto de la de los brotes que los mantuvieron hasta su recolección, tanto cuando se estudió en la panícula individual como en el árbol completo (Tabla 3.2). Por el contrario, el contenido de los azúcares de transporte fue alterado la modificar el número de frutos. Al despuntar las panículas en el estado $703 \mathrm{BBCH}$ del crecimiento del fruto, la concentración de sorbitol en el floema en la época de inducción floral fue de $48.8 \mathrm{mg} \mathrm{g}^{-1} \mathrm{~ms}$, significativamente más alta que la del floema de los brotes que habían soportado todos los frutos hasta la maduración, que fue de $40.3 \mathrm{mg}$ $\mathrm{g}^{-1} \mathrm{~ms}$ (Tabla 3.2). La concentración de sacarosa, aunque más alta ( $7.1 \mathrm{mg} \mathrm{g}^{-1} \mathrm{~ms}$ ) en los brotes despuntados que en los que mantuvieron sus frutos $\left(5.7 \mathrm{mg} \mathrm{g}^{-1} \mathrm{~ms}\right)$, no alcanzó la significación estadística. Sin embargo, la presencia de todos los frutos en el árbol hasta su recolección, no solo aumentó significativamente la concentración foliar de sorbitol en un $38.5 \%$ en el momento de la inducción floral, sino también la de sacarosa en un $22.2 \%$, respecto de la de los 
árboles a los que se les eliminaron todos los frutos al inicio de su crecimiento (estado 703 $\mathrm{BBCH}$ ). En términos absolutos, aquellos que mantuvieron toda su carga hasta la recolección presentaron, en la época de inducción floral, mayor concentración de ambos azúcares (61.7 $\mathrm{mg} \mathrm{g}^{-1} \mathrm{~ms}$ de sorbitol y $25.7 \mathrm{mg} \mathrm{g}^{-1} \mathrm{~ms}$ de sacarosa) que los árboles a los que se les eliminaron todos los frutos (48.0 $\mathrm{mg} \mathrm{g}^{-1} \mathrm{~ms}$ y $15.8 \mathrm{mg} \mathrm{g}^{-1} \mathrm{~ms}$, respectivamente) (Tabla 3.2). En el floema, mientras la concentración de sacarosa no se alteró por la presencia de los frutos $\left(4.7 \mathrm{mg} \mathrm{g}^{-1} \mathrm{~ms}\right.$ en los árboles con fruto y $3.4 \mathrm{mg} \mathrm{g}^{-1} \mathrm{~ms}$ en los árboles sin fruto), la de sorbitol aumentó significativamente en $36.1 \mathrm{mg} \mathrm{g}^{-1} \mathrm{~ms}$ en los árboles con fruto $\left(62.5 \mathrm{mg} \mathrm{g}^{-1} \mathrm{~ms}\right)$ en relación a los árboles sin fruto (26.4 $\mathrm{mg} \mathrm{g}^{-1} \mathrm{~ms}$ ) (Tabla 3.2). El almidón de reserva solo se determinó en las hojas, no encontrándose diferencias significativas debidas a la presencia del fruto (Tabla 3.2).

Debe destacarse la importancia cuantitativa del sorbitol frente a los otros tres azúcares, con independencia del que la descarga de los frutos fuera parcial (despuntado de panículas) o total (árboles sín frutos). Así, mientras en éste se alcanzaron valores máximos entre 50 y $60 \mathrm{mg} \mathrm{g}^{-1}$ $\mathrm{ms}$, en la sacarosa apenas se superaron los $25 \mathrm{mg} \mathrm{g}^{-1} \mathrm{~ms}$, en la glucosa los $14 \mathrm{mg} \mathrm{g}^{-1} \mathrm{~ms}$ y en la fructosa los $8 \mathrm{mg} \mathrm{g}^{-1} \mathrm{~ms}$. Esto refleja la importancia del sorbitol como principal azúcar de transporte en el níspero japonés.

Tabla 3.2.- Influencia de la eliminación de todos los frutos de una panícula (PANíCULA INDIVIDUAL) y del árbol (ÁRBOL COMPLETO) al inicio de su crecimiento (estado $703 \mathrm{BBCH}$ ) en comparación con su presencia hasta la recolección, sobre la concentración de carbohidratos reductores, de transporte y de reserva en las hojas y en el floema del níspero japonés Cv. 'Algerie', en el momento de la inducción floral. Cada valor es la media de cuatro árboles. Clave de tratamientos como en las Figs. 2.1, 2.7 y 2.16. Letras distintas en una misma columna indican diferencias significativas ( $P \leq 0.05)$. n.d: no determinado.

\begin{tabular}{|c|c|c|c|c|c|c|}
\hline & \multicolumn{6}{|c|}{ HOJAS } \\
\hline \multirow{5}{*}{ 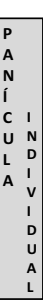 } & Tratamiento & Glucosa ( $\left.\mathrm{mg} \mathrm{g}^{-1} \mathrm{~ms}\right)$ & Fructosa $\left(\mathrm{mg} \mathrm{g}^{-1} \mathrm{~ms}\right)$ & Sacarosa $\left(\mathrm{mg} \mathrm{g}^{-1} \mathrm{~ms}\right)$ & Sorbitol ( $\left.\mathrm{mg} \mathrm{g}^{-1} \mathrm{~ms}\right)$ & Almidón $\left(\mathrm{mg} \mathrm{g}^{-1} \mathrm{~ms}\right)$ \\
\hline & Dsptd II & 6,1 & 5,8 & 6,4 & 32,0 & 18,5 \\
\hline & Cnt & 6,0 & 5,9 & 7,5 & 27,7 & 17,8 \\
\hline & \multicolumn{6}{|c|}{ FLOEMA } \\
\hline & Dsptd II & 10,2 & 8 & 7,1 & $48,8 \mathrm{~b}$ & n.d \\
\hline \multirow{7}{*}{ 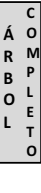 } & Cnt & 13,9 & 7,8 & 5,7 & $40,3 \mathrm{a}$ & n.d \\
\hline & \multicolumn{6}{|c|}{ HOJAS } \\
\hline & CF & 6,9 & 4,2 & $25,7 \mathrm{a}$ & $61,7 \mathrm{a}$ & n.d \\
\hline & SF & 7,3 & 4,3 & $15,8 \mathrm{~b}$ & $48,0 \mathrm{~b}$ & n.d \\
\hline & \multicolumn{6}{|c|}{ FLOEMA } \\
\hline & $\mathrm{CF}$ & 5,7 & 4,8 & 4,7 & 62,5 a & n.d \\
\hline & $S F$ & 4,6 & 4,6 & 3,4 & $26,4 \mathrm{~b}$ & n.d \\
\hline
\end{tabular}


En relación al metabolismo del $\mathrm{N}$, un resumen del contenido durante la inducción floral de las fracciones nitrogenadas en las hojas y en el floema de aquellos árboles que mantuvieron todos sus frutos hasta la recolección y de los que carecieron de todos ellos desde el inicio de su

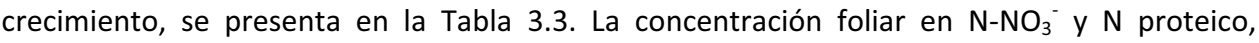
aunque ligeramente superior en los árboles sin frutos, no se alteró significativamente por la presencia de los frutos. La de $\mathrm{N}-\mathrm{NH}_{4}{ }^{+}$, por el contrario, fue un $94 \%$ superior en los árboles que no tuvieron frutos frente a los que los mantuvieron hasta la maduración. Como consecuencia de ello, la concentración de $\mathrm{N}_{-} \mathrm{NH}_{4}^{+}$en el floema de estos árboles también fue significativamente superior $\left(28.0 \mu \mathrm{g} \mathrm{g}^{-1} \mathrm{~ms}\right)$ a la de los árboles con frutos $\left(11.8 \mu \mathrm{g} \mathrm{g}^{-1} \mathrm{~ms}\right)$. Por tanto, la presencia del fruto alteró la concentración amoniacal en las hojas y floema de los árboles durante la inducción floral, reduciéndola significativamente (Tabla 3.3). A este respecto resulta interesante comparar la relación $\mathrm{N}_{-} \mathrm{NO}_{3}{ }^{-} / \mathrm{N}-\mathrm{NH}_{4}{ }^{+}$entre las hojas de ambos tipos de árboles. Mientras en los árboles sin fruto fue de 3.1, en los árboles con fruto fue de 45.0, lo que indica una disfunción en la actividad de reducción de los nitratos en los últimos.

Tabla 3.3.- Influencia de la presencia del fruto en el árbol sobre la concentración foliar y en el floema en el momento de la inducción floral de las distintas fracciones nitrogenadas en el níspero japonés cv. 'Algerie',. Cada valor es la media de cuatro árboles. CF: árboles que conservaron todos sus frutos hasta la maduración. SF: árboles a los que se les eliminaron los frutos en el estado 703 de la escala BBCH. Letras distintas en una misma columna indican diferencias significativas $(P \leq 0.05)$. n.d: no determinado.

\begin{tabular}{|c|c|c|c|}
\hline \multicolumn{4}{|c|}{ HOJAS } \\
\hline Tratamiento & $\mathbf{N}-\mathrm{NO}_{3}^{-}\left(\mu \mathrm{g} \mathrm{g}^{-1} \mathrm{~ms}\right)$ & $\mathbf{N}-\mathrm{NH}_{4}{ }^{+}\left(\mu \mathrm{g} \mathrm{g}^{-1} \mathrm{~ms}\right)$ & Nproteico $\left(\mathrm{mg} \mathrm{g}^{-1} \mathrm{~ms}\right)$ \\
\hline $\mathrm{CF}$ & 58,5 & $1,3 \mathrm{a}$ & 12,4 \\
\hline SF & 64,7 & $21,5 b$ & 13,0 \\
\hline \multicolumn{4}{|c|}{ FLOEMA } \\
\hline $\mathrm{CF}$ & n.a & $11,8 \mathrm{a}$ & 4,8 \\
\hline SF & n.a & $28,0 \mathrm{~b}$ & 4,9 \\
\hline
\end{tabular}

El balance hormonal de estos árboles en el momento de la inducción floral estuvo marcadamente alterado por la presencia de los frutos. Este efecto alcanzó a las tres hormonas estudiadas que vieron modificada de manera diferente su concentración en el floema. Así, la de AIA aumentó, significativamente, en un $10.6 \%$ en los árboles con frutos en relación a la de los árboles sin frutos, mientras que las de $A B A$ y Zeatina se redujeron, significativamente, en un $20.1 \%$ y $22.6 \%$, respectivamente (Tabla 3.4). Debe destacarse la mayor relación AIA/Zeatina en los árboles que mantuvieron todos los frutos hasta su maduración, 1.31, frente a la de los árboles sin frutos, 0.91 . Dado que este ratio se ha relacionado con la brotación de las yemas laterales, tanto mayor cuanto menor es dicho ratio, la menor brotación, y con ello la menor 
floración, de los árboles que conservaron todos los frutos en comparación con la de los árboles sin frutos queda de este modo explicada. La relación AIA/ABA sigue una tendencia similar, menor en los árboles sin frutos (1.41), con tendencia a una mayor intensidad de floración, que en los con frutos (1.60). La relación Zeatina/ABA, por el contrario, no mostró diferencia significativa entre los árboles $\sin (1.25)$ y con frutos (1.20).

Tabla 3.4.- Influencia de la presencia del fruto en el árbol sobre la concentración de AIA, ABA y Zeatina en el floema del níspero japonés cv. 'Algerie', en el momento de la inducción floral. Cada valor es la media de cuatro árboles. Clave de tratamientos como en la tabla 3.3. Letras distintas en una misma columna indican diferencias significativas $(P \leq 0.05)$.

\begin{tabular}{|c|c|c|c|}
\hline \multicolumn{4}{|c|}{ FLOEMA } \\
\hline Tratamiento & AIA $\left(\mathrm{ng} \mathrm{g}^{-1} \mathrm{~ms}\right)$ & ABA $\left(\mathrm{ng} \mathrm{g}^{-1} \mathrm{~ms}\right)$ & Zeatina $\left(\mathrm{ng} \mathrm{g}^{-1} \mathrm{~ms}\right)$ \\
\hline CF & $79.9 \mathrm{a}$ & $50,0 \mathrm{a}$ & $60,6 \mathrm{a}$ \\
SF & $71,4 \mathrm{~b}$ & $62,6 \mathrm{~b}$ & $78,3 \mathrm{~b}$ \\
\hline
\end{tabular}

Estas alteraciones en las concentraciones de AIA, ABA y Zeatina durante el periodo de inducción floral como consecuencia de la presencia del fruto (Tabla 3.4), unidas a la reducción del número total de flores en el árbol que éste provocó a partir del momento en que había completado prácticamente su crecimiento (Fig. 3.1 C) y con ello, el de sus semillas, abrió la puerta al estudio del control hormonal de la floración de esta especie. En efecto, los árboles con frutos partenocárpicos tuvieron en el momento de la antesis un $21.7 \%$ y $24.8 \%$ más de flores en sus panículas principales y anticipadas, respectivamente, que los árboles control de frutos con semillas (Fig. 3.2). Este efecto también alcanzó al número de brazos de las panículas que aumentó en un $18 \%$ en los primeros respecto a los segundos.

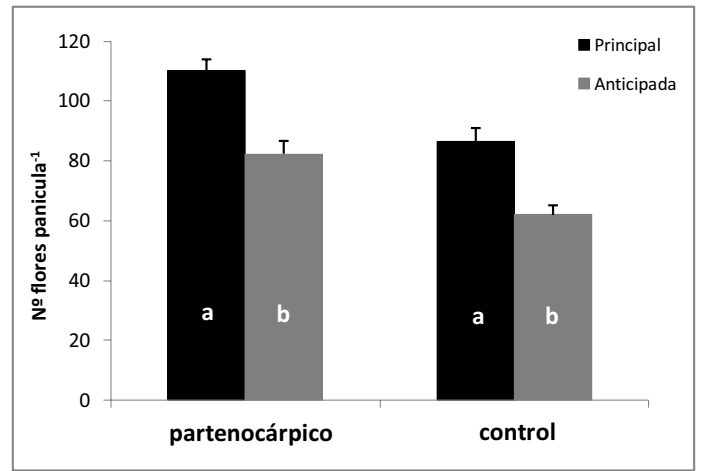

Fig. 3.2.- Influencia de la presencia (control) o ausencia de semillas en los frutos (partenocárpicos) sobre el número de flores de las panículas principales y anticipadas de los brotes mixtos de níspero japonés cv. 'Algerie'. Cada valor es la media de 20 brotes repartidos en cinco árboles. Las barras verticales indican el ES. Letras diferentes para la misma panícula indican diferencias significativas $(P \leq 0.05)$. 
A la vista de nuestros resultados, la existencia de una relación entre la capacidad de brotación de las yemas axilares, floración y acción del fruto era posible. Por otra parte, el conocimiento previo de la acción de las giberelinas sintetizadas en el embrión de las semilla (no analizadas en nuestro estudio) inhibiendo la brotación de las yemas laterales, aconsejaba el estudio de su utilización exógena con el fin de ligar brotación-floración-fruto. Es más, la posibilidad de que las giberelinas interfirieran directamente en la expresión de la floración de los meristemos terminales del brote principal y los brotes anticipados, aconsejaban asimismo su utilización como medio idóneo para el estudio del proceso.

La aplicación de ácido giberélico $(A G)$ redujo significativamente el número de panículas por árbol, si bien la respuesta dependió de la época en que se realizó y de su concentración. La aplicación de $150 \mathrm{mg} \mathrm{l}^{-1}$ de AG entre mediados de mayo y principios de junio, y entre principios de agosto y el inicio de la floración (mediados de septiembre) redujo significativamente entre un $40 \%$ y un $65 \%$ el número de panículas por $\mathrm{m}^{3}$ de copa respecto de los árboles sin tratar (Fig. 3.3). Los tratamientos realizados a principios de mayo y desde mediados de junio a mediados de julio, por el contrario, no lo redujeron y el número de panículas por $\mathrm{m}^{3}$ de copa fue prácticamente el mismo que en los controles (Fig. 3.3).

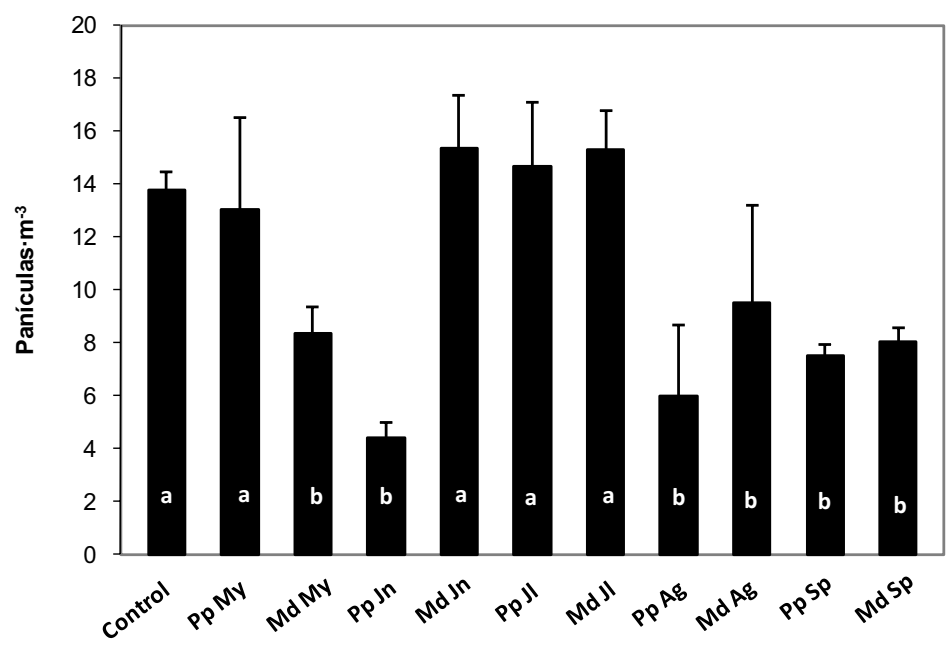

Fecha de aplicación de AG

FFig. 3.3.- Influencia del ácido giberélico $\left(150 \mathrm{mg} \Gamma^{1}\right)$ sobre la intensidad de floración del níspero japonés cv. 'Algerie'. Efecto de la época del tratamiento. Las barras verticales indican el error estándar. Valores expresados por $m^{3}$ de copa. Cada valor es la media de 6 árboles. Medias con letras distintas difieren

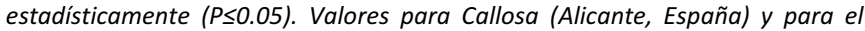
año 2007. Pp: principios; Md: mediados; Jn: Junio; Jl: Julio; Ag: Agosto; Sp: Septiembre. 
Cincuenta $\mathrm{mg} \mathrm{I}^{-1}$ de AG aplicados a principios de septiembre también redujeron en un $45 \%$ el número de panículas por $\mathrm{m}^{3}$ de copa en comparación con los controles, alcanzando, también en este caso, la significación estadística (Fig. 3.4). Es más, el incremento de la concentración hasta $200 \mathrm{mg} \mathrm{I}^{-1}$ no mejoró los resultados, estableciéndose, por tanto, $50 \mathrm{mg} \mathrm{I}^{-1}$ como la concentración idónea para reducir la floración en esta especie. Una respuesta similar se obtuvo cuando el AG se aplicó a principios de junio a esta misma concentración (datos no presentados).

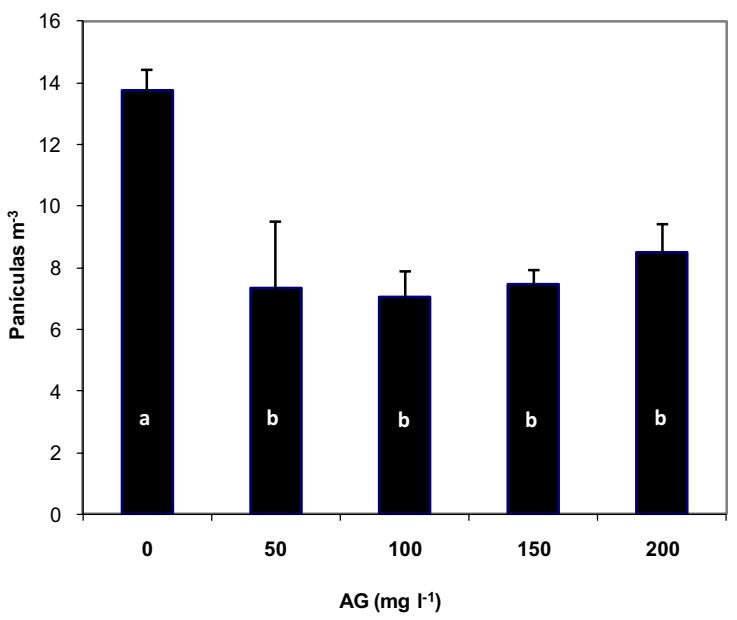

Fig. 3.4.- Efecto de la concentración de ácido giberélico sobre la intensidad de floración del níspero japonés cv. 'Algerie'. Los tratamientos se realizaron 4 meses después de la brotación (principios de septiembre). Las barras verticales indican el error esandar. Valores expresados por $\mathrm{m}^{3}$ de copa. Cada valor es la media de 6 árboles. Medias con letras distintas difieren estadísticamente $(P \leq 0.05)$. Valores para Callosa (Alicante, España) y 2007.

Cuando esta concentración de $A G, 50 \mathrm{mg} \mathrm{I}^{-1}$, se aplicó indistintamente a principios de junio o de septiembre, el número de panículas por $\mathrm{m}^{3}$ siempre se redujo, por término medio, entre un $40 \%$ y un $60 \%$, y, como consecuencia de ello, la floración lo hizo entre un $30 \%$ y un $70 \%$ (Tabla 3.5). Esta respuesta fue independiente de la zona de cultivo, del cultivar y del año. No obstante, ni el número de flores por panícula ni el de hojas por brote fue modificado significativamente por acción del AG (Tabla 3.5). Las características morfológicas de la panícula, es decir, el tamaño, la forma, y el número de racimos, tampoco fueron alteradas por el AG (datos no presentados). La reducción de la brotación, sin embargo, fue suficiente para reducir significativamente la floración, siendo la intensidad de la respuesta variable con la zona y el año (Tabla 3.5). 
Tabla 3.5. Efecto del ácido giberélico $\left(50 \mathrm{mg} \mathrm{I}^{1}\right.$ ) aplicado en las dos épocas de sensibilidad (principios de juni, Pp.Jn, y principios de septiembre, Pp.Sp), sobre el número total de panículas desarrolladas por $\mathrm{m}^{-3}$, número de flores y hojas por panícula, y sobre el porcentaje de inhibición de la floración en el níspero japonés cvs. 'Algerie' y 'San Filipparo' cultivados en Callosa d'En Sarriá (Alicante, España) y Palermo (Sicilia, Italia). Valores correspondientes a los años 2007 y 2008. Cada valor es la media de seis árboles.

\begin{tabular}{|c|c|c|c|c|c|c|c|}
\hline Cv & $\begin{array}{l}\text { Area de } \\
\text { cultivo }\end{array}$ & Fecha de tratamiento & $\begin{array}{l}\text { Concent. } \\
\left(\mathrm{mg} \mathrm{l}^{-1}\right)\end{array}$ & Panículas $\mathrm{m}^{-3}$ & Flores panícula $^{-1}$ & Hojas panícula ${ }^{-1}$ & Inhibición (\%) \\
\hline \multirow[t]{9}{*}{ Algerie } & Callosa & --- & 0 & $13.8 \pm 0,7 \mathrm{a}$ & $113.4 \pm 3.1$ & $8,4 \pm 1.0$ & --- \\
\hline & & 2007 Pp. Jn & 50 & $8.4 \pm 1.0 \mathrm{~b}$ & $114.7 \pm 1.1$ & $7.9 \pm 0.3$ & 39.1 \\
\hline & & 2007 Pp. Sp & 50 & $7.3 \pm 0.2 b$ & $116.6 \pm 7.3$ & $9.9 \pm 1.0$ & 40.8 \\
\hline & Palermo & --- & 0 & $8.4 \pm 0.1 \mathrm{a}$ & $81.4 \pm 5.2$ & $8.2 \pm 0.3$ & --- \\
\hline & & 2007 Pp. Jn & 50 & $3.8 \pm 0.1 b$ & $75.8 \pm 3.2$ & $6.2 \pm 0.4$ & 70.2 \\
\hline & & 2007 Pp. Sp & 50 & $3.7 \pm 0.4 b$ & $60.1 \pm 3.6$ & $6.6 \pm 0.4$ & 68.6 \\
\hline & Callosa & --- & 0 & $7.8 \pm 0.5 a$ & $126.4 \pm 9.5$ & $8.3 \pm 3.5$ & --- \\
\hline & & 2008 Pp. Jn & 50 & $4.7 \pm 0.4 b$ & $116.5 \pm 9.2$ & $8.6 \pm 3.1$ & 29.4 \\
\hline & & 2008 Pp. Sp & 50 & $5.7 \pm 0.3 b$ & $111.0 \pm 6.3$ & $9.2 \pm 4.1$ & 31.9 \\
\hline \multirow[t]{3}{*}{ San Filipparo } & Palermo & --- & 0 & $6.1 \pm 0.3 \mathrm{a}$ & $70.5 \pm 3.8$ & $7.0 \pm 0.5$ & --- \\
\hline & & 2008 Pp. Jn & 50 & $3.6 \pm 0.2 b$ & $78.6 \pm 3.2$ & $8.3 \pm 3.5$ & 33.9 \\
\hline & & 2008 Pp. Sp & 50 & $3.2 \pm 0.1 b$ & $82.1 \pm 3.0$ & $7.9 \pm 0.4$ & 36.3 \\
\hline
\end{tabular}

${ }^{z}$ Porcentaje de inhibición del total de flores $\mathrm{m}^{-3}$

Medias con letras distintas en el mismo campo son significativamente distintas $(P \leq 0.05$.)

Cuando el AG se aplicó directamente al ápice en crecimiento, en lugar de al árbol completo, en la época de diferenciación floral (principios de septiembre), el número de flores por panícula se redujo significativamente en un $25 \%$ - $35 \%$ por término medio. Sin embargo, todos los ápices tratados se diferenciaron en una panícula de flores cuando se aplicaron entre 100 y $250 \mathrm{mg} \mathrm{I}^{-1}$, independientemente del año del tratamiento (Tabla 3.6). Con $50 \mathrm{mg} \mathrm{I}^{-1}$ de AG también se redujeron significativamente el número de flores por panícula y su respuesta fue intermedia entre los controles y las concentraciones más altas, como $250 \mathrm{mg} \mathrm{I}^{-1}$, que las redujo hasta en un $50 \%$, aproximadamente (Tabla 3.6). Una respuesta similar se obtuvo para los tratamientos efectuados a principios de junio (datos no presentados). 
Tabla 3.6.- Efecto de la concentración de ácido giberélico aplicado localmente al ápice de níspero japonés cv.'Algerie', próximo a su diferenciación floral (principios de septiembre), sobre el número de flores de su panícula en el momento de la antesis. Cada ápice recibió $5 \mathrm{ml}$ de una solución de AG a la concentración indicada. Valores correspondientes a tres años de estudio en Callosa d'En Sarriá (Alicante, España). Cada valor es la media de 15 panículas por árbol y 5 árboles. Medias con letras distintas en el mismo campo son significativamente distintas $(P \leq 0.05)$.

\begin{tabular}{cccc}
\hline Concentración & $\mathbf{2 0 0 5}$ & $\mathbf{2 0 0 6}$ & $\mathbf{2 0 0 8}$ \\
\hline 0 & $100.2 \pm 9.2 \mathrm{a}$ & $133.9 \pm 12.6 \mathrm{a}$ & $129.6 \pm 15.2 \mathrm{a}$ \\
50 & & $100.3 \pm 11.1 \mathrm{~b}$ \\
100 & & $86.9 \pm 3.5 \mathrm{bc}$ \\
150 & & $82.0 \pm 5.0 \mathrm{bc}$ \\
200 & $66.4 \pm 3.8 \mathrm{~b}$ & & $80.6 \pm 4.6 \mathrm{bc}$ \\
250 & & $68.6 \pm 4.0 \mathrm{c}$ \\
\hline
\end{tabular}

Cincuenta $\mathrm{mg} \mathrm{I}^{-1}$ de AG aplicados al árbol completo también redujeron significativamente el número de brotes anticipados, tanto por brote como por $\mathrm{m}^{3}$ de copa, independientemente de la época del tratamiento (principios de junio o principios de septiembre), área de cultivo, y cultivar (Tabla 3.7). Dado que los brotes anticipados siempre desarrollan una panícula, la reducción de su número por acción del AG redujo, consecuentemente, el número total de panículas por $\mathrm{m}^{3}$ de copa. Concentraciones más elevadas, hasta $200 \mathrm{mg} \mathrm{l}^{-1}$, provocaron resultados similares (datos no presentados). Esta reducción del número total de panículas por $\mathrm{m}^{3}$ de copa explica la reducción de la floración presentada en la Tabla 3.5 que, como consecuencia, redujo el tiempo de aclareo de 17.3 min por operario en los árboles control a 6.5 y $6.1 \mathrm{~min}$ en los tratados con $50 \mathrm{mg} \mathrm{l}^{-1}$ a principios de junio y principios de septiembre, respectivamente. La reducción del número de flores correlacionó negativa y significativamente con el aumento, también estadísticamente significativo, del porcentaje de flores cuajadas ( $r=$ 0.566, P $\leq$ 0.01). Este incremento del cuajado compensó, por otra parte, la reducción de la floración, de modo que la cosecha $\left(\mathrm{Kg} \mathrm{tree}^{-1}\right)(\mathrm{r}=+0.157)$ y el peso medio final del fruto $(\mathrm{g})(\mathrm{r}=$ +0.290 ) aumentaron, pero sin alcanzar la significación estadística. 
Tabla 3.7.- Efecto de $50 \mathrm{mg} \Gamma^{1}$ de ácido giberélico aplicados en las dos épocas de sensibilidad sobre el número de brotes anticipados (PA) y panículas del año (PP) en el níspero japonés cvs. 'Algerie' y 'San Filipparo 'cultivados en Callosa d'En Sarriá (Alicante, España) y Palermo (Sicilia, Italia) . Valores para 2008. Cada valor es la media de seis árboles. Medias seguidas de letras diferentes en la misma línea de una misma variedad son estadísticamente diferentes $(P \leq 0.05)$.

\begin{tabular}{|c|c|c|c|c|c|c|c|c|c|}
\hline & \multicolumn{6}{|c|}{ Palermo } & \multirow{2}{*}{\multicolumn{3}{|c|}{$\begin{array}{l}\text { Callosa } \\
\text { 'Algerie' }\end{array}$}} \\
\hline & \multicolumn{3}{|c|}{ 'Algerie' } & \multicolumn{3}{|c|}{ 'San Filipparo' } & & & \\
\hline & Control & Pp. Jn & Pp. Sp & Control & Pp. Jn & Pp. Sp & Control & Pp. Jn & Pp. Sp \\
\hline PA.brote ${ }^{-1}$ & $1.4 \pm 0.2 \mathrm{a}$ & $0.8 \pm 0.1 \mathrm{~b}$ & $0.8 \pm 0.1 \mathrm{~b}$ & $1.3 \pm 0.2 \mathrm{a}$ & $0.7 \pm 0.1 \mathrm{~b}$ & $0.8 \pm 0.2 b$ & $1.6 \pm 0.0 \mathrm{a}$ & $0.4 \pm 0.1 \mathrm{~b}$ & $0.5 \pm 0.1 \mathrm{~b}$ \\
\hline$P A \cdot m^{-3}$ & $4.8 \pm 0.0 \mathrm{a}$ & $1.7 \pm 0.0 \mathrm{~b}$ & $1.6 \pm 0.0 \mathrm{~b}$ & $3.4 \pm 0.1 \mathrm{a}$ & $1.5 \pm 0.0 \mathrm{~b}$ & $1.0 \pm 0.0 \mathrm{~b}$ & $20.9 \pm 1.6 \mathrm{a}$ & $7.6 \pm 1.9 \mathrm{~b}$ & $7.6 \pm 1.6 \mathrm{~b}$ \\
\hline$P P \cdot m^{-3}$ & $3.4 \pm 0.0$ & $2.0 \pm 0.0$ & $2.0 \pm 0.0$ & $2.6 \pm 0.1$ & $2.0 \pm 0.1$ & $2.1 \pm 0.0$ & $12.6 \pm 0.8 \mathrm{a}$ & $19.0 \pm 2.4$ & $19.3 \pm 3.7$ \\
\hline
\end{tabular}

El número de brotes vegetativos por $\mathrm{m}^{3}$ de copa también se vio reducido por la aplicación de 50 ó $150 \mathrm{mg} \mathrm{l}^{-1}$ de AG a principios de junio y principios de septiembre. La reducción, en este caso, fue del 30\%-40\%, con independencia de la época de aplicación y de la concentración (Fig. 3.5).

Brotes vegetativos $\mathrm{m}^{-3}$

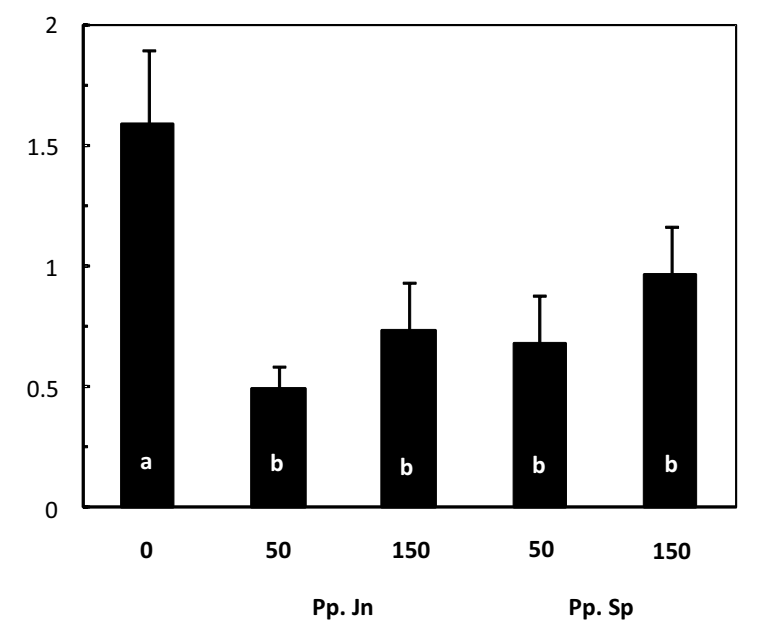

AG $\left(\mathrm{mg} \cdot \mathrm{l}^{-1}\right)$ y fecha de tratamiento
Fig. 3.5.- Efecto de la concentración y época de aplicación del ácido giberélico sobre el desarrollo de brotes vegetativos en el níspero japonés cv. 'Algerie' (Callosa d 'En Sarriá, Alicante, España). Las barras verticales indican el error estándar. Valores expresados por $\mathrm{m}^{3}$ de copa. Cada valor es la media de 6 árboles. Medias con letras distintas difieren estadísticamente $(P \leq 0.05)$. Valores para 2007. 
Las características de los frutos apenas se vieron alteradas por los tratamientos en el momento de su recolección. Así, mientras la resistencia al punzamiento y la concentración de SST prácticamente no se modificaron, la acidez del zumo se redujo significativamente y el color del fruto, aunque mejoró por acción de los tratamientos, no alcanzó la significación estadística (datos no presentados). También el diámetro medio aumentó hasta un $4 \%$ ( $45.6 \mathrm{~mm}$ ) para el mejor de los tratamientos, con respecto a los controles $(43.9 \mathrm{~mm})$, pero sin alcanzar tampoco la significación estadística. Dado que el tamaño del fruto, su color y la maduración de la pulpa son los factores determinantes en la decisión del momento de la recolección, su mejora, aunque escasa, permitió anticiparla ligeramente.

De acuerdo con lo previsto, por tanto, el efecto global del AG sobre la inhibición de la floración de esta especie pone de manifiesto la regulación hormonal del proceso, así como el de la brotación de sus yemas. Para una mejor demostración de ésta, se eliminaron completamente los ápices indiferenciados de los brotes, en las dos épocas en que éstos fueron más sensibles a la acción del AG, a principios de junio y a finales de agosto (ver Fig. 3.3), y de los brotes anticipados que se iniciaron como consecuencia de ello se evaluó el número de los que desarrollaron una panícula con flores. Con independencia de las condiciones del campo, de la zona de cultivo y de la variedad estudiada, el despunte de los ápices del cv. 'Algerie' en junio y en Callosa, provocó que el 7.7\% de sus brotes quedaran indiferenciados como vegetativos; pero cuando éstos mismos se despuntaron en agosto este porcentaje aumentó significativamente hasta el $90.8 \%$. Por el contrario, la permanencia del ápice en el brote hasta la antesis de sus flores, consiguió que prácticamente todos ellos se diferenciaran en una panícula y, por lo tanto, el $100 \%$ de sus brotes anticipados fueran reproductivos (Tabla 3.8). Aunque este comportamiento se presentó de manera generalizada en todos nuestros experimentos, las diferencias cuantitativas entre variedades y zonas se pueden atribuir a cambios de sensibilidad y adaptación varietal. En cualquier caso, la eliminación del ápice del brote principal durante la época de inducción floral y en etapas próximas a su diferenciación, aumentó significativamente el número de brotes vegetativos respecto de los controles, hasta 80 veces mayor en el segundo caso, como consecuencia de la indiferenciación de sus yemas (Tabla 3.8). Resulta interesante destacar la localización de estos brotes. En los controles, el ápice del brote principal siempre diferencia una panícula, la principal, y las yemas axilares que brotan anticipadamente lo hacen a partir de su mitad basal formando, de esta manera, un brote anticipado que también siempre desarrolla una panícula, por tanto, anticipada, tal como se vio en el capítulo de la brotación. En los brotes despuntados, por el contrario, no todas las yemas axilares que brotaron anticipadamente dieron lugar a una panícula, por tanto, 
anticipada. En efecto, en éstos las yemas que brotaron fueron siempre las más próximas a la zona del corte y ello significa que cuando el ápice se eliminó en junio las que brotaron eran yemas que acababan de ser inducidas a florecer y dieron lugar a brotes anticipados con panícula al menos en un $50 \%$ de los casos (Tabla 3.8), mientras que cuando la eliminación del ápice se hizo en agosto las que brotaron (las más próximas al corte) eran yemas que en junio (en época de inducción floral) no estaban presentes y, por tanto, no pudieron ser inducidas a florecer y por eso desarrollaron brotes vegetativos (Tabla 3.8). Es más, la señal inductiva que había recibido el ápice terminal, eliminado, no se transmitió a las yemas axilares más próximas. Las yemas que habían sido inducidas, y que estaban situadas en posiciones más basales, no brotaron. Este efecto también alcanzó al crecimiento de los brotes principales que se detuvo como consecuencia de la eliminación de sus ápices. A ello se deben las diferencias encontradas en el número de hojas de sus brotes, entre un $39 \%$ y $25.8 \%$ mayor en los brotes principales de los controles que en los que se había eliminado el ápice en junio o agosto, cuando éstos medían 7 y $20 \mathrm{~cm}$, respectivamente (Tabla 3.8).

Tabla 3.8.- Efecto de la presencia de los ápices en los brotes principales (Control) o de su eliminación durante la inducción floral (Dsptd Jn) y en etapas próximas a su diferenciación floral (Dsptd Ag), sobre la naturaleza de los brotes anticipados de níspero japonés de diferentes cvs, campos y zonas de cultivo, en el momento de la antesis. Cada valor es la media de 25 brotes repartidos en cinco árboles. Porcentajes calculados como la suma de los correspondientes brotes dividido por su número total y multiplicado por 100.Letras distintas en una misma columna indican diferencias estadísticas $(P \leq 0.05)$.

\begin{tabular}{|c|c|c|c|c|c|c|}
\hline Campo & Zona & Cultivar & Tratamiento & \%Brotes vegetativos & \%Brotes reproductivos & № Hojas brote ppal \\
\hline Callosa & Callosa & Algerie & $\begin{array}{l}\text { Control } \\
\text { Dspt Jn } \\
\text { Dspt Ag }\end{array}$ & $\begin{array}{c}0,0 \mathrm{a} \\
7,7 \mathrm{~b} \\
90,8 \mathrm{c}\end{array}$ & $\begin{array}{c}100 \mathrm{a} \\
92,3 \mathrm{a} \\
9,2 \mathrm{~b}\end{array}$ & $\begin{array}{c}12,8 \mathrm{a} \\
7,8 \mathrm{~b} \\
9,5 \mathrm{~b}\end{array}$ \\
\hline Callosa & Callosa & Golden & $\begin{array}{l}\text { Control } \\
\text { Dspt Jn } \\
\text { Dspt Ag } \\
\end{array}$ & $\begin{array}{c}0,0 \mathrm{a} \\
21,2 \mathrm{~b} \\
100 \mathrm{c}\end{array}$ & $\begin{array}{c}100 \mathrm{a} \\
78,7 \mathrm{~b} \\
0,0 \mathrm{c}\end{array}$ & $\begin{array}{c}12,5 \mathrm{a} \\
5,9 \mathrm{~b} \\
7,7 \mathrm{~b}\end{array}$ \\
\hline Castelvetrano & Trapani & Algerie & $\begin{array}{l}\text { Control } \\
\text { Dspt Jn } \\
\text { Dspt Ag }\end{array}$ & $\begin{array}{l}18,9 \mathrm{a} \\
79,2 \mathrm{~b} \\
94,1 \mathrm{c}\end{array}$ & $\begin{array}{c}81 \mathrm{a} \\
20,8 \mathrm{~b} \\
5,9 \mathrm{c}\end{array}$ & $\begin{array}{l}8,5 \mathrm{a} \\
5,6 \mathrm{~b} \\
8,4 \mathrm{a} \\
\end{array}$ \\
\hline Castelvetrano & Trapani & S. Filipparo & $\begin{array}{l}\text { Control } \\
\text { Dspt Jn } \\
\text { Dspt Ag }\end{array}$ & $\begin{array}{c}0,0 \mathrm{a} \\
66,7 \mathrm{~b} \\
88,9 \mathrm{c}\end{array}$ & $\begin{array}{l}100 \mathrm{a} \\
33,3 \mathrm{~b} \\
11,1 \mathrm{c}\end{array}$ & $\begin{array}{c}9,1 \mathrm{a} \\
5,9 \mathrm{~b} \\
10,7 \mathrm{a}\end{array}$ \\
\hline S. Maria Gesu & Palermo & Algerie & $\begin{array}{l}\text { Control } \\
\text { Dspt Jn } \\
\text { Dspt Ag }\end{array}$ & $\begin{array}{c}0,0 \mathrm{a} \\
30,7 \mathrm{~b} \\
94,6 \mathrm{c}\end{array}$ & $\begin{array}{c}100 \mathrm{a} \\
69,3 \mathrm{~b} \\
5,4 \mathrm{c}\end{array}$ & $\begin{array}{c}6,4 \mathrm{a} \\
7,6 \mathrm{a} \\
10,2 \mathrm{~b}\end{array}$ \\
\hline S. Maria Gesu & Palermo & S. Filipparo & $\begin{array}{l}\text { Control } \\
\text { Dspt Jn } \\
\text { Dspt Ag }\end{array}$ & $\begin{array}{c}2,9 \mathrm{a} \\
56,7 \mathrm{~b} \\
100 \mathrm{c}\end{array}$ & $\begin{array}{c}97,1 \mathrm{a} \\
43,3 \mathrm{~b} \\
0,0 \mathrm{c}\end{array}$ & $\begin{array}{c}11,0 \mathrm{a} \\
7,2 \mathrm{~b} \\
8,0 \mathrm{~b}\end{array}$ \\
\hline
\end{tabular}

El contenido hormonal de los nuevos brotes, vegetativos y reproductivos (determinados porque su ápice terminal engrosaba ligeramente), inmediatamente antes de completarse la diferenciación floral de los segundos (estado 500 de la escala $\mathrm{BBCH}$ ), se vio alterado por la 
época en que se eliminó el ápice principal. Así, cuando éste se eliminó en junio, la concentración de $\mathrm{ABA}$ en el floema de los nuevos brotes vegetativos fue el doble que la de los reproductivos (Fig. 3.6 A). Sin embargo, la concentración de esta hormona en sus correspondientes ápices fue justo lo contrario. Los ápices ya diferenciados, pero todavía sin flores, presentaron una concentración de ABA significativamente superior, $180.2 \mathrm{ng} \mathrm{g}^{-1} \mathrm{~ms}$, a la de los ápices vegetativos y, por tanto, indiferenciados que, para la misma fecha, apenas era de $33.5 \mathrm{ng} \mathrm{g}^{-1} \mathrm{~ms}$ (Fig. 3.6 B). Un retraso en la eliminación de los ápices principales, hasta 2 meses después (agosto), modificó significativamente el contenido floemático de ABA de estos brotes. Por una parte, el floema de los brotes con ápices reproductivos incrementó espectacularmente su concentración de $\mathrm{ABA}$, hasta en un $94.5 \%$, respecto a la que tenía en junio y, como consecuencia de ello, en fechas próximas a completar su diferenciación, ésta fue significativamente superior ( $16.7 \mathrm{ng} \mathrm{g}^{-1} \mathrm{~ms}$ ) a la de los brotes vegetativos (9.1 $\left.\mathrm{ng} \mathrm{g}^{-1} \mathrm{~ms}\right)$ que sólo consiguieron incrementarla en un 75\% (Fig. 3.6). En el propio ápice eliminado en esta época (agosto) la concentración de ABA fue la misma estuviera o no diferenciado. En cualquier caso, la concentración de esta hormona siempre fue cuantitativamente más importante en los ápices que en el floema de estos brotes, de manera que los valores mínimos alcanzados por los primeros fueron hasta el doble de los máximos alcanzados por los segundos.
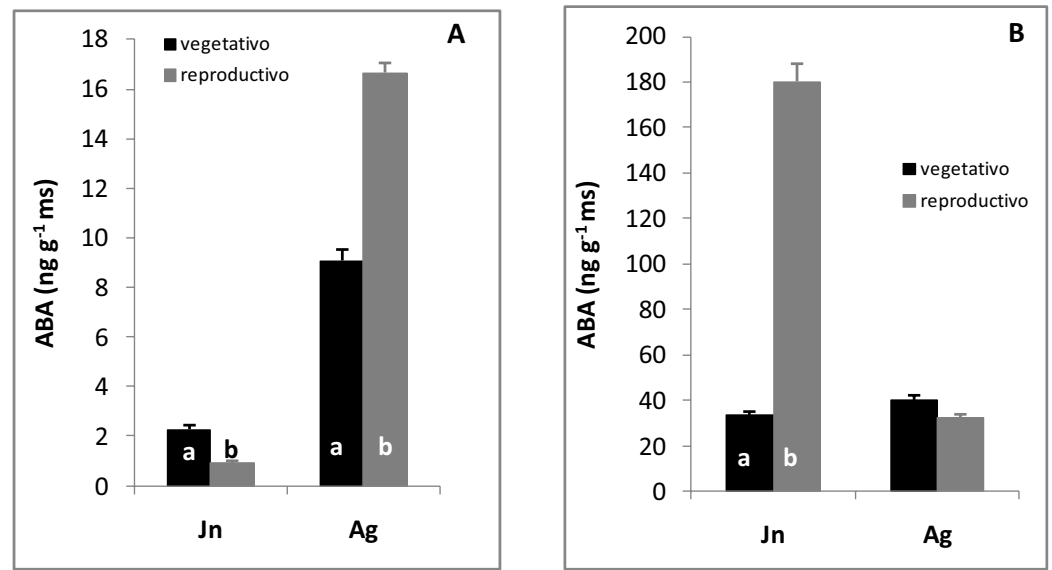

Fig. 3.6.- Efecto de la época de eliminación de los ápices principales de los brotes mixtos de níspero japonés cv. 'Algerie' en la concentración de ABA del floema de los nuevos brotes vegetativos y reproductivos (A) y en la de sus correspondientes ápices (B), inmediatamente antes de completarse la diferenciación floral. Las barras verticales indican el error estándar. Cada valor es la media de 5 brotes repartidos en cinco árboles. Letras distintas para una misma época difieren

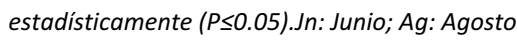


Algo parecido ocurrió al estudiar el contenido de AIA en estos mismos brotes, de modo que la respuesta a la eliminación de los ápices principales en la primera fecha (junio) fue idéntica a la obtenida para el ABA. La concentración de AIA en el floema de los brotes vegetativos fue superior a la de los reproductivos, inmediatamente antes de que se formaran las flores en estos últimos, sólo que en este caso no se llegó a la significación estadística (Fig. 3.7 A). Pero la concentración en los ápices diferenciados fue casi 4 veces superior $\left(274.5 \mathrm{ng} \mathrm{g}^{-1}\right.$ ms) que en la de los vegetativos (74.2 $\mathrm{ng} \mathrm{g}^{-1} \mathrm{~ms}$ ) (Fig. $3.7 \mathrm{~B}$ ). El retraso en el despunte de los ápices principales hasta etapas próximas a su diferenciación (agosto), provocó, contrariamente a lo obtenido para el ABA, que la concentración de AIA en el floema de los nuevos brotes vegetativos tuviera 3.3 $\mathrm{ng} \mathrm{\textrm {g } ^ { - 1 }}$ ms más que la de los reproductivos, inmediatamente antes de que éstos completaran la formación de su inflorescencia (Fig. 3.7 A). También en este momento, sus correspondientes ápices vegetativos tuvieron un $30 \%$ más de AIA que los reproductivos (Fig. 3.7 B). Queda clara, por tanto, la respuesta diferencial encontrada en el floema y en los ápices de ambos tipos de brotes. Así, mientras en el floema de ambos brotes, vegetativos y reproductivos, la concentración de AIA aumentó significativamente un $73.6 \%$ y un $74.3 \%$, respectivamente, de efectuarse la eliminación del ápice principal en junio a hacerlo en agosto, la de sus correspondientes ápices, por el contrario, descendió, sobre todo en los reproductivos hasta cerca de un 85\% (Fig. 3.7). Como ya ocurrió con el $\mathrm{ABA}$, debe destacarse la mayor importancia cuantitativa del AIA en los ápices frente al floema de ambos tipos de brotes. Así, mientras en los primeros se alcanzaron valores máximos de hasta $274.5 \mathrm{ng} \mathrm{g}^{-1} \mathrm{~ms}$, en el floema nunca se superaron los $13 \mathrm{ng} \mathrm{g}^{-1} \mathrm{~ms}$ (Fig.3.7).
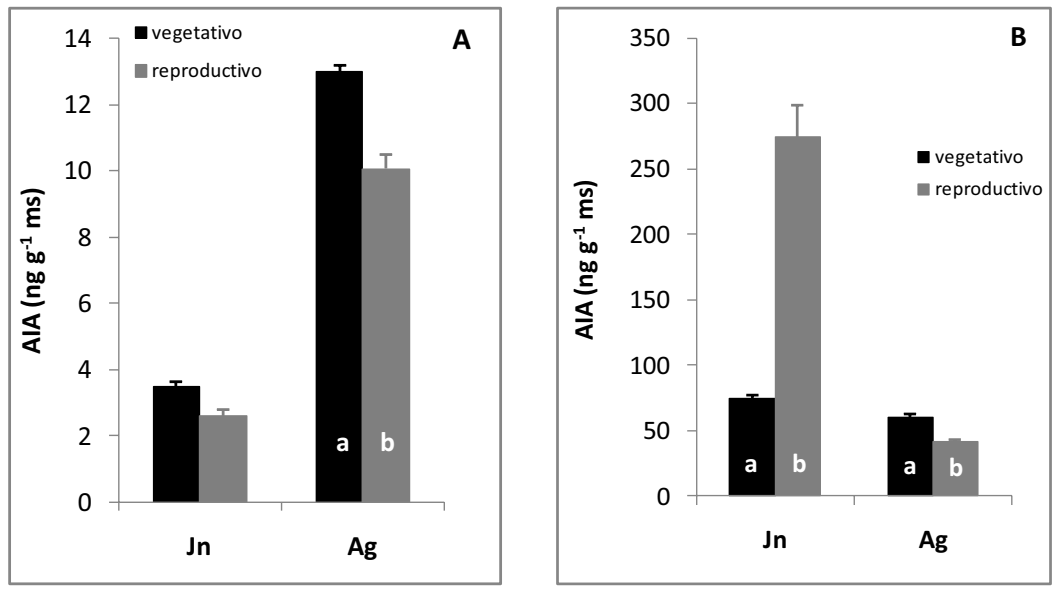

Fig. 3.7.- Efecto de la época de eliminación de los ápices principales de los brotes mixtos de níspero japonés cv. 'Algerie', en la concentración de AIA del floema de los nuevos brotes vegetativos y reproductivos (A) y de la de sus correspondientes ápices (B), inmediatamente antes de completarse la diferenciación floral. Las barras verticales indican el error estándar. Cada valor es la media de 5 brotes repartidos en cinco árboles. Letras distintas

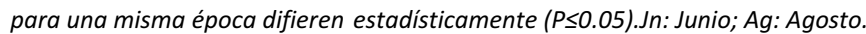




\section{El control del fruto sobre su propio desarrollo.}

La comparación del desarrollo de un fruto partenocárpico y un fruto con semillas del cv. 'Algerie' revela el menor peso final que alcanza el primero respecto del segundo (Fig. 4.1 A). En nuestros experimentos, mientras los frutos partenocárpicos apenas superaron los $22 \mathrm{~g}$ al final del periodo de desarrollo, los frutos con semillas alcanzaron los $59 \mathrm{~g}$. La comparación evidenció, además, diferencias básicas entre sí. Tanto la acumulación de materia seca (Fig. 4.1 B) como de agua (Fig. 4.1 C) fue significativamente menor en el primero a partir de principios de marzo (estadio 704 de la escala fenológica BBCH), y persistió hasta finales de abril (estado 709 de la escala $\mathrm{BBCH})$.
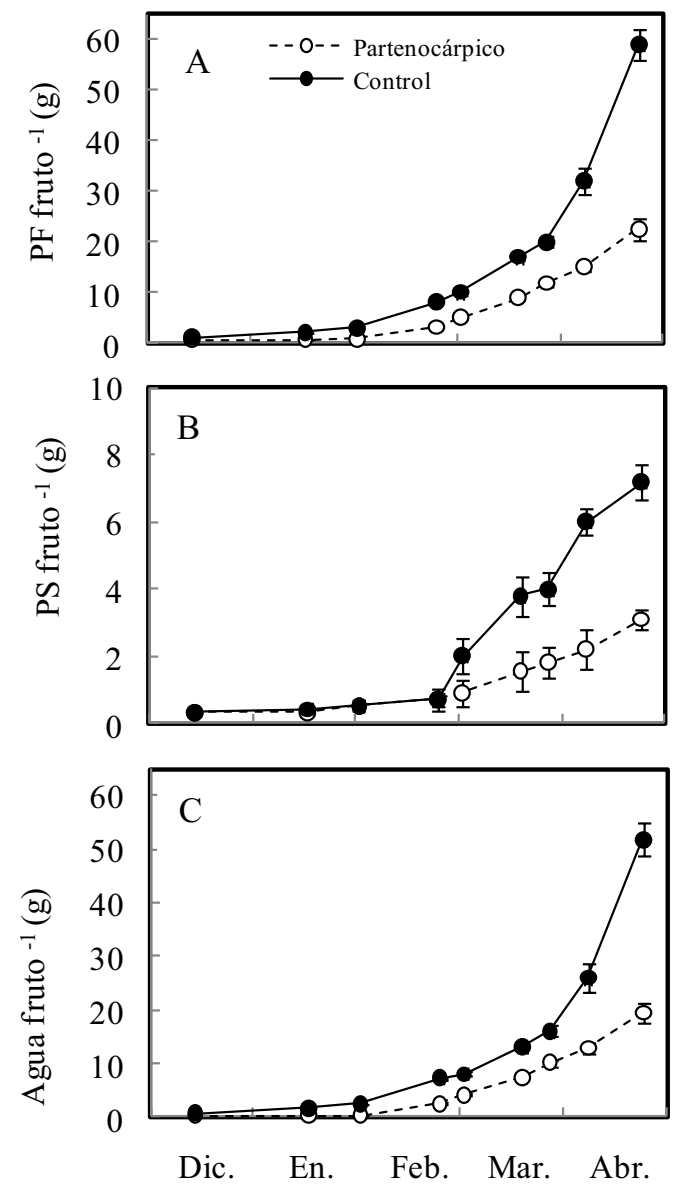

Fig. 4.1.- Desarrollo de un fruto partenocárpico de níspero japonés cv. 'Algerie' en comparación con un fruto con semillas. Valores para 2009. Cada valor es la media de 10 frutos y 5 árboles. Las barras verticales indican el error estándar. 
La comparación de estas curvas de desarrollo indica, por una parte, la dependencia que tiene el peso final que puede adquirir el fruto de su capacidad de absorción de agua que, por otra parte, está parcialmente determinada por el peso seco, esto es, por la capacidad sumidero del fruto. Dado que ésta depende de un control hormonal y la diferencia crucial entre ambos tipos de fruto es la presencia de semillas, es en éstas en las que queda demostrado, al menos indirectamente, que radica la capacidad hormonal del desarrollo del fruto.

A ello contribuye el hecho de la ausencia de una relación significativa entre el número de frutos por árbol y el peso fresco medio individual que adquieren (Fig. 4.2). En efecto, todos los frutos poseen, por término medio, el mismo número de semillas $y$, por tanto, la misma capacidad sumidero de atraer nutrientes, de ahí que para un rango tan amplio de número de frutos por árbol como 1000 - 3000, la relación entre éste y su peso individual (g) se hallen relacionados mediante una función lineal sin apenas pendiente $\left(\mathrm{m}=-3.9 \times 10^{-3}\right)$ y un coeficiente de variación no significativo $\left(R^{2}=0.142\right)$.

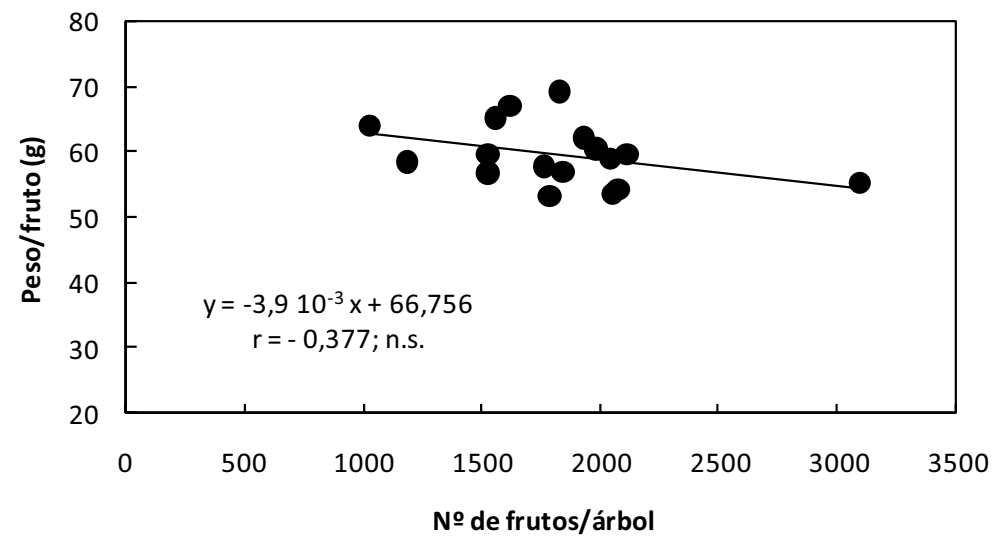

Fig. 4.2.- Relación entre el número de frutos por árbol y su peso individual en el níspero japonés cv. 'Algerie'. El peso medio de los frutos es el de 5 árboles y 25 frutos por árbol seleccionados al azar.

Sin embargo, la misma relación para el número de frutos por panícula es negativa y estadísticamente significativa (Fig. 4.3). En efecto, en panículas aclaradas manualmente desde 1 a 12 frutos, el peso medio individual de éstos y el número de frutos por panícula se correlacionan negativa y significativamente según una función potencial, lo que indica que el crecimiento del fruto además de poseer un control hormonal está regulado nutricionalmente. El hecho de que el aclareo manual no altere el número de semillas por fruto pero sí el tamaño de éste (Tabla 4.1), así lo ratifica. A ello contribuye la autonomía de los brotes que soportan las 
panículas con un número de hojas suficiente para desarrollar sus frutos sin necesidad de requerir carbohidratos de otras partes del árbol.

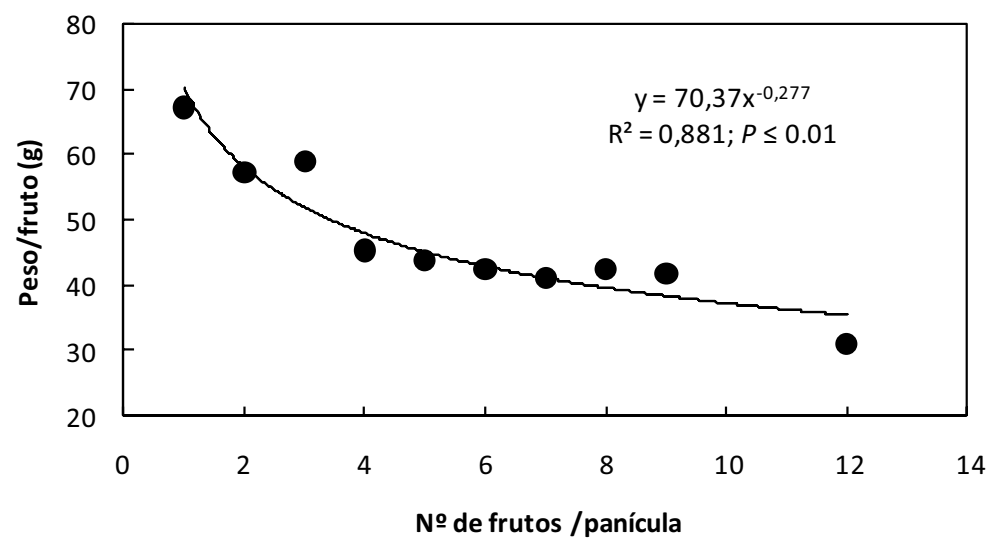

Fig. 4.3.- Relación entre el número de frutos por panícula y su peso individual en el níspero japonés cv. 'Algerie'. Cada valor es la media de 10 panículas por árbol, seleccionadas al azar, y 5 árboles.

Tabla 4.1.- Influencia del número de frutos por panícula sobre la cosecha, el diámetro final del fruto y el número de semillas por fruto. Los valores de la cosecha son la media de 20 árboles y el tamaño final del fruto y el número de semillas son la media de los frutos de 10 panículas y 5 árboles.

\begin{tabular}{lllll}
\hline Panículas & $\begin{array}{l}\text { № } \\
\text { frutos/panícula }\end{array}$ & $\begin{array}{l}\text { Cosecha } \\
\mathrm{Kg} / \text { árbol }\end{array}$ & $\begin{array}{l}\varnothing / \text { fruto } \\
(\mathrm{mm})\end{array}$ & Semillas/fruto \\
\hline $\begin{array}{l}\text { No } \\
\text { aclaradas }\end{array}$ & 7 & 20,3 & 43,7 & 3,7 \\
$\begin{array}{l}\text { Aclaradas } \\
\text { Significación }\end{array}$ & 3 & & & \\
\hline
\end{tabular}

El desarrollo de este fruto es exponencial (Fig. 4.4) y está determinado por el crecimiento del peso fresco de la pulpa, prácticamente paralelo al del peso total del fruto. La semilla, sin embargo, detiene su crecimiento, medido en peso fresco, cuando el fruto inicia el cambio de color (el 7 de abril, en nuestro experimento). 


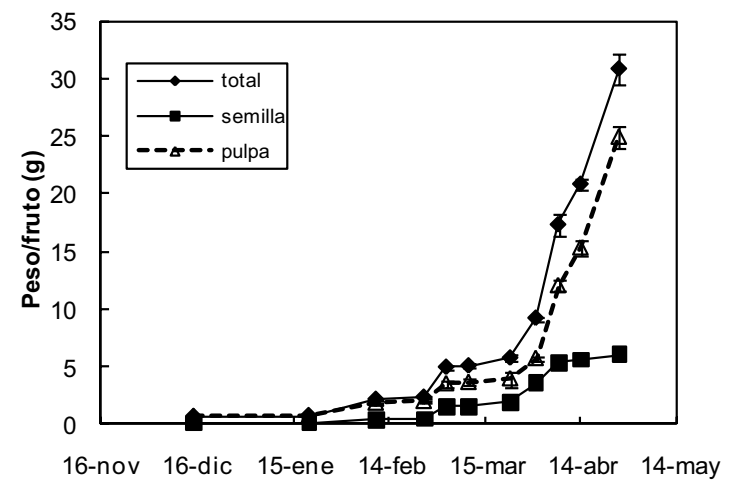

Fig. 4.4. Evolución del crecimiento del fruto, su pulpa y las semillas, del níspero japonés cv. 'Algerie'. Valores en peso fresco. Cada valor es la media de 25 frutos por árbol elegidos al azar de 5 árboles. La flecha indica la fecha de cambio de color del fruto.

De acuerdo con el control nutricional señalado, en nuestros experimentos el crecimiento del fruto fue tanto más reducido cuanto mayor fue el número de frutos desarrollados por panícula, coincidente con un menor desarrollo de la pulpa y una menor absorción de agua por parte de ésta (Fig. 4.5).
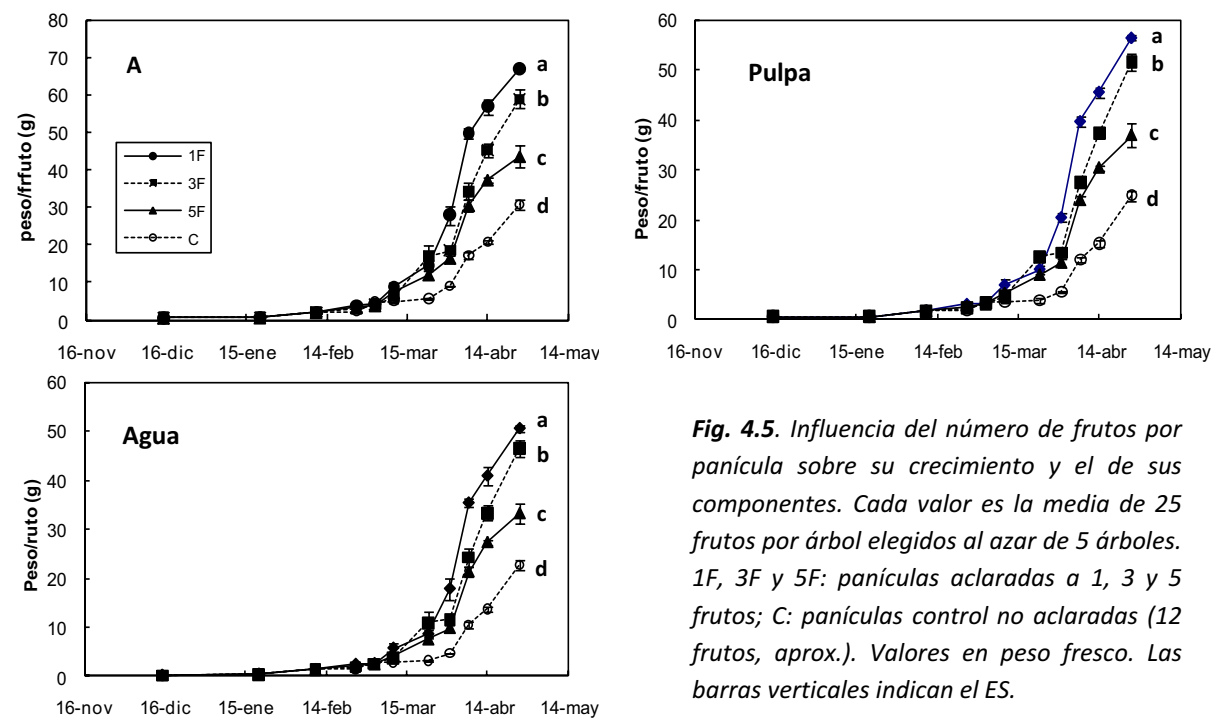

Fig. 4.5. Influencia del número de frutos por panícula sobre su crecimiento y el de sus componentes. Cada valor es la media de 25 frutos por árbol elegidos al azar de 5 árboles. 1F, 3F y 5F: panículas aclaradas a 1, 3 y 5 frutos; $C$ : panículas control no aclaradas $(12$ frutos, aprox.). Valores en peso fresco. Las barras verticales indican el ES. 
La semilla sigue también una pauta negativa en peso fresco y absorción de agua con el número creciente de frutos por panícula (Fig. 4.6), y cuanto menor es el número de frutos más tiempo sigue creciendo (Fig. 4.6 A). Así, el control (aproximadamente 12 frutos) detiene el crecimiento de la semilla el 7 de abril (ver, también, Fig. 4.4), y a medida que aumenta el número de frutos por panícula la detención del crecimiento se pospone, cesando el 14 de abril (Fig. 4.6 A). Este es un fenómeno, por tanto, también nutricional, es decir, al reducir la competencia entre frutos reduciendo el número de los que se hallan en desarrollo todas las partes de éste que acumulan azúcares crecen más y durante más tiempo.
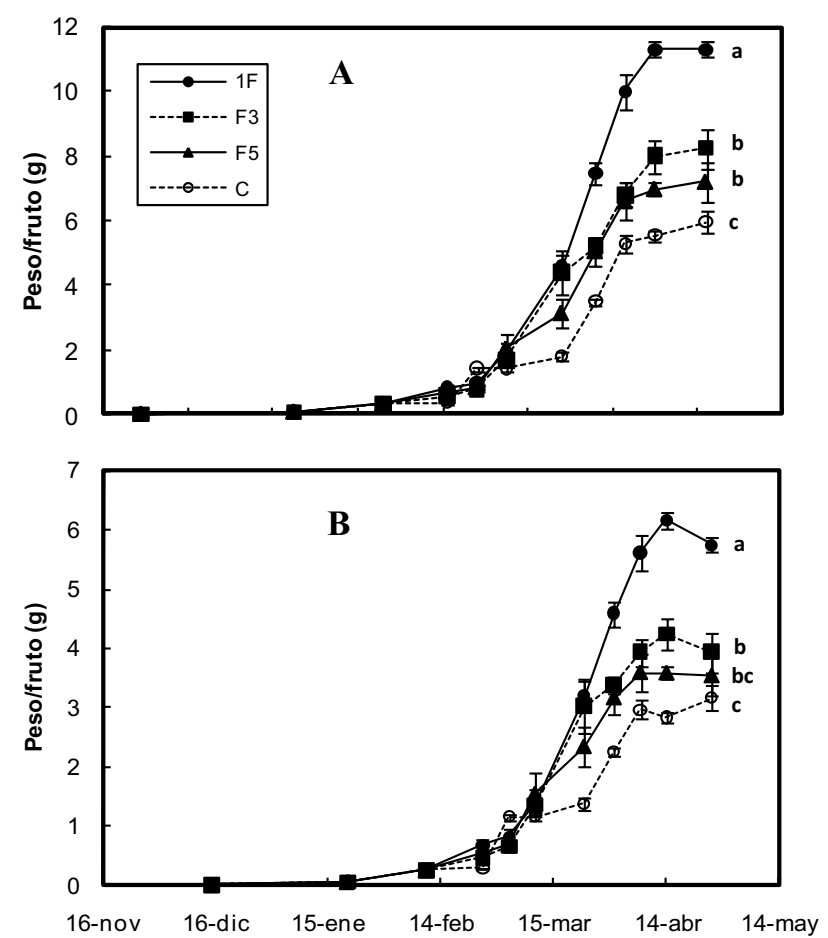

Fig. 4.6.- Influencia del número de frutos por panícula sobre el desarrollo en peso fresco de la semilla (A) y su absorción de agua (B). Cada valor es la media de 25 frutos por árbol elegidos al azar de 5 árboles. 1F, 3F y 5F: panículas aclaradas a 1, 3 y 5 frutos; C: panículas control no aclaradas (12 frutos, aprox.). Las barras verticales indican el ES. 
Ello queda ratificado al estudiar el peso seco de la pulpa y la semilla. La disminución de la competencia entre frutos mediante el aclareo de panículas aumentó el peso de ambas (Tabla 4.2), aunque con una mayor partición de asimilados hacia la pulpa. Así, mientras el peso seco de la semilla aumentó hasta un $85 \%$ al pasar de árboles no aclarados a árboles aclarados a un fruto por panícula, el peso seco de la pulpa lo hizo en un 162\%. De este modo la proporción de pulpa aumentó con la intensidad de aclareo pasando del $44,8 \%$ del peso total en el control al $53,3 \%$ en los árboles aclarados a un fruto por panícula.

Tabla 4.2.- Influencia de la intensidad de aclareo sobre el peso seco de los componentes del fruto del níspero japonés, cv. 'Algerie' en el momento de la recolección. 1F, 3F y 5F: panículas aclaradas a 1, 3 y 5 frutos; C: panículas control no aclaradas (12 frutos, aprox.). Los resultados son la media de 15 repeticiones.

\begin{tabular}{lcc}
\hline & \multicolumn{2}{c}{${\text { Peso seco }\left(\mathrm{g} \mathrm{fruto}^{-1}\right)}$ Frutos / panícula } \\
\cline { 2 - 3 } & Pulpa & Semilla \\
\hline 1 & $5,94 \mathrm{a}$ & $5,20 \mathrm{a}$ \\
3 & $5,16 \mathrm{a}$ & $3,80 \mathrm{~b}$ \\
5 & $3,74 \mathrm{~b}$ & $3,40 \mathrm{~b}$ \\
$\mathrm{C}$ & $2,27 \mathrm{c}$ & $2,80 \mathrm{c}$ \\
\hline
\end{tabular}

Letras distintas en la misma columna indican diferencias estadísticamente significativas, $p \leq 0,05$.

De acuerdo con todo ello, tanto el peso fresco como el peso seco del fruto aumentaron con la intensidad de aclareo, alcanzando una diferencia del $117 \%$ entre el peso fresco de los frutos de árboles aclarados a un fruto por panícula y el de los frutos de los árboles no aclarados (Fig. 4.5). En el caso del peso seco la diferencia alcanzó el 113\%.

Un aspecto de interés que ayuda a comprender el control nutricional del fruto sobre su propio desarrollo es la dependencia que la absorción de agua tiene de la acumulación de materia seca en la pulpa. En efecto, sea cual sea el número de frutos que tiene una panícula y, por tanto, el tamaño final que adquieren sus frutos, la absorción de agua y el peso seco acumulado son, si bien en cuantía absoluta distintos, tanto mayor cuanto menor es el número de frutos (Tabla 4.2; Fig. 4.5), la relación entre el peso seco acumulado y el peso del agua absorbida permanece constante $(\approx 1)$ a lo largo de todo el periodo de crecimiento del fruto (Fig. 4.7). 

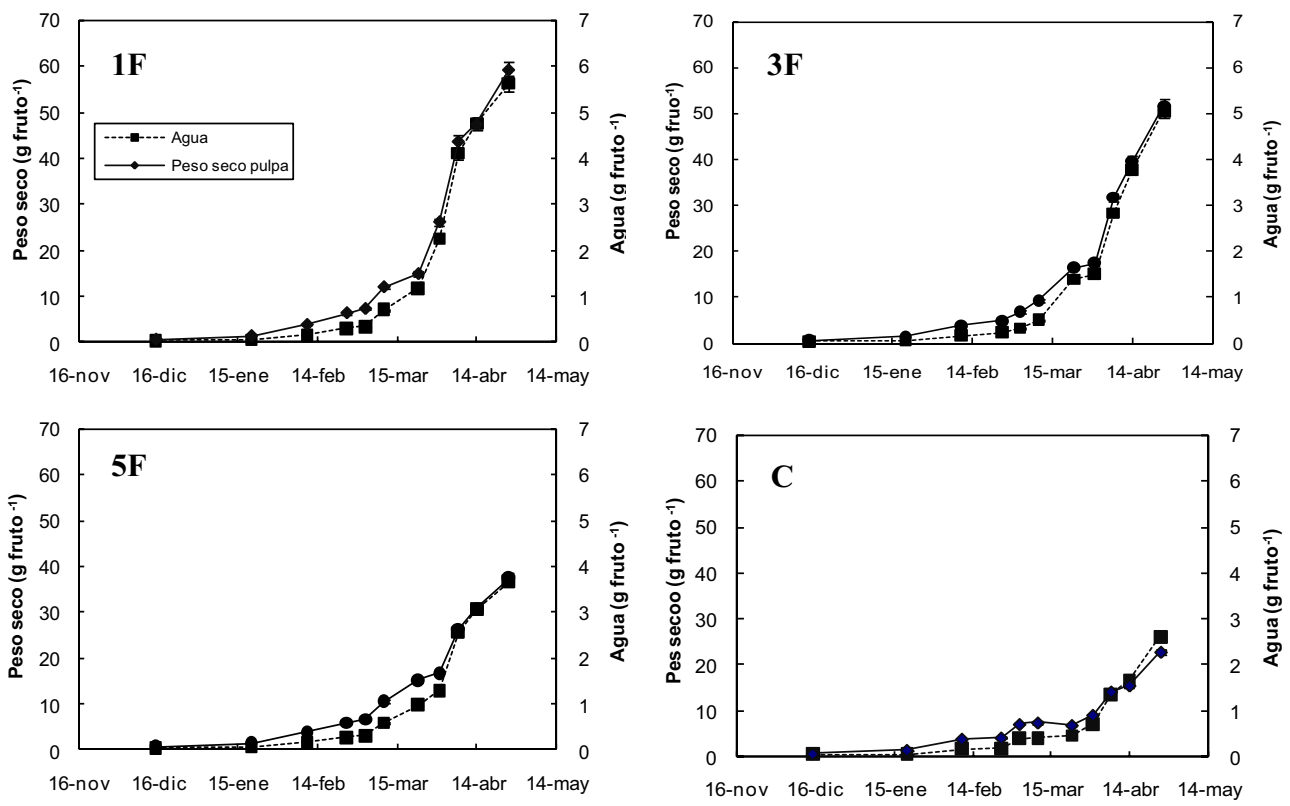

Fig. 4.7.- Evolución del peso seco de la pulpa y el peso del agua absorbida por ella en frutos de níspero japonés localizados en panículas con diferente intensidad de aclareo. Cada valor es la media de 25 frutos por árbol elegidos al azar de 5 árboles. 1F, 3F y 5F: panículas aclaradas a 1, 3 y 5 frutos; C: panículas control no aclaradas (12 frutos, aprox.). Las barras verticales indican el ES.

Pero la demostración más convincente del crecimiento del fruto en competencia con otros frutos de su propia panícula lo constituye el estudio de la absorción de azúcares. La acumulación en la pulpa de glucosa, fructosa $y$, sobre todo, sacarosa es inversamente proporcional al número de frutos por panícula a lo largo de todo el periodo de crecimiento del fruto (Fig. 4.8). La acumulación de sorbitol, sin embargo, no sigue una pauta clara (Fig. 4.8) 

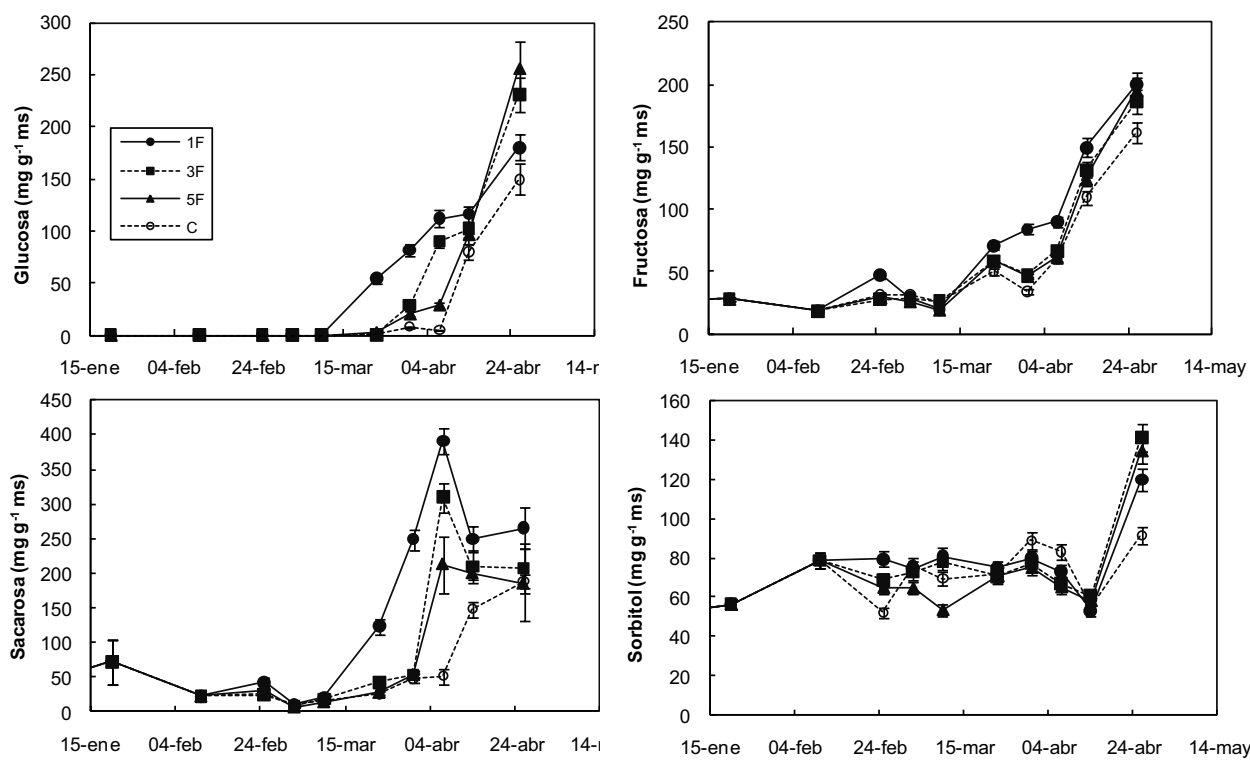

Fig. 4.8.- Influencia del número de frutos por panícula sobre la concentración de azúcares en la pulpa del fruto de níspero japonés '. Cada valor es la media de 25 frutos por árbol elegidos al azar de 5 árboles. $1 F$, 3F y 5F: panículas aclaradas a 1, 3 y 5 frutos; C: panículas control no aclaradas (12 frutos, aprox.). Las barras verticales indican el ES.

Los cambios en las concentraciones de sacarosa y sorbitol en las hojas, esto es, de los azúcares de transporte y, por tanto, los que reflejan la demanda de los frutos, siguió, también, en general, una relación inversa con el número de frutos por panícula (Fig. 4.9). De acuerdo con ello, resulta interesante que las panículas que más frutos tienen son las que demandan más carbohidratos, de ahí su menor contenido foliar y de ahí que sus frutos sean los que menos crezcan.

La comparación de la evolución de estos azúcares con la del crecimiento del fruto muestra perfiles, aparentemente, opuestos. Así, al aumento en el crecimiento del fruto (Fig. 4.5) le corresponde un descenso en la concentración foliar de sacarosa y sorbitol (Fig. 4.9). Y si bien ello podría interpretarse con un vaciamiento de la hoja, como consecuencia de la fuerte demanda del fruto, el aumento posterior de la concentración foliar de azúcares una semana antes del cambio de color (Fig. 4.9) cuando el fruto mantiene su alta tasa de crecimiento no puede explicarse del mismo modo. 

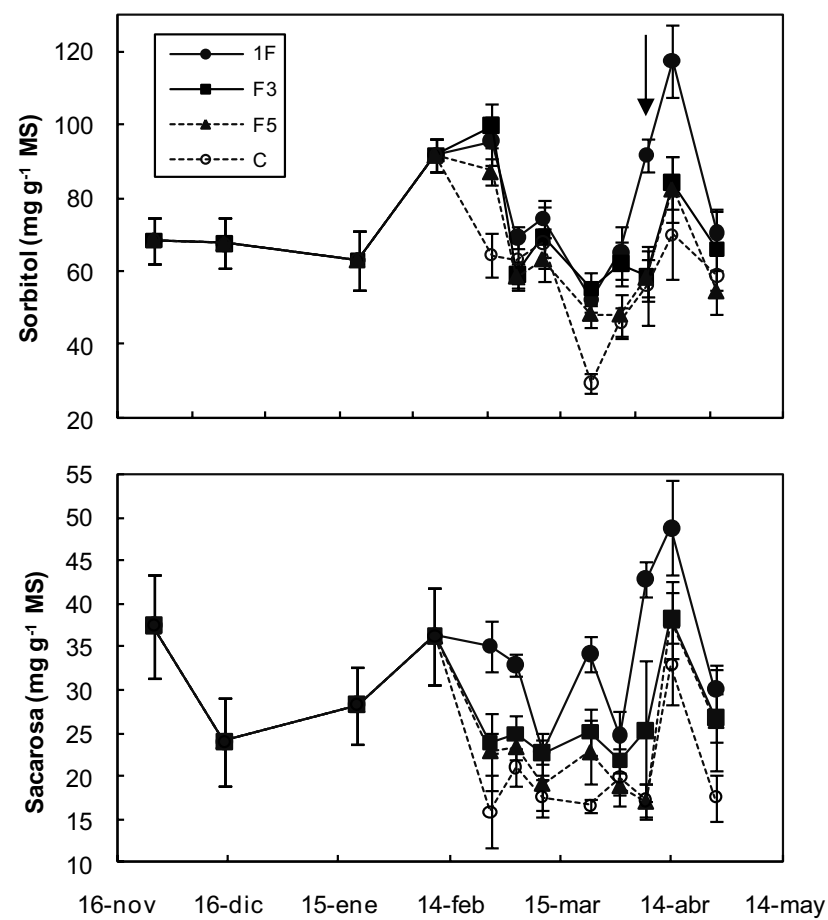

Fig. 4.9.- Evolución del contenido foliar de la concentración de sorbitol y sacarosa en el níspero japonés cv. 'Algerie'. Cada valor es la media de 15 hojas por árbol elegidas al azar en 5 árboles. 1F, 3F y 5F: panículas aclaradas a 1, 3 y 5 frutos; C: panículas control no aclaradas (12 frutos, aprox.). La flecha indica el momento del cambio de color del fruto. Las barras verticales indican el ES.

Este aspecto resulta más evidente al estudiar la evolución de la concentración foliar de azúcares de un árbol control, esto es, sin aclarar. En este caso, cuando el fruto registró la máxima velocidad de crecimiento, en el momento del cambio de color (Fig. 4.4), los niveles foliares de azúcares mostraron una tendencia alcista (Fig. 4.10). La respuesta, por tanto, parece estar desfasada. Así, la disminución del contenido de azúcares observado en las hojas el 22 de marzo (Fig. 4.10) ocurrió dos semanas después de haberse iniciado la fase exponencial de crecimiento del fruto (Fig. 4.4). Igualmente, se observó una disminución de la concentración de azúcares en las hojas 15 días después del cambio de color del fruto. Por lo tanto, el contenido de azúcares en las hojas sí parece disminuir en respuesta a un aumento de la demanda de asimilados por parte del fruto, pero con un retraso en la respuesta de unos 15 días, aproximadamente. 


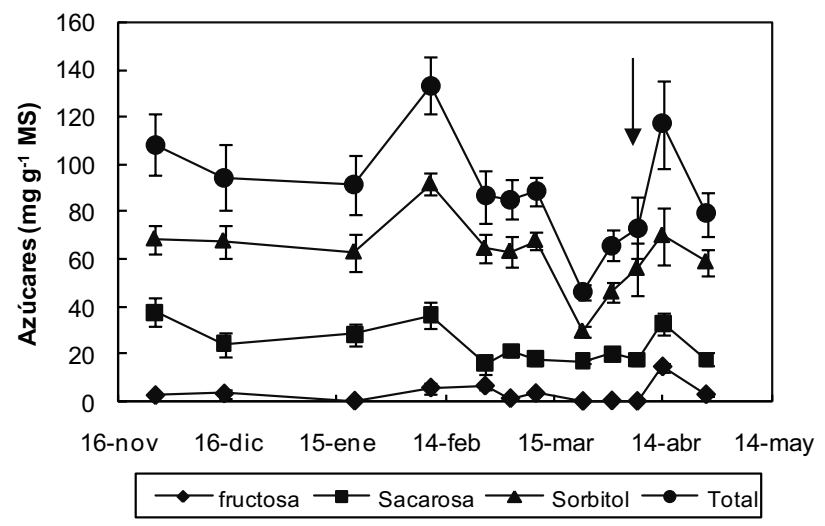

Fig. 4.10.- Evolución del contenido foliar de azúcares en el níspero japonés, cv. 'Algerie', durante el período de crecimiento del fruto. Cada valor es la media de 15 hojas por árbol elegidas al azar en 5 árboles. La flecha indica el momento del cambio de color del fruto. Las barras verticales indican el ES.

Considerando los azúcares en su totalidad, la pulpa sufrió marcados cambios cualitativos y cuantitativos en su composición a lo largo del periodo de crecimiento del fruto, con un cambio notable marcado por el cambio de color del fruto (Fig. 4.11). El sorbitol fue el azúcar más abundante a lo largo del periodo de crecimiento del fruto, representando el $60 \%$ del total de azúcares, pero tras el cambio de color el aumento de la concentración de otros mono y disacáridos redujo su incidencia relativa hasta valores del $15 \%$ del total de azúcares, manteniendo constante su concentración hasta el final del periodo de maduración (Fig. 4.11).

La fructosa siguió en importancia al sorbitol, representando entre el 15\% y $33 \%$ del total de los azúcares acumulados en las etapas iniciales del crecimiento del fruto. Al cambio de color y en la madurez, su concentración prácticamente se triplicó, pero su incidencia relativa se mantuvo en valores cercanos al 30\% (Fig. 4.11). La glucosa, sin embargo, apenas se detectó durante las etapas iniciales de crecimiento del fruto, pero 15 días antes del cambio de color su concentración se incrementó rápidamente hasta alcanzar valores semejantes a los de fructosa en el momento de la maduración (Fig. 4.11).

Las mayores fluctuaciones se registraron para la sacarosa, que osciló entre el $4,5 \%$ y el $45 \%$ del total de azúcares en la pulpa durante el crecimiento del fruto. En la maduración su concentración aumentó continuamente siendo el azúcar más abundante en el momento de plena madurez, con un $37 \%$ de concentración relativa (Fig. 4.11). 

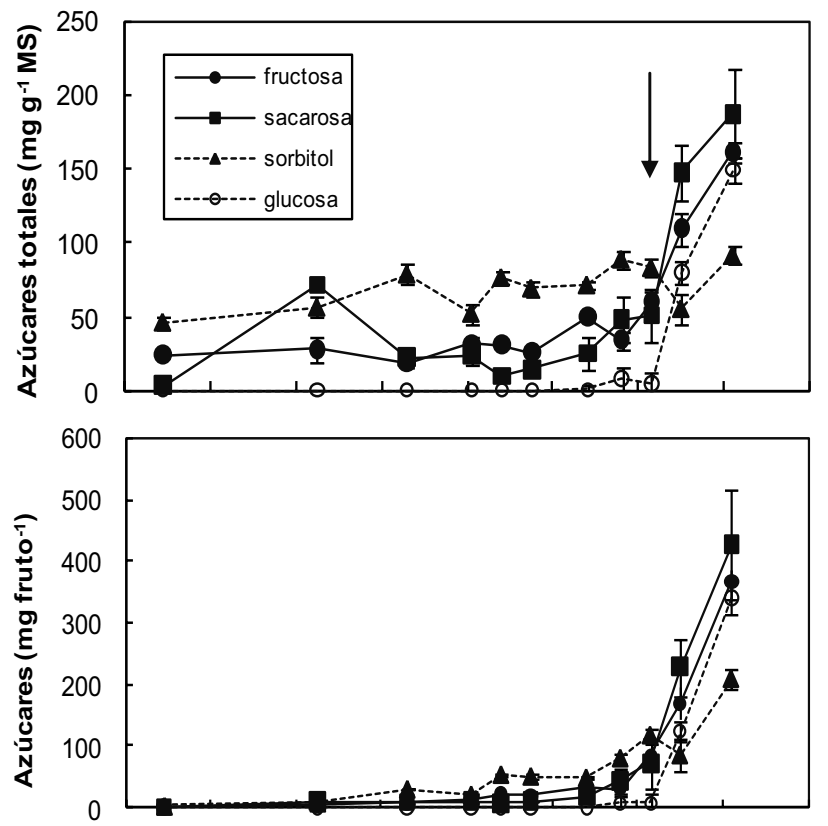

06-dic 26-dic 15-ene 04-feb 24-feb 15-mar 04-abr 24-abr 14-may

Fig. 4.11.- Evolución de la concentración y contenido total de azúcares en la pulpa de frutos de níspero japonés, cv. 'Algerie', de árboles sin aclarar. La flecha indica el momento de cambio de color. Las barras verticales representan el $E S$.

En resumen, con la excepción del sorbitol la concentración de azúcares en la pulpa presentó un aumento brusco a partir del momento del cambio de color y durante maduración del fruto. En 15 días, la concentración de azúcares totales pasó de 198 a $590 \mathrm{mg} \mathrm{g}^{-1} \mathrm{~ms}$. Y teniendo en cuenta el cambio de peso del fruto, en sólo 15 días se acumuló el 82,6\% del total de sus azúcares (Fig. 4.11). Ello explica el crecimiento exponencial de este fruto.

En la semilla, la concentración de azúcares, glucosa, fructosa, sacarosa y sorbitol, se mantuvo prácticamente constante hasta principios de marzo, experimentando un incremento posterior seguido de un declive hasta el momento del cambio de color del fruto y una leve recuperación final (Fig. 4.12). Resulta interesante que la menor concentración de estos azúcares se dé justo cuando se inicia la acumulación de más del $70 \%$, en valor absoluto, de su contenido, esto es, una semana antes del cambio de color del fruto (Fig. 4.12). 

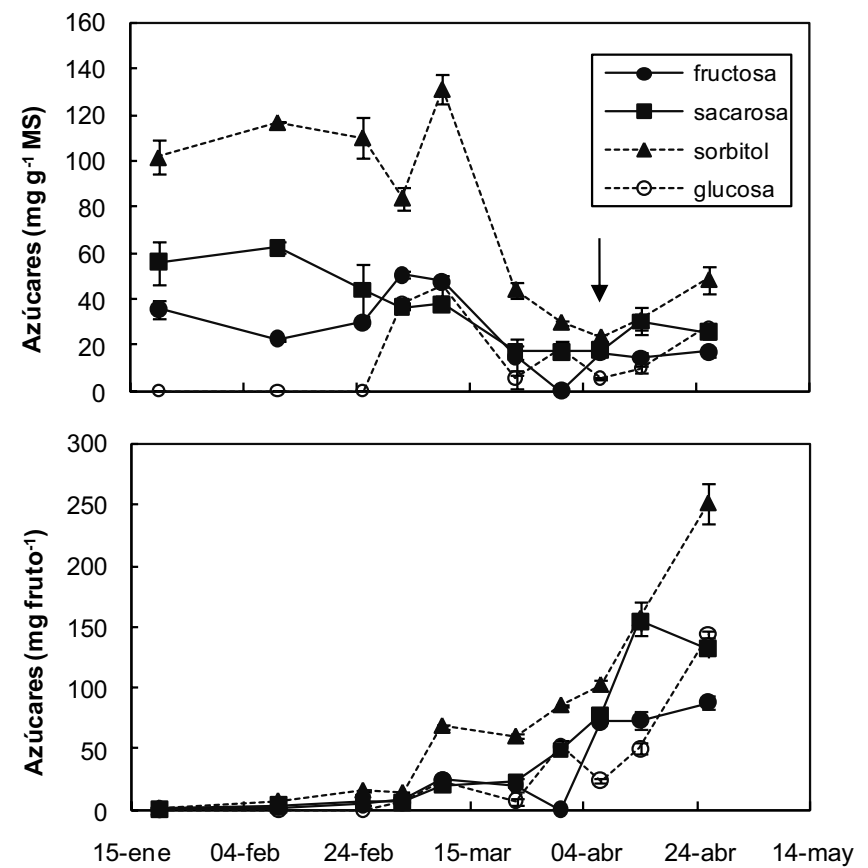

Fig. 4.12.- Evolución de la concentración y contenido total de azúcares en la semilla de frutos de níspero japonés, cv. 'Algerie', de árboles sin aclarar. La flecha indica el momento de cambio de color. Las barras verticales representan el ES.

También en la semilla el azúcar más abundante fue el sorbitol, oscilando entre el $40 \%$ y el $60 \%$ del total de los azúcares a lo largo del período de crecimiento del fruto y hasta la maduración (Fig. 4.12), pero desde principios de marzo hasta el momento del cambio de color su concentración disminuyó de 110 a $23 \mathrm{mg} \mathrm{g}^{-1}$ de materia seca, manteniéndose a partir de ese momento en niveles similares al resto de azúcares analizados (Fig. 4.12).

La evolución de la concentración de almidón mostró un comportamiento inverso a la del total de los azúcares, ya que cuando la concentración de azúcares tendió a aumentar, la de almidón disminuyó y viceversa (Fig. 4.13). Teniendo en cuenta esta evolución de la concentración de almidón y la del peso de la semilla (ver Fig. 4.4), la mayor parte de aquél (en valor absoluto) se acumuló en ésta a partir del momento del cambio de color del fruto. 


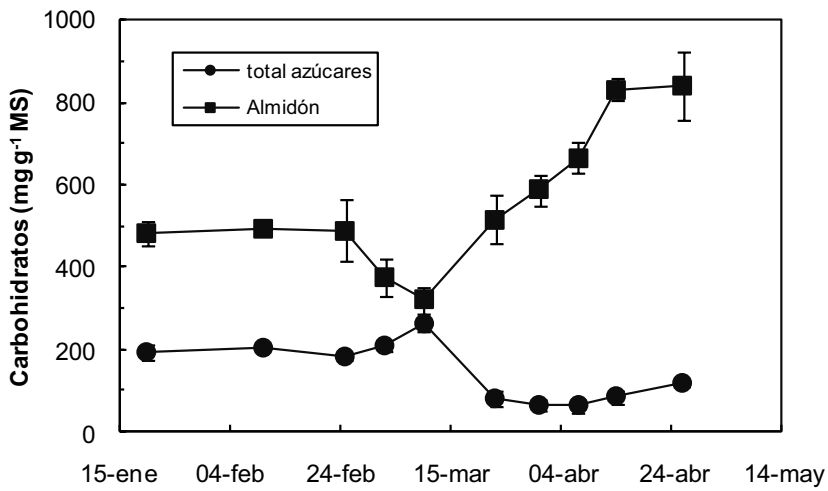

Fig. 4.13.- Evolución de la concentración total de azúcares y almidón en las semillas de los frutos del níspero japonés, cv. 'Algerie', procedentes de árboles no aclarados. El almidón se expresa como glucosa liberada después de una reacción enzimática con amiloglucosidasa. Las barras verticales indican el ES. 



\section{5.- INFLUENCIA DEL FRUTO EN EL DESARROLLO RADICULAR. LA MADURACIÓN.}

La presencia del fruto también afectó a las raíces del árbol que vieron significativamente reducida su actividad. Mientras el fruto aumentaba progresivamente su tamaño, la tasa de crecimiento radicular disminuía hasta alcanzar valores mínimos en el momento en que el fruto alcanzaba su tamaño final. A partir de este momento, y hasta el final del periodo estudiado, el fruto cambió de color y maduró, al mismo tiempo que las raíces retomaban su crecimiento. Este comportamiento fue idéntico en los dos cultivares, 'Algerie' y 'Piera', de níspero japonés estudiados (Fig. 5.1).
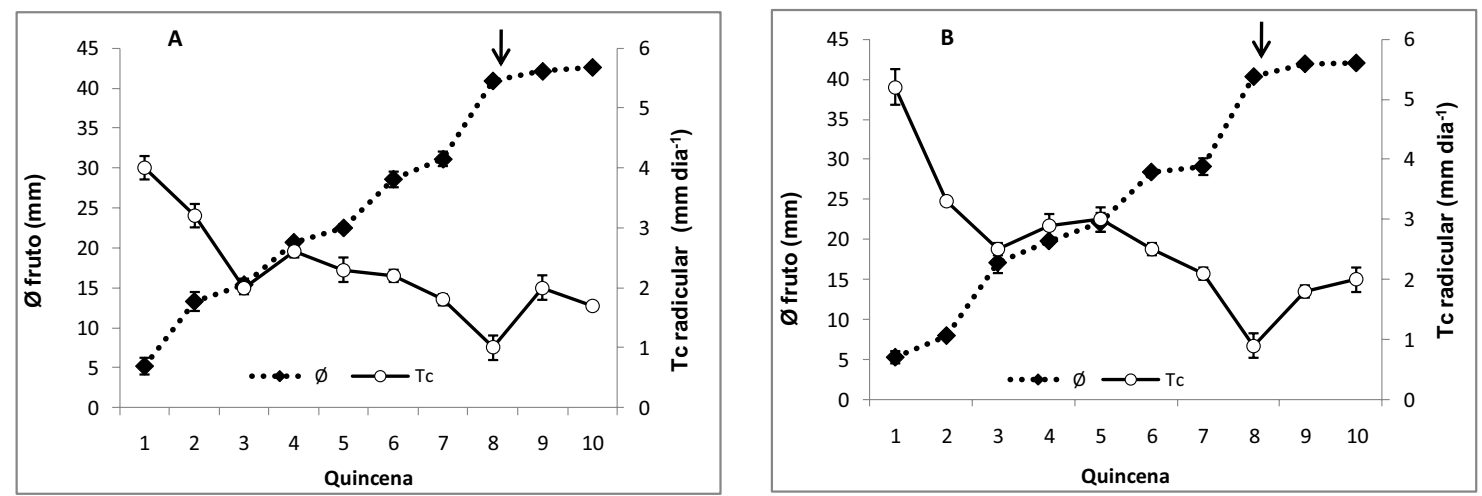

Fig. 5.1.- Cinética de crecimiento del fruto y la raíz de níspero japonés cvs. 'Algerie' (A) y 'Piera' (B). Cada valor es la media de 10 frutos y 5 raíces repatidos en 5 árboles. En fruto del cv. Piera corresponde a la Generación I. Las barras verticales indican el ES. La flecha representa el estado fenológico 709 de la escala BBCH (25 de abril). Quincena 1: 1-15 de enero; quincena 10 : 1-15 de mayo. Tc: tasa de crecimiento diario

De acuerdo con ello, el estudio de la evolución del crecimiento radicular de ambos cultivares a lo largo del ciclo vegetativo revela un punto de mínima tasa de crecimiento, común para ambos cultivares, en el momento en que los frutos ya habían completado su crecimiento, o lo que es lo mismo, cuando habían alcanzado el estado fenológico 709 de la escala $\mathrm{BBCH}$, si bien desplazados una semana entre ellos. Un segundo pico, correspondiente a la segunda generación de frutos, se detectó en el cv. Piera (Fig. 5.2). Con el cambio de color de los frutos, las raíces de ambos cvs. retomaron intensamente su crecimiento, hasta alcanzar valores máximos en el momento de su maduración que, como para su valor mínimo, se anticipó en el cv. 'Piera en unas 3 semanas, aproximadamente. Tras la recolección éste descendió nuevamente coincidiendo con el desarrollo de los nuevos brotes vegetativos que, en el caso del cv. Piera coincidió, además, con la antesis de las sucesivas generaciones, desde la III hasta la VIII, separadas quincenalmente (ver figura 1.1, Capítulo 1) (Fig. 5.2). 


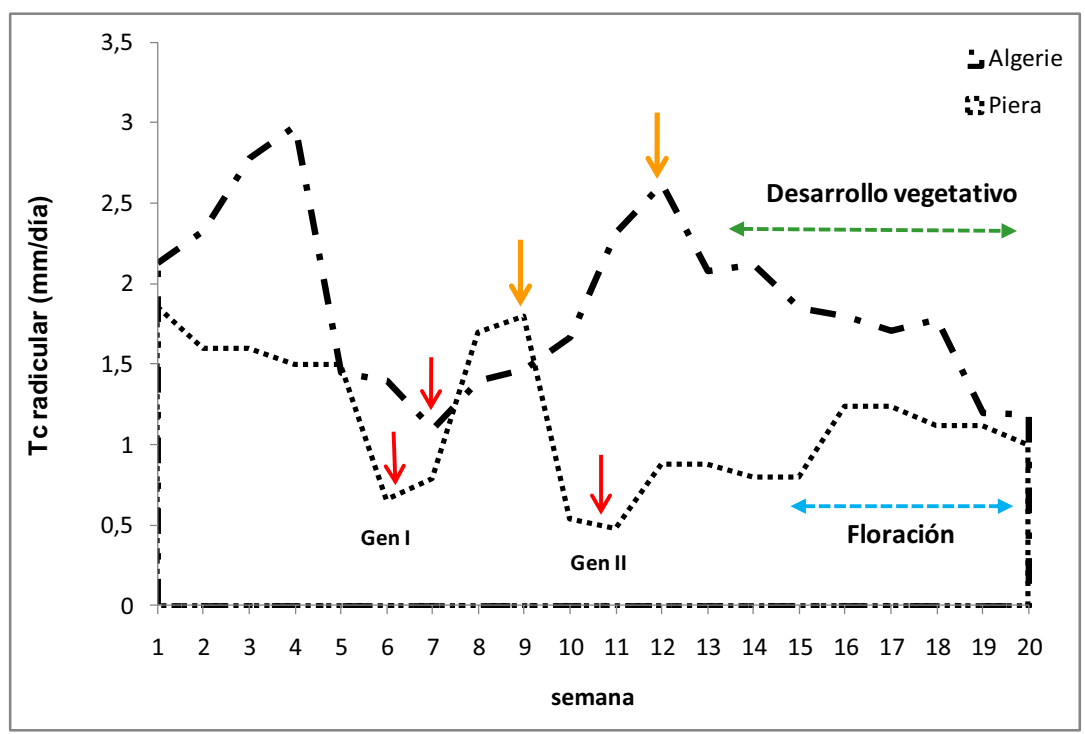

Fig. 5.2.- Evolución de la tasa diaria de crecimiento radicular de los cvs. 'Algerie' y 'Piera' de níspero japonés. Para los dos cultivares, las flechas rojas y naranjas indican los estados fenológicos 709 y 809 de la escala $B B C H$, respectivamente. El desarrollo vegetativo hace referencia a ambos cultivares. La floración en esa época solo se presentó en el cv. Piera. Gen I y II: primera y segunda generación de frutos del cv. Piera. Semana 1: 14-20 de marzo; semana 20: 25-31 de julio. Cambio de color del cv. Algerie: 25 de abril; cambio de color del cv. Piera: 18 de abril y 28 de mayo

Por lo tanto, a la vista de nuestros resultados, el propio crecimiento de los frutos controló en gran medida el de las raíces del árbol, debido, al menos en parte, a fenómenos de competencia nutricional entre ambos órganos. Es por ello que la evolución en el contenido de carbohidratos reductores en los frutos y en las raíces fue completamente opuesta en los dos cultivares estudiados. Así, en el cv. Piera, mientras los frutos aumentaron progresivamente su concentración conjunta de glucosa y fructosa a medida que crecían, las raíces la disminuyeron sincronizadamente, hasta que éstos alcanzaron, prácticamente, su tamaño final (Fig. 5.3 A). Quince días después, cuando los frutos del cv. Piera cambiaban de color (estado $801 \mathrm{BBCH}$ ), la concentración radicular de estos azúcares aumentó en un 22.4\%, y más tarde, con la maduración de éstos y su máxima concentración de glucosa y fructosa (estado $809 \mathrm{BBCH}$ ), se incrementó un $52.5 \%$ y hasta un 70\% en pleno desarrollo de los brotes (estado $325 \mathrm{BBCH}$ ); finalmente, la concentración de estos azúcares descendió nuevamente en las raíces con la parada estival (estado $339 \mathrm{BBCH}$ ) hasta valores mínimos prácticamente coincidentes con los alcanzados en el estado fenológico 709 de la escala BBCH. En el cv. Algerie, el comportamiento fue idéntico, si bien su concentración radicular se mantuvo prácticamente estable después de que descendiera significativamente coincidiendo con el estado fenológico del fruto 709 de la escala BBCH (Fig. 5.3 B), probablemente por la ausencia de otras generaciones en desarrollo. Debe 
destacarse la importancia cuantitativa de los azúcares reductores en el fruto frente a las raíces; así, mientras en los primeros se alcanzaron valores máximos entre 452.7 y $441.4 \mathrm{mg} \mathrm{g}^{-1} \mathrm{~ms}$, dependiendo del cultivar, en los segundos nunca se superaron los $30 \mathrm{mg} \mathrm{g}^{-1} \mathrm{~ms}$.
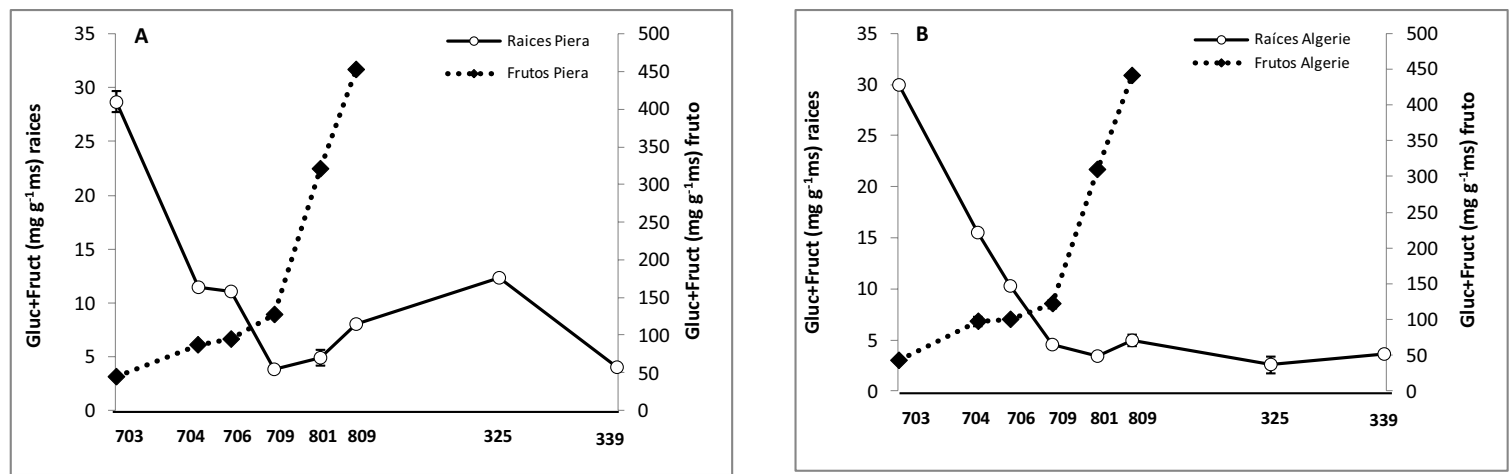

Fig. 5.3.- Evolución del contenido en carbohidratos reductores, glucosa + fructosa, en los frutos y en las raíces de níspero japonés cvs. 'Piera' (A) y 'Algerie' (B). Cada valor es la media de 5 árboles. Las barras verticales indican el ES. El eje de abscisas representa los estados fenológicos según la escala $B B C H$.

La evolución del contenido en azúcares de transporte en los frutos y en las raíces de los dos cultivares estudiados también presentó tendencias opuestas. Del mismo modo que para los azúcares reductores, la concentración conjunta de sacarosa y sorbitol en los frutos aumentó progresivamente con el crecimiento de éstos, en ambos cultivares, hasta valores máximos en el momento de su maduración de 187.5 y 197.6 $\mathrm{mg} \mathrm{g}^{-1} \mathrm{~ms}$ para el 'Piera' y 'Algerie', respectivamente (Fig. 5.4). Contrariamente y, de manera paralela, descendió progresivamente la de las raíces hasta valores mínimos de 10.0 y $10.7 \mathrm{mg} \mathrm{g}^{-1} \mathrm{~ms}$ para ambos cultivares, respectivamente, en el momento del cambio de color de los frutos (estado 801 BBCH). Como ya ocurrió con la concentración radicular de glucosa y fructosa, la de sacarosa y sorbitol también aumentó, en ambos cultivares, a los pocos días de haber alcanzado sus valores mínimos, coincidiendo con la maduración de los frutos. El incremento, además, alcanzó la misma magnitud, $24.8 \%$, en los dos cultivares estudiados. A partir de este momento y hasta el final del periodo estudiado la concentración de azúcares de transporte se mantuvo prácticamente estable en ambos cultivares. También en este caso, la concentración de estos azúcares fue cuantitativamente más importante en los frutos que en las raíces. Así, mientras en los primeros se alcanzaron valores entre 187.5 y $197.6 \mathrm{mg} \mathrm{g}^{-1} \mathrm{~ms}$, dependiendo del cultivar, en los segundos apenas se superaron los $50 \mathrm{mg} \mathrm{g}^{-1} \mathrm{~ms}$ (Fig. 5.4). 

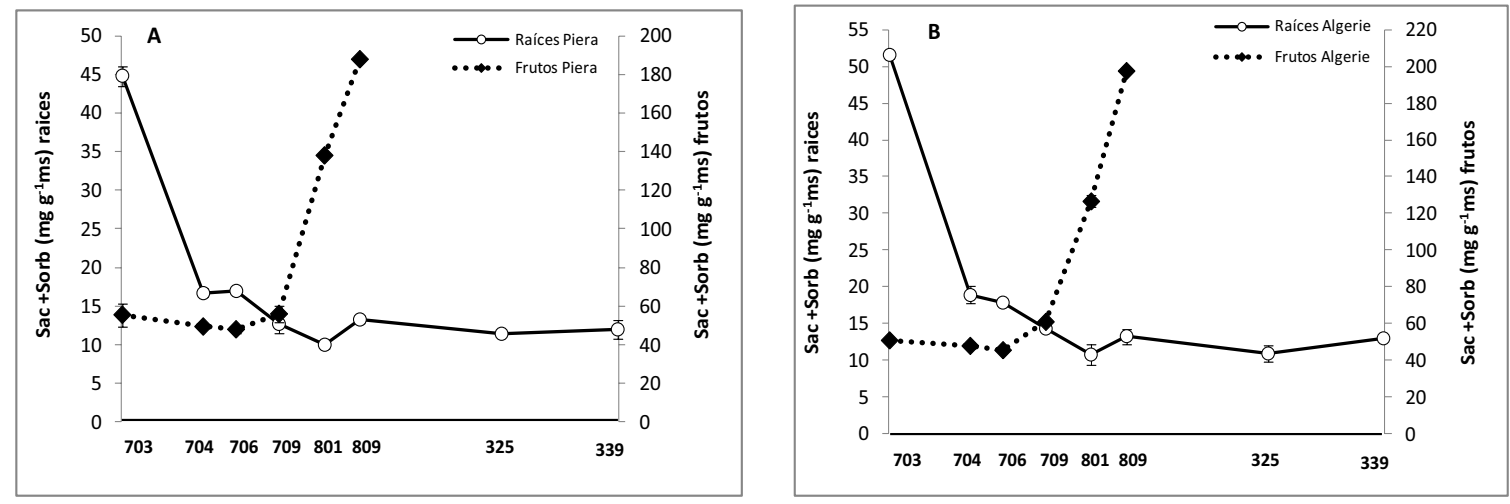

Fig. 5.4.- Evolución del contenido en carbohidratos de transporte, sacarosa + sorbitol, en los frutos y en las raíces de níspero japonés cvs. 'Piera' (A) y 'Algerie' (B). Cada valor es la media de 5 árboles. Las barras verticales indican el ES. El eje de abscisas representa los estados fenológicos según la escala $B B C H$.

El estudio comparativo de la evolución conjunta de los azúcares reductores y de transporte en los frutos y en las raíces de los cvs. 'Piera' y 'Algerie', reflejó un comportamiento idéntico ya que la concentración radicular de estos azúcares descendió significativamente como consecuencia del crecimiento de los frutos. El descenso de los azúcares reductores se produjo antes, en el estado fenológico 709 de la escala $\mathrm{BBCH}, \mathrm{y}$ con mayor intensidad, hasta en un 85.6\%, que el de los de transporte que fue en el estado fenológico 801 de la misma escala, y de un $71.9 \%$ (Figs. 5.3 y 5.4). Por otra parte, así como en los frutos la glucosa y la fructosa, conjuntamente, fueron cuantitativamente más importantes (447 $\mathrm{mg} \mathrm{g}^{-1} \mathrm{~ms}$ ), por término medio, en ambos cultivares, que la sacarosa y el sorbitol (192.5 $\left.\mathrm{mg} \mathrm{g}^{-1} \mathrm{~ms}\right)$, en las raíces, por el contrario, lo fueron los de transporte, con un $39.1 \%$ más que los reductores (Figs. 5.3 y 5.4). Estos resultados ponen de manifiesto, la competencia existente entre los frutos y las raíces del árbol por el suministro de carbohidratos, a favor de los primeros. De ahí que la presencia de los frutos en el árbol alterara también el contenido en azúcares de reserva de las raíces de ambos cultivares. La evolución de la concentración de almidón presentó un pico máximo en el estado fenológico 706 de la escala BBCH, de hasta 25.3 y $27.8 \mathrm{mg} \mathrm{g}$

${ }^{1}$ ms para los cvs. 'Piera' y 'Algerie', respectivamente, seguido de un descenso progresivo de ésta hasta el momento de la maduración, a partir del cual se mantuvo prácticamente constante hasta el final del periodo estudiado (Fig. 5.5). 


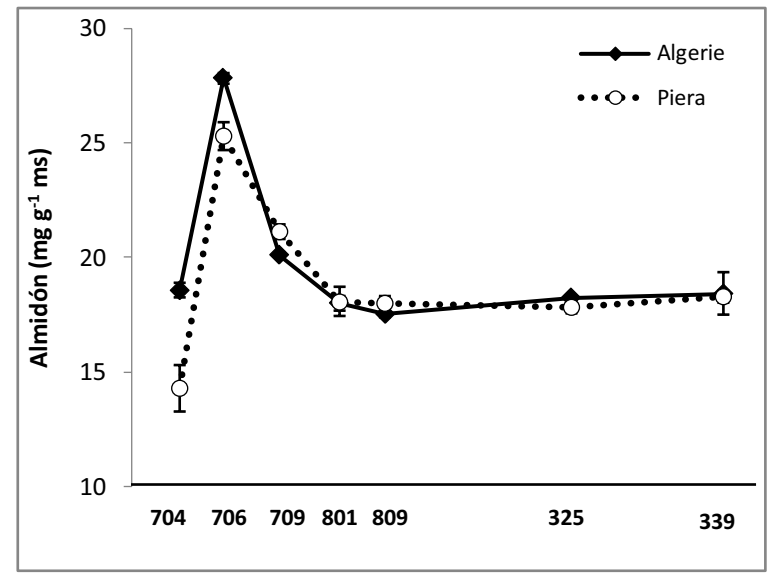

Fig. 5.5.- Evolución de la concentración de almidón en las raíces de níspero japonés cvs. 'Piera' y 'Algerie' a lo largo del ciclo vegetativo. Valores expresados como la concentración de glucosa liberada después de una reacción enzimática con amiloglucosidasa. Cada valor es la media de 5 árboles. Las barras verticales indican el ES. El eje de abscisas representa los estados fenológicos según la escala $B B C H$.

Esta acumulación de almidón detectada en las raíces de ambos cultivares cuando sus frutos tenían el 60\% de su tamaño final, coincidió exactamente con el aumento significativo de la concentración de glucosa-6fosfato hasta valores máximos de 25.8 y $42.3 \mathrm{mg} \mathrm{g}^{-1} \mathrm{~ms}$ para los cvs. 'Piera' y 'Algerie', respectivamente. Cuando los frutos completaron su crecimiento, esto es, cuando alcanzaron el estado fenológico 709 de la escala $\mathrm{BBCH}$, la concentración radicular de este azúcar se redujo significativamente en un $54.6 \%$ en el cv. Piera y en un $\mathbf{7 4 . 7 \%}$ en el cv. Algerie, coincidiendo, también en este caso, con el descenso en el contenido de almidón de sus raíces (Figs. 5.5 y 5.6). En ambos cultivares, esta concentración aumentó nuevamente en $4.3 \mathrm{mg} \mathrm{g}^{-1} \mathrm{~ms}$ durante el cambio de color de los frutos, alcanzando la significación estadística respecto de etapas anteriores, que mantuvo durante la maduración de éstos. Tras la recolección y, durante el crecimiento vegetativo de los nuevos brotes, hubo un descenso generalizado de la concentración radicular de glucosa-6-fosfato, en ambos cultivares, que también alcanzó la significación estadística (Fig. 5.6).

Aunque el perfil de la evolución de la concentración de glucosa-6-fosfato en las raíces de los dos cultivares fue prácticamente idéntica ésta fue significativamente superior en el cv.'Algerie' que en el 'Piera' durante las primeras fases de desarrollo de los frutos. Así, en el máximo detectado en el estado fenológico 706 de la escala $\mathrm{BBCH}$, la del primero fue un 39\% superior a la del segundo. Algo parecido ocurrió con la concentración de almidón en las raíces de estos árboles, aunque en este caso la diferencia sólo fue de un 8.9\% y no alcanzó la significación estadística (Fig. 5.5). 


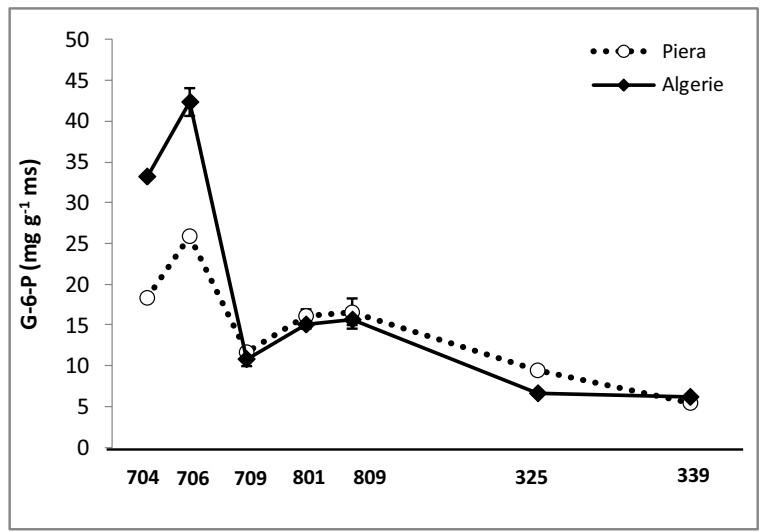

Fig. 5.6.- Evolución de la concentración de glucosa-6fosfato en las raíces de níspero japonés cvs. 'Piera' y 'Algerie'a lo largo del ciclo vegetativo. Cada valor es la media de 5 árboles. Las barras verticales indican el ES. EI eje de abscisas representa los estados fenológicos según la escala $\mathrm{BBCH}$.

Sin embargo, al estudiar la evolución de estos azúcares en la parte aérea del árbol, se observó que la presencia de los frutos mantuvo prácticamente constante la concentración foliar de glucosa y fructosa en los dos cultivares estudiados (Fig. 5.7). La de sacarosa y sorbitol, por el contrario, descendió progresivamente con el crecimiento de los frutos hasta valores mínimos en el momento en que éstos alcanzaron su tamaño final, para aumentar posteriormente hasta que completaron su maduración (Fig. 5.7 A). Los cambios durante la maduración fueron más suaves en el cv. Piera que en el cv. Algerie (Fig. 5.7 B).
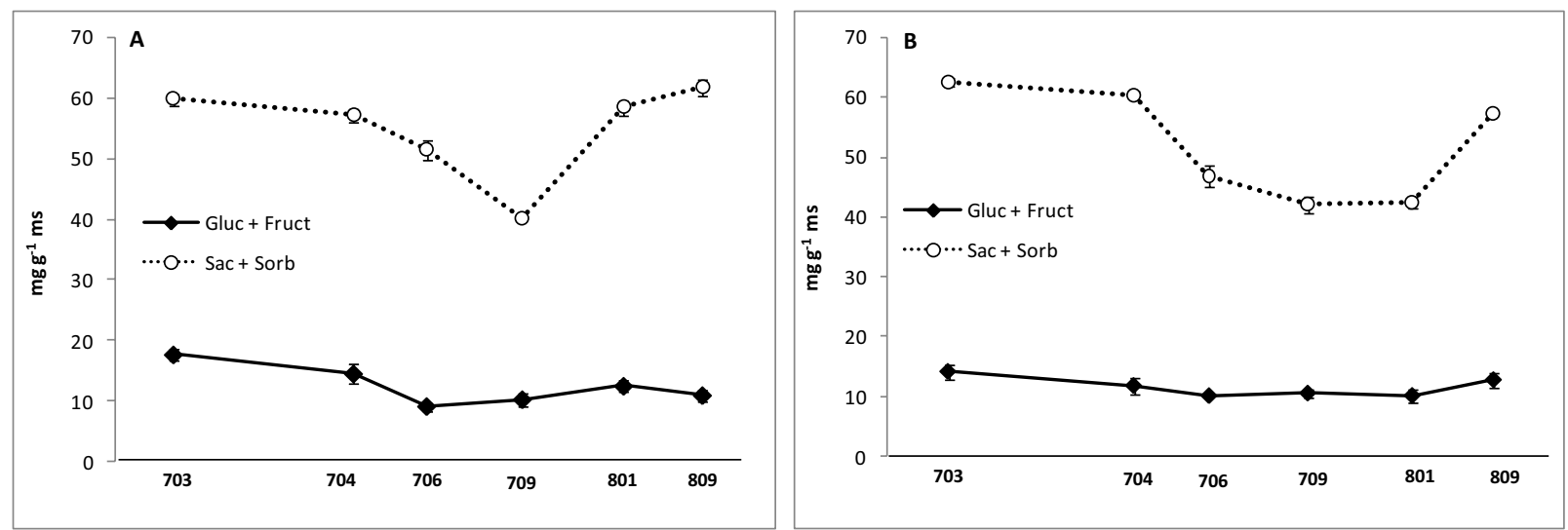

Fig. 5.7.- Evolución del contenido en carbohidratos de transporte, sacarosa + sorbitol, y reductores, glucosa + fructosa, en las hojas de los brotes mixtos de níspero japonés cvs. 'Piera' (A) y 'Algerie' (B) a lo largo del crecimiento de sus frutos y hasta su maduración. Cada valor es la media de 5 árboles. Las barras verticales indican el ES. El eje de abscisas representa los estados fenológicos según la escala $\mathrm{BBCH}$. 
La concentración en el floema de azúcares reductores tampoco se vio alterado por la presencia de los frutos en los dos cultivares estudiados. Así, la concentración conjunta de glucosa y fructosa en el floema desde que los frutos tenían el 30\% del tamaño final hasta que maduraron se mantuvo prácticamente constante en ambos cultivares, con valores promedio, en los dos casos, de $14.5 \mathrm{mg} \mathrm{g}^{-1} \mathrm{~ms}$. La concentración de azúcares de transporte en el floema, por el contrario, dependió marcadamente del estado fenológico de los frutos (Fig.5.8). Hasta que éstos alcanzaron el 60\% de su tamaño final, la concentración conjunta de sacarosa y sorbitol en el floema, aumentó progresivamente hasta valores máximos de 62.4 y $66.4 \mathrm{mg} \mathrm{g}^{-1} \mathrm{~ms}$ en el cv. Piera y el cv. Algerie, respectivamente. A partir de este momento descendió progresivamente hasta en un $39.3 \%$ y $54.5 \%$, respectivamente, cuando los frutos cambiaron de color. Posteriormente, con la maduración (estados 801 a 809 de la escala BBCH), la concentración de sacarosa y sorbitol en el floema de ambos cultivares aumentó de nuevo hasta igualar los valores iniciales (Fig. 5.8). Del mismo modo que en las hojas, la concentración de los azúcares de transporte fue cuantitativamente más importante que la de los reductores; hasta 4 veces superior fue la concentración conjunta de sacarosa y sorbitol en el floema de ambos cultivares que la de glucosa y fructosa (Fig. 5.8).
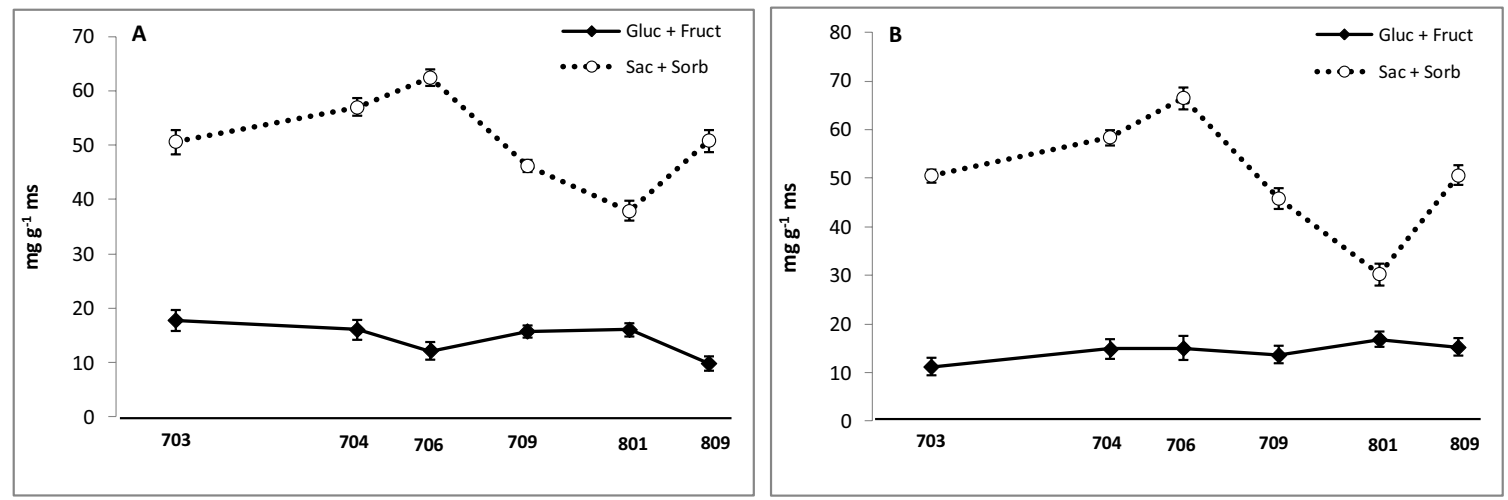

Fig. 5.8.- Evolución del contenido en carbohidratos de transporte, sacarosa + sorbitol, y reductores, glucosa + fructosa, en el floema de brotes mixtos de níspero japonés cvs. 'Piera' (A) y 'Algerie' (B) a lo largo del crecimiento de sus frutos y hasta su maduración. Cada valor es la media de 5 árboles. Las barras verticales indican el ES. El eje de abscisas representa los estados fenológicos según la escala $B B C H$. 
De acuerdo con estos resultados, el reparto de carbohidratos entre los órganos sumidero del árbol dependió, entre otras cosas, de la fuerza competitiva de éstos. Los frutos fueron los sumideros más potentes y, como consecuencia de ello, el balance total de carbohidratos en las raíces del árbol se vio significativamente alterado. Así se confirmó al estudiar la movilización del C desde las hojas hacia los diferentes órganos del árbol, utilizando para ello ${ }^{13} \mathrm{C}$. En efecto, en los experimentos realizados en Valencia (España), a los 4 y a los 7 días de haber expuesto las hojas a una atmósfera de ${ }^{13} \mathrm{CO}_{2}$ en la época de pleno crecimiento de los frutos, esto es, en los estados fenológicos 703 y 708 de la escala $\mathrm{BBCH}$, el ${ }^{13} \mathrm{C}$ transportado únicamente se detectó en los frutos. La exposición en estados más avanzados del desarrollo del fruto, estados fenológicos 801 y 809 de la escala $\mathrm{BBCH}$, ya permitió detectar ${ }^{13} \mathrm{C}$ en el floema de la rama principal a la que estaba insertado el brote con las hojas expuestas y portador de la panícula de frutos, independientemente del tiempo transcurrido desde la exposición de las hojas al ${ }^{13} \mathrm{C}$ (Fig. 5.9). Es necesario destacar que el floema analizado es un indicador del transporte basípeto hacia las raíces ya que, de acuerdo con su localización descrita más arriba, se hallaba situado en una rama principal situada en el extremo opuesto a la localización de los frutos en la panícula. Estos resultados indican que la capacidad de traslocación de los carbohidratos desde los órganos de fotosíntesis hacia los sumideros en desarrollo del árbol queda restringida por el fruto, de modo que el transporte a otros sumideros, como por ejemplo las raíces, solo se produce cuando los frutos han completado su crecimiento y, con ello, su demanda. La ausencia de ${ }^{13} \mathrm{C}$ en las raíces del árbol, en los mismos estados fenológicos en los que se encontró en el floema de la base del brote, se debe a una movilización más lenta, consecuencia de la larga distancia existente entre éstas y las hojas que requiere, por tanto, de más tiempo. Por otro lado, el mayor contenido de ${ }^{13} \mathrm{C}$ en los frutos que estaban en pleno crecimiento que en sus hojas expuestas directamente a él 4 días antes, indica que el flujo de los carbohidratos fue exclusivamente hacia éstos, como consecuencia de su potente capacidad sumidero. Por el contrario, cuando éstos cambiaron de color y maduraron, este balance ya no fue exclusivamente favorable a los frutos (Fig. 5.9 B), e incluso se invirtió a favor de las hojas a los 4 días de la exposición que exportaron, por tanto, más lentamente el ${ }^{13} \mathrm{C}$ recibido (Fig. 5.9 A) permitiendo, además, la llegada a otros sumideros en desarrollo del árbol y atender sus necesidades energéticas, como lo demuestra su presencia en el floema de la parte basal del brote (Fig. $5.9 \mathrm{~A}$ ). El contenido en ${ }^{13} \mathrm{C}$ de las hojas a los 7 días de la exposición fue siempre más bajo que a los 4 días, pero este descenso no siempre se vio acompañado de un incremento proporcional en los frutos; es más, la recuperación de ${ }^{13} \mathrm{C}$ a los 7 días fue, en general, inferior al recuperado a los 4 días (Fig. 5.9). Estas variaciones cuantitativas detectadas con el tiempo transcurrido desde que se marcaran sus hojas pueden deberse, en parte, a pérdidas por la respiración de hojas y frutos. 

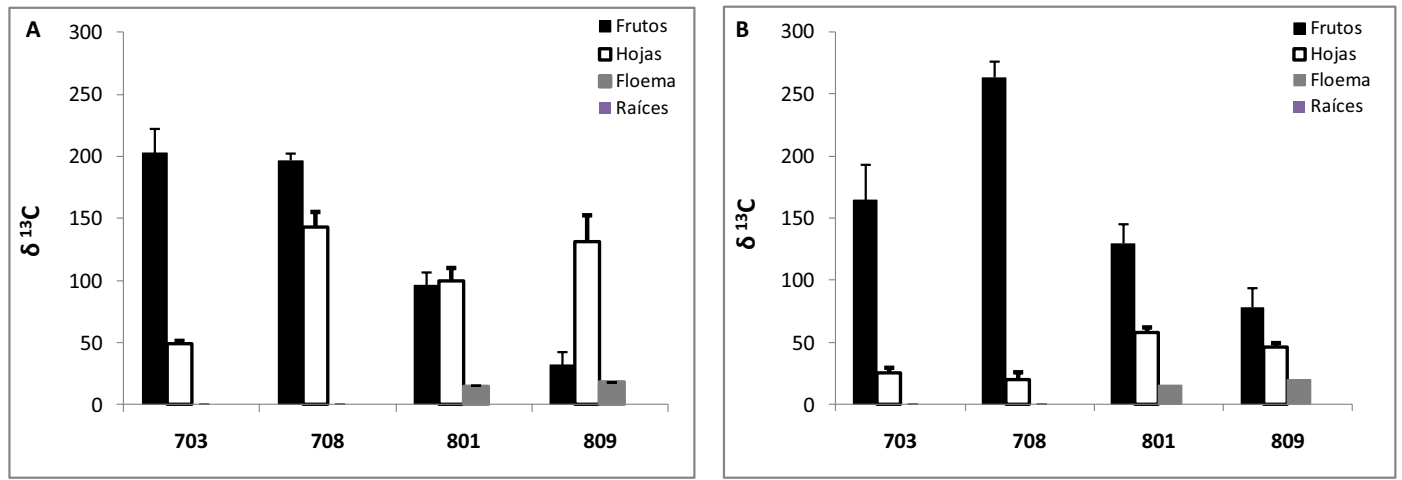

Fig. 5.9.- Evolución del contenido en ${ }^{13} \mathrm{C}$ en los diferentes órganos del níspero japonés cv. Algerie a los 4 (A) y a los 7 días (B) de la exposición de sus hojas al isótopo, en árboles jóvenes en plena producción en Valencia (España). Cada valor es la media de 3 árboles. Las barras verticales indican el ES. El eje de abscisas representa los estados fenológicos según la escala BBCH.

Algo parecido se encontró cuando se cambiaron las condiciones climáticas y de cultivo de los árboles en estudio (Fig. 5.10). También en los experimentos llevados a cabo en Palermo (Sicilia, Italia) el ${ }^{13} \mathrm{C}$ sólo se encontró en el floema más alejado de la panícula cuando la exposición de las hojas se llevó a cabo a partir del momento en que los frutos habían completado su crecimiento, es decir, a partir del estado fenológico 801 de la escala $\mathrm{BBCH}$. Es más, el máximo contenido floemático no se detectó hasta más tarde, cuando éstos completaron su maduración (estado $809 \mathrm{BBCH}$ ) (Fig. $5.10 \mathrm{C}$ ). Por otro lado, el mayor contenido de ${ }^{13} \mathrm{C}$ en los frutos a lo largo de los 15 días de su determinación cuando la exposición al mismo se realizó cuando los frutos estaban recién cuajados (estado $609 \mathrm{BBCH}$ ) y, sobre todo, cuando ya tenían el 30\% de su tamaño final y frente a los que iniciaban su maduración (estado 801 BBCH) (Fig. 5.10 B) indicó, también aquí, la elevada exigencia energética por parte de éstos en el momento del cuajado y, sobre todo, en pleno crecimiento. El descenso generalizado en el tiempo de su contenido en todos los órganos estudiados, demuestra una movilización de los fotoasimilados en el árbol fuertemente influida por el estado de desarrollo de los diferentes sumideros. En coherencia con ello, el contenido de ${ }^{13} \mathrm{C}$ en los frutos durante el cuajado y su crecimiento, estados fenológicos 609 y 703 de la escala BBCH, siempre fue superior al de sus hojas, a pesar de ser éstas las que recibieron directamente el ${ }^{13} \mathrm{C}$ (Fig. $5.10 \mathrm{~A}$ y B). 

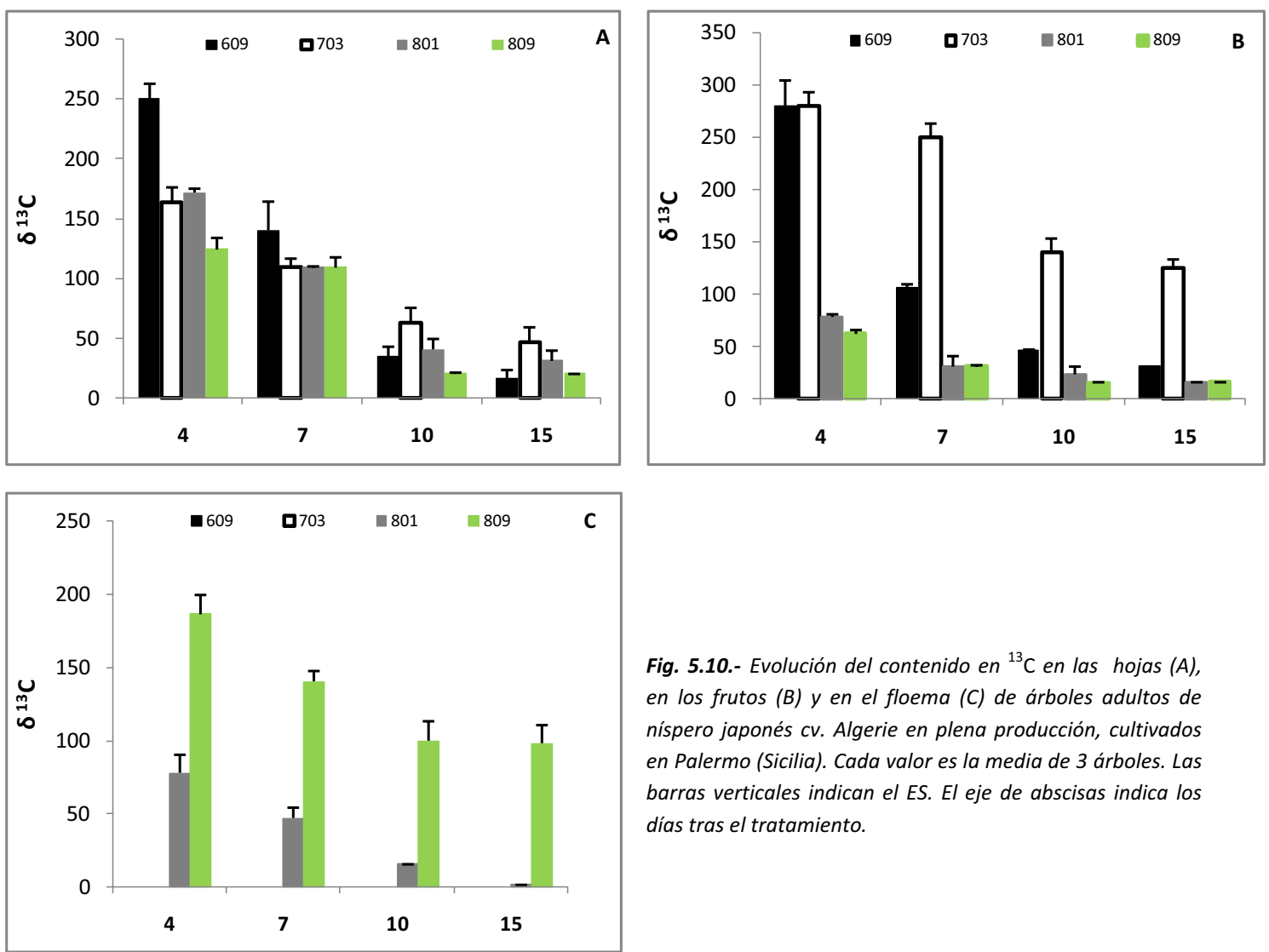

Fig. 5.10.- Evolución del contenido en ${ }^{13} \mathrm{C}$ en las hojas $(A)$, en los frutos (B) y en el floema (C) de árboles adultos de níspero japonés cv. Algerie en plena producción, cultivados en Palermo (Sicilia). Cada valor es la media de 3 árboles. Las barras verticales indican el ES. El eje de abscisas indica los días tras el tratamiento.

La concentración de las fracciones nitrogenadas en las raíces del cv.'Piera' y 'Algerie' se analizaron durante todo el periodo de crecimiento y maduración de sus frutos y hasta el final del crecimiento vegetativo. La concentración de nitratos en las raíces del cv. Algerie descendió espectacularmente hasta que el fruto alcanzó el $60 \%$ de su tamaño final, aumentando significativamente a continuación hasta 4 veces cuando éste completó su crecimiento y descendiendo progresivamente de nuevo hasta que, con la parada estival, los brotes detuvieron su crecimiento (Fig. 5.11 A). La evolución del cv. Piera fue prácticamente idéntica, sólo que, en este caso, el descenso inicial de la concentración se acortó hasta el estado fenológico 704 de la escala BBCH, mientras que el aumento posterior de ésta se anticipó al estado 706 de esta misma escala. A pesar de ello, este incremento de hasta de hasta 2.5 veces duró también para este cultivar hasta que los frutos completaron su crecimiento (Fig. $5.11 \mathrm{~A}$ ). Las diferencias en la concentración de $\mathrm{NO}_{3}{ }^{-}$en las raíces de ambos cultivares alcanzaron la significación estadística a partir del estado 706 de la escala BBCH de desarrollo del fruto. En el estado fenológico 709, cuando se detectó el 
segundo máximo en ambos cultivares como consecuencia del crecimiento del fruto, las raíces del cv. Piera tenían una concentración superior en $569.9 \mu \mathrm{g} \mathrm{g}^{-1} \mathrm{~ms}$ a las del cv. Algerie (Fig. $5.11 \mathrm{~A}$ ). El efecto del fruto alcanzó, por tanto, a las raíces que, por un lado, redujeron su absorción de nitratos, como indica el descenso de su concentración durante el periodo de crecimiento del fruto, y, por otra, alteraron la actividad del enzima responsable de reducirlos a amonio, como muestra la acumulación de éste en la fase final de su crecimiento (Fig. $5.11 \mathrm{~A}$ ).

La evolución del contenido en amonio en las raíces de los cvs. 'Piera' y 'Algerie' fue idéntica hasta que sus frutos cambiaron de color, disminuyendo progresivamente con su crecimiento hasta valores mínimos de $108.7 \mu \mathrm{g} \mathrm{g}^{-1} \mathrm{~ms}$ y $30.4 \mu \mathrm{g} \mathrm{g}^{-1} \mathrm{~ms}$, respectivamente, cuando éstos alcanzaron su tamaño final, aumentando posteriormente, al inicio del cambio de color, hasta $300 \mu \mathrm{g} \mathrm{g}^{-1} \mathrm{~ms}$ y $200 \mu \mathrm{g} \mathrm{g}^{-1} \mathrm{~ms}$, aproximadamente. En el momento de la maduración (estado $809 \mathrm{BBCH}$ ), mientras en los primeros la concentración disminuyó en $80.7 \mu \mathrm{g} \mathrm{g}^{-1} \mathrm{~ms}$, en los segundos aumentó en $35.6 \mathrm{mg} \mathrm{g}^{-1} \mathrm{~ms}$, igualándose prácticamente (Fig. 5.11 B). A partir de este momento, y hasta el final del crecimiento vegetativo, la concentración de amonio en la raíces del cv. Algerie se mantuvo prácticamente constante, a diferencia de la del cv. Piera que aumentó hasta duplicarse en pleno desarrollo de los brotes, para reducirse prácticamente a la mitad, 45 días más tarde con la parada estival (Fig. 5.11 B).

La acumulación de nitratos detectada en las raíces de ambos cultivares en el estado fenológico 709 de la escala $\mathrm{BBCH}$ y su posterior descenso se corresponde estequiometricamente con el descenso en la concentración de iones amonio en estado 709 BBCH y su incremento posterior en el estado fenológico 801

(Fig 5.11). Es de destacar la importancia cuantitativa del ión nitrato frente al amonio en las raíces. Así, mientras la concentración de los primeros alcanzó valores máximos entre 1600 y $1800 \mu \mathrm{g} \mathrm{g}{ }^{-1} \mathrm{~ms}$, la de los segundos apenas superó los $800 \mu \mathrm{g} \mathrm{g}^{-1} \mathrm{~ms}$.
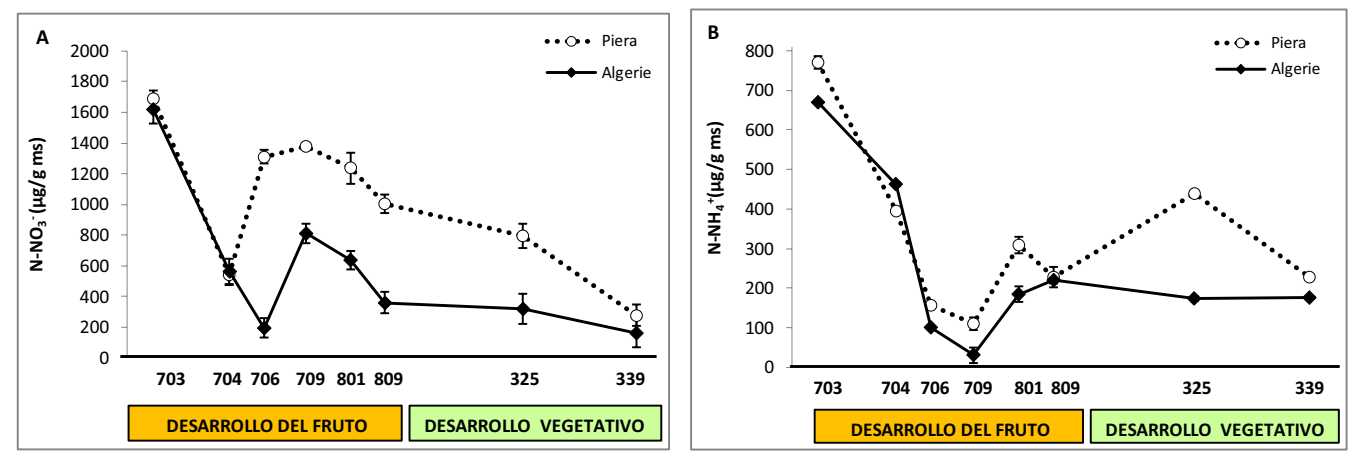

Fig. 5.11.- Evolución de la concentración de las fracciones nitrogenadas, $\mathrm{N}-\mathrm{NO}_{3}^{-}$(A) y $\mathrm{N}-\mathrm{NH}_{4}^{+}$(B), en las raíces de árboles adultos de níspero japonés cvs. 'Algerie' y 'Piera' a lo largo del ciclo vegetativo. Cada valor es la media de 5 árboles. Las barras verticales indican el ES. El eje de abscisas representa los estados fenológicos según la escala BBCH. 
La evolución de la concentración de nitrógeno proteico en las raíces de estos mismos árboles también estuvo marcadamente influida por la presencia de sus frutos, que vieron significativamente reducida su concentración mientras crecían. Aunque este comportamiento se presentó de manera generalizada en los dos cultivares estudiados, en el 'Piera' este descenso se prolongó hasta que sus frutos completaron el crecimiento (estado fenológico 709 de la escala BBCH), mientras que en el cv. Algerie se anticipó al estado fenológico 706 de la misma escala, y fue significativamente más pronunciado (Fig. 5.12). Posteriormente, al finalizar el crecimiento de los frutos, las raíces del primero aumentaron significativamente su concentración en un $60 \%$ hasta igualarse prácticamente con la del segundo. Con el cambio de color de los frutos, únicamente el cv. Piera aumentó significativamente la concentración de nitrógeno proteico en sus raíces, hasta en un 34.5\%, que posteriormente con su maduración, continuó hasta alcanzar el máximo con $14.8 \mathrm{mg}$ $\mathrm{g}^{-1} \mathrm{~ms}$ (Fig. 5.12). Aunque las raíces del cv. Algerie también aumentaron la concentración de esta fracción nitrogenada cuando maduraron sus frutos, ésta fue significativamente inferior, hasta $3.8 \mathrm{mg} \mathrm{g}^{-1} \mathrm{~ms}_{\text {menos, }}$ que la del cv. Piera que siempre fue superior en todos los estados fenológicos estudiados (Fig. 5.12). Tras la recolección de los frutos y en pleno desarrollo de los brotes, la concentración de nitrógeno proteico en las raíces de ambos cultivares descendió progresivamente hasta que el crecimiento se detuvo como consecuencia de la parada estival. Pero mientras la concentración en el cv. Piera apenas descendió un 10\% respecto a su valor inicial, la del cv. Algerie fue un 35\% más baja (Fig. 5.12). Es de destacar la importancia cuantitativa de esta fracción nitrogenada respecto del resto de las estudiadas. Así, mientras en ésta se alcanzaron valores máximos de $14800 \mathrm{\mu g} \mathrm{g}^{-1} \mathrm{~ms}$, en la de nitratos y amonio nunca se superaron los $1700 \mathrm{y}$ $800 \mu \mathrm{g} \mathrm{g}^{-1} \mathrm{~ms}$, respectivamente. El contenido en esta fracción de las raíces, como ocurrió con las hojas (ver Fig. 2.37), también representó entre el $95 \%$ y $98 \%$ del nitrógeno total, y aunque su concentración, por tanto, apenas estuvo cuantitativamente influida por la del resto de las fracciones nitrogenadas, el metabolismo de éstas sí.

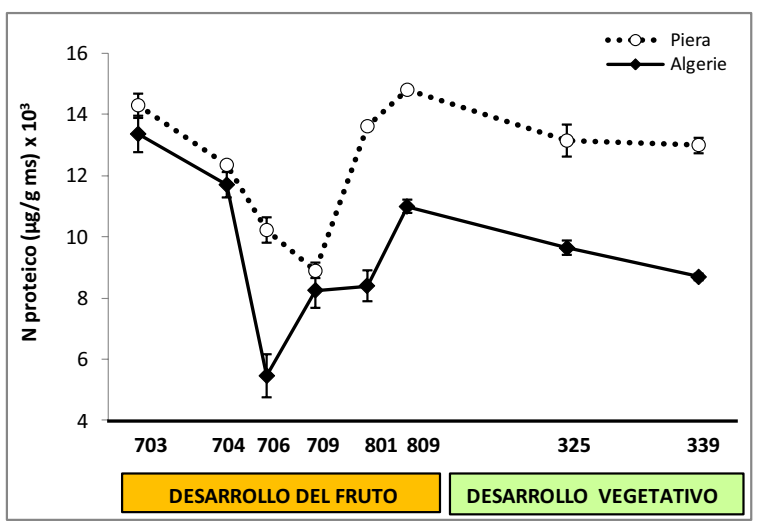

Fig. 5.12.- Evolución de la concentración de N proteico en las raíces de árboles adultos de níspero japonés cvs. 'Algerie' y 'Piera' a lo largo del ciclo vegetativo. Cada valor es la media de 5 árboles. Las barras verticales indican el ES. El eje de abscisas representa los estados fenológicos según la escala $\mathrm{BBCH}$. 
La presencia de los frutos en el árbol alteró marcadamente el crecimiento (ver Figs. 5.1 y 5.2) y la actividad de sus raíces y, como consecuencia de ello, la absorción y el transporte de las fracciones nitrogenadas a la copa. De este modo, la concentración de nitratos en las raíces y en el xilema del cv. Algerie siguió, paralelamente y de manera sincronizada, el mismo perfil en su evolución a lo largo de su ciclo vegetativo. Esto es, un descenso generalizado en ambos órganos, durante el periodo de máximo crecimiento de los frutos, seguido de un aumento significativo de la misma cuando éstos alcanzaron su tamaño final, para descender nuevamente desde que cambiaron de color y hasta el final del ciclo estudiado (Fig. 5.13 A). La marcada reducción de los nitratos registrada en las raíces del cv. Algerie entre los estados fenológicos 703 y 704 de la escala BBCH, afectó directamente a la del xilema que se redujo hasta en un $70.4 \%$, alcanzando de esta forma su valor más bajo. El mínimo contenido de esta fracción nitrogenada en las raíces se alcanzó más tarde, cuando los frutos ya tenían el 60\% de su tamaño final, a pesar de ello, éstas tuvieron significativamente más nitratos (194.4 $\left.\mu \mathrm{g} \mathrm{g}^{-1} \mathrm{~ms}\right)$ que su correspondiente xilema $\left(5.1 \mu \mathrm{g} \mathrm{g}^{-1} \mathrm{~ms}\right)$. Cuando los frutos completaron su crecimiento, estado fenológico 709 de la escala BBCH, la acumulación de nitratos detectada en las raíces del cv. Algerie, provocó un aumento significativo de éstos en su xilema hasta valores máximos de $15.5 \mu \mathrm{g} \mathrm{g}^{-1} \mathrm{~ms}$ (Fig. $5.13 \mathrm{~A}$ ). Con el cambio de color de éstos, la concentración radicular de nitratos disminuyó hasta un $33.5 \%$ y, con ello, el transporte de los mismos hacia la parte aérea del árbol que se mantuvo prácticamente estable hasta que maduraron. El flujo de estos iones hacia los nuevo brotes en desarrollo también disminuyó, hasta $4.2 \mu \mathrm{g} \mathrm{g}^{-1} \mathrm{~ms}$, cuando detuvieron su crecimiento con la llegada de la parada estival (Fig. 5.13 A).

La evolución de amonio en las raíces y en el xilema de estos mismos árboles también mostró un descenso generalizado de la concentración durante el periodo de crecimiento de los frutos. Este efecto también alcanzó al transporte de esta fracción nitrogenada hacia la parte aérea del árbol, que se vio significativamente reducida entre un $53 \%$ y $56.9 \%$ cuando los frutos estaban cerca de alcanzar su tamaño final, esto es, entre los estados fenológicos 706 y 709 de la escala BBCH (Fig. 5.13 B). Con el cambio de color de éstos (estado $801 \mathrm{BBCH}$ ), las raíces del cv. Algerie retomaron su actividad y el flujo de iones amonio por el xilema hacia la copa del árbol aumentó hasta $90.4 \mu \mathrm{g} \mathrm{g}^{-1} \mathrm{~ms}$, y más tarde, con la maduración de éstos (estado $809 \mathrm{BBCH}$ ) o en pleno crecimiento de los brotes (estado $325 \mathrm{BBCH}$ ), alcanzó los 134.5 y $212 \mu \mathrm{g} \mathrm{g}^{-1}$ $\mathrm{ms}$, respectivamente (Fig. 5.13 B). Las altas temperaturas, propias del verano, registradas durante el estado fenológico 339 de la escala BBCH, detuvieron temporalmente el crecimiento de estos brotes, por lo que la concentración amoniacal en el xilema de estos árboles se redujo de nuevo, hasta igualarse prácticamente con la que tenían en el momento de la maduración de sus frutos (Fig. 5.13 B). 

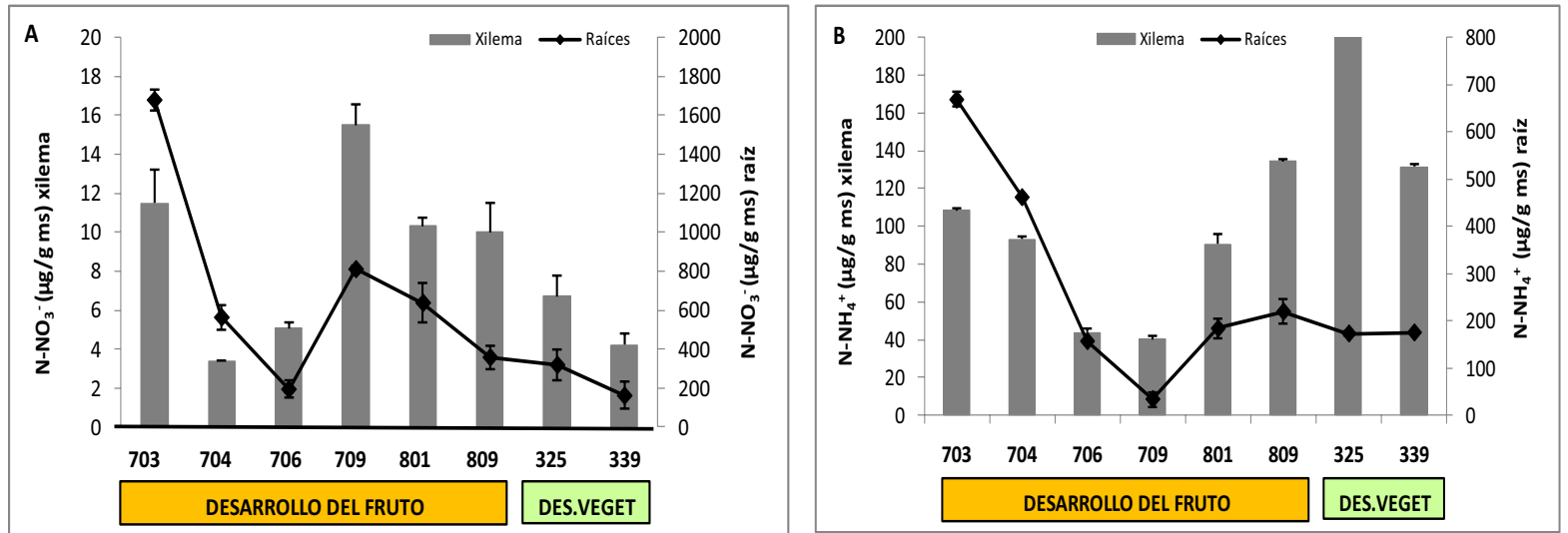

Fig. 5.13.- Evolución de la concentración de las fracciones nitrogenadas $\mathrm{N}-\mathrm{NO}_{3}^{-}(\mathrm{A})$ y $\mathrm{N}-\mathrm{NH}_{4}^{+}(\mathrm{B})$, en las raíces de árboles adultos y en el xilema de sus brotes mixtos en el níspero japonés cv. Algerie a lo largo del ciclo vegetativo. Cada valor es la media de 5 árboles. Las barras verticales indican el ES. El eje de abscisas representa los estados fenológicos según la escala BBCH.

En coherencia con ello, la evolución del contenido en nitrógeno proteico en las raíces y en el xilema del cv. Algerie mostró una tendencia complementaria a la del resto de las fracciones nitrogenadas. Esto es, un descenso significativo de esta concentración en ambos órganos durante el periodo de máximo crecimiento de sus frutos, seguido del aumento progresivo de ésta en las etapas próximas a su cambio de color y maduración, para descender ligeramente más tarde con el crecimiento de los nuevos brotes (Fig. 5.14). Al igual que con los nitratos y el amonio, el transporte de nitrógeno proteico hacia la parte aérea del árbol, estuvo fuertemente condicionado por balance de esta fracción en sus raíces. Por ello, la reducción significativa de su concentración en las raíces del cv. Algerie, hasta $6.3 \mathrm{mg} \mathrm{g}^{-1} \mathrm{~ms}$, en el estado fenológico 706 de la escala $\mathrm{BBCH}$, provocó una reducción de la misma en el xilema hasta de un $28.2 \%$ y 33.3\%, en los 2 estados fenológicos inmediatamente más próximos (Fig. 5.14).

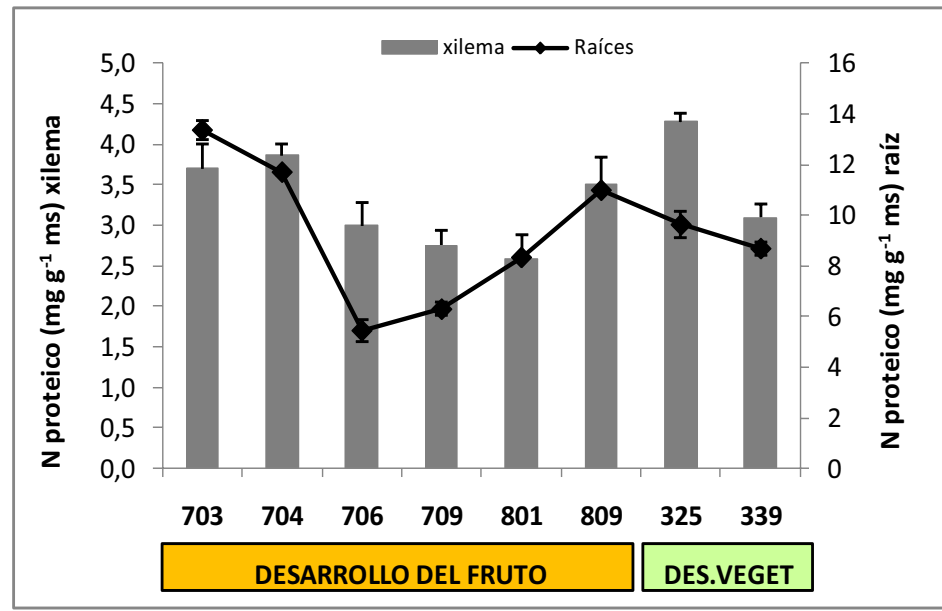

Fig. 5.14.- Evolución de la concentración de $N$ proteico en las raíces de árboles adultos y en el xilema de sus brotes mixtos en el níspero japonés cv. Algerie a lo largo del ciclo vegetativo. Cada valor es la media de 5 árboles. Las barras verticales indican el ES. El eje de abscisas representa los estados fenológicos según la escala $\mathrm{BBCH}$. 
El comportamiento del cv. Piera fue prácticamente el mismo, y las diferencias encontradas en la evolución de estas fracciones nitrogenadas se atribuyeron fundamentalmente a las diferentes generaciones que coexistían en el árbol. Así, por ejemplo, mientras la concentración de nitratos en las raíces del árbol, cuando la mayoría de sus frutos tenían el 30\% del tamaño final, era de $1438.2 \mu \mathrm{g} \mathrm{g}^{-1} \mathrm{~ms}$, el transporte de esta fracción nitrogenada hacia éstos o hacia aquellos de otras generaciones que ya habían cambiado de color era de $8.8 \mu \mathrm{g} \mathrm{g}^{-1} \mathrm{~ms}$ y $5.1 \mu \mathrm{g} \mathrm{g}^{-1} \mathrm{~ms}$ (círculo rojo), respectivamente (Fig. $5.15 \mathrm{~A}$ ). El estado de desarrollo de los frutos condicionó, por tanto, la movilización de los nitratos desde las raíces hacia la parte aérea del árbol.

Algo parecido ocurrió con el amonio que también vio modificada su concentración en el xilema por efecto del fruto. En este caso, ante la misma concentración amoniacal de las raíces del cv. Piera $\left(771.7 \mu \mathrm{g} \mathrm{g}^{-1} \mathrm{~ms}\right)$, cuando la mayoría de sus frutos estaban en el estado fenológico 703 de la escala $\mathrm{BBCH}$, la de su correspondiente xilema fue un $12.2 \%$ inferior a la del xilema de los brotes cuyos frutos, de otras generaciones, ya habían cambiado de color, es decir, aquellos que estaban en el estado 801 BBCH (círculo rojo; Fig. 5.15 B). Sin embargo, el transporte amoniacal hacia los frutos, cuando la mayoría de éstos estaban cambiando de color (estado $801 \mathrm{BBCH}$ ), fue significativamente inferior (94.5 $\mathrm{g} \mathrm{g} \mathrm{g}^{-1} \mathrm{~ms}$ ) a cuando solo existía una pequeña proporción de frutos, de otras generaciones, cambiando de color $\left(182.1 \mu \mathrm{g} \mathrm{g} \mathrm{gs}^{-1} \mathrm{~ms}\right.$ círculo rojo) (Fig. 5.15 B). Debe destacarse que este efecto fue el contrario al encontrado para los nitratos, cuya concentración fue significativamente superior en el primer caso $\left(11.7 \mu \mathrm{g} \mathrm{g}^{-1} \mathrm{~ms}\right.$, estado $\left.801 \mathrm{BBCH}\right)$ que en el segundo (5.1 $\mu \mathrm{g} \mathrm{g}^{-1} \mathrm{~ms}$; círculo rojo) (Fig. $5.15 \mathrm{~A}$ ).

Al igual que con el 'Algerie', la concentración de nitrógeno proteico en las raíces y en el xilema del cv. Piera también se vio alterada por la presencia de los frutos, así como por su estado de desarrollo. Así, para la misma concentración de nitrógeno proteico en sus raíces, cuando la mayoría de los frutos del árbol habían alcanzado el 30\% de su tamaño final y coexistían, a su vez, con una baja proporción de frutos de otras generaciones que ya habían cambiado de color, la concentración en el xilema de los primeros fue significativamente inferior $\left(2.9 \mathrm{mg} \mathrm{g}^{-1} \mathrm{~ms}\right)$ que la de los segundos $\left(4.6 \mathrm{mg} \mathrm{g}^{-1} \mathrm{~ms}\right.$ ) (Fig. $5.15 \mathrm{C}$ ). La presencia simultánea de varias generaciones de frutos, en diferentes estados del desarrollo en el cv. Piera, modificó, por tanto, el reparto de las fracciones nitrogenadas en el mismo. Solamente la concentración de nitrógeno proteico en el xilema entre los estados fenológicos 703 y 801 BBCH se mantuvo constante(Fig. 5.15 C). 

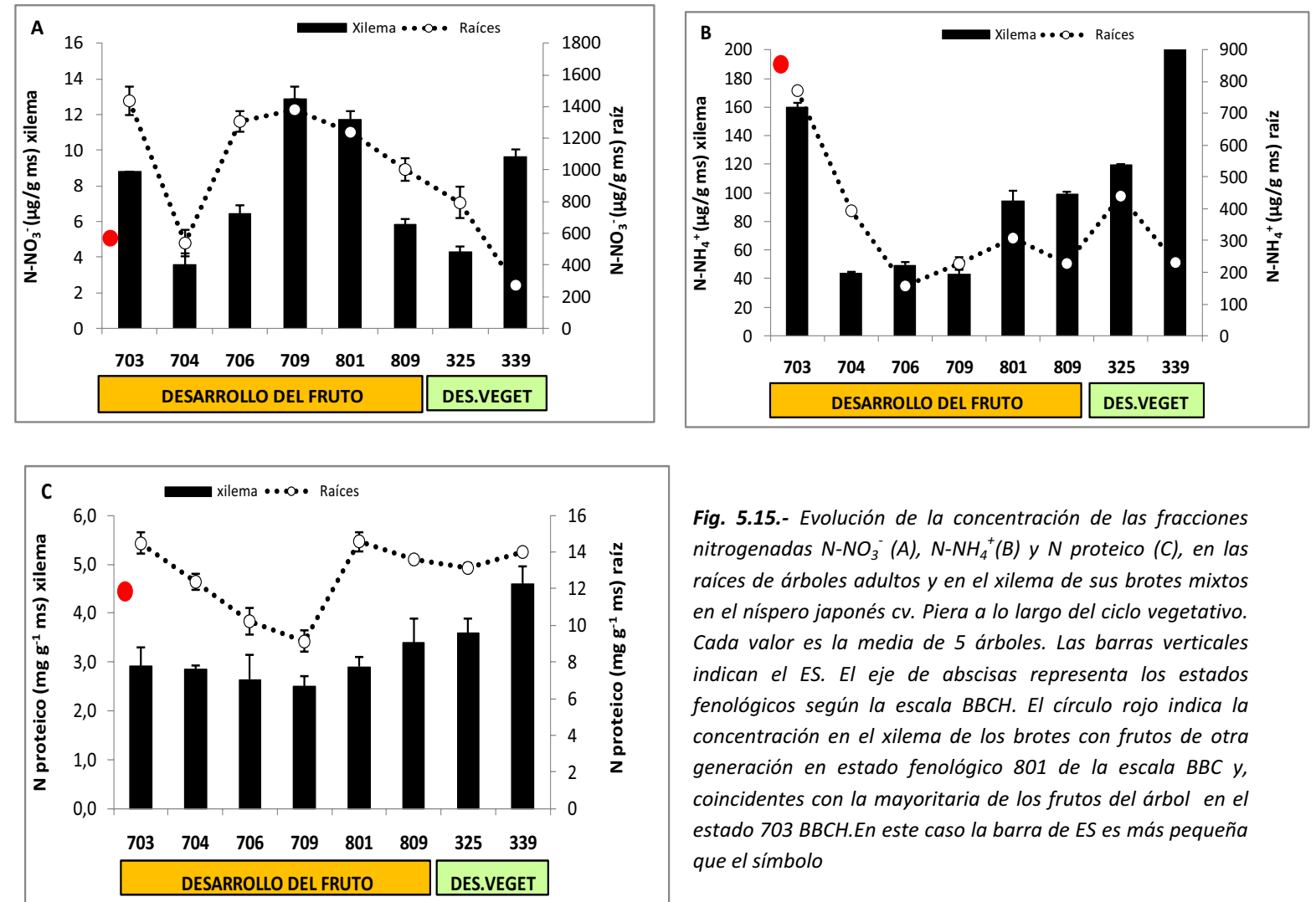

Fig. 5.15.- Evolución de la concentración de las fracciones nitrogenadas $\mathrm{N}-\mathrm{NO}_{3}^{-}(A), \mathrm{N}-\mathrm{NH}_{4}^{+}(B)$ y $\mathrm{N}$ proteico (C), en las raíces de árboles adultos y en el xilema de sus brotes mixtos en el níspero japonés cv. Piera a lo largo del ciclo vegetativo. Cada valor es la media de 5 árboles. Las barras verticales indican el ES. El eje de abscisas representa los estados fenológicos según la escala $B B C H$. El círculo rojo indica la concentración en el xilema de los brotes con frutos de otra generación en estado fenológico 801 de la escala BBC $y$, coincidentes con la mayoritaria de los frutos del árbol en el estado 703 BBCH.En este caso la barra de ES es más pequeña que el símbolo

La evolución de la concentración del ión amonio en el floema de un brote con frutos demostró, en ambos cultivares, un descenso progresivo con el desarrollo del fruto hasta alcanzar valores mínimos a partir del momento del cambio de color del fruto, que persistieron durante su maduración (Fig. 5.16).

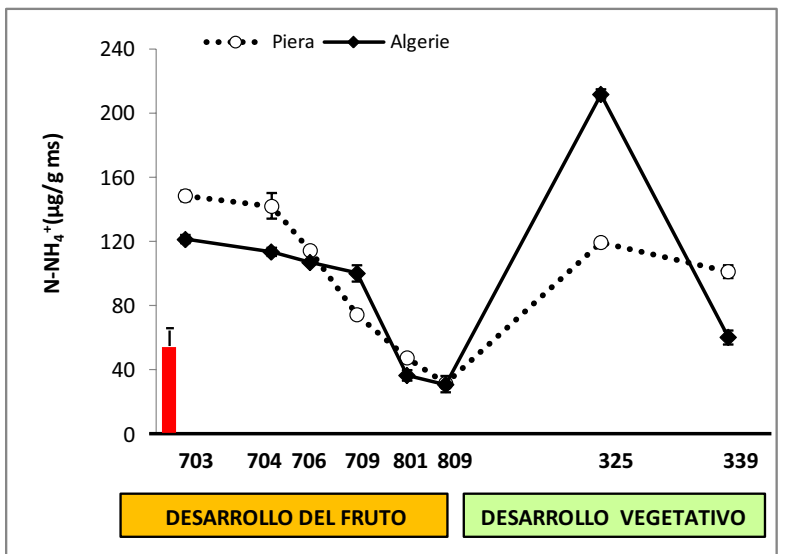

Fig. 5.16. Evolución de la concentración de la fracción $\mathrm{N}-\mathrm{NH}_{4}^{+}$en el floema de brotes con frutos de los cvs. 'Piera' y 'Algerie' de árboles adultos de níspero japonés a lo largo del ciclo vegetativo. Cada valor es la media de 5 árboles. Las barras verticales indican el ES. El eje de abscisas representa los estados fenológicos según la escala $B B C H$. La barra roja indica la concentración en el brote con otra generación de frutos estado 801 de la escala fenológica $B B C H$ y coincidentes con la mayoría de los frutos del árbol en el estado $703 \mathrm{BBCH}$. 
Superada la maduración, la concentración de $\mathrm{N}^{-\mathrm{NH}_{4}}{ }^{+}$se incrementó con el desarrollo vegetativo hasta alcanzar valores 6 veces superiores en el cv. Algerie y 4 veces superiores en el cv. Piera. Posteriormente descendió, pero de un modo más pronunciado y alcanzando valores significativamente inferiores en el primero y similares a los de la maduración (Fig. 5.16). La existencia de generaciones posteriores de frutos en desarrollo en el cv. Piera pueden explicar su descenso menos pronunciado, poniendo de manifiesto, una vez más, la mayor demanda a las hojas por parte de los frutos frente a los brotes en crecimiento.

Es de destacar que en el cv. Piera cuando la mayoría de los frutos del árbol se encontraban iniciando su crecimiento (estado 703 de la escala $\mathrm{BBCH}$ ) y la concentración de $\mathrm{N}_{-} \mathrm{NH}_{4}{ }^{+}$en el floema de los brotes que soportaban dichos frutos era próxima a $150 \mu \mathrm{g} \mathrm{g}^{-1} \mathrm{~ms}$, en el floema de los brotes con frutos de otras generaciones que estaban iniciando su cambio de color (estado $801 \mathrm{BBCH}$ ) su concentración era próxima a $60 \mu \mathrm{g} \mathrm{g}^{-1} \mathrm{~ms}$ y similar a la que los frutos que iniciaban el crecimiento alcanzarían al llegar al mismo estado fisiológico (Fig. 5.16).

El comportamiento de árboles jóvenes de los cvs. 'Piera' y 'Algerie' en el transporte de iones nitrato y amonio hacia sus frutos en desarrollo (Fig. 5.17) fue idéntico al de los árboles adultos (Figs. 5.13 y 5.15). También en ellos el desarrollo del fruto alteró la actividad de sus raíces. Así, en el periodo de máximo crecimiento del fruto, cuando alcanzó los estados fenológicos 706 y 709 de la escala BBCH, la concentración de nitratos en la raíz del cv. Algerie fue máxima, con valores en promedio de $317.8 \mu \mathrm{g} \mathrm{g}^{-1} \mathrm{~ms}$, mientras que la de amonio fue mínima, alrededor de $50 \mu \mathrm{g} \mathrm{g}^{-1} \mathrm{~ms}$. Como consecuencia de ello, la primera aumentó en el xilema de estos árboles en un 62.2\% al mismo tiempo que se reducía la segunda en un 32\% (Fig. $5.17 \mathrm{~A}$ ). Con la maduración de los frutos (estado $809 \mathrm{BBCH}$ ) las raíces retomaron su actividad y la concentración de nitratos se redujo significativamente hasta $80.1 \mu \mathrm{g} \mathrm{g}^{-1} \mathrm{~ms}$ coincidiendo, de esta forma, con el aumento del ion amonio hasta $67.4 \mu \mathrm{g} \mathrm{g}^{-1} \mathrm{~ms}$ (Fig. 5.17 A). Esta respuesta modificó el transporte de estas fracciones nitrogenadas hacia la copa, de manera que en el xilema se encontró un $50.2 \%$ más de amonio y un $29.7 \%$ menos de nitratos (Fig. 5.17 A). Con el crecimiento vegetativo, la raíz mantuvo prácticamente constante su concentración de $\mathrm{N}^{-\mathrm{NO}_{3}}{ }_{3}$, con valores superiores a $70 \mu \mathrm{g} \mathrm{g}{ }^{-1} \mathrm{~ms}$, mientras la de $\mathrm{N}^{-} \mathrm{NH}_{4}{ }^{+}$aumentaba 3.5 veces, hasta valores del orden de $275 \mathrm{\mu g} \mathrm{g}^{-1} \mathrm{~ms}$; esta acumulación se correspondió con el descenso de su concentración en el xilema que paso de valores próximos a $215 \mu \mathrm{g} \mathrm{g}^{-1} \mathrm{~ms}$ a valores ligeramente superiores a $70 \mu \mathrm{g} \mathrm{g}^{-1} \mathrm{~ms}$ (Fig. 5.17 A). Los combios en la concentración de $\mathrm{N}^{-\mathrm{NO}_{3}}{ }^{-}$en el xilema con el desarrollo vegetativo apenas fueron perceptibles.

El comportamiento del cv. Piera fue prácticamente el mismo, si bien las raíces de éste alcanzaron valores máximos de nitratos y mínimos de amonio, un $17.2 \%$ y un $19.4 \%$ inferiores, respectivamente, a los del cv. Algerie en los mismos estados fenológicos (Fig. 5.17 B). Estas diferencias en las raíces afectaron su 
transporte, y la concentración en el xilema de los árboles del cv. Piera fue $12.3 \mu \mathrm{g} \mathrm{g}^{-1} \mathrm{~ms}$ y $0.8 \mu \mathrm{g} \mathrm{g}^{-1} \mathrm{~ms}$ inferior en iones amonio y nitrato, respectivamente, que el cv. Algerie (Fig. 5.17B).

Es de destacar las diferencias notables detectadas en las concentraciones de estos metabolitos en árboles adultos y árboles jóvenes. Diferencias en el tamaño del sistema radicular y del volumen de copa, en el número de frutos en desarrollo (limitado en los segundos a no más de 20 por árbol frente a más de 450 en los primeros) y el propio cultivo (fertilización, suelo, etc.) son responsables de ello.
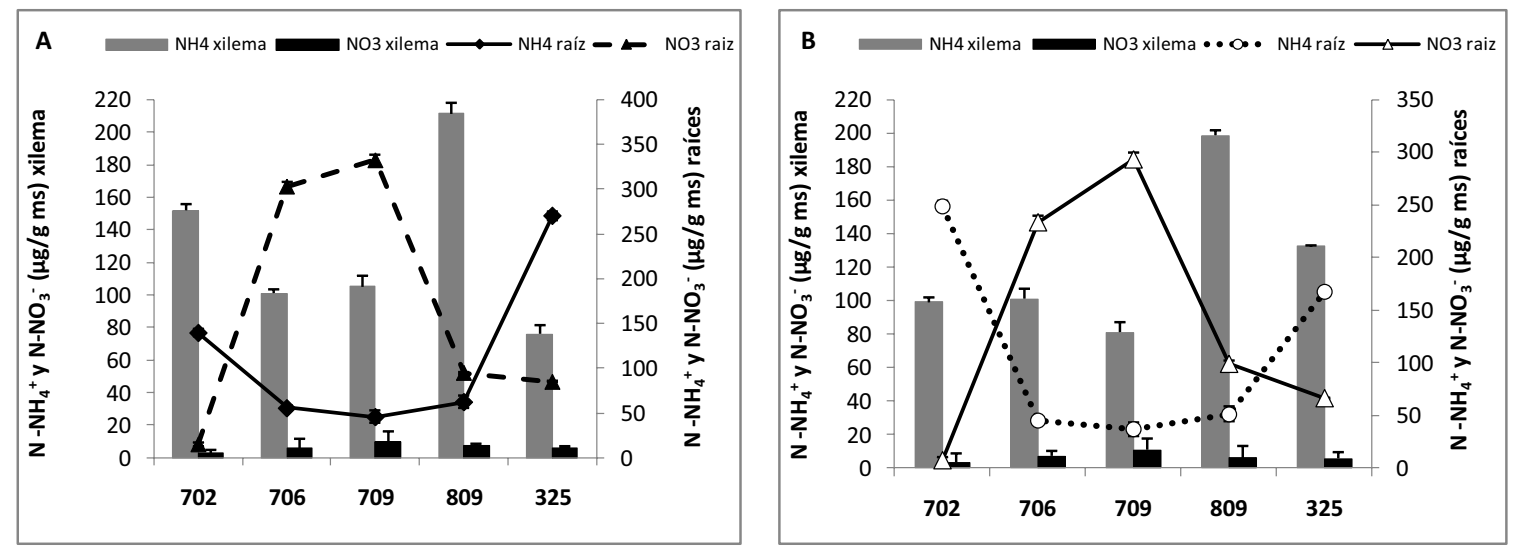

Fig. 5.17.- Evolución de la concentración de las fracciones nitrogenadas $\mathrm{N}_{-} \mathrm{NO}_{3}{ }^{-}$y $\mathrm{N}_{-} \mathrm{NH}_{4}^{+}$en las raíces de árboles jóvenes y en el xilema de sus brotes mixtos en el níspero japonés cvs. 'Algerie' (A) y 'Piera' (B) a lo largo del ciclo vegetativo. Cada valor es la media de 5 árboles. Las barras verticales indican el ES. El eje de abscisas representa los estados fenológicos según la escala $B B C H$.

La concentración de nitrógeno proteico de los diferentes órganos del árbol también se vio modificada por la presencia de sus frutos durante las etapas finales de su crecimiento, esto es, entre los estados fenológicos 706 y 709 de la escala BBCH. En la Fig. 5.18 se presenta el reparto porcentual de la fracción Nproteico en los diferentes órganos de un árbol del cv. Algerie cuando el fruto se encontraba en ambos estados fenológicos. Las hojas fueron las que mayor concentración de éste presentaron, independientemente del estado de desarrollo de sus frutos, con un $25 \%$ y un $32 \%$ del $\mathrm{N}$-proteico total del árbol en los estados fenológicos 706 y 709, respectivamente, seguidas muy de cerca por las raíces, que representaron el $24 \%$ y el $29 \%$ en promedio del nitrógeno proteico total, respectivamente. No obstante, el contenido foliar de éste cuando los frutos tenían el $60 \%$ de su tamaño final fue mayor $\left(10.5 \mathrm{mg} \mathrm{g}^{-1} \mathrm{~ms}\right)$ que cuando prácticamente lo habían completado $\left(8.9 \mathrm{mg} \mathrm{g}^{-1} \mathrm{~ms}\right)$ pero sin llegar a la significación estadística. Las raíces de los primeros también tuvieron mayor concentración de esta fracción nitrogenada que los 
segundos, 10.1 y $7.8 \mathrm{mg} \mathrm{g}^{-1} \mathrm{~ms}$, respectivamente, aunque en este caso, estas diferencias sí alcanzaron la significación estadística (Fig. 5.18). En coherencia con ello, su transporte desde las raíces, es decir, la concentración en el xilema, también fue superior en los primeros $\left(2.8 \mathrm{mg} \mathrm{g}^{-1} \mathrm{~ms}\right)$ que en los segundos (1.9 $\mathrm{mg} \mathrm{g}^{-1} \mathrm{~ms}$ ), aunque éstas sólo representaran, en ambos casos, el 7\% del nitrógeno total del árbol (Fig. 5.18). La concentración en el floema y en los tejidos de la panícula con frutos en estado fenológico 706 de la escala BBCH también fue superior a la analizada cuando éstos alcanzaron el estado 709 BBCH. Así, la concentración de nitrógeno proteico en los primeros fue de 3.4 y $5.8 \mathrm{mg} \mathrm{g}^{-1} \mathrm{~ms}$, respectivamente, mientras en los segundos fue de $2.5 \mathrm{mg} \mathrm{g}^{-1} \mathrm{~ms}$ en ambos órganos. Como consecuencia de ello, los frutos del cv. Algerie en estado fenológico 706 de la escala $\mathrm{BBCH}$, presentaron un $8 \%$ más de esta fracción nitrogenada que cuando éstos alcanzaron el estado 709 de la misma escala, lo que en términos absolutos significa valores de 9.4 y $3.9 \mathrm{mg} \mathrm{g}^{-1} \mathrm{~ms}$, respectivamente.
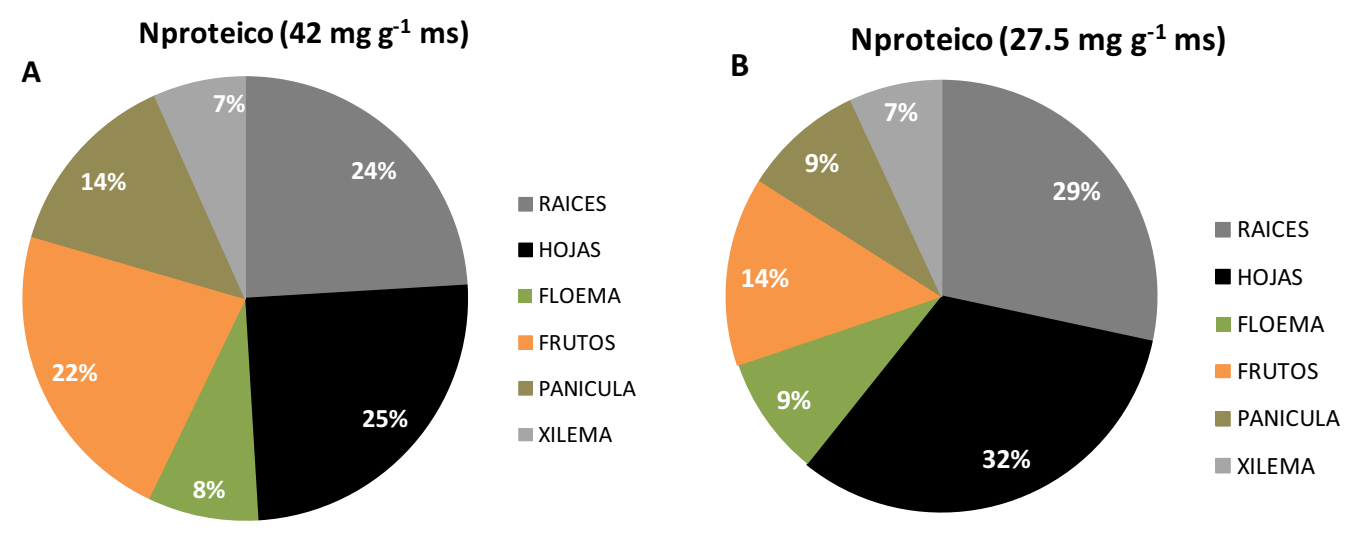

Fig. 5.18.- Influencia del estado de desarrollo de los frutos 706 (A) y 709 (B) de la escala BBCH en la distribución del nitrógeno proteico en los diferentes órganos de un árbol joven de níspero japonés cv. Algerie. Cada valor es la media de 4 árboles. El valor indicado en cada órgano representa su concentración de nitrógeno proteico y el porcentaje que ésta representa sobre el total del árbol.

En el cv. Piera, el reparto del nitrógeno proteico entre órganos fue muy similar al del cv. Algerie. Su concentración en todos los órganos analizados también fue superior en el estado fenológico 706 que en el 709 de la escala $\mathrm{BBCH}$, excepto el de las hojas que fue un $13 \%$ superior en los segundos. El contenido más elevado también se encontró en las hojas y en las raíces de estos árboles, aunque con pequeñas variaciones cuantitativas que, al igual que con los árboles adultos, se atribuyeron al solape de generaciones en diferentes estados fenológicos (Fig.5.19). 

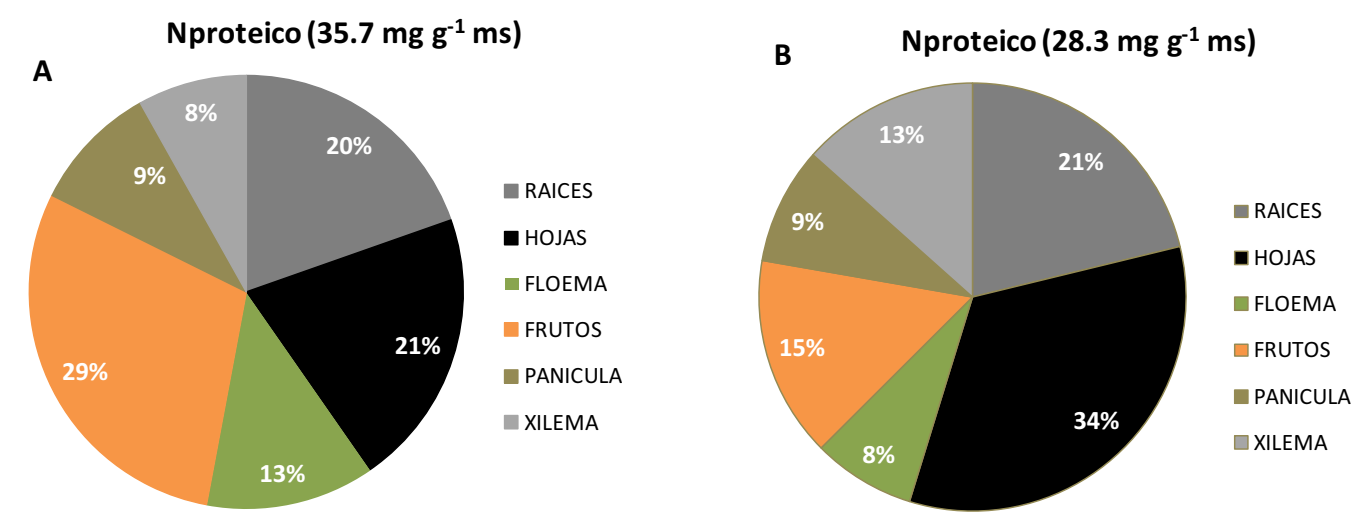

Fig. 5.19.- Influencia del estado de desarrollo de los frutos, 706 (A) y 709 (B) de la escala BBCH, en la distribución del nitrógeno proteico en los diferentes órganos de un árbol joven de níspero japonés cv. Piera. Cada valor es la media de 4 árboles. El valor indicado en cada órgano representa su concentración de nitrógeno proteico y el porcentaje que ésta representa sobre el total del árbol.

El balance hormonal en los diferentes órganos del árbol también se vio alterado por la presencia de los frutos en el árbol. Así, la concentración de AIA en las raíces y en el xilema del cv. Algerie, descendió progresivamente a lo largo del periodo de crecimiento de los frutos de manera paralela, hasta valores mínimos de 46.8 y $38.5 \mathrm{ng} \mathrm{g}^{-1} \mathrm{~ms}$, respectivamente, cuando éstos habían alcanzado prácticamente su tamaño final (estado 709 BBCH) (Fig. 5.20). Con el cambio de color de los frutos (estado 801 BBCH) esta auxina aumentó significativamente en ambos órganos, hasta valores, próximos entre sí, de 65.9 y 61.9 ng g ${ }^{1}$ ms en cada caso (Fig. 5.20 A). A partir de este momento y hasta que éstos maduraron, la evolución del AIA en las raíces y en el xilema de este árbol fue completamente divergente. Mientras en las primeras siguió aumentando ligeramente su concentración para luego descender suavemente, en el segundo se redujo hasta en un $14.9 \%$ para luego aumentar suavemente. En pleno desarrollo de los brotes (estado $325 \mathrm{BBCH}$ ), las diferencias en el contenido de esta hormona en las raíces y en el xilema desaparecieron (Fig. 5.20 A). El solape de sucesivas generaciones de frutos en el cv. Piera afectó al contenido de AIA de sus raíces y de su xilema que fue diferente al del cv. Algerie. Así, cuando la mayoria de los frutos de ambos ya habían alcanzado el 30\% de su tamaño final, es decir, en el estado fenológico 703 de la escala BBCH, las raíces y el xilema del cv. Algerie tuvieron mayor contenido auxínico, 92.7 y $68.3 \mathrm{ng} \mathrm{g}^{-1} \mathrm{~ms}$, respectivamente, que los correspondientes al cv. Piera que fueron 72.9 y $59.4 \mathrm{ng} \mathrm{g}^{-1} \mathrm{~ms}$. Además, la presencia simultánea en el cv. Piera de algunos de sus frutos en el estado fenológico 801 de la escala $\mathrm{BBCH}$, hizo que, para el mismo contenido radicular de AIA, el del xilema de los brotes con los frutos en dicho estado fenológico fuera un 
14.7\% menor que el mismo en el estado fenológico $703 \mathrm{BBCH}$. Además éste también fue menor $\left(50.7 \mathrm{ng} \mathrm{g}^{-1}\right.$ ms) que el del xilema del cv. Algerie en el mismo estado fenológico (61.9 $\mathrm{ng} \mathrm{g}^{-1} \mathrm{~ms}$ ) (Fig. 5.20 A). También en estados fenológicos más avanzados se encontraron diferencias en el balance hormonal de ambos cultivares. Así, cuando la mayoría de sus frutos habían alcanzado el estado fenológico 706 de la escala $\mathrm{BBCH}$, el contenido radicular del cv. Piera en AIA fue ligeramente inferior $\left(72.8 \mathrm{ng} \mathrm{g}^{-1} \mathrm{~ms}\right)$ que el del cv. Algerie (78.9 $\left.\mathrm{ng} \mathrm{g}^{-1} \mathrm{~ms}\right)$. Sin embargo, el efecto contrario se detectó en el xilema de estos árboles que fue un $18.1 \%$ superior en los primeros (Fig. 5.20 A).

La evolución de esta hormona en el floema y en los frutos del 'Algerie' fue prácticamente idéntica. Así, la concentración de ésta descendió progresivamente y de manera sincronizada en ambos órganos durante el crecimiento de los frutos, hasta valores mínimos cuando éstos alcanzaron, prácticamente, su tamaño final. Con el cambio de color de los mismos y hasta que completaron su maduración aumentó, por término medio, en el floema de estos árboles un 33.3\% y, como consecuencia, también lo hizo en sus frutos en un 9.9\% (Fig. 5.20 B). Tras su recolección, en pleno desarrollo de los brotes, la concentración de AIA en el floema de los brotes mixtos del cv. Algerie apenas se alteró con valores de $66.4 \mathrm{ng} \mathrm{g}^{-1} \mathrm{~ms}$. El contenido auxínico en los frutos del 'Algerie' fue, durante todo el periodo estudiado, significativamente superior a del floema de sus brotes reproductivos. Es de destacar, por tanto, la importancia cuantitativa de los primeros cuyos valores oscilaron entre 167.6 y $120.0 \mathrm{ng} \mathrm{g}^{-1} \mathrm{~ms}$, frente a los segundos que apenas superaron los 70

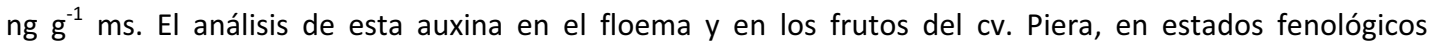
puntuales, mostró diferencias cuantitativas respecto del cv. Algerie. En efecto, cuando la mayoría de los frutos de ambos cultivares estaban en el estado fenológico 703 de la escala BBCH, el floema del primero tenían más AIA, $47.4 \mathrm{ng} \mathrm{g}^{-1} \mathrm{~ms}$ que el del segundo, $43.1 \mathrm{ng} \mathrm{g}^{-1} \mathrm{~ms}$. No obstante, la presencia simultánea de una parte de los frutos del cv. Piera en estados del desarrollo más avanzados, concretamente en el 801 de la escala BBCH no alteró su contenido respecto de los que estaban en el estado 703 BBCH. La comparación con frutos del cv. Algerie del mismo estado fenológico tampoco reveló diferencias significativas entre ellos. Pero, la presencia de diversas generaciones con diferentes estados del desarrollo en el cv. Piera sí influyó en el contenido floemático de esta hormona. Así, el floema de los brotes con frutos en estado fenológico 801 presentó un 16.3\% menos de AIA que el de los brotes con frutos en estados más precoces del desarrollo, esto es, en el $703 \mathrm{BBCH}$, con los que coexistían. La comparación con el cv. Algerie para el mismo estado fenológico de los frutos apenas mostró diferencias en el contenido de esta hormona (Fig. 5.20 B). En estados fenológicos posteriores también se encontraron diferencias en el balance hormonal de ambos cultivares. Así, cuando la mayoría de sus frutos habían alcanzado el $60 \%$ de su tamaño final, el contenido floemático del cv. Piera en AIA fue ligeramente superior $\left(57.9 \mathrm{ng} \mathrm{g}^{-1} \mathrm{~ms}\right)$ al del cv. Algerie $\left(52.5 \mathrm{ng} \mathrm{g}^{-1} \mathrm{~ms}\right)$ (Fig. 5.20 B). Como consecuencia de ello, los frutos de los primeros tuvieron un $15 \%$ más de esta hormona que los de los segundos. 

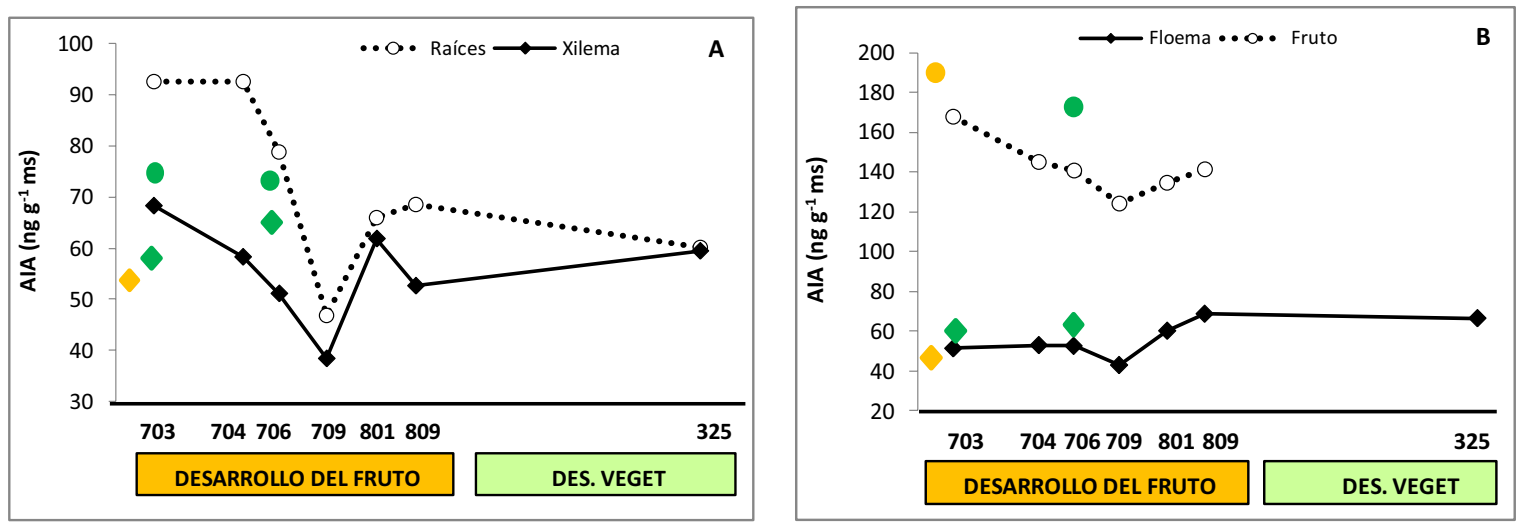

Fig. 5.20.- Evolución de la concentración de AlA en las raíces y en xilema (A) y en el floema y en los frutos (B) del níspero japonés cv. Algerie a lo largo del ciclo vegetativo. Cada valor es la media de 5 árboles. Las barras verticales del ES son más pequeñas que los símbolos. El eje de abscisas representa los estados fenológicos según la escala BBCH. El círculo y el rombo de color verde indican la concentración de AIA en los correspondientes órganos del cv. Piera en el estado fenológico representado. El círculo y el rombo de color naranja indican lo mismo pero para frutos del cv. Piera en el estado fenológico 801 de la escala BBCH.

El crecimiento de los frutos también alteró el balance de ABA en las raíces y en el xilema de los árboles. Su evolución en el cv. Algerie reveló un incremento progresivo de su concentración en los dos órganos hasta que sus frutos lalcanzaron el estado fenológico 706 de la escala $\mathrm{BBCH}$. A partir de este momento y hasta que éstos cambiaron de color el comportamiento entre ambos fue completamente divergente. Mientras las raíces disminuyeron significativamente su concentración de $A B A$ hasta en un $24.5 \%$, el xilema lo aumentó en un $12.8 \%$ (Fig. 5.21 A). Con la maduración de los frutos las raíces reestablecieron su concentración hasta igualarse, prácticamente, con la que tenían en el estado fenológico 706 de la escala BBCH. Ambos órganos alcanzaron en este momento sus valores máximos, con concentraciones de 150.2 y $96.6 \mathrm{ng} \mathrm{g}^{-1} \mathrm{~ms}$ en las raíces y en el xilema, respectivamente (Fig. 5.21). Tras la recolección, en pleno desarrollo de los brotes, la concentración de $\mathrm{ABA}$ en las raíces se mantuvo prácticamente estable mientras que su transporte desde éstas hacia la copa se redujo significativamente hasta en un 38.9\% (Fig. $5.21 \mathrm{~A}$ ). El análisis puntual de esta hormona en estos mismos órganos del cv. Piera reveló diferencias importantes en su concentración al compararlos con los del cv. Algerie. En efecto, cuando la mayoría de los frutos de ambos cultivares alcanzaron el estado fenológico 703 de la escala $\mathrm{BBCH}$, las raíces del primero tuvieron significativamente

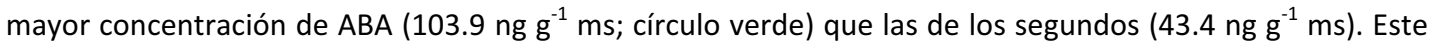
marcado incremento de ABA en las raíces del cv. Piera no se encontró en su xilema que, por el contrario, fue similar al del 'Algerie'. La presencia al mismo tiempo en el árbol de frutos en estados más avanzados de su desarrollo, en el 801 de la escala BBCH, tampoco modificó su transporte hacia éstos (Fig. 5.21 A). 
La evolución de ABA en el floema y en los frutos del cv. Algerie fue idéntica. Aumentó espectacularmente en ambos órganos durante las primeras fases del crecimiento del fruto, hasta valores máximos en éstos de $65.4 \mathrm{ng} \mathrm{g}^{-1} \mathrm{~ms}$, cuando habían alcanzado el $40 \%$ de su tamaño final, y de $51.8 \mathrm{ng} \mathrm{g}^{-1} \mathrm{~ms}$ en su correspondiente floema. En los periodos de máximo crecimiento de los frutos, es decir, hasta que alcanzaron prácticamente su tamaño final (estado $709 \mathrm{BBCH}$ ), su concentración de $\mathrm{ABA}$ se redujo significativamente hasta en un $40 \%$. En coherencia con ello y, de manera paralela, la de su floema también disminuyó hasta valores prácticamente similares a los de sus frutos (Fig. 5.21 B). Con el cambio de color y, hasta que éstos completaron su maduración, la concentración de esta hormona en ambos órganos aumentó de nuevo hasta alcanzar prácticamente los mismos valores que en el estado fenológico 704. Tras la recolección y, con ello la eliminación de los frutos, el nivel de ABA en el floema durante el crecimiento de sus brotes descendió significativamente hasta un 40\%, igualándose con su valor inicial (Fig. 5.21 B). El contenido de éste en el floema y en los frutos del cv. Piera también se vio afectado por el estado de desarrollo de éstos, sindo tanto mayor cuanto más avanzado era en su desarrollo. Así, la concentración de $A B A$ en ambos órganos, en el estado fenológico 706 de la escala $B B C H$, fue superior, 41.1 y $48.5 \mathrm{ng} \mathrm{g}^{-1} \mathrm{~ms}$, respectivamente, que en el 703 de la misma escala que fue, en cada caso, 30.9 y $43.6 \mathrm{ng} \mathrm{g}^{-1} \mathrm{~ms}$. La presencia de algunos frutos del cv. Piera cambiando de color, al mismo tiempo que la mayoría de ellos aún tenían el 30\% de su tamaño final, provocó diferencias cuantitativas importantes en el nivel su nivel de ABA. Así, el floema y los frutos del estado fenológico 801 de la escala $\mathrm{BBCH}$, tuvieron un $34.8 \%$ y $76.7 \%$ más de $A B A$, respectivamente, que los del estado 703 (Fig. 5.21B).
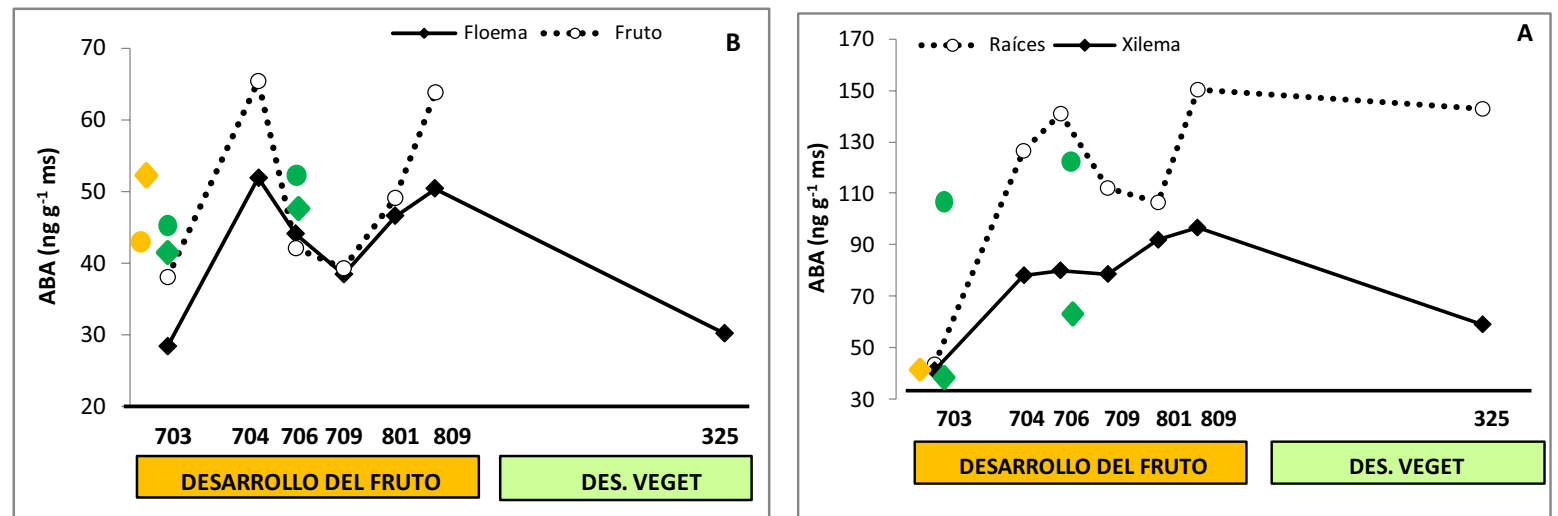

Fig. 5.21.- Evolución de la concentración de $A B A$ en las raíces y en xilema ( $A$ ) y en el floema y en los frutos (B) del níspero japonés cv. Algerie a lo largo del ciclo vegetativo. Cada valor es la media de 5 árboles. Las barras verticales del ES son más pequeñas que los símbolos. El eje de abscisas representa los estados fenológicos según la escala BBCH. El círculo y el rombo de color verde indican la concentración de AIA en los correspondientes órganos del cV. Piera en el mismo estado fenológico representado. El círculo y el rombo de color naranja indican lo mismo pero para frutos del cv. Piera en el estado fenológico 801 de la escala BBCH. 
El fruto también alteró el nivel de zeatina en las raíces y en el xilema del cv. Algerie. En ambos órganos y, de manera sincronizada, la concentración de ésta se redujo progresivamente a lo largo del crecimiento del fruto hasta valores mínimos de 40.6 y $35.3 \mathrm{ng} \mathrm{g}^{-1}$ ms en las raíces y en el xilema, respectivamente, en el estado fenológico 709 de la escala BBCH (Fig. 5.22). Esta reducción, sin embargo, en general afectó más a las primeras que disminuyeron su concentración un 70\%, mientras que en el xilema la reducción fue del $54 \%$ más que el segundo (Fig. 5.22 A). Con el cambio de color de los frutos y hasta que éstos completaron su maduración, el contenido de esta citoquinina aumentó espectacularmente en las raíces y en el xilema, de manera casi coincidente, hasta 79.9 y $66.5 \mathrm{ng} \mathrm{g}^{-1} \mathrm{~ms}$, respectivamente. A partir de este momento y, hasta el final del periodo estudiado, ésta se mantuvo prácticamente constante en ambos órganos (Fig. 5.22 A). Los análisis puntuales de zeatina, en las raíces y en xilema del cv. Piera, durante los estados fenológicos 703 y 706 de la escala BBCH, mostraron diferencias cuantitativas con las del cv. Algerie en estos mismos estados. Así, en el primero de ellos, la concentración de esta hormona en las raíces y en el xilema del cv. Piera fue significativamente inferior, 72.6 y $60.2 \mathrm{ng} \mathrm{g}^{-1} \mathrm{~ms}$, respectivamente, que en el cv. Algerie que fue, para los mismos órganos, 112.9 y $77.3 \mathrm{ng} \mathrm{g}^{-1} \mathrm{~ms}$ (Fig. 5.22). Sin embargo, la presencia simultánea en el cv. Piera de algunos de sus frutos cambiando de color, es decir, en el estado 801 BBCH, también mostró diferencias cuantitativas en el transporte de esta hormona hacia las diferentes generaciones de frutos. En efecto, para la misma concentración radicular de ésta $\left(72.6 \mathrm{ng} \mathrm{g}^{-1} \mathrm{~ms}\right)$, el xilema de los brotes con sus frutos en estado fenológico 703 de la escala BBCH presentó un 5\% más de esta citoquinina que el de aquelllos cuyos frutos estaban en el estado 801 de la misma escala (Fig. 5.22 A). De la misma manera, cuando los frutos de ambos cultivares alcanzaron el estado fenológico 706 de la escala BBCH, la concentración de esta hormona en los dos órganos del cv. Piera fue ligeramente superior, con 6.8 y $1 \mathrm{ng} \mathrm{g}^{-1} \mathrm{~ms}$ más en sus raíces y en su xilema, respectivamente, que la del cv. Algerie (Fig. 5.22 A).

La alteración del balance hormonal de la raíz también afectó a la parte aérea del mismo. De este modo, la evolución de la concentración de zeatina en el floema y en los frutos del cv. Algerie fue idéntica hasta que éstos completaron su crecimiento, invirtiéndose completamente en el momento en que cambiaron de color y hasta el final su maduración. Es decir, desde el estado fenológico 703 hasta el 709 de la escala BBCH, hubo un descenso generalizado de la concentración en ambos óganos, de manera más acusada en los frutos que la redujeron en un $22.9 \%$, que en el floema que lo hizo en un $17.8 \%$ (Fig. 5.22 B). El cambio de color de éstos, es decir, el estado fenológico 801 de la escala $\mathrm{BBCH}$, supuso un punto de inflexión en la evolución de esta hormona en el floema, en el que aumentó en $12.1 \mathrm{ng} \mathrm{g}^{-1} \mathrm{~ms}$; en el fruto, por el contrario,

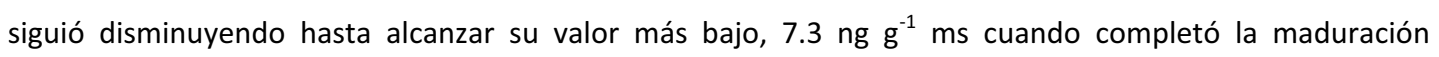
(estado $809 \mathrm{BBCH}$ ) (Fig. 5.22). Tras su recolección y con el desarrollo de los brotes, la concentración floemática de esta citoquinina se redujo ligeramente hasta igualar, prácticamente, la que tenía en el 
momento en que sus frutos cambiaron de color (estado fenológico 801 de la escala BBCH) (Fig. 5.22 B). La presencia simultánea en el cv. Piera, de frutos en diferentes estados de su desarrollo, también afectó significativamente al nivel de zeatina de estos frutos y del floema de sus correspondientes brotes. Así, el floema de los brotes que tenían sus frutos en el estado fenólogico 703 de la escala BBCH tuvo un $13.6 \%$ menos de zeatina que el del cv. Algerie en este mismo estado fenológico. Como consecuencia de ello, el nivel de esta hormona en los frutos del primero fue significativamente menor ( $84.2 \mathrm{ng} \mathrm{g}^{-1} \mathrm{~ms}$ ) que en los del segundo (93.5 $\mathrm{ng} \mathrm{g}^{-1} \mathrm{~ms}$ ). La acumulación de algunos de los frutos del cv. 'Piera en el estado fenológico 801 , presentes en el árbol al mismo tiempo que la mayoría de ellos lo estaban en el 703, fue un $7.8 \%$ inferior a la de estos últimos (Fig. 75.22B). Sin embargo, a diferencia de lo observado en los frutos, el nivel de esta hormona en el floema de los brotes, fue escasamente superior en el momento en que éstos cambiaron de color ( $46 \mathrm{ng} \mathrm{g}^{-1} \mathrm{~ms}$ ) que cuando alcanzaron el $30 \%$ de su tamaño final (43 $\mathrm{ng} \mathrm{g}^{-1} \mathrm{~ms}$ ). Cuando los frutos de ambos cultivares alcanzaron en su mayoría el estado fenológico 706 de la escala BBCH, su nivel de zeatina en los frutos del cv. Algerie fue un $11.8 \%$ superior a los del cv. Piera. Por el contrario y, de manera similar a lo detectado anteriormente, el floema del cv. Algerie presentó $9.9 \mathrm{ng} \mathrm{g}^{-1} \mathrm{~ms}$ menos de ésta que el del cv. Piera (Fig. 5.22 B).
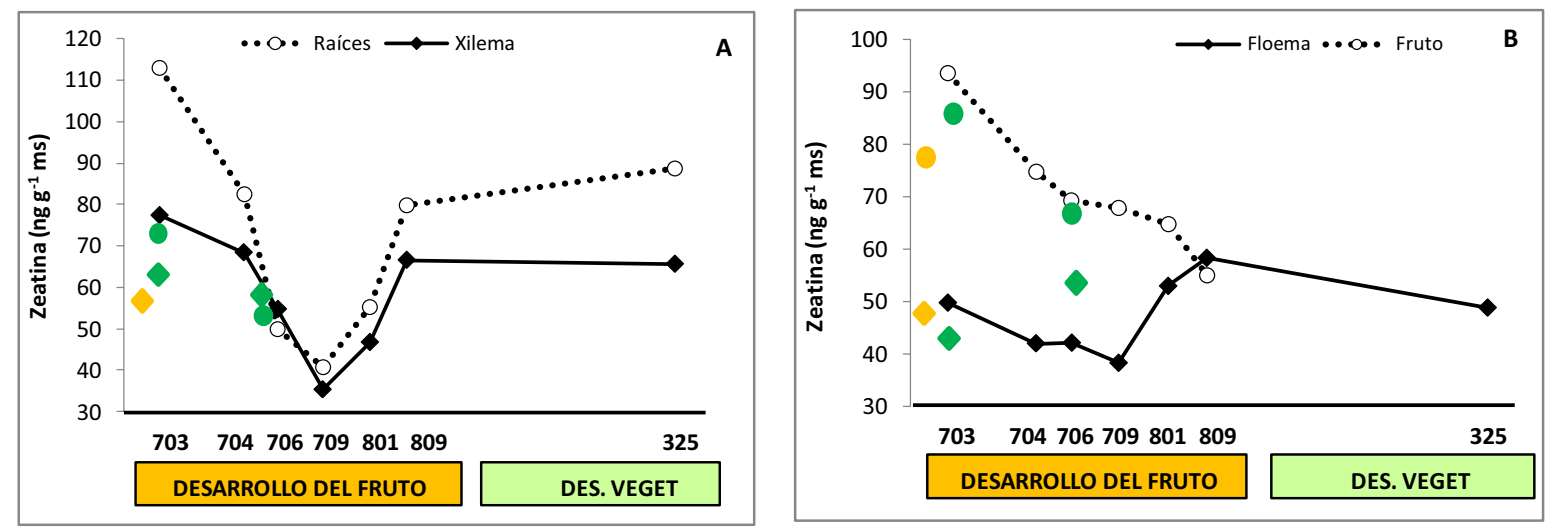

Fig. 5.22.- Evolución de la concentración de Zeatina en las raíces y en xilema (A) y en el floema y en los frutos (B) del níspero japonés cv. Algerie a lo largo del ciclo vegetativo. Cada valor es la media de 5 árboles. Las barras verticales del ES son más pequeñas que los símbolos. El eje de abscisas representa los estados fenológicos según la escala BBCH. El círculo y el rombo de color verde indican la concentración de AIA en los correspondientes órganos del cv. Piera en el mismo estado fenológico representado. El círculo y el rombo de color naranja indican lo mismo pero para frutos del cv. Piera en el estado fenológico 801 de la escala BBCH. 
El balance hormonal en los árboles jóvenes del cv. Algerie y del cv. Piera también se vio alterado por el crecimiento del fruto, como los demuestran los análisis de AIA, ABA y Zeatina. Las raíces de ambos cultivares redujeron significativamente su concentración de AIA hasta sus valores más bajos en el momento en que sus frutos completaron prácticamente su crecimiento, esto es, en el estado fenológico 709 de la escala BBCH. La magnitud de esta respuesta dependió del cultivar, siendo más sensible el 'Algerie' que la redujo más del doble de lo que lo hizo el 'Piera' (Fig. 5.23). Como consecuencia de ello, el contenido de esta hormona en el xilema de ambos cultivares también disminuyó hasta en un $13.2 \%$ en el cv. Algerie y un 20.3\% en el cv. Piera, respectivamente. En este caso, la reducción de la concentración de esta auxina fue de menor intensidad que la que registraron sus respectivas raíces. Con la maduración de los frutos de ambos cultivares, la concentración de AIA se recuperó hasta valores de 9.9 y $20.4 \mathrm{ng} \mathrm{g}^{-1} \mathrm{~ms}$ y, 2.2 y $3 \mathrm{ng} \mathrm{g}^{-1} \mathrm{~ms}$ más en las raíces y el xilema de los cvs. 'Algerie' y 'Piera', respectivamente (Fig. 5.23). Las diferencias encontradas en el comportamiento de ambos cultivares se relacionaron más con la coexistencia de generaciones de frutos en estados muy diferentes del desarrollo en el cv. Piera que con un efecto de sensibilidad varietal. La mayor concentración de AIA durante la maduración en las raíces que en el xilema de éste, contrariamente a lo observado en el cv. Algerie, es una prueba de ello (Fig. 5.23).
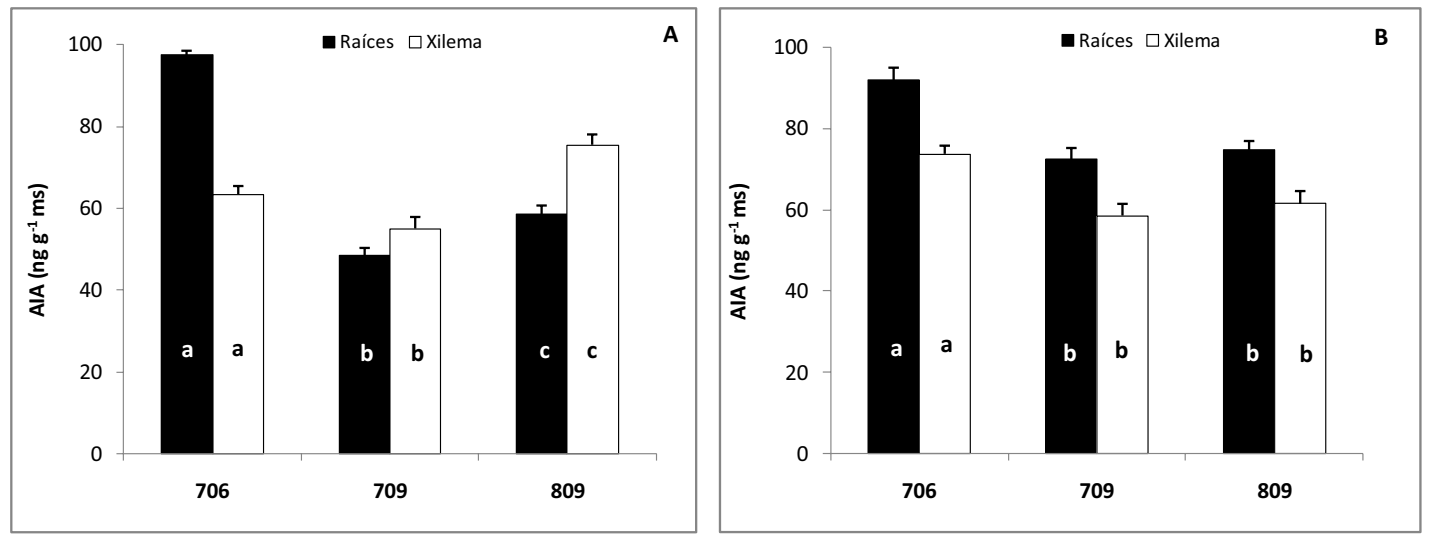

Fig. 5.23.- Evolución de la concentración de AIA en raíces y xilema de los brotes reproductivos de árboles jóvenes de níspero japonés cvs. 'Algerie' (A) y 'Piera' (B) en las etapas finales del crecimiento del fruto y durante su maduración. Cada valor es la media de 3 árboles. El eje de abscisas representa los estados fenológicos según la escala BBCH. Letras diferentes indican diferencias significativas ( $P \leq 0.05$ ) para un mismo órgano. 
El análisis de esta hormona en la parte aérea de los árboles reflejó un descenso significativo de su concentración en el floema y en los frutos de ambos cultivares (Fig. 5.24), coincidente con el detectado en sus raíces y xilema (Figs. 5.23). Así, los frutos del cv.' Algerie' que, prácticamente, habían completado su crecimiento, presentaron menor concentración de esta AIA (130 $\mathrm{ng} \mathrm{g}^{-1} \mathrm{~ms}$ ) que aquellos que sólo habían alcanzado el $60 \%$ de su tamaño final (169.9 $\mathrm{ng} \mathrm{g}^{-1} \mathrm{~ms}$ ) (Fig. 5.24). Esta respuesta se repitió exactamente en el cv. Piera, pero con concentraciones ligeramente más altas, 182.2 y $133.4 \mathrm{ng} \mathrm{g}^{-1} \mathrm{~ms}$, respectivamente (Fig 5.24 B). En el momento de la maduración, el AIA aumentó de nuevo su concentración un 29.5\% y un 33.9\% en los cvs. 'Algerie' y 'Piera', respectivamente. En coherencia con ello, el floema de estos árboles también la redujo en el estado fenológico 709 de la escala $\mathrm{BBCH}$, aumentándola posteriormente con la maduración de sus frutos (Fig. 5.24). Esta reducción fue más acusada en el cv. 'Piera, en el que la concentración de AIA pasó de 54.9 a $36.8 \mathrm{ng} \mathrm{g}^{-1} \mathrm{~ms}$ (Fig. 5.24 B), que en el cv. Algerie, en el que la diferencia sólo fue de $9.8 \mathrm{ng} \mathrm{g}^{-1}$ ms (Fig. 5.24 A). De la misma manera, el primero de ellos aumentó un 11.3\% más su concentración de AIA que el segundo en el momento en que sus frutos alcanzaron el estado fenológico 809 de la escala BBCH. Es de destacar la importancia cuantitativa de esta hormona en el fruto frente al floema de sus brotes reproductivos. Así, mientras en el primero se alcanzaron valores entre 130 y $200 \mathrm{ng} \mathrm{g}^{-1} \mathrm{~ms}$, en función del cultivar y de su estado fenológico, en el segundo apenas se superaron los $75 \mathrm{ng} \mathrm{g}^{-1} \mathrm{~ms}$ (Fig 5.24).
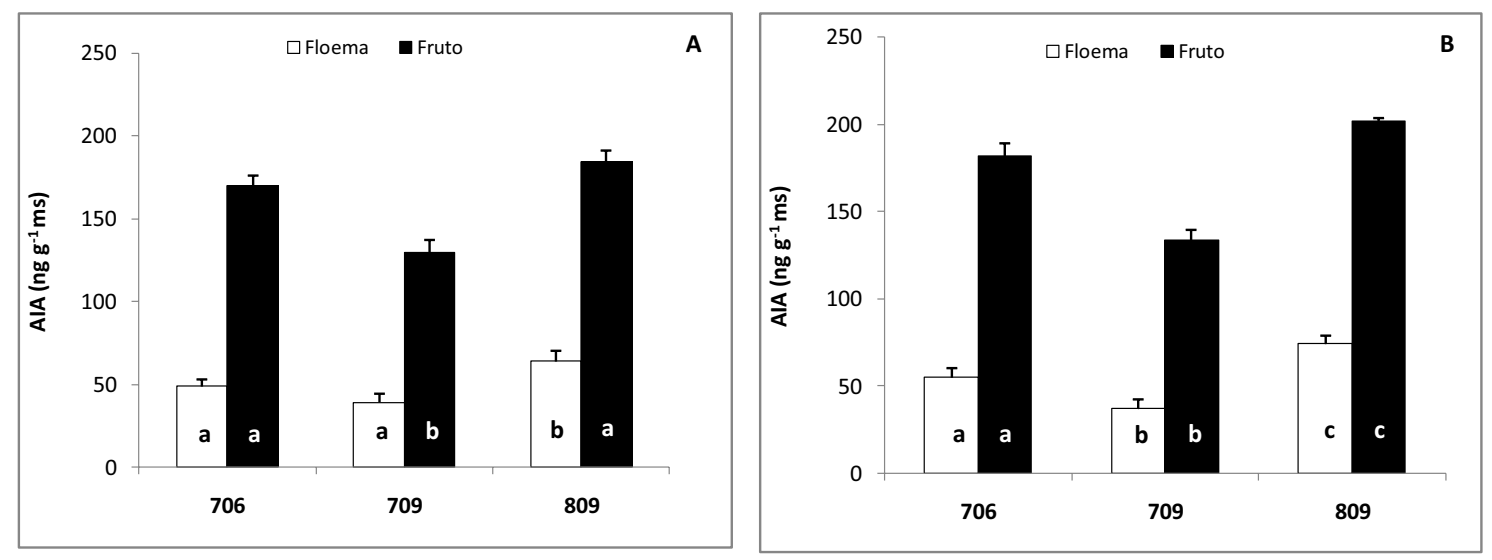

Fig. 5.24.- Evolución de la concentración de AIA en frutos y floema de los brotes reproductivos de árboles jóvenes de níspero japonés cvs. 'Algerie' (A) y 'Piera' (B) en las etapas finales del crecimiento del fruto y durante su maduración. Cada valor es la media de 3 árboles. El eje de abscisas representa los estados fenológicos según la escala BBCH. Letras diferentes indican diferencias significativas ( $P \leq 0.05$ ) para un mismo órgano. 
La concentración más baja de ABA en las raíces y el xilema de ambos cultivares también se correspondió con el estado fenológico 709 de la escala BBCH, es decir, cuando sus frutos habían, prácticamente, finalizado su crecimiento. En este momento, la concentración radicular de esta hormona en el cv. Algerie y en el cv. Piera se había reducido un $19.2 \%$ y $9.3 \%$, respectivamente, respecto de la registrada en el estado fenológico 706 (Fig. 5.25). Su concentración en el xilema siguió una pauta paralela y en el estado 709 BBCH presentó 5.0 y $16.1 \mathrm{ng} \mathrm{g}^{-1}$ ms menos de $A B A$, para cada cultivar, respectivamente, que el que tenía en el estado fenológico anterior (706 BBCH). Es de destacar que esta reducción fue más acusada en las raíces del cv. Algerie que en las del cv. Piera, contrariamente a lo detectado en sus xilemas. De nuevo, la presencia simultánea de varias generaciones de órganos reproductivos en diferentes estados fenológicos en el cv. Piera son responsables de sus diferencias con el cv. Algerie. En cualquier caso, con la maduración (estado 809 BBCH), el nivel de ABA en ambos cultivares aumentó en los dos órganos mencionados, alcanzando sus valores máximos. Hasta un $32.6 \%$ y $25.9 \%$ lo incrementaron, respectivamente, las raíces y el xilema del cv. Algerie $y$, aproximadamente en la misma proporción, pero con el orden invertido, lo hicieron los órganos del cv. Piera, $24.4 \%$ y $34.7 \%$, respectivamente (Fig. 5.25). Cabe destacar que la concentración de ABA en estos órganos, y para ambos cultivares, fue más baja en las etapas finales del crecimiento de los frutos que en el momento de su maduración. Así, las raíces y el xilema del cv. Algerie presentaron, antes de la maduración, valores promedio de 127.2 y $82.9 \mathrm{ng} \mathrm{g}^{-1} \mathrm{~ms}$, respectivamente, mientras que en el momento de la maduración la incrementaron hasta 168.6 y $108.5 \mathrm{ng} \mathrm{g}^{-1} \mathrm{~ms}$ en cada caso (Fig. 5.25 A). De la misma manera y, siguiendo el mismo orden, estos valores en el cv. Piera fueron, 111.9 y $82.9 \mathrm{ng} \mathrm{g}^{-1} \mathrm{~ms}$ en la primera fase, y 140.8 y $114.4 \mathrm{ng} \mathrm{g}^{-1} \mathrm{~ms}$, en la maduración (Fig. 5.25 B).
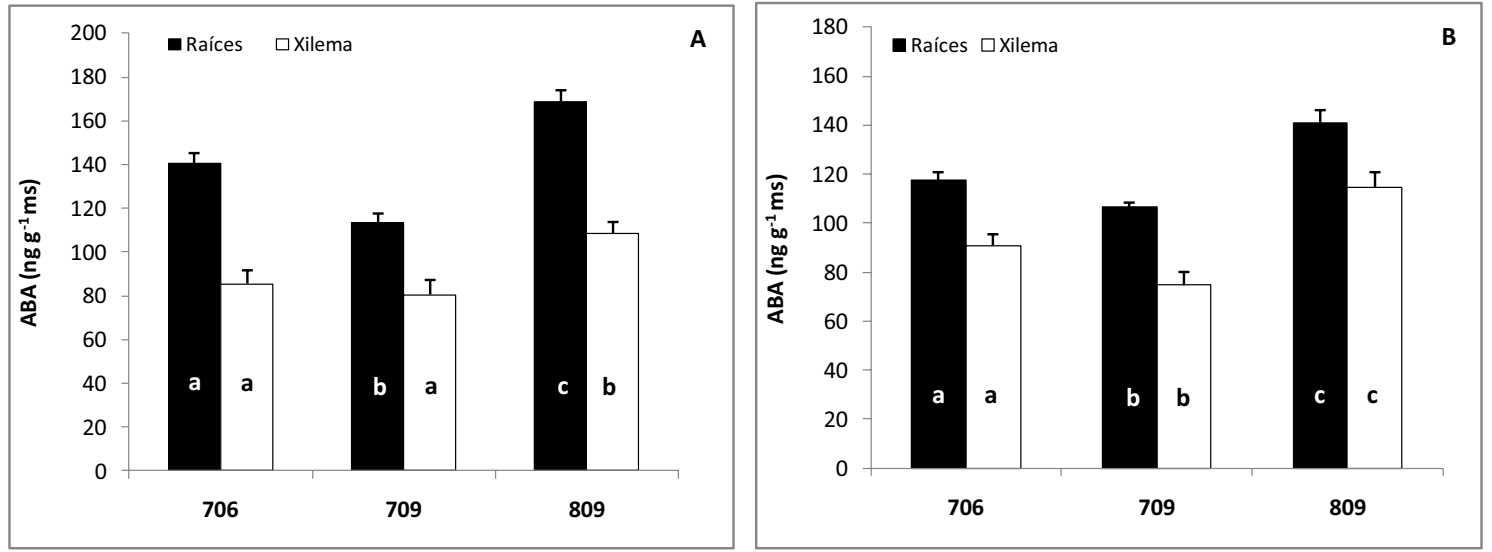

Fig. 5.25.- Evolución de la concentración de ABA en raíces y xilema de los brotes reproductivos de árboles jóvenes de níspero japonés cvs. 'Algerie' (A) y 'Piera' (B) en las etapas finales del crecimiento del fruto y durante su maduración. Cada valor es la media de 3 árboles. El eje de abscisas representa los estados fenológicos según la escala BBCH. Letras diferentes indican diferencias significativas $(P \leq 0.05)$ para un mismo órgano. 
El balance hormonal en la parte aérea de los árboles también se vio alterado por el crecimiento de sus frutos, así como por los cambios que éstos provocaron en el balance de sus raíces. Contrariamente a lo observado en las raíces de ambos cultivares, el nivel de ABA en sus frutos aumentó hasta valores máximos de 76.9 y $72 \mathrm{ng} \mathrm{g}^{-1} \mathrm{~ms}$, en los cvs. 'Algerie' y 'Piera', respectivamente, en el momento en que éstos completaron su crecimiento. En el momento de su maduración éste descendió de nuevo en ambos cultivares hasta igualarse, prácticamente, con el que tenía en el estado fenológico 706 de la escala BBCH en el caso del cv. Algerie o hasta valores inferiores (13.4\%) en el cv. Piera (Fig. 5.26). Como consecuencia de ello, la concentración de ABA en el floema de estos árboles también varió en función del estado fenológico del fruto. Así, mientras los frutos estaban creciendo su concentración en el floema se mantuvo prácticamente constante, con valores promedio en torno a los $50.0-55 \mathrm{ng} \mathrm{g}^{-1} \mathrm{~ms}$ en ambos cultivares. Sin embargo, en el momento de su maduración, esto es, en el estado fenológico 809 de la escala $\mathrm{BBCH}$, mientras en el cv. Algerie aumentó hasta $56.9 \mathrm{ng} \mathrm{g}^{-1} \mathrm{~ms}$, en el cv. Piera disminuyó hasta $47 \mathrm{ng} \mathrm{g}^{-1} \mathrm{~ms}$ (Fig. 5.26).
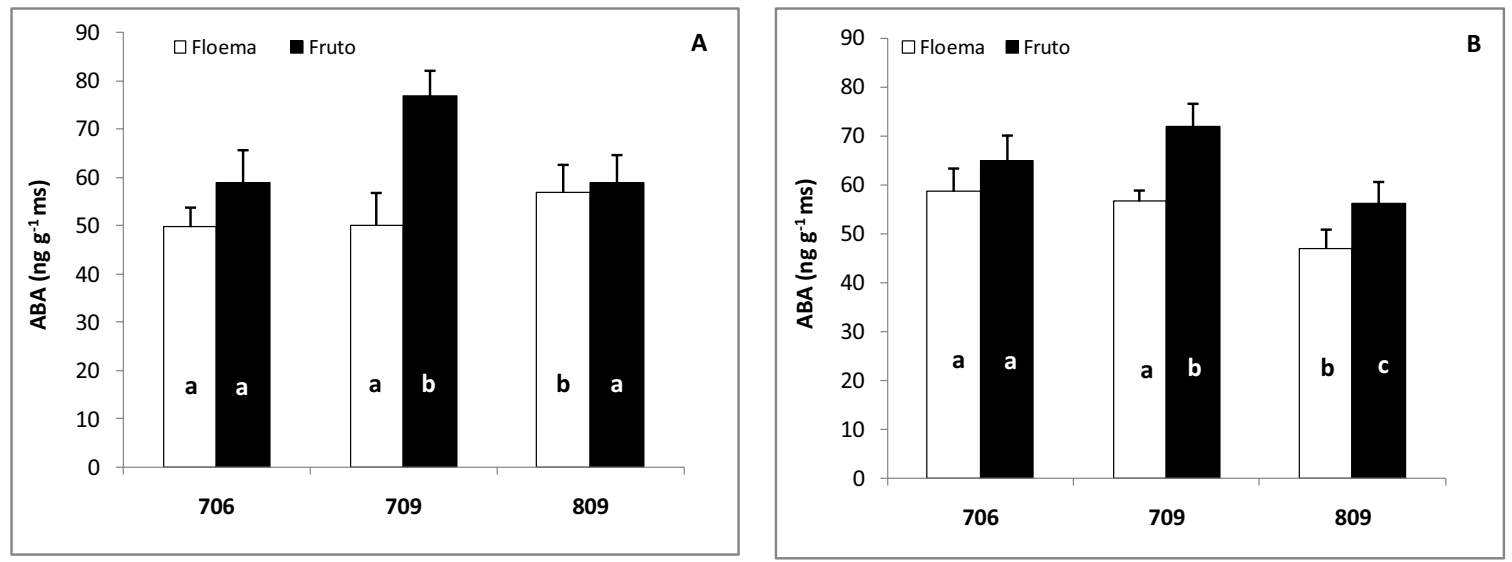

Fig. 5.26.- Evolución de la concentración de $A B A$ en frutos y floema de los brotes reproductivos de árboles jóvenes de níspero japonés cvs. 'Algerie' (A) y 'Piera' (B) en las etapas finales del crecimiento del fruto y durante su maduración. Cada valor es la media de 3 árboles. El eje de abscisas representa los estados fenológicos según la escala BBCH. Letras diferentes indican diferencias significativas ( $P \leq 0.05$ ) para un mismo órgano. 
La concentración de zeatina en las raíces y el xilema de estos árboles también se vio modificado por el estado de desarrollo de sus frutos. En este caso, al igual que con el resto de las hormonas estudiadas, los valores mínimos, 59.1 y 44.3 ng g $\mathrm{g}^{-1} \mathrm{~ms}$ en el cv. Algerie y 60.9 y $56.7 \mathrm{ng} \mathrm{g} \mathrm{ms}^{-1} \mathrm{en}$ el cv. Piera, respectivamente, se consiguieron en el estado fenológico 709 de la escala BBCH (Fig. 5.27). En ese momento, las raíces del primero habían reducido un $40.7 \%$ su concentración de zeatina, respecto a la que tenían en el estado fenológico anterior, y un $45.6 \%$ las del segundo. Como consecuencia de ello, la concentración en el xilema también se redujo un $42.3 \%$ en el primero y apenas un $6.2 \%$ en el segundo. En el momento de la maduración, es decir, en el estado fenológico 809 de la escala BBCH, esta citoquinina

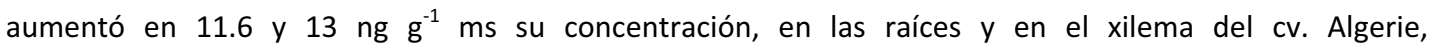
respectivamente, mientras en el cv. Piera el aumento fue prácticamente inapreciable(Fig. 5.27).
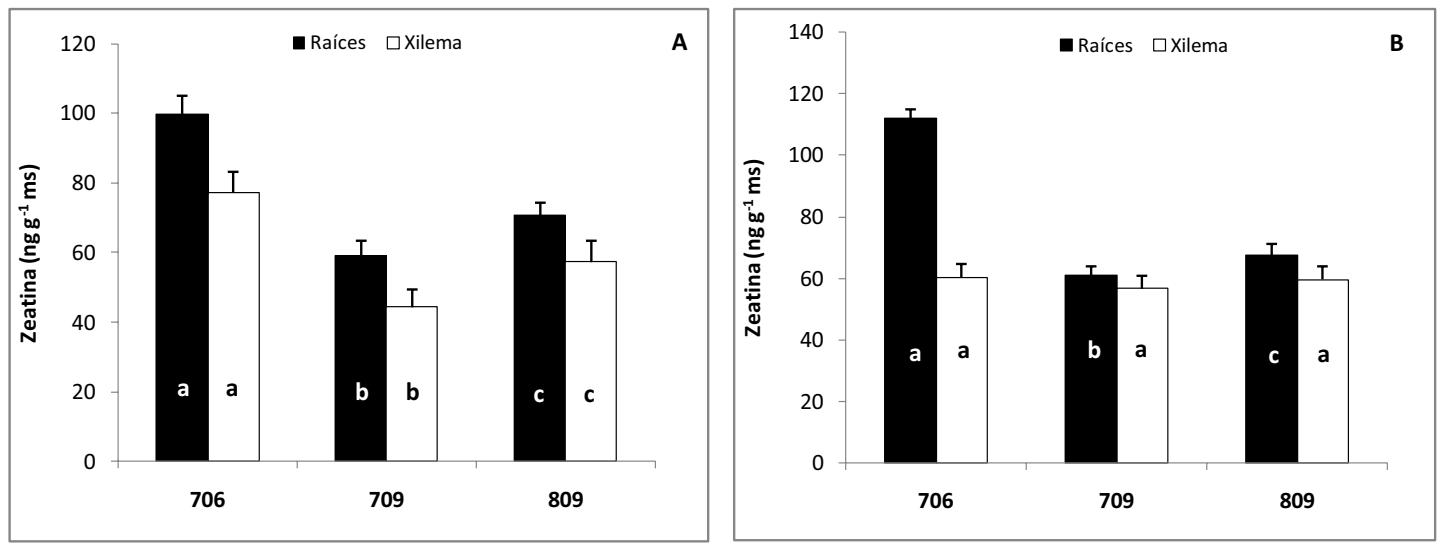

Fig. 5.27.- Evolución de la concentración de zeatina en raíces y xilema de los brotes reproductivos de árboles jóvenes de níspero japonés cvs. 'Algerie' (A) y 'Piera' (B) en las etapas finales del crecimiento del fruto y durante su maduración. Cada valor es la media de 3 árboles. El eje de abscisas representa los estados fenológicos según la escala BBCH. Letras diferentes indican diferencias significativas $(P \leq 0.05)$ para un mismo órgano.

Este efecto repercutió en el contenido de zeatina en el floema y en los frutos de estos árboles que, en general, también alcanzaron sus valores más bajos cuando éste último alcanzó el estado fenológico 709 de la escala BBCH, excepto en los frutos del cv. Piera. En ambos cultivares, 'Algerie' y 'Piera', a partir del momento en que los frutos alcanzaron el $60 \%$ de su tamaño final y hasta que prácticamente completaron su crecimiento, la concentración de esta citoquinina en el floema de los brotes reproductivos se redujo en un $24.6 \%$ y $33.7 \%$, respectivamente (Fig. 5.28). Como consecuencia de ello, el de sus respectivos frutos lo hizo en un $37 \%$ y $23.3 \%$, respectivamente. Estos porcentajes de reducción, que alcanzaron valores muy próximos entre ambos cultivares, afectaron de diferente manera a sus órganos. En el cv. Algerie, el aumento de la concentración de zeatina en el floema en $27.4 \mathrm{ng} \mathrm{g}^{-1} \mathrm{~ms}$ con la maduración del fruto (estado 
fenológico 809 de la escala BBCH), no consiguió aumentar la del fruto, que se mantuvo prácticamente igual que en el estado fenológico anterior (709 BBCH) (Fig. 5.28 A). Sin embargo, en el cv. Piera un incremento de $14.4 \mathrm{ng} \mathrm{g}^{-1} \mathrm{~ms}$ en la concentración del floema se vio acompañado de un descenso en la de sus frutos de $13.5 \mathrm{ng} \mathrm{g}^{-1} \mathrm{~ms}$, llegando a igualarse la concentración, prácticamente, con la de los frutos del cv. Algerie en la maduración (Fig. 5.28 B). Resulta interesante destacar el descenso progresivo de la concentración de esta hormona en los frutos de ambos cultivares a medida que éstos se acercaron a su maduración. En el floema, sin embargo, este descenso sólo duró hasta que los frutos completaron su crecimiento (Fig. 5.28).
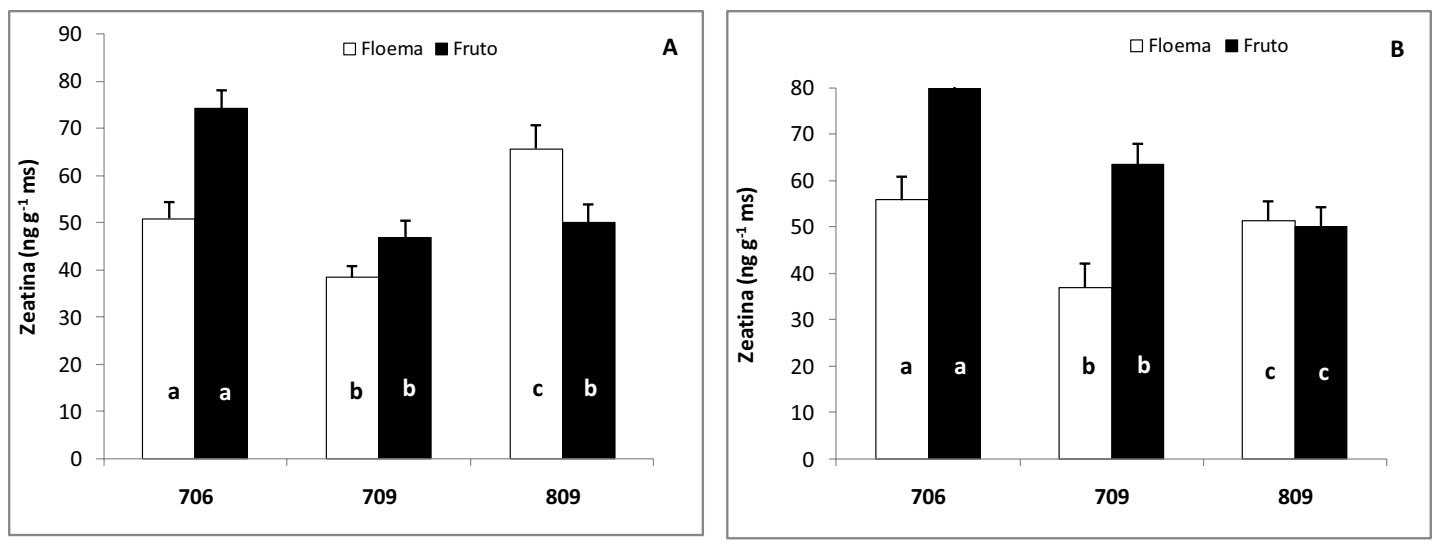

Fig. 5.28.- Evolución de la concentración de zeatina en frutos y floema de los brotes reproductivos de árboles jóvenes de níspero japonés cvs. 'Algerie' $(A)$ y 'Piera' $(B)$ en las etapas finales del crecimiento del fruto y durante su maduración.. Cada valor es la media de 3 árboles. El eje de abscisas representa los estados fenológicos según la escala BBCH. Letras diferentes indican diferencias significativas $(P \leq 0.05)$ para un mismo órgano.

El crecimiento del fruto, por tanto, alteró la concentración de AIA, ABA y Zeatina en los diferentes órganos de árboles jóvenes de níspero japonés, sobre todo cuando alcanzaron el estado fenológico 709 de la escala $\mathrm{BBCH}$, con una acción similar a la detectada en árboles adultos en cultivo (Figs. 5.20, 5.21 y 5.22). En las figuras 5.29, 5.30 y 5.31 se presenta un resumen esquemático, para dicho estado fenológico, del reparto porcentual de sus concentraciones en los diferentes tejidos del árbol. El $48 \%$ y el $44 \%$ del contenido total de AIA en los árboles de los cvs. 'Algerie' y 'Piera', respectivamente, correspondió a sus frutos, seguido de sus raíces, con el $18 \%$ y $24 \%$. Los valores más bajos correspondieron a los órganos de transporte, esto es, floema y xilema, con porcentajes entre el $12 \%$ y el $20 \%$ en ambos cultivares (Fig. 5.29). 

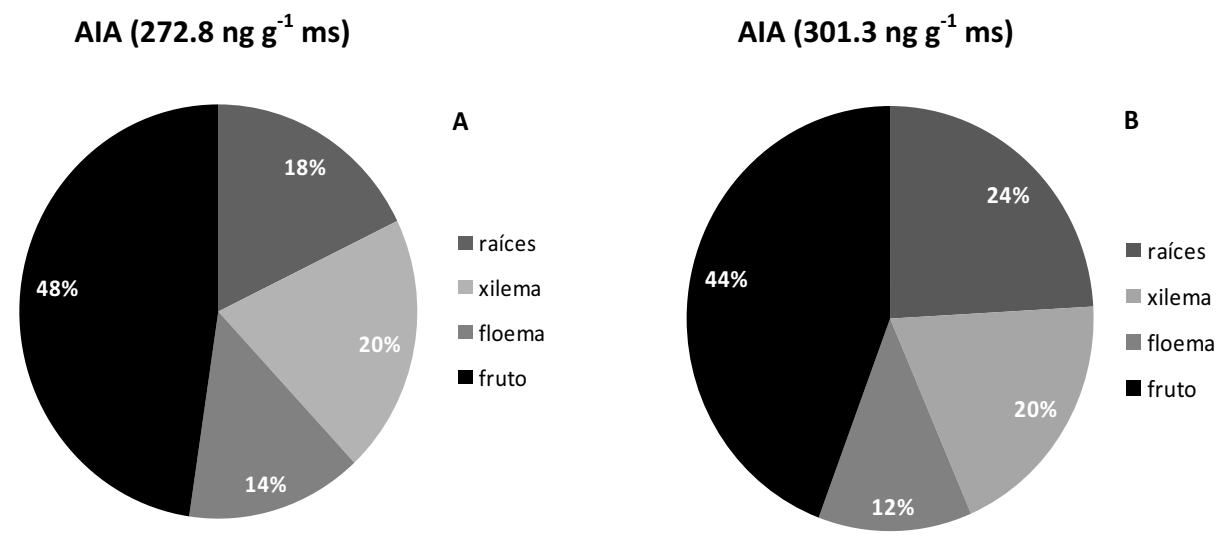

Fig. 5.29.- Distribución porcentual de la concentración de AlA en los órganos de un árbol joven de níspero japonés CV. Algerie (A) y cv. Piera (B) cuando el fruto completó el crecimiento (estado fenológico 709 de la escala BBCH). Cada valor es la media de 3 árboles. El valor indicado en cada órgano representa el porcentaje que cada uno de ellos representa sobre el total del árbol.

La distribución de la concentración de ABA y Zeatina en los dos cultivares siguió un comportamiento prácticamente idéntico. La mayor concentración de ABA se encontró en las raíces, con un 35\% de su contenido total, seguido del xilema y de los frutos con el 23\%-25\% en promedio. El resto se detectó en el floema (16\%-18\%) de los brotes reproductivos (Fig. 5.30). Valores similares presentó la Zeatina (Fig. 5.31). La acumulación porcentual de AIA en los frutos de ambos cultivares fue, aproximadamente, el doble que el de las otras dos hormonas estudiadas (Figs. 5.29, 5.30 y 5.31). Por otro lado, la mayor concentración de estas hormonas en el xilema que en el floema de los dos cultivares, 'Algerie' y 'Piera', indica que el transporte de éstas es mayoritariamente desde sus raíces hacia la copa y que está influido marcadamente por el crecimiento de sus frutos. Así lo refleja su reparto porcentual en los órganos sumidero y de transporte de ambos cultivares, en el momento en que sus frutos ejercían su máxima acción sobre el desarrollo de los órganos de la planta, es decir, en el estado 709 de la escala BBCH (Figs. 5.29, 5.30 y 5.31). 

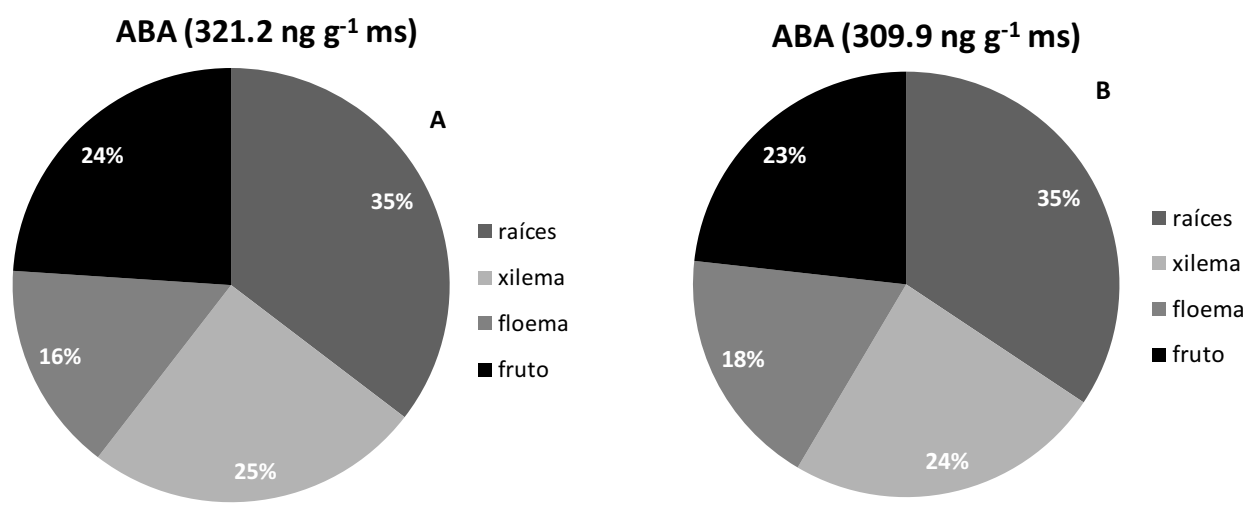

Fig. 5.30.- Distribución porcentual de la concentración de $A B A$ en los órganos de un árbo ljoven de níspero japonés cv. Algerie (A) y cv. Piera (B) cuando el fruto completó el crecimiento (estado fenológico 709 de la escala BBCH)Cada valor es la media de 3 árboles. El valor indicado en cada órgano representa el porcentaje que cada uno de ellos representa sobre el total del árbol
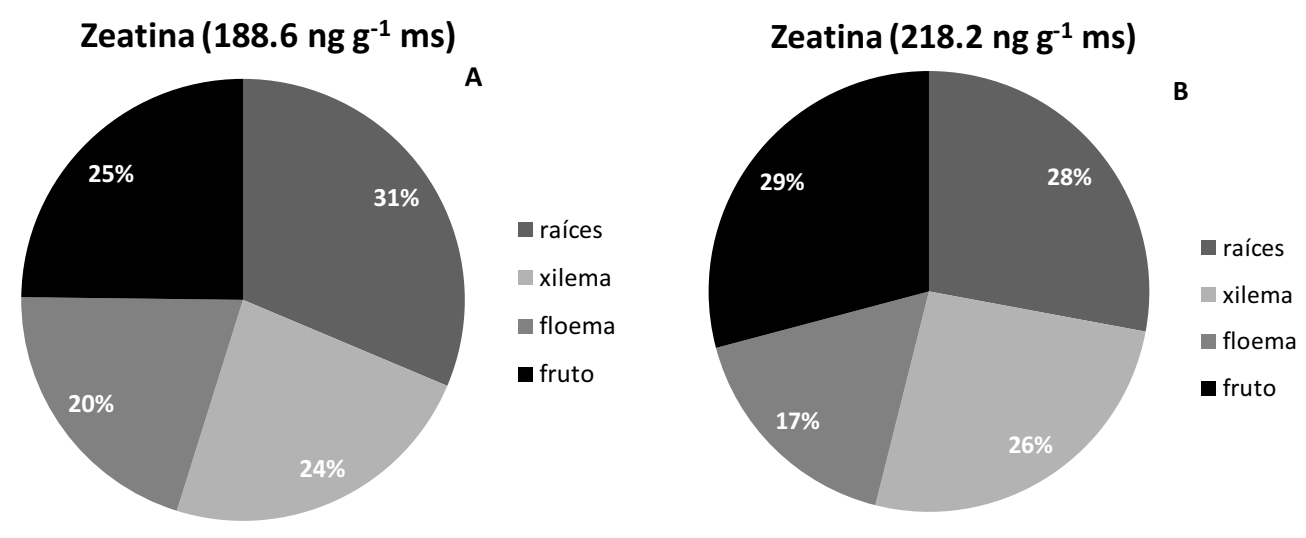

Fig. 5.31.- Distribución porcentual de la concentración de zeatina en los órganos de un árbol joven de níspero japonés cv. Algerie (A) y cv. Piera (B) cuando el fruto completó el crecimiento (estado fenológico 709 de la escala BBCH). Cada valor es la media de 3 árboles. El valor indicado en cada órgano representa el porcentaje que cada uno de ellos representa sobre el total del árbol. 
La comparación de árboles con frutos y sin frutos revela claramente esta acción del fruto, mientras crece, sobre el desarrollo de sus órganos y su concentración hormonal. Así, la presencia de todos los frutos en el árbol hasta su recolección alteró su actividad radicular, en intensidad variable con el estado de su desarrollo. En efecto, el número de puntos mitóticos de los tricloblastos de las raíces jóvenes de estos árboles disminuyó significativamente cuando los frutos completaron su crecimiento en comparación con estados más precoces de su desarrollo (estado $706 \mathrm{BBCH}$, por ejemplo) (Fig. 5.32). Cuando los frutos habían alcanzado el $60 \%$ de su tamaño final, los puntos de proliferación celular en los meristemos radiculares de estos árboles eran, por término medio, 4.1 puntos mitóticos $\mathrm{cm}^{-1}$, que se redujeron significativamente hasta 1.0 puntos mitóticos $\mathrm{cm}^{-1}$, en el momento en que el fruto completó su crecimiento (Fig. 5.32). Posteriormente, con el cambio de color de los frutos, los meristemos radiculares reiniciaron ligeramente su actividad, 1.7 puntos mitóticos $\mathrm{cm}^{-1}$, que incrementaron más tarde, con la maduración, hasta alcanzar 3.0 puntos mitóticos $\mathrm{cm}^{-1}$. Ambos incrementos alcanzaron la significación estadística. Por el contrario, la eliminación de todos los frutos al inicio de su crecimiento, no modificó la actividad radicular de éstos árboles evaluada por el número de puntos mitóticos de los tricloblastos por unidad de longitud, que se mantuvo prácticamente constante hasta el final del experimento con $2.5-2.9$ puntos mitóticos $\mathrm{cm}^{-1}$ (Fig. 5.32). Sus raíces, por tanto, permanecieron más activas durante el periodo estudiado, demostrando que es la presencia del fruto en crecimiento la que reduce drásticamente su actividad.

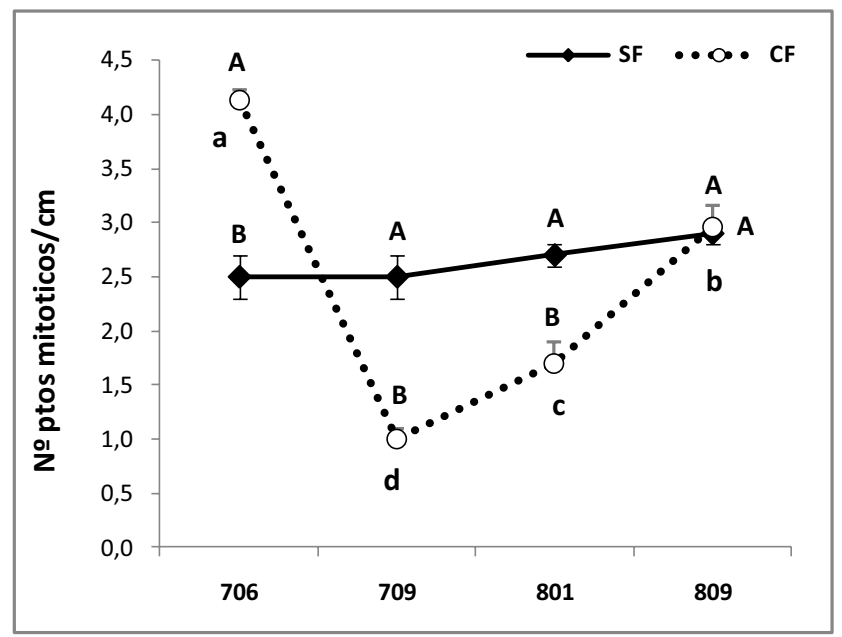

Fig. 5.32.- Influencia de la presencia del fruto en el árbol hasta la maduración en la actividad mitótica de los tricloblastos de la raíz en árboles de níspero japonés cv. Algerie. Cada valor es la media de 15 raíces, de $5 \mathrm{~cm}$ de longitud, procedentes de cuatro árboles. Las barras verticales indican el ES. El eje de abscisas representa los estados fenológicos según la escala BBCH. CF: árboles con todos sus frutos; SF: árboles sin frutos, eliminados en el estado 702 de la escala fenológica BBCH. Letras minúsculas diferentes indican diferencias significativas $(P \leq 0.05)$ entre estados fenológicos para un mismo tratamiento y mayúsculas entre tratamientos para un mismo estado fenológico. Los valores de SF no muestran diferencias significativas con los estados fenológicos. 
La concentración de AIA, ABA y Zeatina en los árboles que mantuvieron todos sus frutos hasta su recolección estuvo marcadamente influida por su estado de desarrollo. Así, un descenso generalizado de la concentración de AIA hasta que los frutos alcanzaron el 70\% de su tamaño final se detectó en las raíces de los árboles con frutos; y un descenso similar se detectó en los árboles sin fruto para el mismo periodo. Sin embargo, mientras su concentración en las raíces de los que tenían todos sus frutos continuó disminuyendo hasta el estado fenológico 809 de la escala $\mathrm{BBCH}$, la de los árboles que no tenían frutos aumentó en un $11 \%$ en el estado 709, para disminuirla ligeramente más tarde. Con la recolección de los frutos, las raíces mantuvieron prácticamente estable su concentración de AIA hasta el pleno desarrollo vegetativo (estado $325 \mathrm{BBCH}$ ), mientras la de los árboles que no habían tenido frutos se redujo a lo largo de ese período (709-325 $\mathrm{BBCH}$ ) en $8.9 \mathrm{ng} \mathrm{g}^{-1} \mathrm{~ms}$, hasta igualarse la concentración de las raíces de ambos grupos de árboles (Fig. $5.33 \mathrm{~A}$ ).

La evolución en el xilema mostró un comportamiento similar. Así, en los árboles que mantuvieron todos sus frutos hasta la recolección la concentración de AIA en su xilema descendió progresivamente con el crecimiento de éstos, hasta valores mínimos de $62.9 \mathrm{ng} \mathrm{g}^{-1} \mathrm{~ms}$ en el momento de su maduración (estado $809 \mathrm{BBCH})$, mientras que en los árboles que no tuvieron frutos desde el inicio de su desarrollo aumentó hasta valores máximos, en el estado fenológico 709 de la escala $\mathrm{BBCH}$, de $85.8 \mathrm{ng} \mathrm{g}^{-1} \mathrm{~ms}$, para reducirse posteriormente hasta valores mínimos de $54.9 \mathrm{ng} \mathrm{g}^{-1}$ ms en el estado fenológico equivalente 809 BBCH (Fig. 5.33 B). A partir de este momento, y a lo largo del periodo de crecimiento vegetativo, el xilema de ambos grupos de árboles aumentó ligeramente su concentración de AIA.

La evolución de esta hormona en el floema de ambos tipos de árboles mostró una tendencia distinta. En efecto, cuando la concentración floemática de esta auxina fue máxima en los árboles sin frutos, en los árboles con frutos apenas cambió respecto de su contenido en etapas anteriores, permaneciendo estable desde el estado fenológico 705 (ver Fig. 2.40). Posteriormente, cuando los frutos alcanzaron el estado fenológico 809 de la escala BBCH, el floema de sus árboles siguió manteniendo su concentración de AIA prácticamente constante, al mismo tiempo que el de los primeros disminuía significativamente. Tras la recolección del fruto, y coincidiendo con el desarrollo de los brotes en ambos grupos de árboles (estados 809 - $325 \mathrm{BBCH})$, los que habían soportado toda la cosecha siguieron con prácticamente la misma concentración floemática de AIA que en el estado 705, mientras que en los árboles que no habían tenido frutos aumentó significativamente hasta valores muy próximos a los de los árboles del primer grupo (ver fig. 2.40). 

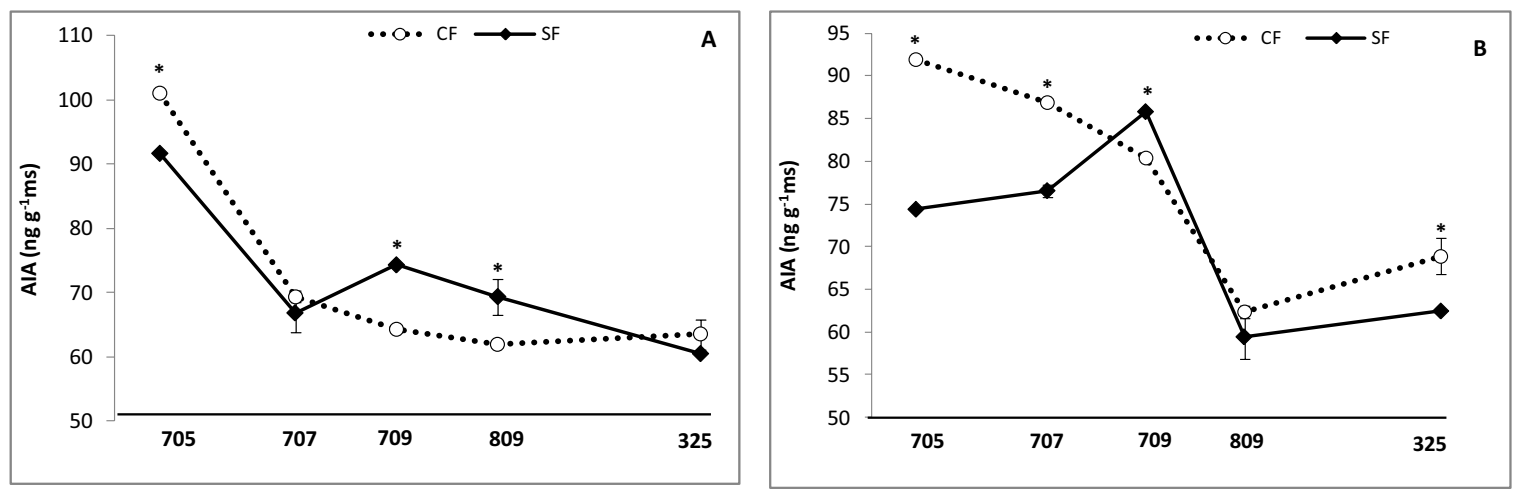

Fig. 5.33.- Influencia de la presencia del fruto en el árbol hasta la maduración en la evolución de la concentración de AlA en las raíces (A) y en el xilema (B) de árboles adultos de níspero japonés cv. Algerie Cada valor es la media de 4 árboles. El eje de abscisas representa los estados fenológicos según la escala BBCH. Clave de tratamientos como en la Fig. 5.32. * indica diferencias significativas $(P \leq 0.05)$ para un mismo estado fenológico.

La evolución de la concentración de ABA en las raíces de los árboles a los que se les eliminaron todos sus frutos en las primeras fases de su desarrollo y en las que los mantuvieron todos hasta su recolección fueron paralelas durante todo el ciclo estudiado, aunque cuantitativamente superior en estos últimos (Fig. 5.34 A). En ambos casos, la concentración aumentó progresivamente hasta valores máximos de 208.8 y 171.3 ng g-1 $\mathrm{ms}$, en los segundos y en los primeros, respectivamente, en el momento de máximos crecimiento de los frutos (en aquellos árboles que los tenían), esto es, en el estado fenológico 709 de la escala BBCH. Posteriormente, con la maduración, se redujo un $21.7 \%$, y un $30.0 \%$ en los árboles con y sin frutos, respectivamente. Finalmente, tras la recolección y en pleno crecimiento vegetativo, aumentó de nuevo hasta valores de 199.3 y $159.9 \mathrm{ng} \mathrm{g}^{-1}$ ms en ambos grupos de árboles, respectivamente (Fig. 5.34 A). Como consecuencia de ello, la evolución de esta hormona en el xilema de estos árboles mostró un comportamiento de perfil asimismo paralelo. La concentración de ABA en éste se mantuvo prácticamente constante, independientemente de la presencia o ausencia de frutos, durante todo el periodo de crecimiento de éstos (estados $705-709$ BBCH) (Fig. 5.34 B). En el estado fenológico 809 de la escala BBCH, coincidiendo con lo observado en sus raíces, la concentración de $A B A$ en el xilema se redujo significativamente en un $18.6 \%$ y un $27.2 \%$, según los frutos estuvieran o no presentes (Fig. 5.34 B). A partir de ese momento y hasta el final del periodo estudiado, ésta aumentó ligeramente en en ambos grupos de árboles, de manera similar y complementaria a como lo hicieron sus respectivas raíces, aunque con valores más bajos que éstas (Fig. 5.34).

En el floema, la eliminación de los frutos en las primeras fases de su crecimiento provocó un aumento significativo de la concentración de ABA en su floema hasta valores máximos en el estado fenológico 709 de 
la escala $\mathrm{BBCH}$, seguido de un descenso significativo de la misma hasta los valores iniciales en el estado fenológico 809 BBCH. Posteriormente, durante el desarrollo vegetativo la concentración volvió a aumentar, significativamenre, en más de un 50\%. En el floema de los árboles que mantuvieron todos sus frutos hasta la recolección, se registró un incremento moderado en las primeras fases de crecimiento del fruto (estados $703-705 \mathrm{BBCH}$ ), seguido de una época de estabilidad hasta que el fruto completó su crecimiento (estados $705-709 \mathrm{BBCH}$ ) y un descenso progresivo a lo largo del desarrollo vegetativo (ver Fig. 2.42 A).
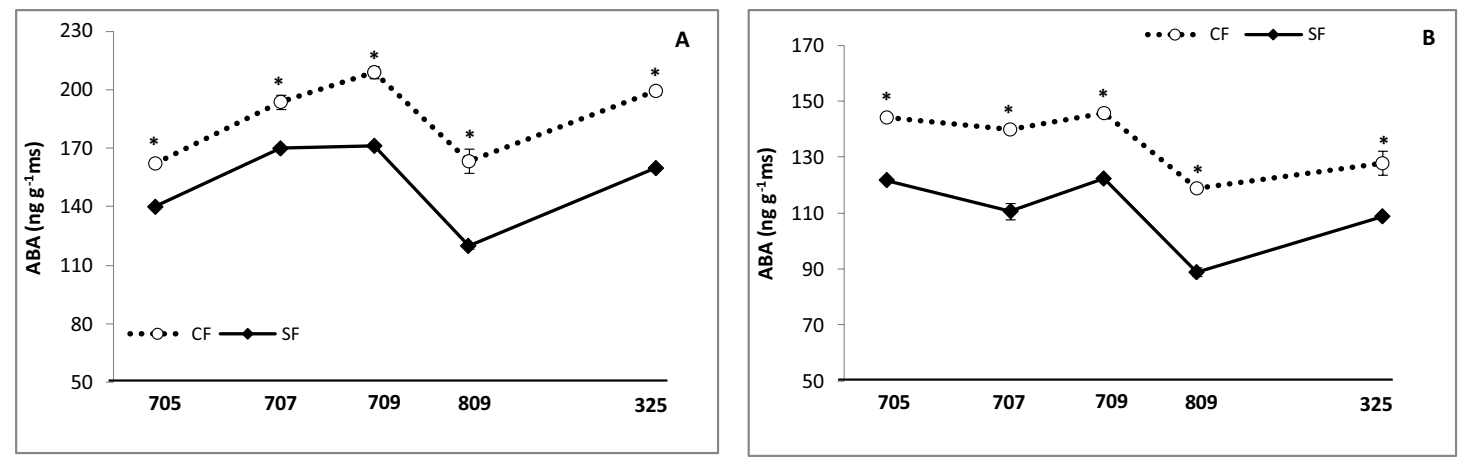

Fig. 5.34.- Influencia de la presencia del fruto en el árbol hasta la maduración en la evolución de la concentración de $A B A$ en las raíces $(A)$ y en el xilema $(B)$ de árboles adultos de níspero japonés cv. Algerie. Cada valor es la media de 4 árboles. El eje de abscisas representa los estados fenológicos según la escala BBCH. Clave de tratamientos como en la Fig. 5.32. * indica diferencias significativas $(P \leq 0.05)$ para un mismo estado fenológico.

La concentración de Zeatina en las raíces de los árboles que mantuvieron todos sus frutos hasta su recolección, también estuvo marcadamente influido por la presencia de éstos. En efecto, su concentración se redujo significativamente, hasta en un $46.7 \%$, durante el crecimiento del fruto, alcanzando sus valores más bajos cuando éstos ya habían, prácticamente, completado su crecimiento e iban a iniciar el cambio de color, esto es, en el estado fenológico 709 de la escala BBCH (Fig. 5.35 A). Con la maduración de los mismos, la concentración aumentó significativamente hasta valores de $98.2 \mathrm{ng} \mathrm{g}^{-1} \mathrm{~ms}$ en el estado 809 $\mathrm{BBCH}$, descendiendo ligeramente a continuación durante el desarrollo vegetativo. En las raíces de los árboles que no tenían frutos desde el estado 702 de la escala $\mathrm{BBCH}$, la concentración de zeatina también disminuyó hasta valores mínimos de $93.8 \mathrm{ng} \mathrm{g}^{-1} \mathrm{~ms}$ en el estado $809 \mathrm{BBCH}$, permaneciendo prácticamente constante hasta que el fruto completó su maduración (estado 809 BBCH) (Fig. 5.35 A). Posteriormente, con el desarrollo vegetativo, aumentó en un $23.4 \%$ hasta alcanzar valores similares a los que tenía en el estado fenológico 707 de la escala BBCH al inicio del experimento (Fig. 5.35 A). Estas alteraciones detectadas en la concentración de 
zeatina en las raíces de estos árboles afectaron significativamente a la de sus respectivos xilemas. Así, la evolución de ésta en el xilema de los árboles con frutos aumentó significativamente hasta un $21 \%$ en el estado fenológico 707 de la escala $\mathrm{BBCH}$, disminuyendo progresivamente más tarde hasta valores mínimos de $79.1 \mathrm{ng} \mathrm{g}^{-1} \mathrm{~ms}$ en pleno crecimiento de sus brotes (estado 325 BBCH) (Fig. 5.35 B). La concentración en los árboles sin frutos, sin embargo, mostró una reducción más acusada de la concentración de zeatina en el estado fenológico 709 de la escala $\mathrm{BBCH}$, de manera que su xilema tenía un 39\% menos de zeatina que el de los árboles con frutos. A partir de este momento, y hasta el final del periodo estudiado, su nivel en el xilema aumentó progresivamente hasta que, en pleno desarrollo de los brotes (estado $325 \mathrm{BBCH}$ ), tenía $10.9 \mathrm{ng} \mathrm{g}^{-1} \mathrm{~ms}$ más que el xilema de los árboles con frutos (Fig. 5.35 B).

La evolución de la concentración de zeatina en el floema de estos árboles mostró cómo la presencia del fruto la incrementaba progresivamente hasta que completó su crecimiento (estado $709 \mathrm{BBCH}$ ), descendiendo ligeramente durante su maduración (estado $809 \mathrm{BBCH}$ ), e incrementándose durante el desarrollo vegetativo (ver Fig. 2.42 B). En los árboles sin frutos la concentración de zeatina se incrementó dramáticamente entre los estados fenológicos equivalentes del desarrollo del fruto 705 y 709 de la escala $\mathrm{BBCH}$, alcanzando valores dos veces superiores a los iniciales (estados $703-705$ BBCH) (ver Fig. 2.42 B). Posteriormente, la concentración floemática de zeatina se redujo hasta alcanzar valores similares a los inciales, para volver a incrementarse durante el desarrollo vegetativo (estado $325 \mathrm{BBCH}$ ) hasta lacanzar, de nuevo, valores máximos.
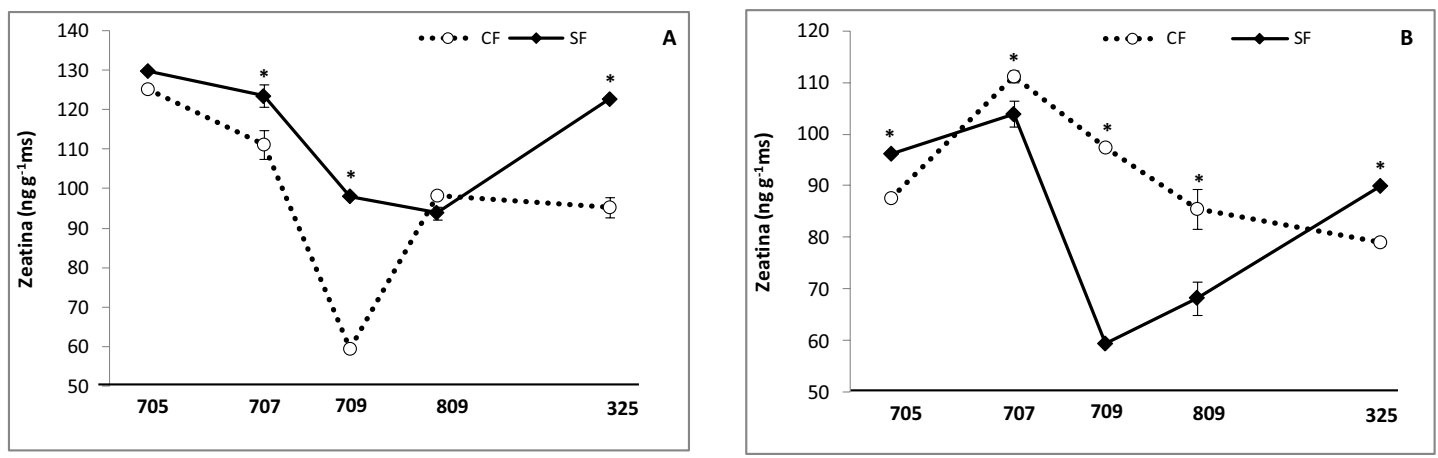

Fig. 5.35.- Influencia de la presencia del fruto en el árbol hasta la maduración en la evolución de la concentración de Zeatina en las raíces $(A)$ y en el xilema (B) de árboles adultos de níspero japonés cv. Algerie. Cada valor es la media de 4 árboles. El eje de abscisas representa los estados fenológicos según la escala BBCH. Clave de tratamientos como en la Fig. 5.32. * indica diferencias significativas $(P \leq 0.05)$ para un mismo estado fenológico. 
Un aspecto de interés en el estudio comparativo de los árboles con y sin frutos lo constituye el seguimiento de la actividad radicular a través de su respiración y almacenamiento de carbohidratos de reserva. Así, mientras las raíces de los árboles que perdieron todos sus frutos al inicio de su crecimiento mantuvieron prácticamente constante la concentración de glucosa - 6 - fosfato, un azúcar de la glicolisis, hasta el estado fenológico 707 de la escala $\mathrm{BBCH}$, en los que mantuvieron todos los frutos hasta la maduración aumentó progresivamente hasta valores máximos de $76.1 \mathrm{mg} \mathrm{g}^{-1} \mathrm{~ms}$ para el mismo estado fenológico (Fig.5.36 A). Una semana después, cuando los frutos alcanzaron el 80\% de su tamaño final, las raíces redujeron en un $40 \%$ la concentración de glucosa - 6 - fosfato, contrariamente a lo que ocurrió en los primeros que la aumentaron en la misma proporción y alcanzando, en ese momento, sus valores máximos. En las etapas finales del crecimiento de los frutos y, hasta que éstos cambiaron de color (estado $801 \mathrm{BBCH})$, dicha concentración siguió disminuyendo en las raíces de los árboles con frutos hasta valores mínimos de $28.7 \mathrm{mg} \mathrm{g}^{-1} \mathrm{~ms}$, mientras que en los árboles sin frutos se mantuvo prácticamente constante, en torno a los $50 \mathrm{mg} \mathrm{g}^{-1} \mathrm{~ms}$ (Fig.84 A). Cuando los frutos maduraron, la concentración de glucosa-6-fosfato en las raíces de los árboles con frutos aumentó, significativamente, en un 39.2\% hasta igualarse con la de los árboles sin frutos que permanecía constante desde el estado fenológico 801 de la escala BBCH (Fig. 5.36 A). Con la recolección de éstos y, por tanto, ante la ausencia de carga en ambos árboles, el comportamiento de sus raíces fue idéntico, disminuyendo ligeramente la concentración de glucosa-6-fosfato al mismo tiempo que se desarrollaban los brotes (Fig. 5.36 A). El descenso de la concentración de glucosa-6-fosfato en las raíces, en los periodos de máximo crecimiento de los frutos, y dado que se trata de un azúcar propio de la respiración, demuestra, indirectamente, una ralentización de la actividad de éstas como consecuencia del crecimiento del fruto.

Otra prueba de la interacción entre la actividad radicular y el desarrollo de los frutos de un mismo árbol lo constituye la evolución de la concentración de los azúcares de reserva a lo largo del ciclo vegetativo. Así, las raíces de los árboles que mantuvieron todos sus frutos hasta la recolección disminuyeron progresivamente su concentración de almidón a medida que éstos completaban su crecimiento, hasta valores mínimos de $14.9 \mathrm{mg} \mathrm{g}^{-1}$ ms en el momento en que cambiaron de color, esto es, en el estado 801 de la escala BBCH. A los que se les eliminaron todos ellos en las primeras fases de su crecimiento, por el contrario, ésta aumentó progresivamente en sus raíces, hasta valores máximos de $20.2 \mathrm{mg} \mathrm{g}^{-1} \mathrm{~ms}$ en el mismo estado fenológico en el que los árboles con frutos presentaban el valor más bajo (Fig. 5.36 B). Con la maduración de los frutos, la concentración de almidón en las raíces de los árboles con frutos disminuyó en un 10\%. Tras la recolección, en pleno crecimiento vegetativo, aumentó significativamente su concentración hasta valores máximos de $20.5 \mathrm{mg} \mathrm{g}^{-1} \mathrm{~ms}$, similares a los iniciales. Las raíces de los árboles sin frutos también aumentaron su concentración de almidón a lo largo del periodo de crecimiento vegetativo, pero en cuantía apenas 
perceptible (Fig. 5.36 B). En resumen, un descenso generalizado de la concentración de glucosa-6-fosfato y de almidón se detectó en las últimas fases del crecimiento de los frutos (estados 707 a 709 BBCH) en las raíces de los árboles que soportaron toda su carga, en contraposición con los cambios apenas inexistentes en las de aquellos que no tenían ninguno fruto desde el estado fenológico 701 de la escala BBCH (Fig. 5.36).
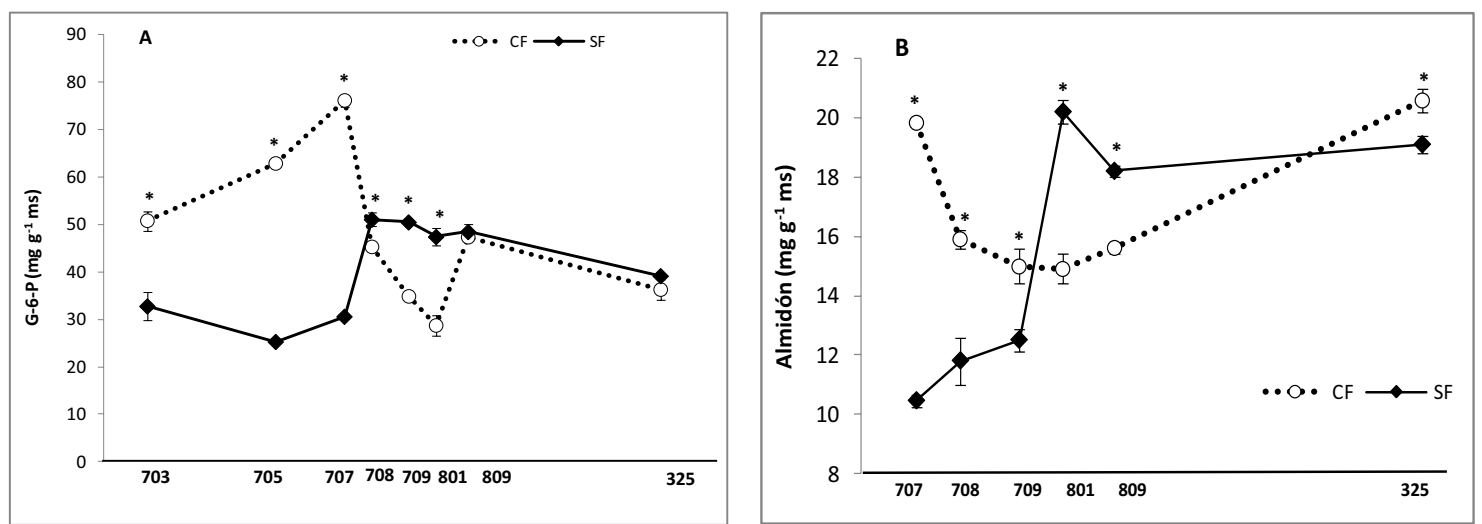

Fig. 5.36.- Influencia de la presencia del fruto en el árbol hasta la maduración en la evolución de la concentración de glucosa-6-fosfato (A) y almidón (B) en las raíces de árboles adultos de níspero japonés cv. Algerie. Valores expresados como la concentración de glucosa liberada después de una reacción enzimática con amiloglucosidasa. Cada valor es la media de 4 árboles. El eje de abscisas representa los estados fenológicos según la escala BBCH. Clave de tratamientos como en la Fig. 5.32. * indica diferencias significativas ( $P \leq 0.05)$ para un mismo estado fenológico. 


\section{Discusión}





\section{DISCUSIÓN}

Las relaciones fuente-sumidero juegan un papel dominante en la utilización de carbohidratos por parte del árbol frutal. Su reparto en el árbol se halla fuertemente influido por los sumideros en desarrollo, de modo que el desarrollo reproductivo, vegetativo y radicular, que difieren temporalmente a lo largo del año, compiten entre sí a lo largo del mismo (Gifford y Evans, 1981; Ho et al, 1989; Patrick, 1989). De acuerdo con el modelo de Landsberg (1980) sobre el reparto de fotoasimilados, un incremento de la cosecha debe reducir proporcionalmente el desarrollo vegetativo y radicular que, más tarde, demostró Lenz (1986) en árboles de manzano aclarados totalmente y sin aclarar. La conclusión de estos trabajos es que la presencia del fruto en crecimiento restringe el transporte de carbohidratos hacia las raíces y partes vegetativas del árbol y retarda y/o reduce su desarrollo. Los resultados de nuestros experimentos son coincidentes con los de estos autores, de modo que los cambios detectados en el contenido de azúcares de transporte en las hojas y en el floema de los árboles sometidos a la carga completa de sus frutos, son consecuencia directa del reparto regido por el fruto, como lo demuestra su comparación con árboles sin frutos. Por eso, desde que éstos alcanzaron la mitad de su tamaño final hasta que maduraron, la síntesis de estos azúcares en las hojas de sus brotes mixtos, evaluada por su concentración en ellas, aumentó como consecuencia de la demanda, al mismo tiempo que la concentración en el floema disminuía con el tiempo porque se transportaban al fruto, donde se acumulaban de manera coordinada con su ritmo de crecimiento. El doble del contenido de azúcares de transporte en el floema de los árboles que conservaban todos sus frutos que en los que no tenían ninguno, pero con brotes en desarrollo, refleja la importancia que el tipo de sumidero tiene en la movilización de los carbohidratos. Prueba de ello es su concentración prácticamente constante de sacarosa y sorbitol en los árboles sin frutos durante el periodo equivalente al crecimiento de éstos en comparación con los cambios señalados en los árboles con frutos en desarrollo y sin brotes en crecimiento. Estos resultados indican que la actividad fotosintética de las hojas se ajusta, en gran medida, a las exigencias de los sumideros.

En este sentido, por tanto, los frutos son sumideros más potentes que los brotes vegetativos jóvenes y las raíces del árbol, y, por tanto, mientras están presentes son responsables del reparto de carbohidratos en la planta. Nuestras determinaciones analíticas utilizando ${ }^{13} \mathrm{CO}_{2}$ así lo ratifican. Éste sólo se localiza en el floema de ramas basales, lo que es reflejo de su transporte a las raíces, cuando el fruto deja de crecer; hasta ese momento sólo en las hojas (órgano diana del ${ }^{13} \mathrm{CO}_{2}$ ) y el fruto pudo ser detectado. En las primeras descendiendo su contenido, en los segundos aumentándolo, lo que indica el sentido polar de su transporte. Por otra parte, es el número de frutos y no su tamaño, el que establece el reparto de carbohidratos en el árbol (Faust, 1989). Por ello, cuando en nuestros experimentos se eliminaron o aislaron temporalmente sólo parte de los frutos del árbol, los resultados en el reparto de carbohidratos en el brote fueron los 
mismos que los conseguidos con su eliminación total, lo que es prueba, a su vez, de la independencia de panículas. Asimismo, las diferencias encontradas en la movilización de las reservas indican que, mientras existió demanda, la actividad fotosintética de las hojas fue contínua y éstas no acumularon almidón porque los azúcares sintetizados rápidamente se exportaron, mayoritariamente al fruto, para satisfacer sus requerimientos energéticos. Con la eliminación o aislamiento del principal sumidero, el fruto, las hojas, ante la falta puntual de demanda, acumularon parte de los azúcares sintetizados en forma de almidón, que más tarde hidrolizarían al reestablecerse la demanda por la cicatrización del anillado o la presencia de los nuevos brotes en desarrollo, según el caso. Estos resultados demuestran que la ausencia del fruto altera la actividad fotosintética de las hojas y que éstas son capaces de autorregularla en función de los requerimientos energéticos. De hecho, el descenso de los azúcares de transporte en el floema de los árboles sin frutos durante el desarrollo de sus nuevos brotes, indica la autonomía de éstos en la síntesis de carbohidratos, que no necesitan del aporte de las hojas viejas del brote. Su menor concentración foliar en estos árboles, en comparación con los árboles con frutos durante el crecimiento vegetativo es, por tanto, lógico, ya que la demanda a las hojas viejas del brote se reduce al convertirse las hojas nuevas en fuentes de carbohidratos. Nuestros estudios a la panícula individual o al árbol completo reflejaron, por tanto, la misma influencia del fruto en el reparto de carbohidratos. De esta manera se demuestra la independencia de panículas en el árbol y la ausencia de una correlación significativa entre el número total de frutos por árbol y su tamaño final, en beneficio de la significación cuando se estudia por panícula.

Por otro lado, la ausencia de frutos en el árbol durante la mayor parte de su ciclo vegetativo deja a las yemas, a los brotes en formación y a las raíces, como únicos órganos de reclamo de carbohidratos. Las raíces son sumideros débiles y en algunas especies su crecimiento sólo se produce cuando cesa el desarrollo vegetativo. En coherencia con ello, el número de brotes desarrollados en el árbol y la acumulación de reservas en sus raíces debería ser mayor sin la presencia de los frutos, como así ocurre. De acuerdo con nuestros resultados, la eliminación de todos los frutos del árbol apenas modificó el número de yemas principales que brotaron al final del crecimiento vegetativo, pero sí el de las anticipadas que se duplicó. No obstante, en ambos casos su desborre se anticipó significativamente y ambos brotes, principales y anticipados, presentaron al final de su crecimiento, mayor número y longitud de entrenudos. Aunque no se encontró ninguna relación entre la longitud o, lo que es lo mismo, el número final de hojas en el brote principal y el número de brotes anticipados desarrollados, de nuestros resultados se deduce que es necesario que el principal haya desarrollado un mínimo de hojas, más de 5 , para que haya anticipados. En el guisante la respuesta a las citoquininas para provocar la brotación se produce en la yema del nudo 2, pero es incapaz de provocarla en las yemas de los nudos 3 ó 4 (King y Van Staden, 1988); los autores proponen que la brotación está determinada por la edad de la yema. De este modo, ambas brotaciones, principal y anticipada, presentan una estrecha relación, por lo que cualquier variación en los 
brotes principales puede explicar la variación encontrada en las características de los brotes anticipados. El efecto del fruto sobre el desarrollo vegetativo es, por tanto, decisivo. Esta acción ha sido demostrada en otras especies, como manzano, melocotonero y cítricos (Faust, 1989). Así, en el manzano, aunque la cosecha detiene, literalmente, el desarrollo radicular, el vegetativo es reducido hasta en un $30 \%$ (en peso seco) en relación con los árboles sin cosecha. De acuerdo con nuestros experimentos a la panícula individual o al árbol completo, el número total de frutos presentes en el árbol y el tiempo que éstos permanecieron en el mismo, influyó de manera similar en muchos aspectos de la brotación y posterior desarrollo de sus brotes. Si bien el desborre de las yemas de ambos árboles se inició al poco tiempo de la eliminación o aislamiento de los frutos, el efecto localizado sobre las yemas al eliminar la panícula tuvo mayor impacto y éstas brotaron en mayor proporción que cuando se aislaron temporalmente, que no se consiguieron aumentar la brotación. Es más, independientemente de si se modificó o no el número final de yemas principales, su desborre se anticipó y estos brotes fueron significativamente más largos al final de su crecimiento. Además "ignoraron" la dominancia apical, lo que permitió que un mayor número de sus yemas axilares brotaran anticipadamente y que estos brotes fueran también de mayor longitud.

El tiempo de permanencia del fruto en la panícula también modificó la respuesta de las yemas de los brotes reproductivos. Los que se despuntaron o anillaron al inicio del desarrollo del fruto (estado 701 $\mathrm{BBCH}$ ) tuvieron mayor número de brotes principales y anticipados, que además fueron más largos que los que se despuntaron cuando el fruto ya tenía el 30\% de su tamaño final (estado $703 \mathrm{BBCH}$ ). El descenso generalizado de la concentración de los azúcares de transporte y reductores en el floema de estos brotes durante el desborre de sus yemas, resalta la importancia de éstos como fuente de energía hasta que el área foliar de los nuevos brotes pueda atender su demanda. Por otro lado, el contenido constante de almidón en las raíces del árbol durante el desborre y crecimiento de los brotes, indica que, en esta especie, no es necesaria la movilización de estas reservas para que la brotación tenga lugar, y que el descenso de éste en las hojas, inmediatamente después de su acumulación, coincidente con el desborre de las yemas, es una autoregulación fotosintética de éstas mediada por la eliminación o aislamiento de los frutos. De acuerdo con nuestros resultados, durante el periodo en el que los frutos están presentes, éstos compiten con el desarrollo vegetativo, impidiendo, por un lado, el desborre de las yemas y reduciendo, por otro, la longitud y el número de los entrenudos y, por tanto, el número de yemas. El hecho de que la presencia de frutos partenocárpicos en el árbol no consiga este efecto, indica que es la semilla el factor responsable de los cambios. A pesar de ello, tanto en frutos partenocárpicos como no partenocárpicos, los nuevos brotes no iniciaron su crecimiento hasta que el fruto alcanzó su tamaño final, y, con ello, el de sus semillas, poniéndose de manifiesto, nuevamente, la competencia existente entre el crecimiento de los frutos y el de los brotes, a favor de los primeros. El hecho de que la semilla controle, en última instancia, la capacidad de 
la yema para brotar, es decir, para desarrollar un nuevo brote o flores, indica que este fenómeno debe estar regulado hormonalmente.

En coherencia con la reducción del número de entrenudos y, consecuentemente de yemas, conseguido por la acción del fruto, el número de flores esperado el otoño siguiente debería ser menor, como así ocurre. En efecto, la presencia del fruto en el árbol desde que éste, prácticamente, había completado su crecimiento (estado fenológico 707-708 de la escala $\mathrm{BBCH}$ ) hasta su senescencia, disminuyó significativamente el número de flores de ambas panículas, principales y anticipadas. Estos mismos resultados se han observado en otras especies, como el naranjo dulce (Martínez-Fuentes et al., 2010), el pomelo 'Marsh' bajo condiciones tropicales (Betancourt et al., 2008) y el melocotonero (Reig et al., 2006). La similitud en los resultados de los árboles que se descargaron, total o parcialmente, demuestra que la acción directa del fruto sobre la floración es la misma con independencia del número de éstos presentes en el árbol; lo que importa es la presencia o no de frutos en el brote mixto, lo cual indica, de nuevo, la autonomía de las panículas, en este caso para florecer. Dado que en la época de inducción floral la concentración de azúcares reductores y de sacarosa no se alteró por la presencia de los frutos, y la de sorbitol fue significativamente mayor en los árboles que mantuvieron toda su carga hasta la recolección y, por tanto, florecieron con menor intensidad, la importancia directa de los carbohidratos en el proceso de inducción floral de las yemas debe ser escaso; es decir, los nutrientes no determinan la brotación, pero son necesarios para que ésta progrese (Srivastava, 2002). Los cambios nutricionales experimentados en las raíces de estos árboles tampoco mostraron ninguna relación con la floración. En el momento de la brotación, el contenido en carbohidratos de transporte y reductores de sus raíces apenas se modificó por la presencia de los frutos. Sin embargo, el de almidón fue superior en los que mantuvieron todos sus frutos hasta su recolección que, como consecuencia florecieron con menor intensidad. No fue necesaria, por tanto, la hidrólisis de este carbohidrato de reserva ni tan siquiera para que se iniciara el desborre de las yemas. El contenido significativamente más bajo en las hojas de los árboles que mantuvieron todos sus frutos hasta la recolección aparece, también, como una buena razón para correlacionar su concentración con la intensidad de floración; sin embargo las diferencias aparecen en la época en que el fruto se muestra ineficaz reduciéndola. Es más, aunque una cierta concentración umbral de almidón podría ser necesaria para que una yema brote y se inicie la floración, la comparación de resultados de diferentes experimentos de sombreado, rayado de ramas o aclareo de frutos, en cítricos y otras especies, prueba que la existencia de otros factores enmascara una posible correlación entre la concentración de almidón en los tejidos y la floración, indicando que ésta permanece sin ser demostrada (García-Luís y Guardiola, 2000; García-Luís et al., 1988; Goldschmidt et al., 1985; Reig et al., 2006). Es más, los nutrientes no determinan la brotación, pero son necesarios para que ésta progrese (Srivastava, 2002) La evolución de los azúcares en las raíces indica que son requeridos por los órganos de diferenciación, es decir, las yemas, en etapas anteriores a su 
brotación.Sin embargo, el alto contenido en azúcares de transporte en el floema de los árboles con frutos durante el desborre y crecimiento de los brotes indica que las reservas para brotar no están en las raíces, sino en la corteza de los brotes próxima a las yemas. Este aspecto ha sido demostrada en otras especies próximas, como el manzano (Johnson y Lakso, 1986), y otras más alejadas, como el cerezo (Kappes, 1985) y el melocotonero (Agustí, 2010). En estas especies caducifolias parece lógico que el proceso sea así, pero resulta interesante que en el níspero japonés, una especie perennifolia, también lo sea. Con la salida de la endolatencia las yemas dependen de la concentración de hexosas de sus tejidos meristemáticos (Maurel et al., 2004) y son, por tanto, nutricionalmente independientes de la presencia de hojas; sólo más tarde, cuando el brote en crecimiento se convierte en verdadero sumidero, reclamará carbohidratos, transitoriamente, a las hojas adultas del brote del que surge, hasta que se convierta en autosuficiente cuando sus propias hojas son ya verdaderas fuentes de carbohidratos. Con todo, pues, y a la vista de nuestros resultados, no es posible afirmar que las variaciones en la densidad de floración sean sólo consecuencia de las alteraciones del desarrollo vegetativo. En efecto, la relación encontrada entre el descenso del número de entrenudos y el de la densidad de floración fue, sin embargo, inexistente con el contenido en carbohidratos, y parece indicar una acción del fruto sobre la floración más bien sujeta a un control hormonal, como se ha demostrado en otras especies (Bernier, 1988; Dickens y van Staden, 1988; García-Luís et al, 1995).

Lo hasta aquí expuesto refleja la importancia del fruto en el reparto de carbohidratos en el árbol y es suficiente argumento para establecer la existencia de una relación directa entre la disponibilidad de carbohidratos y la cosecha. Durante las primeras fases de su desarrollo, los frutos dependen críticamente de los fotoasimilados transportados desde las hojas, como lo demuestra la acumulación de azúcares reductores a lo largo de todo su ciclo de desarrollo. Esta es la razón de que el contenido de azúcares de transporte y reductores en el floema de los árboles con frutos descendiera, al mismo tiempo que aumentaba en sus hojas. El aislamiento temporal de los frutos del resto del brote detuvo puntualmente el crecimiento de éstos en los días inmediatos al anillado, hasta que con su cicatrización reestableció la conexión con el mismo. Como consecuencia de ello, a los pocos días de la realización del anillado, el nivel de azúcares reductores y de transporte de las hojas del brote anillado aumentó, al mismo tiempo que lo hacía el de la parte inferior de su floema por lo que estos frutos fueron, durante todo el periodo de crecimiento y en el momento de su recolección, significativamente más pequeños. A pesar de ello, tras la cicatrización del anillado los frutos reiniciaron el crecimiento, de modo que en el momento de su recolección alcanzaron un diámetro aceptable y maduraron con normalidad. De acuerdo con ello, la defoliación de nuestros brotes mixtos en las primeras fases del crecimiento de sus frutos (estado $701 \mathrm{BBCH}$ ) alteró marcadamente su crecimiento que, en el momento de la recolección, fueron significativamente más pequeños en diámetro y en peso que los controles. Este efecto también alcanzó al crecimiento de sus 
semillas que, en el momento de la recolección, pesaron significativamente menos. El menor contenido de carbohidratos reductores y de transporte en el floema de éstos brotes que en el de los que tenían hojas, explica el resultado. El retraso en la defoliación hasta cuando los frutos ya tenían el 30\% de su tamaño final, dio lugar a una concentración intermedia de estos azúcares en frutos y floema entre los defoliados en la primera fecha y los controles sin defoliar. De estos resultados se deduce que, a pesar de la independencia de panículas, la ausencia de hojas en el brote que soporta la panícula y, por tanto, la restricción de carbohidratos al fruto, podría verse compensada parcialmente por el aporte de éstos desde las hojas de otras panículas, regulando el efecto la propia capacidad sumidero de los frutos de la panícula áfila. Otra evidencia de la alta capacidad sumidero de los frutos es que, a pesar de la ausencia de hojas, en el momento de máximo crecimiento de éstos en los brotes defoliados, el contenido en glucosa y fructosa de su floema fue significativamente superior al de los que no tenían frutos, aunque tuvieran hojas.

Derivado de la baja disponibilidad de carbohidratos, como consecuencia de la eliminación de su principal fuente, las hojas, fue la reducción del número de brotes, principales y anticipados, y la menor longitud de éstos encontrada en los brotes defoliados. Este efecto también se relacionó con el momento de la defoliación, de manera que cuanto más tiempo permaneció el brote inicial sin sus hojas menos crecieron sus nuevos brotes. El número de yemas que iniciaron su desborre, tanto principales como anticipadas, por el contario, no se vio modificado por el tiempo en que éstas estuvieran sin hojas pero sí respecto de los brotes mixtos sin defoliar, brotando significativamente menos. Esta respuesta difiere de la encontrada en plantas de tabaco (ipt)-transformadas en las que la eliminación de las hojas más apicales aumentó la concentración de citoquininas en las yemas axilares promoviendo su brotación (Geuns et al., 2001). La síntesis de citoquininas en hojas adultas ha sido demostrada por Kamboj et al. (1998) en Ricinus communis y en ese sentido la eliminación de las hojas en nuestros experimentos justificarían la reducción de la brotación experimentada. La ausencia de frutos en estas plantas de tabaco y el hecho de que en nuestros experimentos la presencia de éstos redujera la concentración de zeatina en raíces, xilema y floema, puede ser, también, razón suficiente para explicar la diferencia. Esto resalta una vez más, las exigencias energéticas que los nuevos brotes tienen durante su crecimiento y que los carbohidratos constituyen una fuente de energía necesaria para que las yemas inicien su desborre.

De acuerdo con estos resultados, el inicio del desborre de las yemas, por un lado, y el reinicio de la actividad y el crecimiento radicular, por otro, no tuvieron lugar hasta que los frutos completaron su crecimiento y permitieron con ello la exportación de carbohidratos desde las hojas a yemas y raíces. La necesidad de energía para atender estos procesos es, por tanto, determinante, como también lo es para la brotación de las yemas, de madera y de flor, de especies caducifolias como los frutales de hueso (Flore y Layne, 1996), vid (Williams, 1996) y otros frutales (Kozlowski y Pallardy, 1997). Siendo que la concentración de azúcares de transporte en las hojas y en el floema de los árboles con frutos, es decir, aquellos que 
florecieron menos, fue mayor, la acción de éstos sobre la floración no parece relevante, como ha sido demostrado en otras especies (García-Luís et al., 1988; Lovatt et al., 1988b; Srivastava, 2002; Reig et al., 2006).

La influencia del fruto alcanza, también, a las raíces reduciendo su actividad en etapas próximas al cambio de color. De hecho, la tasa de crecimiento radicular disminuyó progresivamente hasta que los frutos alcanzaron prácticamente su tamaño final, y la retomaron, intensamente, más tarde, cuando éstos habían sobrepasado el cambio de color. Este efecto del fruto sobre la raíz ha sido demostrado también en el tomate (Hurd et al., 1979). La ausencia de transporte de fotoasimilados a éstas mientras tiene lugar el crecimiento del fruto, demostrada por el seguimiento del ${ }^{13} \mathrm{C}$ en la planta tras exponer las hojas a una atmósfera de ${ }^{13} \mathrm{CO}_{2}$ y por el descenso continuado de la concentración de azúcares reductores y de transporte en las raíces, revela su alta capacidad sumidero, cuando se compara con la de las raíces, y es una de las causas de que éstas reduzcan su actividad. Esta falta de actividad inducida por el crecimiento del fruto ha sido demostrada en nuestros experimentos por: 1) la reducción de su longitud, 2) el descenso en la proliferación de pelos radiculares, evaluado midiendo la densidad de puntos con actividad mitótica, 3) el aumento de la concentración de glucosa-6-fosfato, que indica un descenso en la respiración compatible con el punto anterior, 4) la acumulación de almidón, que indica la ausencia de consumo de sustratos respiratorios como consecuencia del descenso de la tasa respiratoria, 5) el aumento de la concentración de la fracción $\mathrm{N}-\mathrm{NO}_{3}^{-}$y el descenso simultáneo de la $\mathrm{N}^{-} \mathrm{NH}_{4}{ }^{+}$, y 6) el descenso en la síntesis de AIA, ABA y zeatina, que es reflejo, en sí mismo, de la falta de actividad radicular; en estas condiciones, el cálculo de la relación AIA/zeatina como referente de dicha actividad se hace innecesario.

En nuestros experimentos, la concentración de $\mathrm{N}^{-\mathrm{NH}_{4}}{ }^{+}$ha sido relacionado con la brotación/floración de las yemas. Este aspecto ya había sido recogido por Monselise et al. (1981) al estudiar la alternancia de cosechas en agrios y por Srivastava (2002) estudiando la brotación de plantas transgénicas productoras de conjugados AIA-lisina no activos. Los autores encontraron altos contenidos de $\mathrm{N}^{-\mathrm{NO}_{3}}$ en las plantas tendentes a florecer escasamente al mismo tiempo que su contenido en $\mathrm{N}$ total disminuía, concluyendo que en los árboles sobrecargados de frutos el mecanismo de reducción de nitratos se encontraba alterado. Southwick y Davenport (1986) demostraron, también en los cítricos, que la formación de flores se puede lograr tras la rotura de un estrés hídrico o térmico, y cuando ello ocurre se presenta un aumento de la

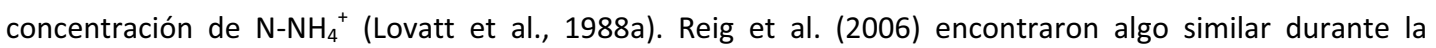
latencia, en el floema próximo a la yema de árboles de melocotonero que soportaron todos sus frutos hasta la recolección en comparación con aquellos a los que se les eliminaron todos en el momento de la lignificación del endocarpo y Martínez-Fuentes (2010) llegó a la misma conclusión en diferentes variedades de naranjo dulce. Nuestros resultados están de acuerdo con esta alteración del mecanismo de reducción de nitratos, ya que a lo largo del periodo de crecimiento de los frutos, mientras la concentración de $\mathrm{N}_{-} \mathrm{NO}_{3}{ }^{-}$en 
las hojas de los árboles que los mantuvieron todos hasta su recolección y en la de los que no tenían ninguno desde el inicio de su crecimiento era la misma, la de $\mathrm{N}-\mathrm{NH}_{4}{ }^{+}$disminuía en los primeros al mismo tiempo que aumentaba en los segundos. De acuerdo con ello, en el níspero japonés, el mecanismo de reducción de nitratos en las hojas es alterado por la presencia de los frutos. Por otra parte, la actividad de la enzima nitrato-reductasa depende directamente de la demanda de iones amonio por parte de los diferentes sumideros en desarrollo. En nuestros experimentos, el aumento de la concentración foliar de nitratos y, consecuentemente de amonio, en los árboles que no tenían ningún fruto desde el inicio de su crecimiento, coincidió con el desborre de las yemas y, por tanto, en el momento en que se determina el número de brotes que van a iniciar su crecimiento. Estos resultados son coherentes con el aumento de la concentración de $\mathrm{N}_{-} \mathrm{NH}_{4}^{+}$y N proteico que se detectó en el floema de estos árboles. El descenso posterior de estas fracciones nitrogenadas en ambos órganos fue consecuencia del crecimiento foliar de los nuevos brotes.

Pero el metabolismo del nitrógeno también se ha relacionado con la floración de las yemas a través de la síntesis de poliaminas (Edwards et al., 1986). La acumulación de iones $\mathrm{NH}_{4}{ }^{+}$en las plantas estresadas invita a pensar que es ésta la responsable de la síntesis de poliaminas y de la posterior división celular, lo que es prerrequisito para la formación de flores (Rabe y Lovatt., 1986; Lovatt et al., 1988a). Nuestros resultados demuestran una reducción significativa de la concentración amoniacal en las hojas y en el floema como consecuencia de la presencia del fruto en el árbol durante la época de inducción floral. A este respecto resulta interesante comparar la relación $\mathrm{N}_{-} \mathrm{NO}_{3}{ }^{-} / \mathrm{N}_{-}-\mathrm{NH}_{4}{ }^{+}$en las hojas de los árboles sin frutos desde el inicio de su crecimiento y de los árboles que los mantuvieron hasta su recolección. Mientras en los primeros fue de 3.1, en los segundos fue de 45.0, evidenciándose una disfunción en la actividad de reducción de los nitratos en los últimos. A pesar de ello, puesto que las concentraciones de $\mathrm{N}-\mathrm{NO}_{3}{ }^{-}$y N-NH${ }_{4}^{+}$ representan fracciones pequeñas del $\mathrm{N}$ total, la relativa alta concentración en la época de inducción floral de $\mathrm{N}_{-} \mathrm{NH}_{4}{ }^{+}$en las hojas y en el floema de los árboles a los que se les eliminaron todos sus frutos al inicio de su desarrollo (estado fenológico 701 de la escala BBCH) y que, por tanto, florecieron más, podría ser más un reflejo metabólico que una acción directa nutricional (Monselise et al., 1981). El hecho de que la aplicación de elevadas concentraciones de urea haya conseguido aumentar significativamente la concentración foliar de $\mathrm{N}^{-\mathrm{NH}_{4}}{ }^{+}$pero no la floración del naranjo dulce "Washington navel" (Lovatt et ., 1985) y de la mandarina Clementina "Nour" (El-Otmani et al., 2000), que sólo se logra en ocasiones esporádicas, y de que la aplicación de poliaminas a árboles de naranjo dulce 'Salustiana' y de tangor 'Ellendale' no consigan incrementar la floración en los años off (Arias, 1999), señala que el papel del metabolismo del nitrógeno en el proceso de floración de las especies leñosas no está claro y exige más estudio.

Su papel en el crecimiento y la maduración de los frutos, sin embargo, resulta más claro. Por una parte contribuye al aporte energético necesario durante el crecimiento de los frutos $y$, por otra, intervienen 
indirectamente en el cambio de color de éstos debido a su acción antisenescente (Alós et al., 2006). En

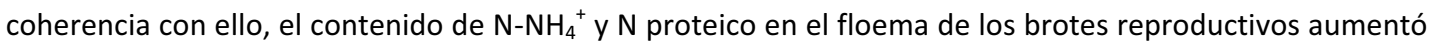
progresivamente hasta que los frutos alcanzaron el 70\% de su tamaño final y descendió posteriormente, desde que completó su crecimiento hasta que maduró. Los cambios experimentados en las fracciones nitrogenadas del fruto fueron coherentes con esta distribución, excepto el $\mathrm{N}$ proteico que disminuyó continuamente desde que los frutos iniciaron su crecimiento hasta que maduraron. La presencia simultánea de varias generaciones de frutos en diferentes estados del desarrollo del cv.'Piera' y la correspondiente modificación en el reparto de las fracciones nitrogenadas que ello supone, ratifican este efecto. Nuestros resultados proporcionan una visión más amplia de este fenómeno al contemplar la relación del metabolismo del nitrógeno con el desarrollo de las raíces. El contenido radicular en fracciones nitrogenadas descendió significativamente con el crecimiento del fruto. Pero, paradójicamente, se detuvo y hasta hubo una acumulación del ión nitrato al final del crecimiento de éste, en el estado fenológico 709 de la escala $\mathrm{BBCH}$, al mismo tiempo que se detectó un aumento del ión amonio, lo que indica que el efecto del fruto alcanzó a las raíces, alterando su mecanismo de reducción de nitratos. Si el descenso paralelo en la concentración de carbohidratos en las raíces, como demostraron nuestros análisis de $\mathrm{C}^{13}$, es responsable de la falta de actividad de la enzima nitrato-reductasa está por estudiar.

El efecto inhibidor del fruto sobre la floración se ha identificado en numerosas especies frutícolas leñosas, tanto perennifolias como caducifolias, tales como el manzano (Jonkers, 1979), el melocotonero (Reig et al., 2006) y los cítricos (Monselise y Goldschmidt, 1982), pero ninguno de estos estudios indican a partir de qué momento del desarrollo el fruto inicia su acción. En el níspero japonés, nuestros resultados demuestran que los árboles a los que se les eliminaron todos los frutos desde el estado 701 al 707 de la escala fenológica $\mathrm{BBCH}$ florecieron, el otoño siguiente, hasta un $69.2 \%$ más que aquellos a los que se les dejaron todos. De acuerdo con ello, el fruto ejerce su acción inhibidora de la floración desde el momento en que está próximo a adquirir su máximo peso, es decir, cuando alcanza el 80\%-90\% de su tamaño final (abril), de un modo similar a como ha sido demostrado en el naranjo dulce (Martínez-Fuentes et al., 2010) y el pomelo (Betancourt et al., 2008). Posteriormente, desde el cambio de color de los frutos hasta su completa senescencia, apenas se observó un efecto adicional en la reducción de la floración. Esta acción del fruto sobre la floración se ha relacionado con la síntesis de giberelinas, capaces de interferir en la inducción floral (ver revisión de El-Otmani et al., 1995). Las giberelinas son hormonas vegetales responsables de la brotación de las yemas en muchas especies frutícolas (Faust, 1989) y se hallan implicadas en al proceso de la floración interfiriendo en la formación de las flores (Goldschmidt et al., 1997). No resulta extraño, por tanto, que su aplicación durante la época de inducción floral reduzca significativamente la densidad de floración de la primavera siguiente (Jourdain y Clanet, 1987; Southwick et al., 1995; Southwick y Glozer, 2000) y se utilice como una práctica común para reducir la floración de los 
cítricos (El-Otmani et al., 2000), aguacate (Salazar-García y Lovatt, 2000), albaricoquero (Southwick et al., 1997), mango (Turnbull et al., 1996; Tomer, 1984; Galán-Saúco, 1999), frutales de pepita (McArtney y Li, 1998), y frutales de hueso (Painter y Stembridge, 1972; Southwick y Glozer, 2000; González-Rossia et al., 2006; 2007). Nuestros resultados con el níspero japonés también muestran una reducción de la floración por acción del ácido giberélico, con dos épocas de sensibilidad a su aplicación bajo condiciones de Clima Mediterráneo, entre mediados de mayo y principios de junio, y desde principios de agosto al inicio de la floración. La primera coincide con la determinada por Fatta del Bosco (1961) defoliando ramas, también bajo condiciones mediterráneas, y coincide, asimismo, con la época señalada por Luckwill (1970) cuando relacionó el crecimiento del embrión de la semilla con la intensidad de floración. La segunda época de sensibilidad no había sido detectada hasta hoy. Entre ambas épocas se ha identificado un periodo de reposo estival con ausencia de crecimiento (Hueso et al., 2007). De acuerdo con el desarrollo fenológico del níspero japonés, la primera época de sensibilidad puede asociarse con la inducción floral y la segunda con la diferenciación floral. En nuestros experimentos, y para una concentración de ácido giberélico determinada, el número de flores por panícula se redujo sólo cuando éste se aplicó directamente a los ápices, lo que indica que la respuesta depende de la cantidad de materia activa aplicada por ápice más que de la concentración aplicada. Este efecto es similar al obtenido en melocotoneros y nectarinas (GonzálezRossia et al., 2006). Bajo este punto de vista debe destacarse que el ácido giberélico aplicado al árbol completo reduce la intensidad de floración porque reduce el número de panículas por $\mathrm{m}^{3}$ de copa y no el número de flores por panícula.

Se ha demostrado que la acción inhibidora de la floración del ácido giberélico en las especies frutales tiene lugar a través de una interferencia en los procesos de inducción y diferenciación floral, reduciendo el número de yemas florales por nudo y el número de flores por yema, respectivamente (Luckwill, 1970; Bradley y Crane, 1960; Monselise y Halevy, 1964; Guardiola et al., 1982), y a través de la reducción de la brotación (García-Luis et al., 1986). Una combinación de la reducción del número de brotes por árbol, el número de yemas florales por nudo, y el número de flores por yema, explica la reducción del número de flores por árbol en estas especies (Reig et al., 2006), incluido el níspero japonés.

No obstante, resulta aparentemente extraño que el ácido giberélico reduzca el número de panículas por $\mathrm{m}^{3}$ siendo que su aplicación directa al ápice, aunque reduzca el número de flores, no evita nunca la existencia de la panícula. El efecto más importante del ácido giberélico observado en nuestros experimentos es la reducción significativa del número de brotes florales anticipados, más que la de brotes mixtos del año cuyo número no se modifica. Este efecto del ácido giberélico reduciendo el número de yemas laterales que brotan, explica la reducción del número total de panículas por $\mathrm{m}^{3}$ de copa al mismo tiempo que se mantiene invariable el de panículas de los brotes del año. Este efecto también demuestra que el ácido giberélico reduce la proporción de yemas que brotan y, por tanto, la de las que pueden dar 
flores. El efecto también alcanza a las yemas vegetativas que ven, asimismo, reducido su número. Algo similar fue señalado en el mandarino Satsuma 'Owari' por el mantenimiento de sus frutos en el árbol (García-Luís et al., 1986) y en el naranjo dulce 'Valencia' (Martínez-Fuentes et al., 2010)

Bajo un punto de vista agronómico, los brotes anticipados son brotes vigorosos que casi siempre desarrollan panículas de frutos de calidad comercial deficiente. De acuerdo con ello, la utilización de ácido giberélico, puesto que reduce su número, se presenta como una técnica útil para reducir los costes de aclareo de estos frutos. Adicionalmente, su ausencia contribuye a que los frutos procedentes de panículas situadas en los brotes del año mejoren su crecimiento y tamaño final (Weinberg, 1941). Este efecto, junto con una mejora significativa en la coloración del fruto y en la reducción de la acidez de la pulpa, permite una ligera anticipación de la recolección.

Por otro lado el aumento del número de flores registrado en las panículas principales y anticipadas de los brotes partenocárpicos, es decir, con frutos sin semillas, y, por tanto, sin la principal fuente de giberelinas, apoya la idea de que es el transporte de éstas hacia las yemas del brote el responsable de la acción inhibidora de la floración. Aunque existe una correlación significativa entre el descenso del número de entrenudos y el descenso de la floración, no se puede afirmar con nuestros resultados que las variaciones en la densidad de floración sean consecuencia sólo de las alteraciones del desarrollo vegetativo, ya que la acción del ácido giberélico es directa sobre la yema.

De acuerdo con esto, el efecto global del AG sobre la inhibición de la floración de esta especie pone de manifiesto la regulación hormonal del proceso, así como el de la brotación de sus yemas. Para una mejor demostración de ésta, se eliminaron completamente los ápices indiferenciados de los brotes, en las dos épocas de mayor sensibilidad, principios de junio y finales de agosto y, en efecto, las yemas de los brotes que iniciaron su desborre fueron siempre las más próximas a la zona de corte y ello significa que cuando el ápice se eliminó en junio las yemas que brotaron acababan de ser inducidas a florecer y, por tanto, dieron lugar a brotes anticipados con panícula al menos en un 50\% de los casos, mientras que cuando los ápices se eliminaron en agosto las yemas que brotaron también eran más próximas al corte, pero eran yemas que en junio (en época de inducción floral) no estaban presentes y, por tanto, no pudieron ser inducidas a florecer y por eso desarrollaron brotes vegetativos. Es más, la señal inductiva que había recibido el ápice terminal eliminado, no se transmitió a las yemas axilares más próximas. Morris et al. (2005) sugieren que tras la eliminación del ápice tiene lugar una señal de acción rápida que permite a las yemas latentes entrar en un estado de transición que le libera de la dominancia apical.

El ácido abscísico (ABA) ha mostrados su capacidad de restringir el desarrollo de las yemas en muchas especies, incluyendo los cítricos (Young y Cooper, 1969). Más tarde, Goldschmidt (1984) demostró, asimismo, que la concentración de ABA en hojas, ramas y yemas de mandarino 'Wilking' durante los años de elevada cosecha y con escasa brotación y floración la primavera siguiente era superior a la encontrada 
en los años de cosecha reducida con elevada brotación y floración, reflejando de este modo el estrés impuesto por la elevada producción, de un modo similar a lo observado en nuestros experimentos. Los árboles que mantuvieron todos sus frutos hasta la recolección, tuvieron, en general, y a lo largo de todo el ciclo vegetativo, una concentración de $A B A$ en el floema superior que aquellos a los que se les eliminaron todos al inicio de su crecimiento. Con la recolección desapareció el estrés, y la concentración descendió hasta valores inferiores al de los árboles sin frutos. Consecuentemente, en el momento de la inducción floral el nivel de ABA era significativamente superior en el floema de los árboles que iban a florecer más. Este aumento del ABA antes de la floración ya fue determinado en el cv. 'Aoshima' de mandarino Satsuma eliminado frutos (Okuda, 2000) y en el limonero sometiéndolo a diferentes tipos de estrés hídrico (Raveh, 2008); en el primer caso, la eliminación del fruto promovía la floración mediada por la concentración de ABA en hojas y floema; en el segundo, la restricción de agua en el verano, técnica conocida como verdelli, promovía la floración fuera de estación, de modo que los árboles sometidos al estrés más eficaz contenían mayor concentración de $\mathrm{ABA}$ en el fluido xilemático y florecían más intensamente. Este efecto, sin embargo, no parece general y, así, los experimentos de Okuda (2000) con el cv. 'Miyagawa', también de mandarino Satsuma, no presentaron la misma respuesta, indicando que la acción del ABA en la floración puede ser a través de un efecto indirecto, inhibiendo el desarrollo de brotes florales sin hojas (Davenport, 1990) o provocando la abscisión de brotes (Plummer et al., 1991), dando lugar, de este modo, a respuestas variables con las especies y cultivares. La acción de esta hormona restringiendo la brotación y el crecimiento de las yemas axilares (Young y Cooper, 1969) y con ello la floración, estaría mediada, por tanto, en nuestros experimentos, por la presencia del fruto. De los ápices despuntados en las dos épocas de sensibilidad, junio (inducción floral) y agosto (diferenciación floral), se deduce que, en el níspero japonés, el ápice para florecer necesita, en el momento de la inducción floral, altos contenidos de $A B A$ y bajos de giberelinas, esto último demostrado indirectamente en nuestros experimentos al reducir el número de flores por panícula con tratamientos de AG directamente al ápice del brote mixto. Por otro lado, los ápices de los brotes todavía indiferenciados tendían a aumentar su contenido en $A B A$ y el valor de los ratios de éste con otras hormonas como el $\mathrm{GA}_{3}$, AlA y zeatina, en etapas próximas a su inducción floral (Hu et al., 2010). Algo similar ocurrió en nuestros experimentos cuando en la época de inducción floral la tendencia del $A B A$ en el floema de los árboles sin frutos y, por tanto, de los que florecieron más intensamente. Es más, la concentración de ABA del ápice terminal alcanzó el máximo inmediatamente antes de su diferenciación. Más claro resulta este efecto al comparar la evolución del ratio AIA/zeatina, más baja en los árboles sin frutos a lo largo de todo el ciclo vegetativo. El descenso de éste se relaciona con la brotación y viceversa, explicándose de este modo las diferencias en la brotación encontradas por la presencia de los frutos. Pero lo relevante es que en pleno crecimiento vegetativo, cuando se estaba iniciando la brotación anticipada en los árboles que no tenían los frutos desde el inicio de su crecimiento, la concentración de AIA 
era menor y la de zeatina mayor que la de los árboles que soportaron toda su carga hasta la recolección, facilitando así, la mayor y más precoz brotación de los primeros frente a los segundos (Yaish et al., 2002; Werner et al., 2001). Sin embargo, no todos los cambios fenotípicos relacionados con la brotación pueden ser explicados por alteraciones del ratio de estas dos hormonas ya que plantas transgénicas sobreproductoras de AIA presentan aspectos distintos del desarrollo que plantas trangénicas infraproductoras de citoquininas (Werner et al., 2001). De modo que la iniciación de un nuevo ápice vene siempre precedida de la acumulación localizada de concentraciones elevadas de citoquininas, tal y como se observa en la evolución de su concentración en nuestros árboles, y la supresión de la yema principal permite el crecimiento de las yemas laterales, como también ocurre en nuestros experimentos, crecimiento que es inhibido cuando se aplica auxina al corte (Tanaka et al., 2006). Aunque estos resultados corroboran la idea de que la auxina procedente del ápice inhibe el crecimiento de las yemas laterales (Tamas, 1995), algunos autores disienten de esta interpretación basándose en que la concentración de auxina exógena necesaria es muy superior a la de la yema suprimida (Fletcher, 2002). En nuestros resultados la concentración de AIA en el floema de los brotes vegetativos fue superior a la de los reproductivos, inmediatamente antes de que se formaran las flores en estos últimos, sin embargo, la de los ápices ya diferenciados fue casi 4 veces superior que la de los vegetativos. Por otra parte, en el momento de la inducción floral la concentración de esta auxina en los árboles que no tenían sus frutos desde el inicio de su crecimiento y que, por tanto, florecieron más intensamente, fue menor que la de aquellos que los mantuvieron todos hasta su recolección. Dado que el ratio AIA/zeatina se ha relacionado con la brotación de las yemas laterales, tanto mayor cuanto menor es dicho ratio (Skoog and Miller, 1957), la menor brotación, y con ello la menor floración, de los árboles que conservaron todos sus frutos en comparación con la de los árboles sin frutos, queda de este modo explicada. Bajo este punto de vista, la acción del AIA en el proceso de la floración se entiende más como un efecto derivado de las alteraciones que la presencia del fruto provocó directamente en el desborre de las yemas y posterior desarrollo de los brotes que como un efecto directo sobre el proceso de la floración.

Por el contrario, las auxinas tienen un papel fundamental en la formación de las raíces laterales y adventicias y son necesarias para las divisiones iniciales que originan el primordio de la raíz lateral (Mylona y Dolan, 2002; Jansen et al., 2010). El brusco descenso de la concentración de AIA detectado en las raíces cuando los frutos estaban finalizando el crecimiento, esto es, en el estado fenológico 709 de la escala $\mathrm{BBCH}$, es compatible con el descenso en la formación de raíces laterales, cuantificado por la densidad de puntos mitóticos, y, por tanto, de su actividad. Además, como consecuencia de dicho descenso, el transporte de auxinas a la parte aérea, fundamentalmente a los frutos, se redujo significativamente, como lo muestra la evolución de la concentración de AIA en el xilema de estos árboles. Overvoorde et al. (2010) han publicado una magnífica revisión sobre el control del desarrollo radicular por las auxinas. 
Se ha demostrado que las auxinas controlan el crecimiento radicular modulando la respuesta celular a las giberelinas. La hipótesis, confirmada por Fu y Harberd (2003) en mutantes de Arabidopsis thaliana, establece que el ápice caulinar ejerce un control a larga distancia del crecimiento de los órganos de la planta a través del efecto de la auxinas modulando la acción de las giberelinas desestabilizadora sobre la proteína DELLA. Esta proteína es un represor del crecimiento y puede ser desestabilizada por las giberelinas que ejercerían así su acción estimulante del crecimiento (Richards et al., 2001; Wen y Chang, 2002). Más oscuro, todavía, resulta el papel del ABA en el desarrollo de la raíz. Así, esta hormona puede inhibir el crecimiento de los primordios radiculares justo antes de que se activen los puntos mitóticos laterales e inmediatamente después de que emerjan (De Smet et al., 2003). Nuestros resultados apuntan en esa dirección, ya que el descenso de su concentración en las raíces coincidió, por una parte, con el de su crecimiento en longitud y, por otra, con las etapas finales del crecimiento de los frutos. Puesto que el $A B A$ se ha relacionado como una respuesta al estrés y, ya que el contenido de éste fue superior a lo largo de todo el ciclo vegetativo en las raíces de los árboles que mantuvieron todos sus frutos hasta la recolección, que en los que los perdieron todos al inicio de su crecimiento, la posibilidad de que la carga total de frutos en un árbol sea motivo suficiente de estrés para sus raíces no es descartable.

En relación al desarrollo del fruto, el AIA y la zeatina juegan un papel esencial. En coincidencia con los resultados de Ding y Zhang (1988) y Ye (1988), durante el cuajado de la flor y el crecimiento inicial del ovario en esta especie, el contenido hormonal en AIA y citoquinias es máximo, mientras que durante la fase de rápido crecimiento del fruto, es decir, desde el estado 705 al 709 de la escala fenológica BBCH, las concetraciones de AIA y de citoquininas alcanzan sus valores mínimos. La elevada concentración de estas sustancias detectada en el fruto cuando éste iniciaba su crecimiento, indica la alta capacidad de síntesis hormonal que éste tiene durante las primeras fases del desarrollo de su embrión. La existencia de giberelinas en las semillas inmaduras de níspero japonés también ha sido confirmada (Koshioka et al., 1988). La acción de estas hormonas sobre el desarrollo del fruto se ha relacionado con la expansión celular y se ha explicado a través de un incremento del contenido en materia seca del fruto, es decir, de su capacidad sumidero. El hecho de que el AG y la kinetina promuevan la partenocarpia del níspero japonés (Kumar, 1976; Yahata et al., 2006; Mesejo et al., 2010), constituye una prueba indirecta de ello.

En muchas especies, el control de la dominacia apical está relacionado con la interacción entre las auxinas y las citoquininas (Tamas, 1995). El AIA sintetizado en el ápice caulinar se transporta en sentido basípeto y suprime el crecimiento de las yemas laterales, mientras que las citoquininas, procedentes de la raíz, promueven el rebrote de las yemas axilares. El transporte acrópeto y basípeto vía xilema y floema ha sido demostrado para auxinas (Baker y Allen, 1988; Savičiené y Anisimoviené, 1988) y citoquininas (Kamboj et al., 1998). Según esto, las raíces de los árboles con mayor desarrollo vegetativo y, con ello, mayor número de yemas principales y anticipadas brotadas, es decir, aquellos a los que se les eliminaron todos sus 
frutos en el estado fenológico 701 de la escala $\mathrm{BBCH}$, deberían tener mayor contenido de citoquininas que los que presentaron menor vigor por la presencia de los frutos, como así ocurre. De hecho, el valor máximo de esta hormona registrado en el floema de los árboles con frutos, en el momento de la recolección, explica el inicio del desborre de las yemas principales y, posteriormente, el de las anticipadas en estos árboles, rompiéndose, de esta manera, la dominancia apical. $Y$ es que, como es conocido, la deficiencia en esta sustancia provoca una reducción en la actividad de los meristemos vegetativos y florales del tallo. Es por ello, que el nivel de zeatina en el floema de los árboles que mantuvieron todos sus frutos hasta su recolección o, lo que es lo mismo, no presentaron ningún indicio de desborre hasta transcurrido un tiempo desde la misma, se mantuvo constante, a diferencia de los que no tenían frutos cuyo contenido, en plena actividad de los meristemos, fue máximo. En el conjunto de la planta, la importancia de las citoquininas en la regulación del ciclo celular se pone de manifiesto por la participación de éstas en el mantenimiento de los meristemos. Así, en lagunas plantas de día largo, la inducción floral conduce a un incremento de la concentración de citoquininas en las yemas inmediatamente antes de que se inicien el proceso de diferenciación (Bernier et al., 1993). Este hecho viene precedido por un incremento transitorio en los niveles de citoquininas del fluido xilemático, lo que sugiere que las citoquininas procedentes de las raíces, participan en la inducción floral (Aiken y Smucker, 1996). En nuestro caso, el mayor contenido de éstas en el floema de los árboles que florecieron más (los que no tenían ningún fruto) y, por tanto, se indujeron mayor número de yemas, por un lado, y el incremento detectado en su xilema, por otro, apoyan esta idea. Pese a ello, se requieren de mayores conocimientos para corroborar la participación de las citoquininas en el control de la floración.

Se ha demostrado que la síntesis de estas hormonas resulta afectada por la fuente disponible de nitrógeno en la planta. Por ejemplo, en condiciones de deficiencia en $\mathrm{NO}_{3}^{-}$, la planta supera la situación acelerando el crecimiento de la raíz principal y aumentando el número de raíces laterales, lo que está ligado a una alta concentración de $\mathrm{NO}_{3}{ }^{-}$(Tranbarger et al., 2003). Para lograrlo, existen, al menos, tres transportadores de $\mathrm{NO}_{3}{ }^{-}$codificados por tres genes, NRT1.1, NRT1.2 y NRT2.1, identificados en Arabidopsis (Cerezo et al., 2001; Munos et al., 2004), que facilitan su absorción por el ápice radicular y elevan su concentración. Es más, sin que se sepa el mecanismo, el NRT1.1 promueve la expresión del gen ANR1 que dispara la elongación de raíces laterales en la zona de acumulación del nitrato (Remans et al., 2006). El estímulo del desarrollo de raíces laterales tiene como efecto secundario la síntesis inducida de citoquininas. Nuestros resultados demuestran que la presencia del fruto en el árbol hasta su recolección reduce la concentración de todas las fracciones nitrogenadas en hojas y floema durante sus últimas etapas de desarrollo, es decir, entre los estados 706 y 709 de la escala fenológica BBCH. El contenido de todas las fracciones nitrogenadas inicialmente, y más tarde de $\mathrm{N}-\mathrm{NH}_{4}{ }^{+}$y $\mathrm{N}$-proteico, en las raíces también se redujo significativamente en las últimas etapas del desarrollo de los frutos, lo que hizo que, al mismo tiempo, se 
redujera el de citoquininas en las raíces y en el xilema de estos árboles en estos mismos estados fenológicos. El posterior incremento de hormonas y fracciones nitrogenadas, indica, por una parte, la recuperación de la actividad radicular, de síntesis hormonal y de reducción de nitratos, y, por otra, la relación entre el balance hormonal y nutricional, del mismo modo que ocurre en el tomate (Hurd et al., 1979).

Puesto que las funciones reguladoras de las hormonas se solapan ampliamente y en las plantas, ninguna hormona tiene el control exclusivo de determinado proceso fisiológico, la interacción entre auxinas y citoquininas podría dar la explicación a muchos de ellos ((Skoog and Miller, 1957; Jansen et al., 2010). La coincidencia en nuestros resultados del descenso de ambas hormonas registrado en las raíces del árbol en el mismo estado fenológico, en el 709 de la escala $\mathrm{BBCH}$, junto con las alteraciones nutricionales detectadas en el mimso, podría explicar que muchos de los procesos fisiológicos de la planta, entre ellos, la actividad y el desarrollo de las raíces, están contolados por la interacción de factores hormonales y nutricionales, entre otros.

En conclusión, en el níspero japonés, el fruto inhibe la floración a partir del momento en que alcanza el $80 \%$ de su tamaño final. Su presencia en el árbol retrasa la brotación y reduce el número de yemas brotadas, fundamentalmente anticipadas, así como la longitud de ambos brotes. Esta acción se atribuye exclusivamente a sus semillas porque con la presencia de frutos partenocárpicos no se consigue. Pero no se puede afirmar con nuestros resultados que las variaciones en la densidad de floración sean consecuencia sólo de las alteraciones del desarrollo vegetativo, ya que la aplicación de AG directamente al ápice indiferenciado reduce el número de flores, al mismo tiempo que demuestra su participación en la acción inhibidora del fruto sobre la floración. Ni la concentración foliar de azúcares solubles ni la de almidón provocada por la eliminación de los frutos, presentan relación con la intensidad de floración pero sí como fuente de energía para que las yemas inicien su desborre. El desajuste en el metabolismo del nitrógeno provocado por el crecimiento de los frutos se ha relacionado con la intensidad de floración y con la actividad radicular. Las alteraciones en la concentración de AIA, ABA y zeatina en las raíces y en el xilema coincidentes con el crecimiento del fruto demuestran su efecto sobre la actividad radicular en esta especie, al mismo tiempo que su influencia en la maduración del fruto.

A la vista de nuestros resultados, los cambios nutricionales y hormonales detectados durante el crecimiento del fruto adquieren su máxima intensidad entre los estados fenológicos 706 y 709 de la escala $\mathrm{BBCH}$, de modo que en esa etapa la raíz, por acción del fruto, ralentiza, hasta casi cesar, su actividad, no reduce $\mathrm{NO}_{3}{ }^{-}$ni transporta $\mathrm{NH}_{4}{ }^{+}$a la copa y apenas sintetiza ni transporta zeatina, ambos factores antisenescentes y necesarios para la brotación que, por ello, no se inicia. El fruto queda, entonces, como el único sumidero del árbol, acumula la casi totalidad de los carbohidratos en detrimento de la raíz, que le 
restringe el aporte de antisenescentes, y cambia de color. Cuando completa su crecimiento y cesa su actividad sumidero, la raíz reinicia su actividad, y cuando se recolecta tiene lugar la brotación. 



\section{Conclusiones}





\section{CONCLUSIONES}

El fruto, a través, de su capacidad sumidero, es factor esencial en el control del desarrollo del árbol del níspero japonés:

1. El fruto mientras está presente en el árbol impide la brotación manteniendo un elevado ratio AIA/zeatina.

2. El fruto regula la floración indirectamente, reduciendo la brotación de yemas anticipadas, y directamente, reduciendo el número de flores por panícula desde que alcanza el $80 \%$ de su tamaño final hasta su senescencia. Nuestros resultados demuestran, indirectamente, el papel de las giberelinas en el proceso.

3. El desarrollo del fruto está controlado por él mismo a través de la competencia por fotoasimilados con los demás frutos en desarrollo.

4. La raíz reduce su desarrollo progresivamente con el crecimiento del fruto hasta que éste lo completa.

5. La síntesis hormonal y la reducción de $\mathrm{NO}_{3}{ }^{-}$en la raíz descienden paralelamente a la reducción de su actividad.

6. De este modo, el fruto regula el final de su crecimiento y su cambio de color, acumulando carbohidratos y sin recibir sustancias antisenescentes, $\mathrm{NH}_{4}^{+}$y zeatina.

\section{CONCLUSIONS}

In loquat, fruit regulates tree development through its sink capacity:

1. Fruit largely reduces bud sprouting by means of an increased IAA/zeatine ratio.

2. Fruit reduces flowering indirectly, by reducing the number of premature shoots, and directly, by reducing the number of flowers per panicle; our results show, indirectly, the role of gibberellins in the flowering process.

3. Fruit size is self-controlled through a competition for carbohydrates among developing fruits.

4. Root growth and root activity are progressively reduced as fruit develops up to it completes the growth.

5. Hormonal synthesis and $\mathrm{NO}_{3}{ }^{-}$reduction lessening paralleled to decreasing of root activity.

6. Thus, fruit self-regulates its growth and colour break, gathering carbohydrates and dispensing with anti-senescing substances, mainly $\mathrm{NH}_{4}{ }^{+}$and zeatine. 



\section{Referencias bibliográficas}





\section{Referencias bibliográficas}

Agustí, J., żpater, M., Iglesias, D. J., Cercós, M., Tadeo, F. R. y Talón, M. 2007. Differential expression of putative 9-cis-epoxycarotenoid dioxygenases and abscisic acid accumulation in wáter stressed vegetative and reproductive tiddues of citrus. Plant Sci., 172: 85-94.

Agustí, M. 2003. Citricultura. Ed. Mundi Prensa, Madrid, España.

Agustí, M. 2010. Fruticultura. Ed. Mundi Prensa, Madrid, España.

Agustí, M. y Reig, C. 2006. Fisiología. En: El Cultivo del Níspero Japonés, M. Agustí, C. Reig y P. Undurraga (Eds.), Gráficas Alcoy, España, pp 97-129.

Agustí,M., Almela, V. y Pons, J. 1992. Effects of girdling on alternate bearing in citrus. J. Hortic. Sci., 67: 203-210.

Agustí, M., Juan, M., Almela, V. y Gariglio, N. 2000. Loquat fruit size is increased through the thinning effect of naphthaleneacetic acid. Plant Growth Regul., 31: 167-171.

Agustí, M., Andreu, I., Juan, M., Almela, V. y żcarías, L. 1998. Effects of ringing branches on fruit size and maturity of peach and nectarine cultivars. J. Hortic. Sci. Biotechnol., 73: 537-540.

Agusti, M., Juan, M., Almela, V., Andreu, I. y Speroni, C. 1997. Estímulo del desarrollo de los frutos de hueso. Generalitat Valenciana, Sèie Divulgació Técnica n. 38, Valencia, España.

Agustí, M., Gariglio, N., Juan, M., Almela, V., Mesejo, C y Martínez-Fuentes, A. 2005. Effect of branch scoring on fruit development in loquat. J. Hortic. Sci. Biotechnol., 80: 370-374

Agustí M., Żragoza, S., Iglesias, D.J., Almela, V., Primo -Millo, E. y Talón, M. 2002. The synthetic auxin 3,5,6-TPA stimulates carbohydrate accumulation and growth in citrus fruit. Plant Growth Regul., 32: 141-147.

Agustí, M., Gariglio, N., Castillo, A., Juan, M., Almela, V., Martínez-Fuentes, A. y Mesejo, C. 2003. Effect of the synthetic auxin 2,4-DP on fruit development of loquat. Plant Growth Regul., 41: $129-132$

Aiken, R. M. y Smucker, A. J. M. 1996. Root system regulation of whole plant growth. Annu. Rev. Phytopathol., 34: 325-346.

Albrigo, L. G. y Galán, V. 2004. Flower bud induction, flowering and fruit-set of some tropical and subtropical fruit tree crops with special reference to citrus. Acta Hortic., 632: 81-90.

Alós, E., Cercós, M., Rodrigo, M. J., żcarías, L. y Talón, M. 2006. Regulation of color break in citrus fruits. Changes in pigment profiling and gene expression induced by gibberellins and nitrate, two ripening retardants. J. Agric. Food Chem., 54: 4888-4895. 
Amorós, A., æpata P., Pretel M.T., Botella M.A. y Serrano M. 2003. Physico-chemical and physiological changes during fruits development and ripening of five loquat (Eriobotrya japonica Lindl) cultivars. Food Sci. Technol. Int., 9: 43-51.

Arbeloa, A., y Herrero, M. 1991: Development of the ovular structures in peach [Prunus persica (L) Batsch]. New Phytol., 118: 527-533.

Archbold, D.D. 1992. Cultivar-specific apple fruit growth rates in vivo and sink activities in vitro. J. Amer. Soc. Hort. Sci., 117: 459-462.

Arias, M. 1999. Cuantificación y evolución de poliaminas en los cítricos. Comparación de especies con diferente comportamiento reproductivo. PhD Tesis. Universidad Politécnica, Valencia, España.

Ateyyeh, A.F. y Qrunfleh, M.M. 1998. Studies on the loquat Eriobotrya japonica Lindl. cv. Tanaka. I. Vegetative and reproductive growth in the Jordan valley. Dirasat Agric. Sci., 25: 5563.

Ayalon, S. y Monselise, S. P. 1960. Flower bud induction and differentiation in the Shamouti orange. Proc. Amer. Soc. Hortic. Sci., 75: 216-221.

Badr, S. A. y Hartman, H. T. 1972. Flowering response of the olive (Olea europaea L.) to certain growthregulators applied under inductive and non inductive environments. Bot. Gazette, 133 : 387-392.

Baker, D. A. y Allen, J. R. F. 1988. Auxin transport in the vascular system. En: Physiology and biochemistry of auxins in plants, M. Kutáček, R. S. Bandurski y J. Krekule (Eds.), SPB Academic Publishing, La Haya, The Netherlands, pp 215-220.

Bernier, G. 1988. The control of floral avocation and morphogenesis. Ann. Rev. Plant Physiol. Plant Mol. Biol., 39: 175-219.

Bernier, G., Havelange, A., Houssa, C., Petitjean, A. y Lajeune, P. 1993. Physiological signals that induce flowerin. Plant Cell, 5: 1147-1155.

Betancourt, M., Martínez-Fuentes, A., García, M.E., Mesejo, C., Sánchez, C.D., Nuñez, M. Reig, C. y Agustí, M. 2008. The influence of fruit load on flowering intensity of grapefruit (Citrus paradisi Macf.) under tropical climatic conditions. 2008 ISC Congress, Abstract P249: 203.

Blumenfeld, A. 1980. Fruit growth of loquat. J. Amer. Soc. Hortic. Sci., 105: 747-750.

Bradley, M.V y Crane, J.C. 1960. Gibberellin-induced inhibition of bud development in some species of Prunus. Science, 13: 825-826.

Buban, T. y Faust, M. 1982. Flower but induction in apple trees: Internal control and differentiation. Hort. Rev., 4: 174-203. 
Byers, R.E., Carbaugh, D.H. y Presley, C.N. 1990. The influence of bloom thinning and $\mathrm{GA}_{3}$ sprays on flower bud numbers and distribution in peach trees. J. Amer. Soc. Hortc. Sci., 65: 143-150.

Canellas, L. P., Lopes-Olivares, F., Okorokova-Faęnha, A. L. y Rocha-Faęnha , A. 2002. Humic Acids Isolated from Earthworm Compost Enhance Root Elongation, Lateral Root Emergence, and Plasma Membrane H-ATPase Activity in Maize Roots. Plant Physiol., 130: 1951-1957.

Carrera, L. 2009. Biología reproductiva del níspero japonés [Eriobotrya japonica (Thunb.) Lindl.]. PhD Tesis, Universidad de Valladolid, España.

Catlin, P.B, Priestley, C.A. 1976. Short-term studies of uptake of nitrogen by young apple trees after soil application of ammonium nitrate. Ann. Bot., 40: 73-82.

Cerezo, M. Tillard, P., Filleur, S., Munos, S., Daniel-Vedele, F. y Gojon, A. 2001. Major alterations of the regulation of root $\mathrm{NO}_{3}{ }^{-}$uptake are associated with the mutation of $\mathrm{Nrt2.1}$ and Nrt2.2 genes in Arabidopsis. Plant Physiol., 127: 262-271.

Cohen, A. 1981. Recent developments in girdling of citrus trees. Proc. Int. Soc. Citriculture, 1: 196-199.

Crane, J. C., Al-Shalan, I. y Carlson, R. M. 1973. Abscission of pistachio inflorescence buds as affected by leaf area and number of nuts. J. Amer. Soc. Hortic. Sci., 98: 591-592.

Cuevas, J., Hueso, J. J., y Puertas, M. 2003ạ Pollination requirements of loquat (Eriobotrya japonica Lindl.), cv. Algerie. Fruits, 58: 157-165.

Cuevas, J., Salvador-Sola, F. J., Gavilan, J., Lorente, N., Hueso, J. J. y Gonzalez-Padierna, C. M. 2003b. Loquat fruit sink strength and growth pattern. Sci. Hortic., 98: 131-137.

Cutting, J. G. M. y Lyne, M. C. 1993. Girdling and the reduction in shoot xylem sap concentrations ofcytokinins and gibberellins in peach. J. Hortic. Sci., 68: 619-626.

Chachin, K; Hamauzu, H, Kurooka, H y Iwata, T. 1990. Physiological changes of loquat fruit after harvest. XXIII Int. Hortic.I Congres, Abstract 2. P3350.

Dann, I. R., Jerie, P. H. y Chalmers, D. J. 1985. Short-term changes in cambial growth and endogenous IAA concentrations in relation to phloem girdling of peach Prunus persica. Australian J. Plant Physiol., 12: 395-402.

Davenport, T L. 1983. Daminozide and gibberellins effects on floral induction of Citrus latifolia. HortSci., 18: 947-949.

Davemport, T.L. 1990. Citrus flowering. Hortic. Rev., 12: 349-408.

De Jong, T. M. y Walton, E. F. 1989. Carbohydrate requirements of peach fruit growth and respiration. Tree Physiol., 5: 229-335. 
De Smet, I., Signora, L., Beeckman, T., Inzé, D., Foyer, D. H. y Zang, H. 2003. An abscissic acid sensitive checkpoint in lateral root development of Arabidopsis. Plant J., 33: 543-555.

Dickens, C.W.S y Van Staden, J. 1988. The induction and evocation of flowering in vitro. South African J. Bot., 54: 325-344.

Ding, C.K. y Zang , H.Z1988. Effects of horm ones on growth and development of loquat fruits. Acta Hortic. Sinica, 15: 148-153.

Domingo, C., Andrés, F., Tharreau, D., Iglesias, D.J. y Talón, M. 2009. Constitutive expression of OsGH3.1 reduces auxin content and enhances defense response and resistance to a fungal pathogen in rice. Amer. Phytopathol. Soc., 22: 201-210.

Dowler, W.M. y King, F.D. 1966. Seasonal changes in starch and soluble sugar content of dormant peach tissues. Proc. Amer. Soc. Hortic. Sci., 89: 80-84.

Edwards, G.R. 1986. Ammonia, arginine, polyamines and flower initiation in apple. Acta Hortic. 179: 363-364.

El-Otmani, M., Coggins, C., Agustí, M. y Lovatt, C.J. 2000. Plant Grwth Regulators in Citriculture: World current Uses. Crit. Rev. Plant Sci.. 19:5: 395-447.

El-Otmani, M., Lovatt, J., Coggins, C.W y Agustí, M. 1995. Plant growth regulators in citricultura: Factors regulating endogenous levels in citrus tissues. Crit. Rev. Plant Sci., 14: 367412.

Erner, Y., Goren, R. y Monselise S. P. 1976. The rough fruit condition of the Shamouti orange connections with the endogenous hormonal balance. J. Hortic. Sci., 51: 367-374.

Espinosa E., Martínez-Calvo J., García-Carbonell S., Badenes M.L. y Llácer G. 1997. Fenología y caracterización pomológica de variedades de níspero japonés. Actas de Horticultura, 15: 425430.

Fatta del Bosco, G. 1961. Indagini sull'epoca di differenziazione delle gemme nel nespolo del giappone. Riv. Ortoflorofrut. It., 86: 104-118.

Faust, M. 1989. Physiology of temperature zone fruit trees, Ed. John Wiley \&ons, NY, E EUU.

Fletcher, J. C. 2002. The vegetative meristem. En: Meristematic tissues in plant growth and development. M. T. McManus y B. E. Veit (Eds.). CRC Press, Fl., EEUU. pp. 16-57.

Flore, J.A. 1994. Stone fruit. En: Handbook of environmental physiology of fruit crops, Vol. I, Temperature crops, Schaffer, B y Anderson, P.C. (Eds). CRC Press, Inc., Boca Raton, Fla, EEUU.

Flore, J.A. y Layne, D.R. 1996. Prunus. En: Photoassimilate distribution in plants and crops, Żmski, E. y Schaffer, A. (Eds.), Marcel Dekker, Inc., NY, EEUU, pp 825-849.

Fu, X. y Harberd, N. 2003. Auxin promotes Arabidopsis root growth by modulating gibberellin response. Nature, 421: 740-743. 
Furr, J.R., Reece, P.C. y Henciar, G. 1945. Nitrogen absorption of ringed orange trees in nsand culture. Proc. Amer. Soc. Hortic. Sci., 46: 51-4.

Galán-Saúco, V. 1999. El cultivo del mango. Ed. Mundi-Prensa. Madrid. España.

García-Luís, A., Almela, V., Monerri, C., Agustí, M. y Guardiola, J. L. 1986. Inhibition of flowering in vivo by existing fruits and applied growth regulators in Citrus unshiu. Physiol. Plant., 66: 515520.

García-Luís, A, Fornes, F y Guardiola, J.L. 1995. Leaf carbohydrates and flower formation in Citrus. J. Amer. Soc. Hortic. Sci., 120:222-227

García-Luís A, Fornes F, Sanz A and Guardiola J L. 1988. The regulation of flowering and fruit set in Citrus: relationship with carbohydrate levels. Israel J. Bot., 37: 189-201.

García-Luís A and Guardiola J L. 2000. Influence of citrus internal factors and climatic effects on flowering. Proc. Int. Soc. Citriculture, 1: 292-295.

Gariglio, N. y Agustí, M. 2005. Effect of fruit thinning on the mineral composition of loquat (Eriobotrya japonica Lindl.) fruit and its connection with purple spot. Spanish J. Agric. Res., 3: 439-445.

Gariglio, N., Castillo, A., Juan, M., Almela, V. y Agustí, M. 2003. Effects of fruit thinning on fruit growth, sugars and purple spot in loquat fruit (Eriobotrya japonica Lindl.). J. Hortic. Sci. Biotechnol., 78: 32-34

Gariglio, N., M. Juan, A. Castillo, V. Almela y M. Agustí. 2002. Histological and physiological study of purple spot of loquat fruit. Sci. Hortic., 92: 225-263.

Génard, M., Bruchou, C., Souty, M. 1991. Variabilité de la croissance et de la qualité chez la pêhe ( Prunus persica L. Batsch) et liaison entre croissance et qualité. Agronomie ,11: 829-845.

Gifford, R.M y Evans, L.T. 1981. Photosynthesis, carbon partitioning and yield. Annu. Rev. Plant Physiol., 32: 485-509.

Goldschmidt, E E . 1984. Endogenous abscisic acid and 2-trans abscisic acid in alternate bearing Wilking" mandarin trees. Plant Growth Regul., 2: 9-13.

Goldschmidt, E. E. y Monselise, S. P. 1972. Hormonal control of flowering in citrus and some other woody perenials. En: Plant growth Substances 1970, D. J. Carr (Ed.), Springer-Verdag, NY, EEUU. pp 758-766.

Goldschmidt E E, Aschkenazi N, Herzano Y, Schaffer A A and Monselise S P. 1985. A role for carbohydrate levels in the control of flowering in citrus. Sci. Hortic., 26: 159-166.

Goldschmidt, E. E., Li, C.Y. y Weiss, D. 2003. Girdling affects carbohydrate-related gene expression in leaves, bark and roots of alternate-bearing citrus trees. Ann. Bot., 92: 219-221. 
Goldschmidt, E. E., Tamim, M. y Goren, R. 1997. Gibberellins and flowering in citrus and other fruit trees: A critical analysis. Acta Hortic., 463: 201-208.

González, L., Lafuente, M.T. y żcarías, L. 2004. Maturation of loquat fruit (Eriobotrya japonica Lindl.) under Spanish growing conditions and its postharvest performance. Options Médit., 58 : 171-179.

González-Rossia, D., Juan, M., Reig, C. y Agustí, M. 2006. The inhibition of flowering by means of gibberellic acid application reduces the cost of hand thinning in Japanese plums (Prunus salicina Lindl.). Sci. Hortic., 110: 319-323.

González-Rossia, D., Reig, C., Juan, M. y Agustí, M. 2007. Horticultural factors regulating effectiveness of $\mathrm{GA}_{3}$ inhibiting flowering in peaches and nectarines (Prunus persica L. Batsch) Sci. Hortic., 111: 352-357.

Goren, R. y Goldschmidt, E. E. 1970. Regulative system in the developing citrus fruit. I. The hormonal balance in orange fruit tissues. Physiol. Plant., 23: 937-947.

Grochowska, M. J. 1968. Translocation of indole-acetic acid-2-14C injected into seeds of five week old apple fruits. Bull. l'Acad. Polonaise Sci. Biol., 16: 577-580.

Grochowska, M. J. 1964. Identification of the growth inhibitor connected with flower bud formation in apple. Bull. L'Acad. Polonaise Sci. Biol., 12: 379-383.

Guardiola, J. L., Agustí, M. y García-Marí, F. 1977. Gibberellic acid and flower bud development in sweet orange. Proc. Int. Soc. Citriculture, 2: 696-699.

Guardiola, J. L., Monerri, C. y Agustí, M. 1982. The inhibitory effect of gibberellic acid on flowering in citrus. Physiol. Plant., 55: 136-142.

Hackett, W. P. y Hartmann, H. T. 1964. Infloresce formation in olive as influenced by low temperature, photoperiod, and leaf area. Bot. Gazette, 125: 65-72.

Hamauzu, Y, Chachin, K., Ding, C.K. y Kurooka, H. 1997. Difference in surface colour, flash firmness, physiological activity, and some components of loquat fruits picked at various stages of maturity. J. Japanese Soc. Hortic. Sci., 65: 859-865.

Harley, C. P., Masure, M. P. y Magness, J. R. 1932. Effect of leaf area, nitrate of soda and soil moisture on fruit bud formation in the Deliciousápple. Proc. Amer. Soc. Hortic. Sci., 29: 193198.

Herrero, M., y Arbeloa, A. 1989: Influence of the pistil on pollen-tube kinetics in peach (Prunus persica). Amer. J. Bot., 76: 1441-1447.

Hirai, M. 1980. Sugar accumulation and development of loquat fruit. J. Japanese Soc. Hortic. Sci., 49: 347-353. 
Ho, L.C, Gange, R.I y Shaw, A.F. 1989. Source/sink regulations. In: Transport of photoassimilates, Baker, D.A; Milburn, J.A. (Eds.), Longman Scientific and Technical, Harlow, UK, pp.306-344.

Hoad, G. V. 1978. The role of seed derived hormones in the control of flowering in apple. Acta Hortic., 80: 93-103.

Hu, Y. L., Yang, S. G. y Zang, ZK. 2010. Changes in nucleic acid and endogenous hormone contents in the apical buds of terminal shoots during the crucial period of floral induction in loquat. III Int. Loquat Symp., Abstract Book, P-29: 73.

Hueso, J.J., Pérez, M., Alonso, F., Cuevas, J., 2007. Harvest prediction in 'Algerie' loquat. Int. J. Biometeorol., 57: 449-455.

Huff, A. 1983. Nutritional control of regreening and degreening in Citrus peel segments. Plant Physiology, 73: 243-249.

Huff, A. 1984. Sugar regulation of plastid interconversions in the epicarp of Citrus fruit. Plant Physiology, 76: 307-312.

Hurd, R. G., Gay, A. P. y Mountifield, A. C. 1979. The effect of partial flower removal on the relation between root, shoot and fruit growth in the indeterminate tomato. Ann. appl. Biol., 93: 77-89.

Iglesias, D. J., Cercós, M., Colemenero-Flores, J. M., Naranjo, M. A., Ríos, G., Carrera, E., RuizRivero, O., Lliso, I., Morillón, R., Tadeo, F. R. y Talón, M. 2007. Physiology of citrus fruiting. Braz. J. Plant Physiol., 19: 333-362.

Jansen, L., De Rybel, B., Vassileva, V. y Beeckman, T. 2010. Root development. En: Plant developmental Biology. Biotechnological perspectives, Vol. 1, Eng-Chong Pua y M. R. Davey (Eds.), Springer, Heidelberg, Alemania. pp 71-90.

Johnson, R.S y Lakso, A.N. 1986. Carbon balance model of a growing apple shoot II: simulated effects of light and temperature on long and short shoots. J. Amer. Soc. Hortic. Sci. 111, 164169.

Jonkers, H. 1979. Biennial bearing in apple and pear: a literature survey. Sci. Hortic., 11: 303317.

Jourdain, J.M. y Clanet, H. 1987. Léclaircissage. Fruit et L egumes, 41:16-20.

Kader A.2002. Loquat. Recomendations for maintaining postharvest quality http://postharvest.ucdavis.edu/produce/fruit/loquat.html

Kamboj, J. S., Blake, P. S. y Baker, D. A. 1998. Cytokinins in the vascular saps of Ricinus communis. Plant Growth Regul., 25: 123-126.

Kan, B. M., Shahid, M., y Chaudhry, M. I. 1986: Effect of honey bee pollination on the fruit setting and yield of loquat. Pakistan J. Forest., 36: 73-77. 
Kappes, E.M. 1985. Carbohydrate production, balance and translocation in leaves, shoots and fruits of 'Montmorency' sour cherry. PhD Thesis, Michigan State University, East Lansing, EEUU.

Karadeniz, K. 2002: Loquat (E. japonica Lindl.) growing in Turkey. First Int. Symp. Loquat, CIHEAM-IAMZpp. $27-28$.

Kaufmane, E., y Rumpunen, K. 2002: Pollination, pollen tube growth and fertilization in Chaenomeles japonica (Japanese quince). Sci. Hortic., 94: 257-271.

Keller, J.D. y Loescher, W.H. 1989. Nonstructural carbohydrate partitioning in perennial parts of sweet cherry. J. Amer. Soc. Hortic. Sci., 114: 969-975.

Kessler, B., Bak, R. y Cohen, A. 1959. Flowering in fruit trees and annual plants as affected by purines, pyrimidines and triiodobenzoic acid. Plant Physiol., 34: 605-608.

King, R.A. y Van Staden, J. 1988. Diferential responses of buds along the shoot of Pisum sativum to isopentyladenine and zeatin application. Plant. Physiol., Biochem., 26: 253-259.

Koshita, Y., Takahara, T., Ogata, T. y Goto, A. 1999. Involvement of endogenous plant hormones (IAA, ABA,GAs) in leaves and flower bud formation of Satsuma mandarin (Citrus unshiu Marc.). Sci. Hortic., 79: 185-194.

Koshioka, M., Pearce, D., Pharis, R.P. y Murakami, Y. 1988. Identification of endogenous gibberellins in immature seeds loquat. Agric. Biol. Chem., 52: 1353-1360.

Kozlowski T. T. y Pallardy, S. G. 1997. Physiological regulation of vegetative growth. En: Growth control in woody plants, T.T. Kozlowski y S. G. Pallardy (Eds.), Academic Press, San Diego, Ca., EEUU, pp 73-165.

Kraft-Klaunzer, P. y Mande, L.N. 1992. Confirmation of structure for the new $11 \beta$-hydroxy gibberellin $\mathrm{GA}_{84}$. Phytochem., 31: 2519-2521.

Kumar, R., 1976. Induction of seedless loquat. Indian J. Hort., 33: 26-32.

Landsberg, J. J. 1980. Limits to apple yields imposed by weather. En: Opportunities for increasing crop yields. R. G. Hard, F. V. Biscoe y C. Dennis (Eds.), Ed. Pittman, Londres, U.K., pp 161-180.

Lavee, S. 1996. Biology and Physiology of the olive En: World Olive Encyclopaedia. Plaza y Janes Editores. Barcelona, España. pp 61-105.

Nitsch, J. P. 1950. The Physiology of Fruit Growth. Ann. Rev. Plant Physiol., 4: 199-236.

Layne, R.E.C., Tan, C.S. y Perry, R.L. 1986. Characterization of peach roots in Fox sand as influenced by sprinkler irrigation and tree density. J. Amer. Soc. Hortic. Sci., 111: 670-677 
Lenz, F. 1986. Fruit effects on transpiration and dry matter production in apple. En: Regulation of photosynthesis in fruit trees, A. N. Lakso y F. Lenz, (Eds.), Symp. Proc., NY State Agric. Expr. Stat., Ginebra, NY, pp 101-104.

Lin, S.Q. 2007. World loquat production and research with special reference to China. Acta Hortic., 750: 37-43.

Lin, S., Sharpe, R.H. y Janick, J. 1999. Loquat: Botany and Horticulture. Hortic. Rev., 23:233-276.

Liu, Z., Lin, S.Q., Chen, H., Zang, S.L. y Chen, K.S. 200 7. Phenological and anatomical observations of morphological differentiation of flower bud in loquat. Acta Hortic., 750: 299305.

Lovatt, C.J. 1985. Evolution of xylem resulted in a requirement for boron in the apical meristems of vascular plants. New Phytol., 99: 509-522.

Lovatt C. J., Beng Y y Hake K. D. 1988a. Demonstration of a Change in Nitrogen Metabolism Influencing Flower Initiation in Citrus. Israel J. Bot., 37: 181-188.

Lovatt C J, Zeng $Y$ y Hake KD. 1988b. A new look at the Kraus-Kraybill hypothesis and flowering in Citrus. Proc. Int. Soc. Citriculture, 1: 475-483.

Luckwill, L. C. 1953. Studies on fruit development in relation to plant hormones. II. The effect of naphthleneacetic acid applied to apple leaves. J. Hort. Sci., 28: 35-40.

Luckwill, L. C. 1957. Studies of fruit development in relation to plant hormones. IV Acidic auxins and growth inhibitors in leaves and fruits of the apple. J. Hortic. Sci., 32: 18-33.

Luckwill, L.C. 1970. The control of growth and fruitfulness of apple trees En: Physiology of tree crops, L. C. Luckwill y C. V.Cutting (Eds.). Academic Press, NY, EEUU. pp 237-254.

MAPA, Ministerio de Medio Ambiente y Medio rural y Marino. 2007. Superficies y producciones de cultivo. http://www.mapa. es/es/estadistica/pags/superficie/superficie.htm.

Martínez-Calvo, J., Badenes, M.L., Llácer, G., Bleiholder, H., Hack, H. y Meier, U. 1999. Phenological growth stages of loquat tree (Eriobotrya japonica (Thunb.) Lindl.). Ann. Appl. Biol., 134: 353-357.

Martínez- Fuentes, A. 2010. El tiempo de permanencia del fruto en el árbol y su relación con la floración en los cítricos. PhD Tesis, Universidad politécnica, Valencia, España.

Martínez-Fuentes, A., Mesejo, C., Reig, C. y Agustí, M. 2010. Timing of the inhibitory effect of fruit on return bloom of 'Valencia' sweet orange (Citrus sinensis (L.) Osbeck). J. Sci. Food Agric., 90: 1936-1943.

McArtney, S.J. y Li, S.H. 1998. Selective inhibition of flowering on "Braebun" apple trees with gibberellins. HortSci., 33: 699-700. 
Maurel, K., Berenhauser Leite, G., Bonhome, M., Guilliot, A., Rageau, R., Pétel, G. y Sakr, S. 2004. Trophic control of bud break in peach (Prunus persica) trees: a possible role of hexoses. Tree Physiol., 24: 579-588.

Mesejo, C., Reig, C., Martínez-Fuentes, A. y Agustí, M. 2010. Parthenocarpic fruit production in loquat (Eriobotrya japonica Lindl.) by using gibberellic acid. Sci. Hortic., 126: 37-41.

Monselise, S. P. 1979. The use of growth regulators in citriculture, a review. Sci. Hortic., 11: 151-162.

Monselise, S. P. y Goldshmindt, E. E. 1982. Alternating bearing in fruit trees. Horti. Rev., 4: 128173.

Monselise, S. P., Goldschmidt, E, E, y Golomb, A. 1981. Alternate bearing in citrus and ways of control. Proc. Int. Soc. Citriculture, 1: 232-242.

Monselise, S.P. y Halevy, A.H. 1964. Chemical inhibition and promotion of citrus bud induction. Proc. Amer. Soc. Hortic. Sci., 84: 141-146.

Morris, S. E., Cox, M. C., Ross, J. J., Krisantini, S. y Beveridge, C. A. 2005. Auxin dynamics after decapitation are not correlated with the initial growth of axilary buds. Plant Physiol., 138: 1665-1672.

Mullins, M. G. 1980. Plantlets from cultured anthers of Vltis species and hybrids. Proc 3rd Int. Symp. Grape Breed., pp: 111-119.

Mullins, M. G. y Rajasekaran, K. 1981. Fruiting cuttings: revised method for producing test plants of grapevine cultivars. Amer. J. Enol. Viticulture, 32: 35-40.

Munos, S., Cazettes, C., Fizmes, C., Gaymard, F., Tillard, P., Lepetit, M. Lejay, L. y Gojon, A. 2004. Transcript profiling in the chl1-5 mutant of Arabidopsis reveals a role of the nitrate transporter Nrt1.1 in the regulation of another nitrate transporter, Nrt2.1. Plant Cell, 16: 24332447.

Mylona, P. y Dolan, L. 2002. The root meristem. En: Meristematic tissues in plant growth and development, M. T. McManus y B. E. Veit (Eds.), CRC Press, FI., EEUU. pp. 279-292.

Okuda, H. 2000. A comparison of IAA and ABA levels in leaves and roots of two citrus cultivars with different degrees of alternate bearing. J. Hortic. Sci. Biotechnol., 75: 355-359.

Overvoorde, P., Fukaki, H. y Beeckman, T. 2010. Auxin control of root development. Cold Spring Harb. Perspect. Biol., 2: a001537.

Painter, J.W. y Stembridge, G.E. 1972. Peach flowering response as related to time of gibberellin application. HortSci., 7: 389-390.

Patrick, J.W. 1989. Asimílate partitioning in relation to crop productivity. Hortsci. 23: 33-40. 
Pharis, R. D. y King, R. W. 1985. Gibberellins and reproductive development in seed plants. Ann. Rev. Plant Physiol., 36: 517-568

Philips, J. B., Robertson, K. R., Rohrer, J. R., y Smith, P. G. 1991. Origins and evolution of subfam Maloideae (Rosaceae). Syst. Bot., 16: 303-332.

Plummer, J. A., Mullins, M. G. y Vine, J. H. 1991. Seasonal changes in endogenous ABA and IAA and the influence of applied $A B A$ and auxine in relation to shoot growth and abscission in Valencia orange (Citrus sinensis (L.) Osbeck). Plant Growth Regul., 10: 139-151.

Potter, D., Eriksson, T., Evans, R. C., Oh, S., Smedmark, J. E. E., Morgan, D. R., Kerr, M., Robertson, K. R., Arsenault, M., Dickinson, T. A., y Campbell, C. S. 2005, Phylogeny and classification of Rosaceae. Plant Systematics and Evolution 266:5-43.

Potter, D., Eriksson, T., Evans, R. C., Oh, S., Smedmark, J. E. E., Morgan, D. R., Kerr,M., Robertson, K. R., Arsenault, M., Dickinson, T. A., y Campbell, C. S. 2007. Phylogeny and classification of Rosaceae. Plant Syst. Evol., 266: 5-43.

Priestley, C.A. 1972. The responses of young apple trees to supplementary nitrogen and their relation to carbohydrates reserves. Ann. Bot., 36: 513-524.

Rabe, E y Lovatt, C.J. 1986. Increased arginine biosíntesis during phosphorus deficiency: A response to the increased ammonia content of leaves. Plant Physiol., 81:774-779.

Raveh, E. 2008. Partial root-zone drying as a possible replacement for 'Verdelli' practice in lemon production. Acta Hortic., 792: 537-541.

Reece, P. C., Furr, J. R. y Cooper, W. C. 1949. Further studies of floral induction in the Hadenímango (Magnifera indica L.). Amer. J. Bot., 36: 734-740.

Reig, C. y Agustí, M. 2006. Morfología y Anatomía. En: El Cultivo del Níspero Japonés, M. Agustí, C. Reig y P. Undurraga (Eds.), Gráficas Alcoy, España, pp 49-72

Reig, C., González-Rossia, D., Juan, M. y Agustí, M. 2006. Effects of fruit load on flower bud initiation and development in peach. J. Hortic. Sci. Biotechnol., 81: 1079-1085.

Remans, T., Nacry, P., Pervent, M., Filleur, S., Diatloff, E., Mounier, E., Tillard, P., Forde, B.G. y Gojon, A. 2006. The Arabidopsis NRT1.1 transporter participates in the signalin pathway triggering root colonozation of nitrate-rich patches. Proc. Nal., Acad. Sci. USA, 103: 1920619211.

Richard, D.E., King, K. E., Ait-ali, T. y Harberd, N. P. 2001. How gibberellin regulates plant growth and development: A molecular genetic analysis of gibberellin signaling. Annu. Rev. Plant Physiol. Plant Mol. Biol., 52: 67-88.

Robertson, K. R., Phipps, J. B., Rohrer, J. R., y Smith, P. G. 1991. A synopsis of genera in Maloideae (Rosaceae). Syst.. Bot., 16: 376-394. 
Rodriguez, A. 1983. El cultivo del níspero y el valle de Algar-Guadalest. Alicante, Sociedad Cooperativa de Crédito de Callosa d’En Sarriá, España.

Rohrer, J. R., Robertson, K. R., y Phipps, J. B. 1994: Floral morphology of Maloideae (Rosaceae) and its systematic relevance. Amer. J. Bot., 81: 574- 581.

Salazar-García, S. y Lovatt, C.J. 2000. Use of $\mathrm{GA}_{3}$ to manipulate flowering and yield of "Hass" avocado. J. Amer. Soc. Hort. Sci., 125: 25-30.

Savičiené, R. y Anisimoviené, N. 1988. IAA synthesis localization and the role of transport for IAA distribution in intact plants. En: Physiology and biochemistry of auxins in plants, $\mathrm{M}$. Kutáček, R. S. Bandurski y J. Krekule (Eds.), SPB Academic Publishing, La Haya, The Netherlands, pp 259-260.

Schiaparelli, A., Schreiber, G. and Bourlot, G. 1995. Fitoregolatori in agricoltura. Edagricole, Bologna, Italy.

Serrano, M., Zpata, P., Pretel, M.P., Amansa, M.S., Botella, M.A. y Amorós, A . 2004. Changes in organic acid and sugars levels during ripening of five loquat (Eriobotrya japonica Lindl.) cultivars. Options Médit., 58: 157-160.

Sheffield, C. S., Smith, R. F., y Kevan, P. G. 2005: Perfect syncarpy in apple (Malus $x$ domestica Summerl and Mclntosh) and its implications for pollination, seed distribution and fruit production (Rosaceae : Maloideae). Ann. Bot., 95: 583-591.

Skoog, F. y Miller, C. O. 1975. Chemical regulation or growth and organ formation in plant tissues cultured in vitro. Soc. Exp. Biol. Symp., 11: 118-131.

Southwick, S.M. y Glozer, K. 2000. Reducing flowering with gibberellin to increase fruit size in stone fruit trees: applications and implications in fruit production. HortTchnol., 10: 744-751.

Southwick, S.M., Weis,K.G., Yeager, J.T. y ßou, H . 1995. Controlling cropping in 'Loadel' cling peach using gibberellin: effects on flower density, fruit distribution, fruit firmess, fruit thinning and yield. J. Amer. Soc. Hortic. Sci., 120 :6. 1087-1095.

Southwick, S.M.; Yeager, J.T. y Weis, K.G. 1997. Use of gibberellins on 'Patterson' apricot (Prunus armeniaca) to reduce hand thinning and improve fruit size and firmness: Effects over three seasons. J. Hortic. Sci., 72: 645-652.

Srivastava. L. M. 2002. Plant growth and development. Hormones and environment, Academic Press, Ca, EEUU.

Tamas, I. A. 1995. Hormonal regulation of apical dominance. En: Plant Hormones. Physiology, Biochemistry and Molecular Biology, P. J. Davies (Ed.), Kluwer Academic Publishers, Dordrecht, The Netherlands, pp 572-597.

Tanaka, m., Takei, K., Kojima, M., Sakakibara, H. y Mori, H. 2006. Auxin controls local cytokinin biosynthesis in the nodal stem in apical dominance. Plant J., 45: 1028-1036. 
Taylor, B.K. 1967. Storage and mobilization of nitrogen in fruit trees . J. Aust. Inst. Agric. Sci., 33: 23-29.

Tomer, E. 1984. Inhibition of flowering in mango by gibberellic acid. Sci. Hortic. 21: 299-302.

Trambarger, T. J., Al-Ghazi, Y., Muller, B., Teyssendier de la Serve, B., Douras, P. y Touraine, B. 2003. Transcription factor genes with expression correlated to nitrate-related root plasticity of Arabidopsis thaliana. Plant Cell Environ., 26: 459-469.

Turnbull, C.G., Anderson, K.L. y Winston, E.C. 1996. Influence of gibberellin treatment on flowering and fruiting patterns in mango. Austr. J. Exp. Agric., 36: 603-611.

Verreynne, J.S. y Lovatt, C. J. 2009. The effect of crop load on budbreak influences return bloom in alternate bearing 'Pixie' mandarin. J. Amer. Soc. Hortic. Sci., 134: 299-307.

Volpe, G., Lo Bianco, R. y Rieger, M. 2008. Carbon autonomy of peach shoots determined by ${ }^{13} \mathrm{C}$-photoassimilate transport. Tree Physiol., 28: 1805-1812.

Wallerstein, I., Goren, R. y Monselise, S. P. 1973. Seasonal changes in giberellin-like substances ofshamouti orange (Citrus sinensis (L.) Osbeck) trees in relation to ringing. J. Hortic. Sci., 48: $75-82$.

Wallerstein, I., Goren, R. y Monselise, S. P. 1974. The effect of girdling on starch accumulation in sourorange seedings. Canadian J. Bot., 52: 935-937.

Wallerstein, I., Goren, R. y Monselise, S. P. 1978. Rapid and slow traslocation of $14 \mathrm{C}$ assimilates in Citrus and Phaseolus with specials references to ringing effect. J. Hortic. Sci., 53: 203-208.

Weinberg, J.H. 1941. Studies on time for peach thinning from blossoming to maturity. Proc. Amer. Soc. Hort. Sci., 38: 137-140.

Wen, C. K. y Chang, C. 2002. Arabidopsis RGL1 encodes a negative regulator of gibberellin responses. Plant Cell, 48: 87-100.

Werner, T., Motyka, V., Strnad, M. y Schmlling, T. 2001. Regulation of plant growth by cytokinin. Proc. Nal. Ac. Sci., 98: 10487-10492.

Williams, L. E. 1996. Grape. En: Photoassimilate distribution in plants and crops, żmski, E. y Schaffer, A. (Eds.), Marcel Dekker, Inc., NY, EEUU, pp 851-881.

Williams, R. R. 1966: Pollination studies in fruit trees. II. The effective pollination period for some apple and pear varieties. Reports of the Long Ashton Research station (for 1965): 136138.

Williams, E. G., Sage, T. L., y Thien, L. B. 1993: Functional syncarpy by intercarpellary growth of pollen tubes in a primitive apocarpous angiosperm, Illicium floridanum (Illiciaceae). Amer. J. Bot., 80: 137-142. 
Yahata, S., Miwa, M., Ohara, H., Ohkawa, K., Matsui, H., 2006. Effect of application of gibberellins in combination with forchlorfenuron (CPPU) on induction of seedless fruit set and growth in triploid loquat. Acta Hortic., 727: 263-267.

Yaish, M. W., Peng, M. y Rothstein, S. J. 2009. AtMBD9 modulates Arabidopsis development through the dual epigenetic pathways of DNA methylation and histone acetylation. Plant J., 59 : 133-135.

Ye, S.Q. 1988. Relationship between ethylene and growth and development of loquat fruits. China Fruits, 2: 15-18.

Young, R. y Cooper, W. C. 1969. Effect of cycocel and abscicic acid on bud growth of Red Blush grapefruit. J. Amer. Soc. Hortic. Sci., 94: 8-10.

Yuda, E. 1987. New gibberellins in developing loquat fruit and hypothetical metabolic patway. Proc. Plant Growth Regul. Soc. Amer.: 167-173.

Yuda, E., Nakagawa, S., Mourfushi, N., Yokota, T., Takahashi, T., Koshioka, M., Murakami, Y., Pearce, D., Pharis, R.P., Patrick, G.L., Mander, L.N. y Kraft-Klaunzer, P. 1992. Endogenous gibberellins in the inmature seed and pericarp of loquat. Biosci. Biotechnol. Biochem., 56: 1720.

Zang, H.Z, Peng, S.A., Cai, L.H. y Fang, D.Q. 199 0. The germplasm resources of the genus Eriobotrya with special reference on the origin of E. japonica Lindl. Plant Breeding Abstracts, 63: 772.

Zeng,Y., Xi, Y. y Ying, T. 1993. S tudies on postharvest respiration an Ethylene production of loquat fruits. Acta Hortic. Sinica, 20: 111-115. 

